El Dr. D. Jose Antonio Fuertes Martín, Profesor Titular del Departamento de Psicología Evolutiva y de la Educación de la Facultad de Psicología de la Universidad de Salamanca,

\title{
CERTIFICA QUE,
}

El presente trabajo de Tesis Doctoral, titulado "Motivaciones y estrategias de negociación sexual en la adolescencia”, realizado por Dña. Paula Román Castillo, Licenciada en Psicología y en posesión del Título de Grado de la Universidad de Salamanca, se ha desarrollado bajo mi dirección y supervisión, reuniendo, a mi juicio, los méritos suficientes de originalidad y rigor científico para obtener el Grado de Doctor.

Para que conste, firmo la presente certificación en Salamanca, a 15 de junio de dos mil nueve.

Dr. D. Jose Antonio Fuertes Martín. 



\section{AGRADECIMIENTOS}

Agradezco en primer lugar y sobre todo, la colaboración prestada por los alumnos y alumnas que decidieron participar en este estudio y que compartieron sus experiencias de manera sincera y desinteresada con nosotros. El esfuerzo y el interés que demostraron por responder válidamente a nuestras preguntas, son un reflejo de la intensidad que caracteriza a este periodo crucial que es la adolescencia.

También quiero agradecer la imprescindible colaboración de los orientadores y profesores de I.E.S. de Salamanca, responsables de estos alumnos, que mostraron disponibilidad e ilusión por participar en el estudio, y facilitaron en todo momento el que la recogida de datos se llevase a cabo de manera válida y organizada. Me consta sin duda, que este mismo apoyo lo brindan reiteradamente a otros muchos trabajos de investigación.

He tenido la suerte de contar con la sólida y constante presencia de Antonio, director de este trabajo, durante un proceso que para mí ha sido muy emocionante, pero también muy dificil. Gran parte de la dificultad de este proceso se ha visto aliviada por la naturalidad con la que Antonio invita a afrontar las cosas, y al mismo tiempo, gran parte de la valía de este trabajo se deriva del carácter crítico de su supervisión. Es necesario expresar mi gratitud por este equilibrio poco frecuente, por su actitud cercana y familiar, por sus comentarios y observaciones estimulantes, y por la confianza depositada en mí.

Asi mismo, quiero agradecer la ayuda de otros profesores e investigadores, como son la profesora Begoña Orgáz y el profesor Michael W. Wiederman, quienes con sus consejos y opiniones han contribuido de manera determinante en el resultado final de este trabajo. Espero haber sabido aprovechar lo máximo posible la experiencia y conocimientos que siempre han estado dispuestos a ofrecerme.

También debo expresar mi agradecimiento a los compañeros y amigos que me rodean y me cuidan, ya sea fisica o telefónicamente. Las maneras de prestar apoyo son muchas, y yo las he 
podido disfrutar todas: apoyo e información directa en la realización de la investigación, apoyo logístico y material, apoyo afectivo, diversión, desconexión, etc. Son las personas que viven conmigo las penas y alegrias no sólo respecto a este trabajo, sino respecto a la etapa o momento evolutivo que compartimos, las expectativas, los temores, las decepciones, y en definitiva la incertidumbre.

Finalmente quiero agradecer a mis padres y mi hermana su presencia constante y la seguridad que siento, al saber que siempre puedo contar con ellos. Mi trayectoria personal y profesional, las decisiones que he tomado y los logros que haya podido conseguir, no son sino un reflejo de los valores que cotidianamente se han manifestado en mi casa y que me han transmitido desde niña. En todo momento han comprendido mis dificultades y la falta de tiempo en los últimos meses, y han sabido expresarme, en la distancia, su cariño y sus ganas de estar conmigo. 


\section{ÍNDICE}

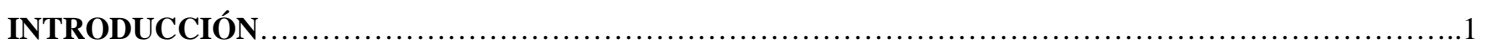

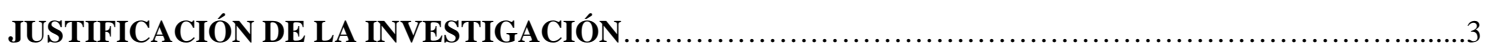

PARTE I - REVISIÓN TEÓRICA

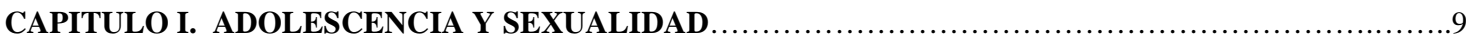

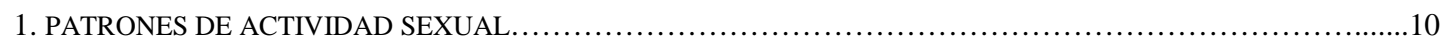

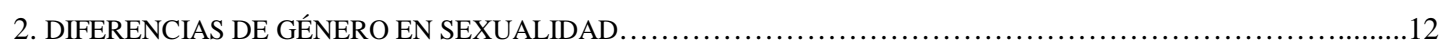

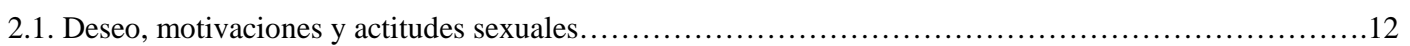

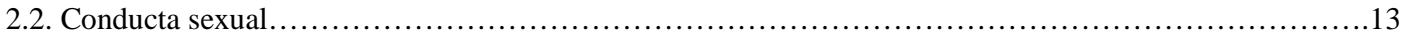

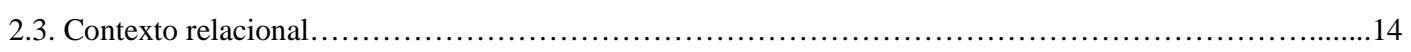

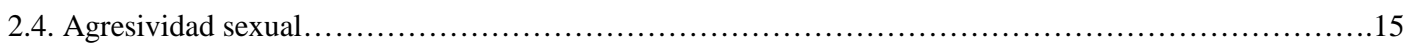

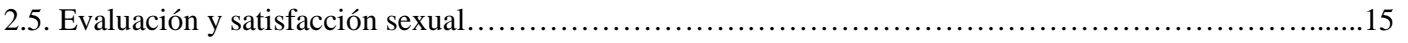

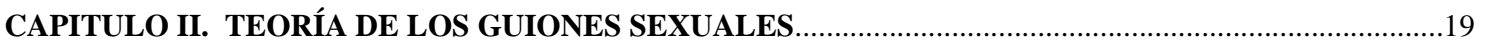

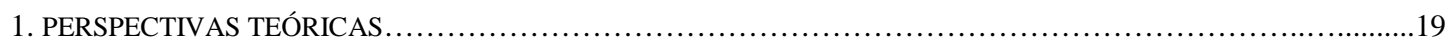

2. APLICACIÓN DE LOS GUIONES SEXUALES: COMUNICACIÓN SEXUAL .................................25

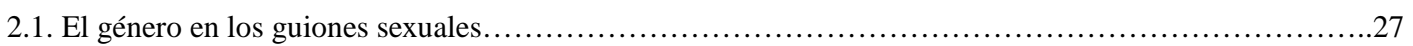

2.1.1. Comunicación de intenciones sexuales....................................................

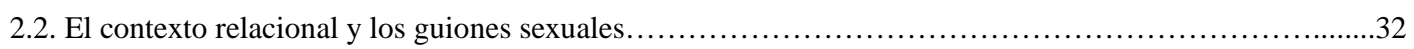

2.2.1. Fases del desarrollo de relaciones románticas en la adolescencia................................33

2.2.2. Aparición de otros contextos relacionales para la actividad sexual................................35

2.2.3. Estudio e importancia del contexto relaciona en la adolescencia..................................36

2.2.4. Características de la comunicación sexual en diferentes contextos...............................38 
CAPITULO III. ESTRATEGIAS DE NEGOCIACIÓN SEXUAL.

1.1. TIPOS DE ESTRATEGIAS DE AVANCE Y LIMITACIÓN SEXUAL....................................41

1.1.1. Estrategias de avance y limitación en la adolescencia.............................................

1.2. DIFERENCIAS DE GÉNERO EN USO DE ESTRATEGIAS SEXUALES ...................................56

1.3. CONTEXTO RELACIONAL, ESTRATEGIAS Y EXPERIENCIA SEXUAL ....................................60

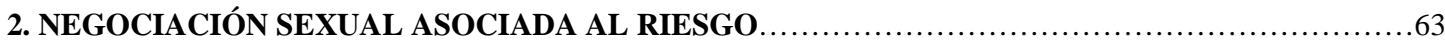

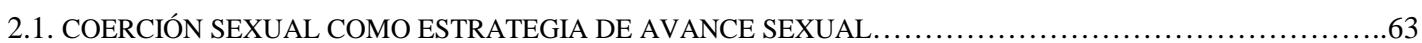

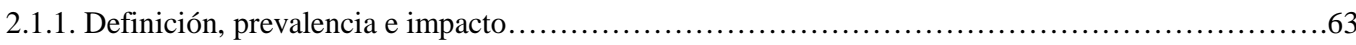

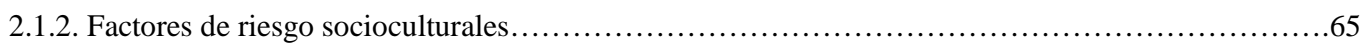

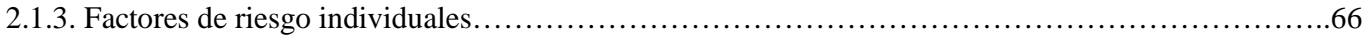

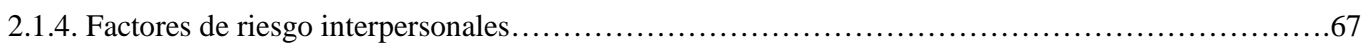

2.2. CONSENTIMIENTO DE ACTIVIDAD SEXUAL NO DESEADA........................................69

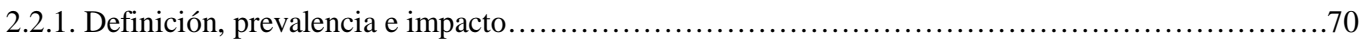

2.2.2. Género y guiones sexuales en el consentimiento sexual......................................74

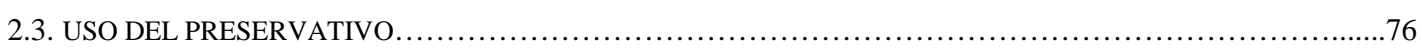

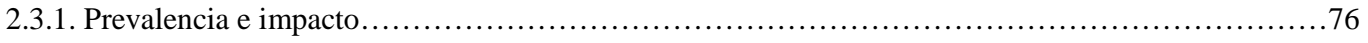

2.3.2. Contexto y guiones interpersonales en el uso del preservativo...................................77

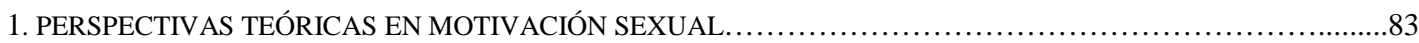

1.1. Modelos del drive o impulso sexual de la motivación sexual......................................83

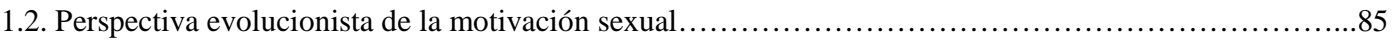

1.3. Perspectiva del construccionismo social de la motivación sexual.................................... 87

1.4. Perspectiva funcional de la motivación sexual: Modelo propuesto.....................................89

1.4.1. Fuentes de diferencias individuales en motivación sexual.....................................90

1.4.2. Implicaciones para el bienestar de los tipos de motivación sexual.................................93

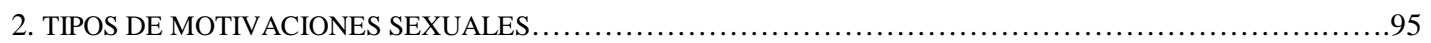

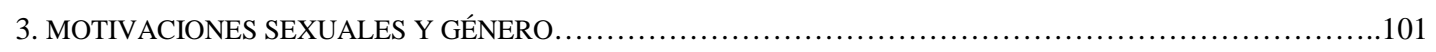

4. MOTIVACIONES SEXUALES Y ESTRATEGIAS DE NEGOCIACIÓN SEXUAL...............................104

4.1. Motivaciones sexuales y estrategias de avance y limitación sexual...............................104

4.2. Motivaciones sexuales y consentimiento de actividad sexual no deseada...............................108

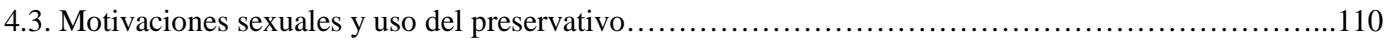




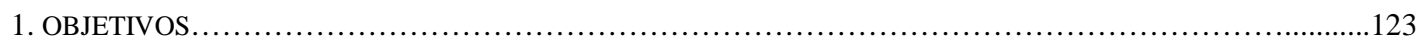

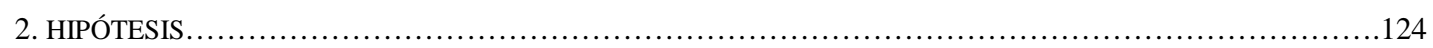

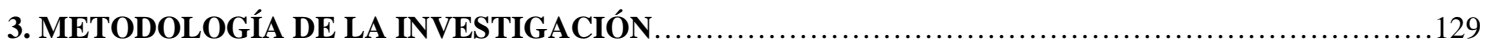

1. SELECCIÓN Y OPERALIZACIÓN DE LAS VARIABLES DE ESTUDIO...................................129

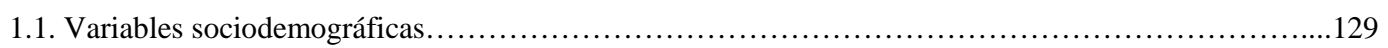

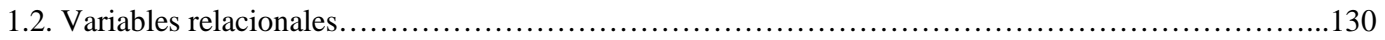

1.3. Estrategias de avance y limitación sexual................................................... 130

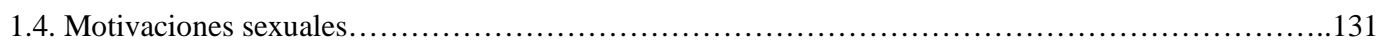

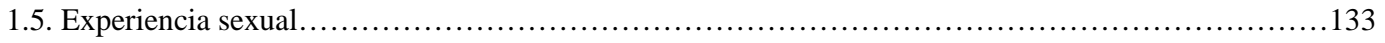

1.6. Conductas de negociación sexual asocias al riesgo.............................................. 134

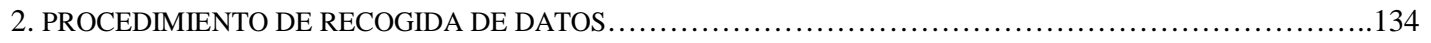

3. SELECCIÓN Y CARACTERÍSTICAS DE LA MUESTRA........................................... 136

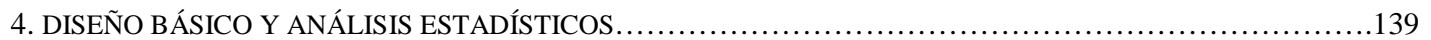

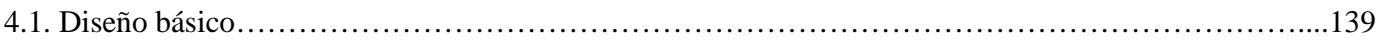

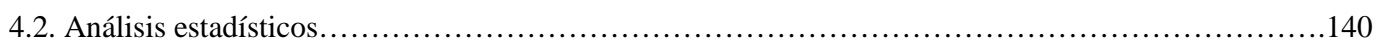

\section{RESULTADOS}

1. USO DE ESTRATEGIAS DE AVANCE Y LIMITACIÓN SEXUAL EN DIFERENTES CONTEXTOS RELACIONALES: RELACIÓN DE PAREJA Y RELACIÓN ESPORÁDICA......................................143

1.1 Análisis factorial y propiedades psicométricas del cuestionario de estrategias sexuales.........................143

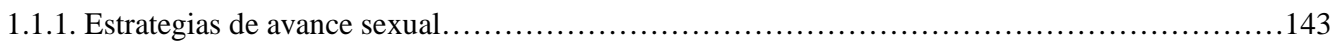

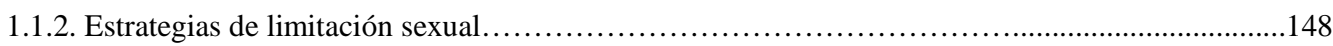

1.2. Correlación entre estrategias sexuales y variables relacionales..........................................151 
2. DIFERENCIAS EN EL USO DE ESTRATEGIAS DE AVANCE Y LIMITACIÓN SEXUAL

EN FUNCIÓN DEL CONTEXTO RELACIONAL Y EL GÉNERO

2.1. Diferencias en el uso de estrategias sexuales en función del contexto relacional y

el género, en un grupo de adolescentes con ambas experiencias relacionales.

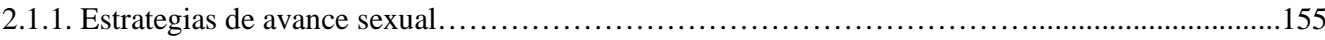

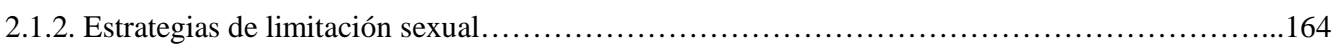

2.2. Diferencias en el uso de estrategias sexuales entre adolescentes con experiencia sólo en contextos de pareja y adolescentes con experiencia sólo encontextos de relaciones esporádicas. 168

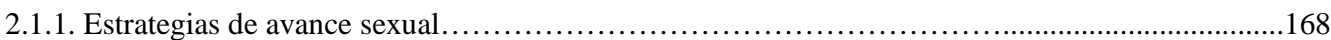

2.1.2. Estrategias de limitación sexual.................................................... 172

3. EXPERIENCIA Y MOTIVACIONES SEXUALES DE LOS ADOLESCENTES EN FUNCIÓN DEL GÉNERO Y LA EXPERIENCIA RELACIONAL, Y SU ASOCIACIÓN CON LAS ESTRATEGIAS

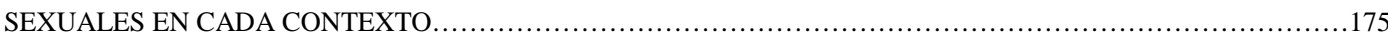

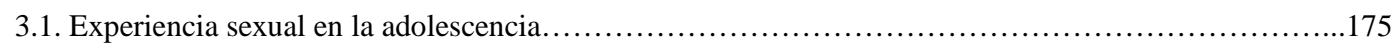

3.1.1. Análisis descriptivo de la experiencia sexual............................................ 175

3.1.2. Diferencias en experiencia sexual en función del género y la experiencia relacional..............177

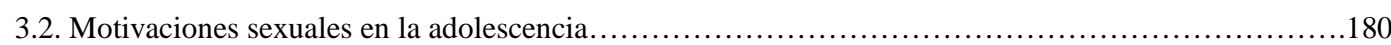

3.2.1. Análisis descriptivo de las motivaciones sexuales.........................................180

3.2.2. Diferencias en motivaciones sexuales en función del género y la experiencia sexual

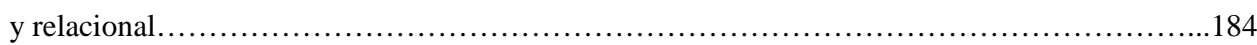

3.3. Experiencia sexual, motivaciones sexuales y estrategias de avance y limitación sexual.................188

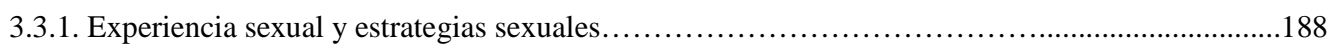

3.3.2. Motivaciones sexuales y estrategias sexuales........................................... 194

4. PRÁCTICAS DE NEGOCIACIÓN SEXUAL RELACIONADAS CON EL RIESGO,

Y SU RELACIÓN CON ESTRATEGIAS Y MOTIVACIONES SEXUALES .....................................

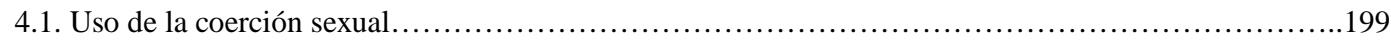

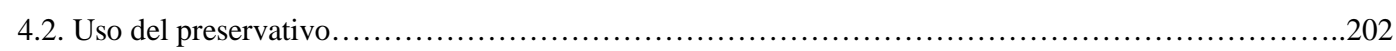

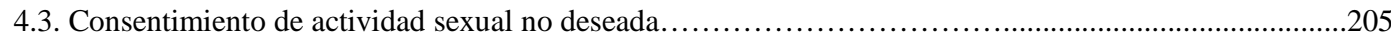

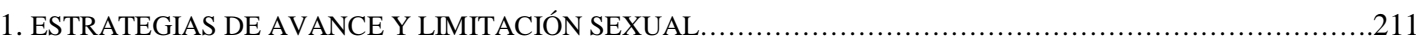

1.1. Contexto relacional y género en el uso de estrategias sexuales...................................214 


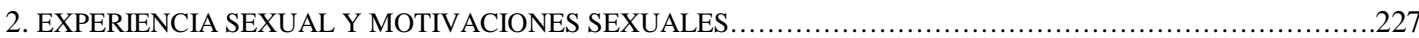

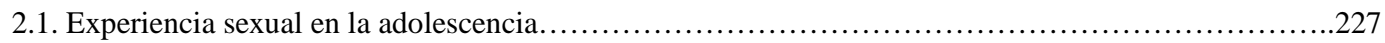

2.1.1. Experiencia sexual y uso de estrategias sexuales.......................................229

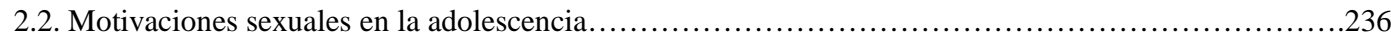

2.2.1. Motivaciones sexuales y uso de estrategias sexuales.....................................238

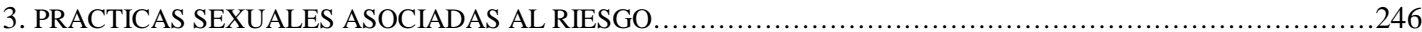

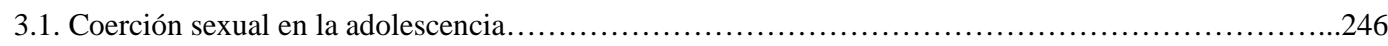

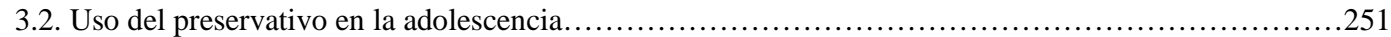

3.3. Consentimiento de actividad sexual no deseada en la adolescencia................................256

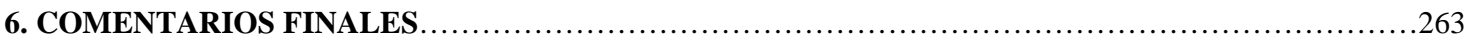

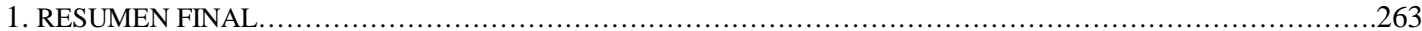

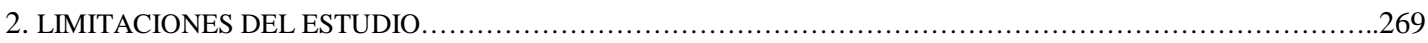

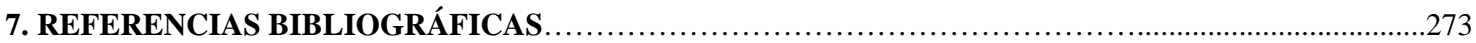

8. ANEXO I. 


\section{ÍNDICE DE TABLAS Y FIGURAS}

\section{TABLAS}

Tabla 1. Total de adolescentes en cada contexto relacional.

Tabla 2. Estadísticos descriptivos de las variables relacionales.

Tabla 3. Matrices de factoriales rotados del cuestionario de estrategias de avance sexual para relaciones de pareja.

Tabla 4. Varianza explicada por cada uno de los factores del cuestionario de estrategias de avance sexual en pareja.

Tabla 5. Matrices de factoriales rotados del cuestionario de estrategias de avance sexual para relaciones esporádicas.

Tabla 6. Varianza explicada por cada uno de los factores del cuestionario de estrategias de avance sexual en r. esporádicas

Tabla 7. Estadísticos descriptivos en frecuencia de uso de tipo de estrategia de avance sexual en pareja............

Tabla 8. Estadísticos descriptivos en frecuencia de uso de tipo de estrategia de avance sexual

en r. esporádicas

Tabla 9. Matrices de factoriales rotados de estrategias de limitación sexual para relaciones de pareja.

Tabla 10. Matrices de factoriales rotados de estrategias de limitación sexual para relaciones esporádicas.

Tabla 11. Varianza explicada por los factores del cuestionario de estrategias de limitación sexual en relaciones de pareja.

Tabla 12. Varianza explicada por los factores del cuestionario de estrategias de limitación sexual en relaciones esporádicas.

Tabla 13. Estadísticos descriptivos en frecuencia de uso de tipo de estrategias de limitación sexual en pareja.

Tabla 14. Estadísticos descriptivos en frecuencia de uso de tipo de estrategias de limitación sexual en r. esporádicas

Tabla 15. Matriz de correlaciones de variables relacionales y estrategias sexuales en ambos contextos relacionales para ambos sexos.

Tabla 16. Composición de grupos en función de su experiencia relacional y del sexo............

Tabla 17. Estadísticos descriptivos en frecuencia de uso de estrategias de avance sexual en dos contextos relacionales.

Tabla 18. Estadísticos descriptivos en frecuencia de uso de estrategias de avance sexual según el tipo de estrategia....

Tabla 19. Estadísticos descriptivos en frecuencia de uso de estrategias de avance sexual en varones y mujeres. 
Tabla 20. Estadísticos descriptivos en frecuencia de uso de estrategias de avance sexual:

Género x Contexto relacional x Tipo de estrategia.

Tabla 21. Resumen de efectos significativos del ANCOVA (contexto relacional x tipo de estrategia x género) en uso de estrategias de avance sexual en adolescentes....

Tabla 22. Estadísticos descriptivos en frecuencia de uso de estrategias de limitación sexual según tipo de estrategia.

Tabla 23. Estadísticos descriptivos en frecuencia de uso de estrategias de limitación sexual según el género.

Tabla 24. Estadísticos descriptivos en frecuencia de uso de tipos de estrategias de limitación sexual según contexto relacional y género.

Tabla 25. Resumen de efectos significativos del ANCOVA (contexto relacional x tipo de estrategia x sexo) en uso de estrategias de limitación sexual en adolescentes.

Tabla 26. Estadísticos descriptivos de uso del avance físico en dos grupos de adolescentes en diferentes contextos

Tabla 27. Estadísticos descriptivos en frecuencia de uso del avance físico directo en varones y mujeres.

Tabla 28. Estadísticos descriptivos en frecuencia de uso de gestos de seducción en varones y mujeres

Tabla 29. Estadísticos descriptivos de uso de la insinuación verbal en dos grupos

de adolescentes en diferentes contextos relacionales.

Tabla 30. Estadísticos descriptivos de uso del avance verbal en dos grupos de adolescentes

en diferentes contextos relacionales.

Tabla 31. Estadísticos descriptivos en frecuencia de uso de estrategias de presión sexual en varones y mujeres.

Tabla 32. Estadísticos descriptivos en frecuencia de uso de estrategias de limitación directas en varones y mujeres.

Tabla 33. Resumen de efectos significativos de los ANOVAs (contexto relacional x sexo) en tipos de estrategias de avance y limitación sexual en adolescentes con experiencia en relaciones de pareja vs.experiencia en relaciones casuales.

Tabla 34. Porcentaje de adolescentes que han realizado al menos una vez, y más de 10 veces cada conducta sexual.

Tabla 35. Estadísticos descriptivos de frecuencia de realización de cada conducta sexual en adolescentes....

Tabla 36. Estadísticos descriptivos en frecuencia de conductas sexuales en función de la experiencia relacional....178

Tabla 37. Resumen de efectos significativos del ANOVA (conducta sexual x experiencia relacional x sexo)....

Tabla 38. Varianza explicada por cada uno de los factores del cuestionario de motivaciones sexuales en la adolescencia.

Tabla 39. Matrices de factoriales rotados del cuestionario de motivaciones sexuales en adolescentes..............182

Tabla 40. Estadísticos descriptivos en importancia concedida a tipos de motivación sexual.

Tabla 41. Resumen de efectos significativos del ANOVA (tipo motivación sexual x experiencia sexual $\mathrm{x}$ experiencia relacional $\mathrm{x}$ sexo).

Tabla 42. Matriz de correlaciones de motivaciones sexuales, experiencia sexual y estrategias sexuales en pareja en muestra masculina.

Tabla 43. Matriz de correlaciones de motivaciones sexuales, experiencia sexual y estrategias sexuales en pareja en muestra femenina. 
Tabla 44. Matriz de correlaciones de motivaciones sexuales, experiencia sexual y estrategias sexuales en r. esporádicas en muestra masculina.

Tabla 45. Matriz de correlaciones de motivaciones sexuales, experiencia sexual y estrategias sexuales en r. esporádicas en muestra femenina.

Tabla 46. Porcentajes de frecuencia de uso del preservativo en relaciones de pareja.............................203

Tabla 47. Porcentajes de frecuencia de uso del preservativo en relaciones esporádicas.............................204

Tabla 48. Porcentajes de frecuencia de consentimiento de actividad sexual no deseada en relaciones

de pareja.

Tabla 49. Porcentajes de frecuencia de consentimiento de actividad sexual no deseada en relaciones

Casuales.

Tabla 50. Estadísticos descriptivos en frecuencia de consentimiento de actividad sexual no deseada en ambos contextos

Tabla 51. Estadísticos descriptivos en frecuencia de consentimiento de actividad sexual no deseada en varones y mujeres.

\section{FIGURAS}

Figura 1: Frecuencia de uso de estrategias de avance sexual en chicos y chicas y en diferentes contextos relacionales

Figura 2: Frecuencia de uso de los tipos de estrategias de avance sexual en chicos y chicas.

Figura 3: Frecuencia de uso de los tipos de estrategia de avance sexual en cada contexto relacional.................161

Figura 4: Frecuencia de uso de tipos de estrategia sexual en chicos y chicas y en diferentes contextos relacionales.

Figura 5: Frecuencia de uso de tipos de estrategia de limitación en chicos y chicas.

Figura 6: Frecuencia de uso de tipos de estrategia de limitación en chicos y chicas en diferentes contextos relacionales.

Figura 7: Frecuencia de uso del avance físico directo en chicos y chicas según el contexto relacional...............169

Figura 8: Frecuencia de uso del avance verbal directo en chicos y chicas según el contexto relacional................171

Figura 9: Experiencia sexual de los adolescentes en función de la experiencia relacional y el sexo...................179

Figura 10: Motivaciones sexuales de los adolescentes según el nivel de experiencia sexual......................186

Figura 11. Motivaciones sexuales de los adolescentes en función de la experiencia relacional. 187 


\section{INTRODUCCIÓN}

La adolescencia es una etapa de cambios significativos, tanto para el adolescente como para los que le rodean. En la adolescencia nacen diversas motivaciones y necesidades que llevan a los adolescentes a participar en actividades sexuales y, lógicamente, estas motivaciones sexuales se ajustan a las características de este periodo del ciclo vital. El estudio en sexualidad de estas motivaciones por tanto, se hace indispensable dadas las especificas necesidades tanto sexuales como psicosociales que se dan en la adolescencia. Como reflejo de la aparición de las nuevas motivaciones sexuales, surgen cambios en el comportamiento social y sexual de los adolescentes, quienes se enfrentan durante este periodo, a la necesidad de poner en marcha formas de conducta que hasta este momento han visto como propias de la adultez. Entre ellas se encuentra la expresión de la sexualidad en un contexto interpersonal: el hecho de compartir y negociar experiencias sexuales con otra persona. En otras palabras, los adolescentes se enfrentan a la tarea de idear y poner en marcha formas de comunicación sexual con los demás.

La comunicación sexual es cualquier acto de transmisión de mensajes o información relacionada con la propia sexualidad y deseos sexuales, a otra persona, y puede consistir en todo tipo de 
conducta, desde un mero contacto visual, hasta una valoración verbal de un acto sexual. Para los propósitos de este proyecto ha sido necesario adoptar una perspectiva más concreta de la comunicación sexual. En este estudio nos centramos en estudiar las estrategias de negociación que los adolescentes utilizan, tanto para iniciar como para limitar algún tipo de actividad sexual con otra persona.

Normalmente esta tarea puede llegar a ser compleja para cualquier persona, pero la falta de experiencia de los adolescentes, en lo que a comunicación de deseos sexuales se refiere, hace que para éstos la tarea sea especialmente difícil, y las consecuencias potencialmente dañinas, según numerosos estudios. La dificultad de esta tarea y lo dañinas que pudieran ser las consecuencias de una comunicación sexual fallida entre dos personas, consideramos que dependen en parte, del tipo de relación que exista entre éstas dos personas. Por eso en este estudio exploramos estrategias de comunicación sexual en la adolescencia, asociadas a diversos contextos relacionales. En la misma dirección que el tipo de contexto relacional, aunque a un nivel más individual, creemos que el tipo de motivación sexual y la experiencia del adolescente, también determinará el grado de dificultad y de ajuste, en la labor de promover encuentros sexuales. En este caso, en lugar de creer que "el fin justifica los medios" consideramos que "el fin 'caracteriza' los medios". Así, el objetivo general de este estudio, será examinar algunas estrategias de comunicación y negociación sexual en adolescentes, así como explorar algunos factores que podrían influir en la puesta en marcha de estas estrategias, como el contexto relacional, las motivaciones y experiencias sexuales, y el género de los adolescentes.

A continuación expondremos una justificación detallada del tema de investigación, comentando las diversas razones que existen para estudiar la comunicación sexual en la adolescencia, en concreto las estrategias que los adolescentes utilizan para iniciar o rechazar la actividad sexual. 


\section{JUSTIFICACIÓN DE LA INVESTIGACIÓN}

Consideramos que una razón fundamental para estudiar las estrategias de iniciación y limitación sexuales reside en su estrecha relación con el desarrollo de relaciones románticas en la adolescencia. La importancia del papel que juegan las relaciones románticas en la adolescencia está sobradamente demostrado, a raíz de las múltiples repercusiones que éste nuevo fenómeno tiene en el ajuste y bienestar psicosocial del adolescente. En este sentido, las estrategias de iniciación y limitación sexual intervienen en multitud de ocasiones en la formación de tales relaciones amorosas y en muchas otras, representan un cambio cualitativo de la naturaleza de esas relaciones, en términos de estabilidad, compromiso e involucración emocional, lo que contribuye a moderar la satisfacción sexual que experimentan los adolescentes, en particular las chicas. Consideramos que, en la amplia variedad de trayectorias de desarrollo relacional que se dan actualmente en la adolescencia, el uso de estrategias de iniciación y limitación sexual juega un papel fundamental.

Por otra parte, las estrategias de avance y limitación sexual, como formas de comunicación, constituyen un modelo de negociación sobre los deseos e intenciones sexuales, que los adolescentes pueden seguir en otros ámbitos no sexuales de la relación, cuando por ejemplo la 
relación acaba de empezar, a raíz de un encuentro sexual. Así, si los diferentes estilos de comunicación del interés sexual pueden generalizarse a otras áreas de la relación, es de gran importancia que conozcamos qué estilos de comunicación son y si se consideran adecuados.

En tercer lugar, la comunicación sexual tiene claras implicaciones en términos de salud. Una mayor comprensión de cómo los adolescentes utilizan la comunicación para iniciar relaciones sexuales sin duda puede ser útil en programas destinados a la educación sexual. Si el objetivo de estos programas educativos es influir en las dinámicas sexuales de los adolescentes para que se integren en ellas medidas de protección ante enfermedades de transmisión sexual y embarazos no deseados, antes es necesario identificar qué pasos dan los adolescentes en la dirección correcta y qué pasos dan en la dirección contraria. Igualmente se podrá intervenir con mayor eficacia si identificamos qué adolescentes y en qué circunstancias tienen más probabilidades de dar los pasos adecuados.

Otra razón para estudiar las estrategias de avance y limitación sexual que utilizan los adolescentes es la creciente preocupación en relación con el uso de la coerción para mantener relaciones sexuales. Numerosos estudios han mostrado que un porcentaje significativo de adolescentes utilizan estrategias de coerción sexual, tanto verbales como no verbales, y con muy diferentes grados de violencia, desde la manipulación hasta el uso de la fuerza. Las consecuencias negativas, sociales y psicológicas, del empleo de la coerción sexual como forma de iniciación sexual, están ampliamente documentadas por la investigación y claramente visibles en nuestro entorno social. Conocer qué uso hacen los adolescentes de la coerción, cómo se integra entre otro tipo de estrategias sexuales y qué otras variables determinan su utilización, puede ayudar a la hora de idear mensajes para campañas e intervenciones en programas educativos, y promover una concienciación social sobre prevención de la coerción sexual.

Finalmente proponemos un último motivo para estudiar la comunicación sexual y es la contribución que el tema de estudio puede hacer a la Teoría de los Scripts o Guiones Sexuales (Gagnon y Simon, 1973), a través del análisis de los guiones de iniciación sexual adolescente. Esta teoría investiga el uso de guiones o esquemas sexuales en tanto a que guían las interacciones que se producen entre miembros de una pareja y perfilan las normas sexuales que existen, en contextos y poblaciones específicas. Así, una descripción detallada de la manera en la que los adolescentes negocian la actividad sexual con otra persona, ofrecerá una información cuando menos interesante, sobre qué scripts o guiones interpersonales subyacen a la iniciación sexual adolescente en la actualidad. 
La contribución a esta teoría no sólo la hará el análisis de las estrategias de iniciación sexual interpersonal sino también el estudio de las motivaciones sexuales en la adolescencia presente en este estudio, en tanto a que forman parte del script intrapsíquico o individual de la sexualidad adolescente. El script o guión intrapsíquico constituye la concepción, deseos y motivaciones que el individuo alberga interiormente sobre la sexualidad, o en otras palabras, el significado personal que tiene la sexualidad para cada individuo. En este sentido otra contribución para la teoría de los guiones sexuales será comprobar qué relación se da entre los dos niveles de los guiones sexuales: el empleo de estrategias sexuales (nivel interpersonal), y las motivaciones sexuales (nivel intrapersonal) en la adolescencia.

Claramente, es importante estudiar y comprender qué tipo de conductas y motivaciones están implicadas en la iniciación de una relación sexual. Así, el propósito de esta investigación es examinar las estrategias de avance y limitación sexual y otras prácticas de negociación sexual asociadas al riesgo, así como las motivaciones sexuales en la adolescencia, teniendo en cuenta el género y el contexto relacional en el que se producen. Para ello, comenzamos por realizar un examen minucioso de la investigación hasta ahora realizada sobre estos temas. 


\section{PARTE I}

Revisión Teórica 


\section{CAPITULO I}

\section{ADOLESCENCIA Y SEXUALIDAD}

La sexualidad es un tema de gran interés y relevancia para la investigación dadas las importantes repercusiones que de una manera u otra, tiene en la vida de las personas. Esta relevancia aumenta cuando consideramos la importancia que tiene la sexualidad en un periodo como la adolescencia, en el que comienzan a esbozarse los primeros acercamientos "oficiales" a la sexualidad.

En los últimos 20 años, la investigación en sexualidad adolescente ha crecido enormemente debido a la preocupación social generada por el impacto del VIH (Navarro-Pertusa, Reig-Ferrer, Barberá y Ferrer, 2006). La sexualidad adolescente aparece sin la protección que ofrecen la experiencia y la madurez psicosocial de edades más avanzadas, y por ello se asocia frecuentemente con una serie de consecuencias negativas como embarazos prematuros, enfermedades de transmisión sexual, abortos etc. Esto ha promovido una masiva recopilación de información sobre cuándo y con quién inician los adolescentes sus relaciones sexuales, tipo de conductas específicas y frecuencia de conductas sexuales, así como de uso de protección contra enfermedades y embarazos. Sin embargo sabemos mucho menos sobre otros aspectos 
cualitativos de la experiencia de adolescentes con la sexualidad, como qué motiva la actividad sexual, cómo se desarrollan normas sexuales y cómo evolucionan, o que significado tiene la sexualidad en la cultura de los adolescentes (Savin-Williams y Diamond, 2004).

A continuación expondremos un breve resumen de lo que sabemos sobre sexualidad adolescente general que consideramos relevante para este estudio.

\section{PATRONES DE ACTIVIDAD SEXUAL}

En general, el estudio de la conducta sexual adolescente sugiere una consistente tendencia hacia un incremento de la actividad sexual en la adolescencia en la actualidad (Martinez, 2000; Centres for Disease Control, 2002; Davis y Lay-Yee, 1999; De Lamater y Friedrich, 2002: Laumann, Gagnon, Michael, y Michaels, 1994). Algunos autores (Reiss, 1967) han argumentado que las actitudes sexuales se han movido de un énfasis en la importancia de la abstinencia premarital, a una adopción de actitudes permisivas hacia el sexo dentro de un marco de afectividad. Este cambio de actitudes ha sido acompañado por supuesto, por cambios sociales fundamentales como la igualdad de género, las diversas construcciones de la familia, y la reducción de la supervisión parental (Hopkins, 2000). Aunque la investigación se ha centrado principalmente en las relaciones coitales, en este apartado consideraremos todo el espectro de conductas sexuales propias de la adolescencia.

Un aspecto clave de la adolescencia es la especificación y consolidación del deseo y la orientación sexual. Es en este periodo en el que la excitación sexual y el orgasmo, aunque ya presente en la infancia, comienzan a ser motivaciones específicas de la conducta de masturbación (Bancroft, 1989). La masturbación es una importante fuente de conocimiento respecto a la propia sexualidad, y acompañada de fantasías eróticas permite enfrentarse con los propios deseos y ensayar con la imaginación posibles interacciones futuras (Katchadourian, 1990). Sin embargo, la masturbación sigue viviéndose con cierta dosis de culpabilidad, que los adolescentes deben aprender a modular (Moore y Rosenthal, 1993).

En cuanto a su prevalencia, en adolescentes españoles se ha encontrado que el porcentaje de chicos que se masturban es del $98,4 \%$ frente a un $73,8 \%$ de las chicas (Fernandez del Valle, Bravo Arteaga, García Ruiz y Uría Urraza, citado en Gómez Zapiaín, 2005). La diferencia entre 
chicas y chicos es aún mayor si se atiende a la frecuencia de masturbación, siendo tres veces más frecuente en los chicos (Leitenberg, Detzler y Srebnik, citado en Ponton y Judice, 2004).

Entre las conductas sexuales que implican a otras personas, podemos extraer una secuencia normativa de conductas (Miller y Dyck, 1993; Miller, Christopherson y King, 1993) en la que aparecen primero los besos y abrazos, seguidos de caricias de pechos y genitales por encima de la ropa, después por debajo de la ropa, el coito, y normalmente después del coito, el sexo oral. Existe variabilidad entorno al lugar que ocupa el sexo oral, si antes o después del coito, en función de si los adolescentes consideran si es una actividad más o menos íntima que el coito. En cualquier caso, el lapso temporal entre las conductas del final de la secuencia es pequeño. Por ejemplo, la masturbación mutua, el sexo oral y el coito se realizan en torno a los 17 años en los chicos y 16 años en las chicas (Weinberg, Lottes y Shaver, citado en Savin-Williams y Diamond, 2004).

En una muestra de adolescentes del País Vasco encontraron que la edad media de experimentación de los besos y abrazos es de 14,2 años, la media de caricias genitales y conductas próximas al coito es de 16,2 y la media de edad para la práctica del coito es de 17,2 años para ambos sexos (Gómez Zapiaín, 2005). Sin embargo en un estudio realizado por el Centro Madrid Salud Joven y la Universidad de Granada (2008) bajaba la edad media en la que las chicas practicaban el coito a 16,3 y la de los chicos a 15,8 años.

En un informe sobre la juventud en España (INJUVE, 2000) indica que el 34\% de los chicos y el $26 \%$ de las chicas entre 16 y 19 años tienen experiencia sexual coital. En otros estudios realizados en España (Ramos, Fuertes, Martínez y Hernández, 2003; Navarro-Pertusa et al., 2006) el porcentaje de adolescentes que ha experimentado el beso íntimo y abrazos está entre el $76 \%$ y el $80 \%$, el porcentaje de adolescentes que ha experimentado caricias genitales está en torno al 55\% y los adolescentes que han realizado el coito forman el 18\% de una muestra de entre 16 y 19 años.

En relación con el significado que tienen estas conductas para los adolescentes, podemos decir que las caricias y abrazos requieren la habilidad de negociar y compartir experiencias sexuales e íntimas, lo que significa un avance importante en el contexto interpersonal del adolescente (Katchadourian, 1990). La práctica del sexo oral tiene diversos significados, por una parte puede representar una forma de actividad sexual libre del riesgo del embarazo, pero por otra parte para algunos adolescentes representa una actividad más íntima que el coito. Las relaciones coitales son el símbolo más importante y más cargado de significado dentro de las relaciones sexuales 
heterosexuales en la adolescencia, ya que muchos adolescentes perciben el primero coito como un símbolo de estatus sexual adulto (Herold y Marshall, 1996). Lo cierto es que normalmente las parejas que practican el coito sobrepasan una línea que irreversiblemente altera el carácter de su relación (Katchadourian, 1990).

\section{DIFERENCIAS DE GÉNERO EN SEXUALIDAD}

\subsection{Deseo, Motivaciones y Actitudes sexuales}

A pesar de cierta tendencia a la convergencia entre los sexos en temas de sexualidad (Curran, 1975), lo cierto es que las diferencias de género que se encuentran en sexualidad siguen siendo claras en algunos aspectos. Uno de ellos es la diferencia en frecuencia e intensidad del deseo sexual entre chicos y chicas que sugiere la revisión de Baumeister, Catanese y Vohs (2001). El deseo sexual es la experiencia subjetiva de sentir interés por objetos o actividades sexuales y desear involucrarse en éstas actividades sexuales (Regan y Berscheid, 1999). Muchas líneas de investigación demuestran que los hombres muestran mayor interés en el sexo que las mujeres. Por ejemplo, se ha encontrado que independientemente de su orientación sexual, los chicos son más conscientes de sus impulsos e intereses sexuales varios años antes que las chicas, así como que informan de excitación sexual más frecuente (Savin-Williams y Diamond, 2000).

Siendo estos resultados claros, lo que continúa siendo materia de debate es el origen de estas diferencias en deseo sexual. Por un lado tenemos la explicación biológica centrada en los diferentes niveles de andrógenos entre ambos sexos y por otra la explicación sociocultural centrada en las normas sociales que disuaden a las mujeres de prestar atención a sus sensaciones sexuales. Esto es consistente con los resultados de un estudio en los que menos del $50 \%$ de las adolescentes conseguía detectar su excitación sexual frente al 90\% de los adolescentes varones (Knoth, Boyd y Singer, citado en Savin-Williams y Diamond, 2004). Por supuesto es posible que ambas perspectivas contribuyan a explicar las diferencias de género en deseo sexual. Baumeister (2000) encontró considerables evidencias empíricas que sugerían que el deseo sexual femenino es más maleable y cambiante que el masculino, en el sentido de que es más sensible o reactivo a factores culturales y sociales, y es más dependiente de las circunstancias externas. 
Relacionado con el deseo sexual están las motivaciones sexuales. Aunque le dedicaremos un capitulo a las motivaciones sexuales en la adolescencia, anticiparemos que son otro aspecto de la sexualidad en el que consistentemente se han encontrado diferencias de género. Las chicas indican el enamoramiento o la vinculación emocional como principal razón para la experiencia sexual compartida, mientras que los chicos la relacionan en mayor medida con el placer obtenido de la satisfacción del deseo (Ramos et al., 2003; Martínez, 2000)

También siguen existiendo diferencias en las actitudes sexuales que mantienen chicos y chicas, siendo los varones los que disfrutan de actitudes más permisivas hacia el sexo sin compromiso o la variedad de parejas sexuales (Ramos et al., 2003; Oliver y Hyde, 1993). En este sentido, los adolescentes de ambos sexos aceptan en mayor medida la actividad sexual en contextos de amor y compromiso que en contextos sin compromiso, pero la diferencia en el grado de aceptación se muestra superior en el caso de las chicas.

\section{2. $\underline{\text { Conducta sexual }}$}

Se encuentran también diferencias en el propio comportamiento sexual. Las diferencias de género en la conducta de masturbación se encuentran entre las más grandes y consistentes de toda la evidencia empírica en sexualidad y psicología en general (Oliver y Hyde, 1993). Sin embargo pocas o ninguna diferencia se han encontrado en la frecuencia de actividad sexual en pareja no coital, como besar, abrazar o el sexo oral (Ramos et al., 2003; Navarro-Pertusa et al., 2006; Larsson y Svedin, 2002; Schwartz, citado en Savin-Williams y Diamond, 2004). Por una parte se pueden entender estos resultados, como la prueba de que el impulso sexual femenino es tan intenso como el masculino, pero la estigmatización de la conducta de masturbación en las mujeres justifica las bajas tasas de masturbación femenina. Sin embargo, también puede entenderse que estas bajas tasas de masturbación reflejan en verdad un impulso sexual más débil, pero que las adolescentes chicas tienden a adaptarse a lo que su pareja desea, en términos de actividad heterosexual (Baumeister et al., 2001). 


\subsection{Contexto relacional}

Las diferencias de género afectan también al contexto relacional en el que se produce la actividad sexual en la adolescencia. Las chicas suelen encontrase en relaciones de mayor intimidad y vinculación emocional durante su primera relación sexual que los chicos (Papadopoulos, Stamboulides y Triantafillou, 2000; Launmann et al., 1994; Oliva, Serra y Vallejo 1992). Más allá de la primera relación coital, vemos que en general los varones señalan tener sus relaciones sexuales en contextos menos comprometidos que las mujeres (Carroll, Volk y Hyde, 1985; Buhrmester, citado en Fuertes 1996; Navarro-Pertusa et al., 2006) Así comprobamos que no hay sólo diferencias en cuanto a las actitudes que los adolescentes de ambos sexos mantienen hacia el sexo sin compromiso, sino que tales diferencias se ven reflejadas en cuanto al contexto que eligen los adolescentes para la práctica de conductas sexuales. Sobre el contexto relacional también hablaremos en profundidad más adelante.

En este sentido también es consistente el mayor número de parejas sexuales que se observan en la población adolescente masculina frente a la femenina (Navarro-Pertusa et al., 2006). En un estudio de Ramos et al. (2003) encontraron que los chicos declaraban haber tenido una media 4,9 frente a la media de 3,6 parejas no coitales de las chicas. En el caso de las parejas coitales se hallaban las mismas diferencias significativas siendo la media masculina de 2,5 y la media femenina de 1,4 parejas sexuales. Parece que las diferencias en número de parejas sexuales se observan consistentemente en diferentes culturas y generaciones, aunque suelen ser mayores en sociedades más tradicionales (Launmann et al., 1994; Papadopoulos et al., 2000).

Sin embargo es importante no equiparar el número de parejas sexuales con la frecuencia general de actividad sexual. Como las mujeres y adolescentes chicas tienen mayores probabilidades de indicar que su actividad sexual se produce en contextos de relaciones de pareja, suelen informar de mayores tasas de actividad sexual que los varones aún con una misma persona. En cambio, éstos suelen tener actividad sexual más infrecuente con una mayor variedad de parejas (Prince y Bernard, citado en Savin-Williams y Diamond, 2004). 


\subsection{Agresividad Sexual}

Otro patrón de diferencias de género se refiere a la asociación entre agresividad y sexualidad. Esta asociación se ha demostrado en varios campos, incluyendo el autoconcepto sexual del individuo, la iniciación de conductas heterosexuales y la actividad sexual coercitiva (Peplau, 2003). Andersen, Cyranowski y Espindle (1999) investigaron las dimensiones que los individuos utilizan para caracterizar su propia sexualidad. Ambos sexos se evaluaban en las dimensiones de romanticismo y apertura sexual, pero sólo los varones se caracterizaban con una dimensión de agresión que evaluaba hasta qué punto se veían como agresivos, arrolladores, experimentados, dominantes e individualistas. En relaciones heterosexuales, los hombres son frecuentemente más asertivos que las mujeres a la hora de iniciar interacciones sexuales (Impett y Peplau, 2003). La violación está en el extremo de esta asociación entre sexualidad y agresividad, siendo la coerción sexual predominantemente una actividad masculina (Felson, 2002), aunque la coerción no se reduce al ámbito de la violación. Este aspecto será estudiado con mayor atención en un capítulo posterior de la investigación, ya que ésta se centra en la iniciación de conductas sexuales, entre ellas la coerción sexual.

\subsection{Evaluación y Satisfacción sexual}

Finalmente existen también diferencias de género en cuanto a la evaluación de las experiencias sexuales. Si bien no hay muchas diferencias en la valoración de las actividades no coitales o la masturbación, el sentimiento de culpa es sólo ligeramente más común entre las chicas (Larsson y Svedin, 2002), la cosa cambia ante las relaciones coitales. Moore y Rosenthal (1993) concluyen en su revisión que es frecuente que las adolescentes chicas no disfruten de la primera relación coital. En general los chicos evalúan más positivamente sus primeras relaciones sexuales y experimentan orgasmos más frecuentemente con sus primeras parejas sexuales que las chicas (Launmann et al., 1994). Hay varios factores que parecen moderar la evaluación que hacen las adolescentes de sus relaciones sexuales. Por ejemplo, la satisfacción de las mujeres con sus experiencias sexuales se relaciona postitivamente con la experiencia, consideración y familiaridad con el cuerpo femenino que tenga su pareja (Savin-Williams y Diamond, 2004). Otro moderador pueden ser los sentimientos de culpa, vergüenza o arrepentimiento de la actividad sexual, que son más comunes entre mujeres que entre hombres (Ramos, Fuertes, 
Martínez y Hernández, 2003; Oliva, Serra, Vallejo, López y Lozoya, 1993; Ponton y Judice, 2004). Estos sentimientos sí que parecen una consecuencia inevitable de la manera en la que las adolescentes chicas son socializadas en términos de sexualidad. El contexto relacional de la actividad sexual en la adolescencia como ya hemos visto, juega un papel importante de cara a la evaluación de las chicas. Las chicas tienen más probabilidad de evaluar como positiva una experiencia si ésta ocurre en el marco de una relación de pareja estable, particularmente si está caracterizada por una buena comunicación (Donald, Lucke, Dunne y Raphael, 1995). Por otro lado, como también hemos visto es más probable que las chicas adolescentes sufran coerción o presión sexual por parte de sus parejas que los chicos, lo que representa otro factor moderador de la evaluación de la experiencia sexual femenina (Felson, 2002; Savin-Williams y Diamond, 2004).

Resumiendo, las diferencias de género halladas a lo largo de multitud de estudios revelan la existencia de lo que Oliva, Serra y Vallejo (1997) denominaron como patrones de comportamiento sexual asociados al género. El patrón general masculino estaría caracterizado por una actividad sexual más precoz y a veces más agresiva, por mayor número de parejas sexuales, mayor experiencia sexual en contextos relacionales sin compromiso y por una mayor aceptación y valoración del placer. Por otra parte, el patrón general femenino presentaría una actividad sexual más vinculada a relaciones de pareja y sentimientos afectivos, y más proclive a generar más sentimientos negativos y menor placer.

Es necesario recordar que las diferencias entre hombres y mujeres no son absolutas, sino que son una cuestión de grado. Hay muchas excepciones a los patrones generales que hemos descrito: algunas mujeres muestran altos niveles de interés sexual y algunos hombres solo buscan actividad sexual en relaciones estables. Por otro lado, se ha avanzado mucho más en la documentación de éstas diferencias que en la investigación de sus orígenes: apenas hemos comenzado a comprender cómo interaccionan la biología, la experiencia previa y la cultura, en la caracterización de la sexualidad de hombres y mujeres (Peplau, 2003). En cualquier caso, el conocimiento de estas diferencias de género puede esclarecer algunos patrones de interacción sexual específicos, como la iniciación y limitación de la actividad sexual, el consentimiento de actividad sexual no deseada o la utilización del preservativo, todas ellas cuestiones estudiadas en la presente investigación. 
En el siguiente apartado comenzamos a centrar el foco de interés hacia la perspectiva teórica desde la que abordamos nuestra investigación: La teoría de los scripts o guiones sexuales (Gagnon y Simon, 1973) 



\section{CAPITULO II}

\section{TEORIA DE GUIONES SEXUALES}

\section{PERSPECTIVAS TEÓRICAS}

Se han utilizados diversas perspectivas teóricas para estudiar la conducta sexual humana. Hasta hace poco, se criticaba que la disciplina de sexualidad carecía de teorías reconocidas, propias del campo (Simon y Gagnon, 1986; Weis, 1998). Un artículo de The Journal of Sex Research en 1998 que se dedicó al estudio explicito de las teorías en el campo de la sexualidad humana, y un libro posterior a propósito del mismo tema (Bancroft, 2000), han proporcionado una base teórica consistente desde la que estudiar la conducta sexual.

Aunque existen diversas teorías desde las que examinar la conducta sexual, una perspectiva teórica, la teoría de los guiones sexuales, parece dominar la actividad investigadora, al menos implícitamente, en términos de comunicación sexual (Dybvig-Pawelko, 2007). Así proponemos esta perspectiva para el estudio de estrategias de iniciación y limitación sexual en la adolescencia. 
La teoría de los guiones sexuales deriva, según sus autores, de tres corrientes intelectuales sobretodo. En primer lugar del interaccionismo simbólico, que es una perspectiva que concibe y examina la vida social fundamentalmente como un proceso comunicativo. En segundo lugar deriva de la influencia de la contribución teórica de Kenneth Burke, quien añade al interaccionismo simbólico un énfasis en el análisis de los efectos de la estructura social sobre los símbolos y de la interacción entre éstos. Finalmente reconocen la tradición y el trabajo monumental creado por Freud.

Los autores de ésta teoría se apoyan sólidamente en las asunciones básicas del interaccionismo simbólico por lo que es importante comprender sus principales premisas. Christopher (2001) propone que hay cinco asunciones básicas: En primer lugar, las personas tratan de crear y mantener significados en sus interacciones. Esto es, los individuos negocian el significado mutuo que existe detrás de las conductas en sus relaciones. Las conductas son pues, símbolos llenos de significado, y el significado que una pareja otorga a estos símbolos determina a su vez, cómo el individuo actúa y reacciona en relación a todas las conductas, incluidas las sexuales. Así, cómo se comunica una pareja en particular, es único y propio de su relación. Los significados que se otorgan varían en función del lugar que se ocupa en la sociedad y ayudan a comprender las actividades sexuales del individuo. En segundo lugar, el significado se crea y se modifica a través de las interacciones sociales. En tercer lugar, los individuos no sólo reaccionan a su entrono, sino que inician sus propias acciones. En cuarto lugar, los individuos pueden reflejarse en sus actos como algo separado de sí mismos y, finalmente, la conducta de un individuo está guiada por cómo éste se ve a sí mismo.

La influencia del psicoanálisis sin embargo, no siempre fue clara, ya que los autores siempre rechazaron el poder explicativo de la biología, que reducía la sexualidad a un instinto o impulso generada por el cuerpo. Según los autores la experiencia fenomenológica del deseo sexual era una manera aprendida de etiquetar sus intereses en el contexto de unas condiciones intrapsíquicas e interpersonales específicas. Lo sexual toma su forma y su significado de su carácter social, y a pesar de que la mayor parte de la actividad sexual en sociedades contemporáneas ocurre en privado, el encuentro sexual sigue siendo un profundo acto social en cuanto a su práctica, e incluso más en cuanto a sus antecedentes y consecuentes. Así, en su trabajo inicial, el pensamiento tradicional freudiano servía fundamentalmente como argumentos contra los que formular su perspectiva. La teoría de los guiones, que formula la pregunta "¿Que representa la sexualidad?", le da la vuelta a la pregunta característica del enfoque clásico psicoanalítico “¿Cómo se representa lo sexual en la conducta?”. Sin embargo, en el intento de 
responder a muchos de los mismos cambios sociales, las revisiones en las tradiciones psicoanalíticas resultaron ser muy útiles a la hora de proporcionar nuevos insights y nuevo lenguaje conceptual (Simon y Gagnon, 2003).

La teoría de los guiones afirma que se observan ciertos patrones en situaciones determinadas. Estos patrones existen en forma de esquemas mentales que permiten a las personas anticipar que es lo siguiente que ocurrirá en una conversación o interacción (Metts y Cupach, 1989), al igual que un actor sabe cual es la siguiente frase en su guión. Así, la mayor parte de la vida social sucede bajo la guía de un sintaxis operativo, de la misma manera que el lenguaje es una precondición del discurso (Simon y Gagnon, 1986). Los guiones sexuales son esquemas en contextos sexuales, que proporcionan significado y dirección para responder a señales sexuales y para comportarse sexualmente (Wiederman, 2005). Así, la conducta sexual está "guionizada" en el sentido de que una cultura determinada define lo que es sexual y cómo debería iniciarse la conducta sexual (Gagnon y Simon, 1973).

De acuerdo con los autores, los guiones operan en dos dimensiones: la interna y la externa. La dimensión externa es el aspecto performativo o comunicativo de los guiones. Son los gestos, verbales y no verbales que los miembros de una cultura utilizan para indicar interés sexual, es decir, la secuencia de conductas. En la dimensión interna, que es el aspecto cognitivo, se encuentra el lenguaje de los motivos que convierte lo biológico en una experiencia psicológica significativa (pensamientos, fantasías y actitudes; Leiblum y Rosen, 1991). Esta dimensión de los guiones permite a los individuos experimentar ciertas conductas como excitantes o placenteras.

Para que algo sexual ocurra, es necesario que este tipo de "guionización" se construya en tres niveles distintos: escenarios culturales, guiones interpersonales y guiones intrapsíquicos. Los escenarios culturales, son las guías instructoras que existen a nivel de la vida colectiva. La influencia que ejercen estos escenarios se produce a través del ejemplo que dan miembros de esa cultura que ya han interiorizado los guiones, así cómo a través de las descripciones que hacen los medios de comunicación de cómo las personas actúan y reaccionan en situaciones sexuales. También las instituciones de una sociedad contribuyen a la formación de guiones apropiados, valiéndose de la promulgación de leyes contra ciertas conductas sexuales o ciertos tipos de pareja sexual por ejemplo (Wiederman, 2005).

Estos escenarios culturales no sólo especifican objetos y metas apropiadas, y cualidades deseables de las relaciones entre uno mismo y el otro, sino que también instruyen en cuanto a 
horas, lugares, secuencias de gestos y palabras y lo más importante, en cuanto a lo que el actor y demás participantes deben estar sintiendo. Sin este tipo de guiones culturales, la conducta sexual pierde significado y se descontextualiza. Este tipo de instrucción cultural, no sólo nos hace estar mucho más entrenados en el momento del primer encuentro sexual de lo que la mayoría nos pensamos, sino que sin ella seríamos incapaces de iniciar o responder a la actividad sexual (Simon y Gagnon, 1986; Gagnon y Simon, 1973).

Sin embargo, los escenarios culturales no son infalibles predictores de la conducta, ya que para que puedan cumplir con su función, deben ser lo suficientemente abstractos y generales como para que se puedan aplicar a todas las circunstancias. Algunas improvisaciones son necesarias cuando existe alguna incoherencia entre el escenario abstracto y la situación concreta y esto debe resolverse en el nivel del guión interpersonal.

La necesidad de crear guiones interpersonales transforma al actor, hasta ahora tan sólo responsable de conocer su papel, en coguionista y le obliga a convertir las instrucciones y escenarios culturales en conductas específicas a un contexto dado. Los guiones interpersonales son pues, los que un individuo utiliza en sus encuentros sexuales con una pareja determinada. Estos guiones están influenciados por las normas culturales, pero cada individuo los pone en marcha de manera coherente con sus propias experiencias comunicativas y con sus propias parejas relacionales. Así estos guiones están influidos por las relaciones interpersonales.

Entre otras funciones, los guiones interpersonales sirven para reducir la incertidumbre, legitimar a los miembros de la interacción sexual, y así facilitar la ocurrencia del intercambio sexual. Aunque muchos sentimientos de los participantes están implicados en la puesta en marcha del guión, sólo los sentimientos apropiados deben ser representados en el mismo, y esto hace que para todos, en un momento u otro, el deseo siga en vez de preceda la conducta.

La necesidad de esquematizar la propia conducta así como la asunción implícita de la naturaleza esquematizada de la conducta de los demás, es lo que provoca un dialogo interno, en forma de primer ensayo. Este es el nivel o guión intrapsíquico. Simon y Gagnon (1986) comparan la relación entre los guiones interpersonales e intrapsíquicos con un planteamiento bakhtiniano. Todo individuo participa en dos actividades perpendiculares: se forman relaciones laterales (horizontales) con otros individuos en actos y discursos específicos, y simultáneamente se forman relaciones internas (verticales) entre el mundo exterior y la propia psique. Estas actividades dobles son constantes y su interacción constituye la psique (Emerson, citado en Simon y Gagnon, 1986). 
El guión intrapsíquico son los elementos motivacionales que llevan a una secuencia particular de conductas sexuales: motivos, deseos y pensamientos. Estos guiones, varían enormemente puesto que cada individuo crea el suyo propio en función de su posición única en el mundo (Metts y Cupach, 1989) y ayudan a definir el "yo sexual" de una manera consistente con las expectativas culturales y la conducta interpersonal. Así, su función es ensamblar los deseos individuales con los significados sociales. El deseo tiene su origen y prototipo en la experiencia de satisfacción, y la experiencia de satisfacción, una vez pasados los primeros momentos de la vida, viene corrupta con significados simbólicos (Laplanche y Pontalis, citado en Simon y Gagnon, 1986).

Los motivos, conscientes o inconscientes, que subyacen a lo que parece conducta sexual manifiesta, pueden ser muy variados. De hecho, como puede decirse de cualquier otro área de conducta, hay muchas más razones para comportarse sexualmente que maneras de comportarse sexualmente. Medio siglo después de la muerte de Freud, parece que la búsqueda de motivos sexuales que mantienen comportamientos no sexuales provoca mucha menos ansiedad que la búsqueda de motivos no sexuales, que en alguna ocasión organizan la conducta sexual (Burke, citado en Simon y Gagnon, 1986).

La parte menos observable pero igualmente importante del guión intrapsíquico es aquella que elicita y mantiene la excitación sexual, y a veces hace posible el orgasmo.

La relevancia de estos tres niveles no es igual en todas las sociedades o para todos los individuos o situaciones. En entornos tradicionales, los escenarios culturales y un limitado repertorio de improvisaciones ritualizadas es lo único que se requiere. Este tipo de sociedades son denominadas sociedades paradigmáticas, en el sentido de que existe un alto grado de significados compartidos. Por el contrario, en sociedades post-paradigmáticas pueden darse diferencias profundas de significado.

Por ejemplo, el ciclo vital tiene profundas implicaciones en la creación de escenarios culturales y roles sociales en términos de sexualidad. En este sentido existen muchas diferencias entre sociedades paradigmáticas, en las que existe un alto grado de consenso en cuanto a expectativas asociadas a etapas de la vida, y sociedades post-paradigmáticas en las que no sólo no están claras las expectativas culturales asociadas a la juventud o la vejez, sino que tampoco está claro quien es joven o viejo.

En estas sociedades occidentales, se produce lo que se ha llamado un desvanecimiento de los límites de las etapas del ciclo vital. Esto implica que las sociedades parecen proporcionar muy pocas instrucciones o poco entrenamiento para que los individuos manejen estas transiciones, 
como consecuencia de la pérdida de relevancia de escenarios culturales. Por ejemplo, la cuestión de qué constituye la madurez sexual mínima varía considerablemente en el panorama social contemporáneo. La involucración en actividades sociosexuales solía marcar los límites entre la adolescencia y la adultez, mientras que cada vez más, marca los límites entre la infancia y la adolescencia.

Una consecuencia es que parte del peso de los escenarios culturales se traslada a los guiones interpersonales y esto tiene el efecto de otorgar mayor poder al actor. La edad o el estadio en el ciclo vital sugieren la posibilidad de la actividad sexual al mismo tiempo que la actividad sexual significa o implica pertenecer a un estadio del ciclo vital. En este sentido es frecuente observar un acercamiento a lo sexual de los adolescentes siguiendo el motivo no sexual de obtener reconocimiento interpersonal o confirmación intrapsíquica. El incremento de actividad sexual en la adolescencia temprana constituye un ejemplo de deseo de significado: confirmación de competencia y estatus (Miller y Simon, 1982) que precede al compromiso con el significado de deseo erótico.

Tampoco la congruencia entre niveles es una característica garantizada. En algunos colectivos, los guiones interpersonales son pequeñas variaciones de escenario cultural dominante, y además satisfacen los requisitos de los guiones intrapsíquicos. Esta congruencia múltiple de los niveles de guiones ocurría por ejemplo cuando los intereses de excitación y orgasmo provenían exclusivamente de un participante: el masculino.

En épocas modernas, el impulso sexual cede el puesto al objeto de deseo y a la calidad de la relación con este objeto. La transformación del objeto en "otro" participante requiere el reconocimiento del "otro" como otro "yo", y entonces no sólo hay que tener en cuenta la conducta del otro, sino también los sentimientos que esa conducta comunica de una manera incierta. Esto conduce a un problema de acomodación puesto que un mismo guión interpersonal debe satisfacer dos guiones intrapsíquicos. Hombres y mujeres, independientemente de su procedencia representan subculturas diferentes (Wiederman, 2005) y existen expectativas diferentes para cada sexo en relación con la conducta sexual y la aceptación social (Gagnon, 1990).

En resumen, la teoría de los guiones sexuales se apoya sobre las siguientes premisas. En primer lugar, la conducta sexual está determinada por la sociedad. Esto implica, que a medida que cambia la sociedad, evoluciona también la conducta sexual, por eso los guiones sexuales son constructos cambiantes en el tiempo. En segundo lugar, los actos sexuales tienen significados 
diferentes en función de los individuos involucrados, sus características y su estatus social. Al mismo tiempo, cómo se ven ellos mismos y los significados que para ellos tiene la sexualidad, determina la elección de acciones sexuales particulares. En tercer lugar, las conductas sexuales se aprenden del guión sexual que predomina en el entorno del individuo. Así, lo que una persona encuentra sexualmente excitante es resultado del guión social sexual. Cuarto, la ciencia dedicada al estudio de la conducta sexual está igualmente sujeta a normas sociales y culturales, creando una lente cultural imposible de separar de la propia investigación. Finalmente, el sexo y la conducta sexual están unidos, implicando expectativas diferentes para hombres y mujeres en términos de comportamiento sexual.

\section{APLICACIÓN DE LOS GUIONES SEXUALES: COMUNICACIÓN SEXUAL}

La comunicación sexual es un componente muy importante en las relaciones íntimas. Idealmente, desde una perspectiva de salud, las relaciones sexuales deberían poder ser minimamente anticipadas (no suceder a modo de shock) deseadas (ambos miembros están preparados y deciden libremente) protegidas (contra embarazos y enfermedades) y disfrutadas (vividas de manera positiva). La comunicación sexual juega un claro papel en la consecución de éstos ideales (Mitchell y Wellings, 1998; Holland, Ramazanoglu, Scout, Sharpe y Thomson, 1990; Kent, 1993).

Sin embargo la comunicación sexual en parejas jóvenes parece ser algo problemático y lleno de frecuentes malentendidos (Wight, 1992; Guzman, Schlehofer-Sutton y Villanueva, 2003; Coleman y Ingham, 1999). El discurso sobre sexo no parece compatible con la pasión sexual, puesto que la comunicación explicita contradice una asunción propia de la cultura occidental: La actividad sexual es espontánea y romántica (Gilbert, Walter, McKinney y Snell, 1999). La falta de habilidad de los adolescentes a la hora de comunicarse durante un encuentro sexual es un predictor significativo de prácticas sexuales poco seguras o poco saludables (Boldero, Moore y Rosenthal, 1992). A pesar de la dificultad que los adolescentes encuentran a la hora de negociar encuentros sexuales y de las repercusiones que la comunicación tiene en el bienestar integral de éstos, se sabe muy poco sobre los factores que influyen en la comunicación sexual. La comunicación sexual ha sido muy documentada entre adolescentes y sus padres o amigos (Lefkowitz, Boone y Shearer, 2004; DiIorio, Kelley y Hockenberry-Eaton, 1999; Clawson y Reese-Weber, 2003; Lefkowitz, Boone, Sigman y Au, 2002), sin embargo existen muchos 
menos estudios que exploren la comunicación sexual entre adolescentes y sus propias parejas sexuales (Widman, Welsh, McNulty y Little, 2006).

La teoría de los guiones sexuales ha resultado de gran utilidad para el estudio de la comunicación sexual (Metts y Spitzberg, 1996; Byers, 1995; Edgar y Fitzpatrick, 1993; Dworkin, Beckford y Ehrhardt, 2007; Meston y O'Sullivan, 2007). En primer lugar, el constructo de guión sexual proporciona a los investigadores una perspectiva desde la que acceder a las formas de comunicación relacional comúnmente aceptadas. Los escenarios culturales ponen de relieve qué actitudes y expectativas existen en relación a la sexualidad así cómo el carácter cambiante de éstas. Además ayuda a los investigadores a situar a los individuos en la estructura social y a examinar el impacto que ésta posición tiene en la elección de formas comunicativas.

Los individuos que siguen guiones sexuales tratan de adaptarse a los roles socialmente construidos de que disponen. Una mayor comprensión de éstos roles puede proporcionar una mayor clarificación de la conducta sexual

Sin embargo existe un problema que los autores de la teoría vieron de cara a la investigación en sexualidad: Cada nivel del proceso de guionización contextualiza e influencia a los demás, pero raramente con el poder de proporcionar una comprensión integral de los mismos (Simon y Gagnon, 2003). Es decir, no se puede establecer una dirección de influencias o un diagrama de conjuntos que integren unos niveles dentro de otros.

En este sentido, hay cierta dificultad en determinar qué contribución exacta, directa o indirecta, hace cada nivel a la puesta en marcha de una determinada conducta o forma de comunicación. Por ejemplo el sexo o género es una variable susceptible de influir desde varios niveles al mismo tiempo. Por un lado, los escenarios culturales proporcionan instrucciones y generan expectativas sobre que papel tiene cada sexo en las interacciones sexuales. Por el otro, el género es también un elemento que contribuye enormemente a la formación de la identidad propia de cada individuo, y con ello a la elaboración de concepciones sobre la propia sexualidad.

Las características de las relaciones interpersonales pueden también influir desde diferentes niveles al mismo tiempo, ya que por ejemplo una relación determinada condiciona el guión interpersonal directamente pero también puede afectar a cualidades individuales y de personalidad, a través de la experiencia personal que esa relación ha supuesto para cada individuo y de una manera indirecta, influir así en el guión interpersonal (Dybvig-Pawelko, 2007). 
De lo que parece haber menos dudas es que tanto el género como la relación interpersonal o contexto relacional afectan a la comunicación sexual. La investigación con la que contamos sugiere que el género es un importante factor predictor de la comunicación sexual (Metts y Spitzberg, 1996; McCabe, 1999). Entre los factores relacionales que intervienen en la forma de comunicación en la adolescencia se encuentra la duración de la relación, la satisfacción con la relación y el compromiso (Metts y Spitzberg, 1996; Byers y Demmons, 1999; Herold y Way, 1988). A continuación veremos cómo estos factores afectan a los guiones de comunicación sexual.

\subsection{El género en los guiones sexuales}

Como ya hemos visto en un apartado anterior hay varios artículos de revisión que indican que hombres y mujeres se diferencian en cuanto a actitudes, sentimientos y conductas sexuales (Baumeister y Tice, 2001; Oliver y Hyde, 1993). Después de haber resumido las principales diferencias y de haber visto cómo la teoría de los guiones sexuales expone que hay diferentes expectativas en cuanto al guión sexual de hombres y mujeres, vamos a ver cómo se desarrollan éstas diferencias de guión sexual.

Anatómicamente, los chicos tienen más facilidades para ver y manejar sus genitales. A los niños se les enseña a sostener su pene para orinar y a manipularlo para lavarlo, mientras que a las niñas no se les enseña a tocar su clítoris, tan sólo a limpiarse cuidadosamente para no transferir bacterias del ano a la vagina y evitar así infecciones. Se les transmiten diferentes mensajes por lo tanto, en relación con sus genitales (Wiederman, 2005). Los niños comienzan pronto a descubrir sensaciones positivas derivadas del manejo de sus genitales y que éstos son tan sólo otra parte más, igual de visible, que otras de su cuerpo. Las niñas es cambio aprenden que sus genitales son prácticamente imposibles de ver y que requieren un manejo cuidadoso.

Estas diferencias anatómicas y los sutiles mensajes correspondientes contribuyen a explicar por qué los chicos se masturban más, y a una edad más temprana que las chicas (Oliver y Hyde, 1993). De la misma manera los roles de género pueden favorecer la exploración sexual en los chicos a los que se les supone asertivos e independientes, y disuadirla por la misma razón en las chicas. Además está el hecho de que las mujeres pueden quedarse embarazadas y los hombres no. En este sentido los padres suelen tener preocupaciones y valores sexuales diferentes para sus 
hijas que para sus hijos, a las que aleccionan más en términos de riesgos sexuales (Fisher, citado en Wiederman, 2005). La consecuencia es que las mujeres terminan teniendo el papel de responsables, vigilantes y en muchos casos restrictoras de la actividad sexual en la mayoría de sus relaciones.

La mayor experiencia en masturbación de los chicos combinada con los ideales de género basados en independencia y autosuficiencia, sientan las bases para la creación de guiones sexuales centrados en sí mismos y en sus sensaciones corporales (García y Carrigan, 1998; Regan y Berscheid, 1996). La estimulación sexual se asocia al simple placer físico y se disocia con facilidad de la relación con la propia pareja. Sin embargo, entender la actividad sexual en el vacío, como una experiencia de placer corporal desprovista de un significado más allá, es un concepto relativamente extraño para las chicas. Menos experiencia con la masturbación, añadido a los ideales de género basados en la interdependencia relacional y el autocontrol en términos de comportamiento, preparan el escenario para guiones sexuales femeninos centrados en las relaciones.

Además la actividad sexual es vista como algo potencialmente peligroso para el cuerpo y la reputación de las chicas, por lo que tiene que haber más incentivo para involucrarse en relaciones sexuales que el simple, y a veces incierto placer físico, que puedan recibir. El resultado es que la conducta sexual femenina se encuadra en el contexto de una relación significativa y se impregna de un significado acorde a ese contexto (Sedikides, Oliver y Campbell, 1994; Taris y Semin, 1997). Así, vemos que las chicas adscriben significados y motivaciones diferentes a la actividad sexual que los chicos (Eyre, Read y Millstein, 1997).

Después de lo expuesto, es razonable pensar que los chicos y chicas otorgan diferentes significados a una primera experiencia sexual con una pareja nueva. La chica corre diversos riesgos como un embarazo, daño a su reputación social, o el riesgo de que sus sentimientos resulten heridos, dada la diferencia de significado relaciónal que ambos sexos dan a la actividad sexual. Esta posición vulnerable lleva a las chicas a dar credibilidad a su papel, primeramente otorgado por otros, como restrictora de la actividad sexual, y a interiorizarlo.

La resistencia sexual presente en los guiones sexuales femeninos hace que lograr actividad sexual con una nueva pareja sea un refuerzo especialmente deseado para los chicos. Es muy probable que la actividad sexual con una nueva pareja suponga un incremento de autoestima masculina ya que la lectura que hace el chico es que la nueva pareja lo encuentra lo suficientemente deseable como para correr los riesgos de la actividad sexual con él (Baumeister 
y Tice, 2001). Para las chicas en cambio, la actividad sexual con una nueva pareja no implica un incremento de autoestima automático puesto que se da la creencia de que los hombres están dispuestos a compartir actividad sexual indiscriminadamente y sin apenas inversión emocional. Así, conseguir una pareja sexual nueva no sólo no es un gran cumplido para las chicas, sino que además contar muchas parejas sexuales puede reflejar un desvío de su guión sexual tradicional, o que no tienen mucho éxito a la hora de seguir el guión y lograr que alguna de sus parejas invierta en una relación significativa. Esta creencia también es compartida por los chicos quienes tradicionalmente han preferido, a la hora de tener relaciones significativas, a chicas que seguían con éxito los guiones sexuales preestablecidos (Seal y Ehrhardt, 2003).

Así, una experiencia bastante común en relación a la actividad sexual con una nueva pareja, es que un chico, tras parecer interesado en una relación potencial con una chica e involucrarse en la primera relación sexual, desaparezca después de la faz de la tierra. Las diferencias entre hombres y mujeres en los guiones sexuales puede explicar esto. El chico puede haber sido sincero en sus intenciones previas, sin embargo, tras haber recibido la inyección de autoestima que supone persuadir a una mujer para tener relaciones sexuales, el balance costes/beneficios asociado a seguir viendo a esta chica en particular, ha cambiado. El puede dudar de si esta chica es efectivamente la adecuada para él. La chica, que pensaba que la relación estaba progresando bien, ya que se sintió lo bastante segura como para iniciar actividad sexual con él, seguramente se sentirá decepcionada y probablemente más precavida de cara a la siguiente relación potencial. Así, es muy probable que la chica requiera incluso mayor indicación de inversión emocional por parte de las futuras parejas, antes de iniciar relaciones sexuales. La conclusión de esta anécdota es que en la medida en la que chicos y chicas utilizan sus respectivos guiones tradicionales, éstos pueden llegar a reforzarse mutuamente (Wiederman, 2005).

Hasta ahora hemos visto la diferencia en cuanto a los significados que las conductas sexuales tienen para ambos sexos, y el posible origen de tales diferencias. Ahora nos centraremos en cómo se reflejan éstos diferentes significados en la comunicación sexual, y en los problemas potenciales que provocan. 


\subsubsection{Comunicación de intenciones sexuales}

Es interesante destacar que en todo momento el rol femenino permite a los hombres adoptar y mantener una actitud libre y un abordaje sin freno en la sexualidad. Es responsabilidad de la mujer limitar el sexo, por el bien de los dos participantes, lo que abre un contexto de libertad masculina para burlar las defensas femeninas en cualquier manera que permita tener actividad sexual (Wiederman, 2005). Este contexto permisivo en cuanto a formas de vencer o superar la resistencia femenina facilita que, en el nivel de comunicación sexual, se produzcan frecuentes "malentendidos" entre hombres y mujeres. Esto es más claro entre adolescentes, que además de no tener otra referencia que los guiones sexuales tradicionales, no han desarrollado enteramente sus habilidades sociales y cognitivas generales, para la comunicación o negociación.

Una de éstas circunstancias, que tiende a estar plagada de malentendidos, es la comunicación de intenciones sexuales (Meston y O'Sullivan, 2007) Según numerosos estudios, en la comunicación de intenciones o interés sexual se utilizan poco formas de comunicación directas y abiertas, a favor de formas no verbales e indirectas de comunicación (Rosenthal y Peart, 1996; Renninger, Wade y Grammer, 2004). Muy frecuentemente la ambigüedad sobre un posible encuentro sexual se mantiene a propósito y hasta el final, por si acaso la pareja, normalmente chica, decidiera no continuar (Lear, 1995).Un mecanismo para mantener la ambivalencia es la utilización de la comunicación no sólo de manera indirecta, sino de manera contradictoria. La comunicación no verbal puede complementar o contradecir la verbal (Knapp, 1980) y en situaciones de ambivalencia, los mensajes tienden a ser contradictorios. Así, movimientos sutiles físicos pueden decidir el curso de la situación, mientras otro tipo de mensajes son expresados verbalmente.

Si resulta claro que la otra persona desea actividad sexual, es más fácil estar preparado para rechazarlo, por lo que un interés típico del guión tradicional masculino es que sólo en un momento tardío del proceso sea obvio que se producirá una relación sexual. Puesto que las chicas tienen menos expectativas sobre cuándo ocurrirá una relación sexual (Mitchell y Wellings, 1998) tienen menos probabilidades de reconocer las señales contextuales que indican la posibilidad sexual. Para los adolescentes chicos en cambio, una vez que la posibilidad sexual aparece, aunque sólo sea como una realidad vaga, ésta tiende a convertirse en una preocupación importante (Spencer, citado en Mitchell y Wellings, 1998). Esto aumenta la probabilidad de que reconozcan las señales que indican posibilidad sexual de una manera más precoz que las chicas. 
A la ambigüedad mantenida hasta el final se une con frecuencia la tendencia a recurrir al discurso del impulso sexual masculino cuando se produce un choque de intereses sexuales (Crawford, Kippax y Waldby, 1994). Este discurso parece apoyarse en la creencia de que a veces es demasiado tarde, a nivel de excitación sexual masculina, para parar la actividad sexual, lo que fomenta sentimientos culpabilizadores si uno se da cuenta "tarde", y se desea detener la escalada sexual. Así, es frecuente que las adolescentes se sientan incapaces de comunicar su ambivalencia a su pareja, y terminen amoldándose al guión sexual masculino en una forma de actividad sexual no deseada consentida.

Ante la tendencia de que las expectativas masculinas sean las que se vean cumplidas, y ante la virtual imposibilidad de negociar (Crawford et al., 1994) algunas adolescentes intentan expresar su resistencia a través de excusas, que una vez superadas por su pareja, las dejan indefensas. Este es uno de los mecanismos por los que se originan más sentimientos de culpa y arrepentimiento tras encuentros sexuales, en las chicas que en los chicos. (Mitchell y Wellings, 1998; Ponton y Judice, 2004; Ramos et al., 2003; Oliva et al., 1993).

Si repasamos la secuencia comunicativa, encontramos diversos fracasos de comunicación. En primer lugar la ambivalencia sobre las intenciones, mantenida a través de comunicación indirecta y contradictoria. En segundo lugar, la trampa a la que lleva la ambigüedad mantenida, que supone "darse cuenta tarde" y tener que ceder ante el discurso del drive sexual masculino. En tercer lugar la sustitución de la negociación o expresión clara de desacuerdo por el ofrecimiento de excusas inventadas. Las dificultades son evidentes.

Sin embargo esta secuencia, es sólo una de tantas que pueden darse, y no siempre el mal uso deliberado de la comunicación sexual se produce por parte del varón. En determinadas circunstancias relacionales, es más probable que el varón emplee formas de comunicación del interés sexual más directas que las chicas (Eyre et al., 1997; Greer y Buss, 1994; Clark, Shaver y Abrahams, 1999). Como ya hemos visto la producción de excusas por parte de las chicas no es una buena manera de comunicar los propios deseos. Hay también otros malentendidos fruto de comunicaciones fallidas tipicamente femeninas, como el fenómeno conocido como token resistance. Este fenómeno consiste en que, debido a los riesgos que supone para una mujer salirse del guión tradicional femenino y que ya hemos visto, es relativamente frecuente que una mujer o una adolescente diga que "no" a la actividad sexual cuando en realidad quiere decir "si" (Muehlenhard y Hollabaugh, 1988; O’Sullivan y Allgeier, 1998). 
Otra forma de comunicación discrepante con las verdaderas intenciones es la provocación sexual, o sexual teasing, caracterizada por la comunicación de intenciones o interés por participar en actividad sexual a pesar de no tener intenciones de llevarlo a cabo (Meston y O'Sullivan, 2007) Aunque es relativamente frecuente tanto en hombres como en mujeres, éstas tienen más probabilidades de haberlo utilizado como estrategia de poder reactivo contra los hombres en guiones heterosexuales (Howard, 1988; Metts y Spitzberg, 1996).

Estas dos últimas formas de comunicación de intenciones sexuales están asociadas con creencias que justifican el uso de la coerción sexual e incluso la agresión sexual como respuesta fundamentalmente masculina (Garcia, 1998; Osman, 2003; Meston y O’Sullivan, 2007). En el primer caso, la falta de credibilidad que tiene el "no" femenino en algunas ocasiones, puede conducir a ilegitimizar todo tipo de resistencia de una forma indiscriminada y a emplear todos los medios disponibles necesarios para conseguir el acceso sexual. En el segundo caso, de nuevo se recurre al discurso del drive sexual masculino y a la creencia de que a los hombres, una vez excitados con un "si", no se les puede frustrar con un "no", para justificar el uso de la coerción sexual.

Como fenómeno opuesto tenemos el consentimiento de actividad sexual no deseada del que hablaremos más detalladamente en otros apartados de ésta revisión. Hay diversos estudios que documentan el consentimiento sexual masculino como consecuencia de la obligación que supone su rol de iniciador de la actividad sexual En el guión sexual tradicional, se espera que el hombre esté disponible para cada oportunidad sexual (Shotland y Craig, 1988), así que si éste no expresa un claro interés sexual, puede haber dudas sobre su masculinidad, su potencia sexual, etc. (O’Sullivan y Allgeier, 1998; Gilbert et al., 1999).

\subsection{El contexto relacional y los guiones sexuales}

Las relaciones románticas son un fenómeno distintivo de la adolescencia. Durante la transición de la infancia a la adolescencia, las relaciones de pareja se convierten en una de las principales bases organizadoras de la cultura de los pares y en el principal contexto para el desarrollo sexual adolescente (Brown, Feiring y Furman, 1999; Miller, Norton, Curtis, Hill, Schvaneveldt y Young, 1997; Moore, Miller, Glei y Morrison, 1995). Sin embargo, los adolescentes también 
tienen actividad sexual fuera de las relaciones de pareja estables (Cooksey, Mott y Neubauer, 2002; Manning, Longmore y Giordano, 2005), aunque estos contextos relacionales están mucho menos estudiados. Así un concepto clave muchas veces ausente en la investigación en la sexualidad adolescente es la naturaleza de la relación en la que se desarrolla la actividad sexual.

\subsubsection{Fases del desarrollo de las relaciones románticas en la adolescencia}

Hay varias tradiciones teóricas en el desarrollo de relaciones románticas en la adolescencia y en todas se propone una evolución asociada a la madurez. En una de estas perspectivas, los adolescentes más jóvenes perciben las relaciones románticas más en términos de amistad y compañía y los adolescentes más maduros en términos de cuidado y apoyo (Shulman y SeiffgeKrenke, 2001). Furman y Wehner (1994) propusieron que la pareja romántica se va incorporando poco a poco a la jerarquía de figuras de apego y afiliación que hasta ese momento tiene el adolescente. A medida que la relación se va desarrollando, la pareja romántica va creciendo en importancia y finalmente se convierte en la primera figura que satisface las necesidades de apego, cuidado, compañía, intimidad y por último, sexualidad.

Brown (1999) y Connolly y Goldberg (1999) propusieron modelos de relaciones románticas en la adolescencia. Ambos modelos describen el desarrollo del romance adolescente en cuatro fases con una secuencia específica y en ambos modelos se reconoce el importante papel del grupo de amigos sobre las relaciones románticas. En la fase de iniciación, la atracción es la principal característica y aunque esta se centra en una persona en particular, no siempre va acompañada de una interacción asociada. Los objetivos básicos de esta primera fase son extender el propio autoconcepto y ganar confianza en cuanto a habilidades de relación con posibles parejas románticas. Como consecuencia de ello, los adolescentes están fundamentalmente preocupados por cómo se sienten, como actúan y cómo aceptan sus amigos su conducta. Durante la segunda fase, fase afiliativa o fase de estatus, los chicos y chicas se reúnen en grupos mixtos. Aunque las necesidades sexuales existen, los motivos relacionados con la afiliación son tan importantes en este momento que la mayoría de las relaciones durante esta fase enfatizan más la compañía que la intimidad (Shulman y Scharf, 2000). La tercera fase, o fase afectiva, viene marcada por la presencia de relaciones románticas íntimas en las que la interacción entre los miembros tiene forma de relación diádica hasta el punto de llegar a formar una pareja. Hay mayor énfasis en la intimidad y en la actividad sexual. El papel que tiene el 
grupo de amigos a la hora de estructurar y regular esta relación decrece. En la cuarta fase, que se da durante etapas tardías de la adolescencia, se establecen las relaciones comprometidas o estables. Son relaciones a largo plazo, y las fuerzas de unión son la atracción, el deseo de intimidad y conductas de cuidado.

Los resultados obtenidos en la mayoría de los estudios apoya la idea de que el romance adolescente está guiado por principios de desarrollo evolutivo. Así la atracción en posibles parejas románticas comienza durante la adolescencia temprana. Los adolescentes más jóvenes se centran en ganar confianza en sus propias habilidades para iniciar experiencias románticas, pero todavía no está claro cómo se inician o se experimentan tales primeros encuentros. En diversos estudios exploran los pensamientos y las acciones encaminadas a iniciar un encuentro romántico, en particular, cómo un adolescente se aproxima a una posible pareja por primera vez. Brown (1999) encontró que los adolescentes prefieren aproximarse a alguien que ya conocen,o bien piden ayuda a un amigo primero. Cuando se sienten atraídos por alguien que no conocen mucho, normalmente intentan llamar la atención sobre sí mismos, a través por ejemplo de conductas cómicas o bromas, o intentan comunicar sus sentimientos de atracción a través de conductas no verbales.

En los comienzos de las relaciones románticas, los adolescentes experimentan altos niveles de estrés y bajos niveles de intimidad (Nieder y Seiffge-Krenke, citado en Shulman y SeiffgeKrenke, 2001). El alto nivel de estrés de las fases tempranas de la relación se asocia con preocupaciones sobre la identidad, el grupo de amigos, y sobre la propia relación en sí misma. Sin embargo, con el tiempo, estos adolescentes no sólo manifestaron menores niveles de estrés romántico sino que también eran capaces de de afrontarlo más eficazmente.

Durante las etapas afiliativas e íntimas, los adolescentes tienden a resaltar la parte más lúdica y entusiasta en cuanto a compartir tiempo e interaccionar con la posible pareja. Así, es posible que durante la segunda fase, la atracción física y la fascinación con el otro sexo ejerza una gran influencia en la búsqueda que hacen los adolescentes de actividades sociales, como que prefieren interaccionar con posibles parejas dentro de un marco de encuentros casuales entre chicos y chicas (Shulman y Kipnis, 2001).

En su estudio, Taradash y Connolly (citado en Shulman y Seiffge-Krenke, 2001) intentan diferenciar entre adolescentes de 16 años que muestran potencial para pasar a la tercera fase y los adolescentes que están en la segunda o incluso en la primera fase. Encontraron que cuanto 
más tiempo pasaban los adolescentes con sus parejas fuera del grupo de amigos, más cómodos estaban éstos expresando sus opiniones y consolidando su autonomía. Al contrario, adolescentes que eran incapaces de establecer relaciones de pareja estables y duraderas, tendían a involucrarse con mayor número de parejas que la mayoría y eran menos competentes socialmente.

En cuanto a la última fase, en un estudio llevado a cabo con estudiantes universitarios de 20 años mostraba que el sentimiento de lazos afectivos mutuos y compromiso eran la clave para una relación romántica óptima a esa edad. Confianza en la disponibilidad de la pareja, cuidado y compromiso en la relación eran predictores de la estabilidad de la pareja un año después.

\subsubsection{Aparición de otros contextos relacionales para la actividad sexual}

Tradicionalmente ha sido la formación de relaciones de pareja el contexto predominante para el desarrollo sexual de los jóvenes. Sin embargo, en la última parte del siglo veinte se han producido una serie de cambios que han posibilitado la aparición de otros contextos relacionales para la actividad sexual, más informales que las relaciones de pareja pero aún así legítimos. Este tipo de relaciones son popularmente llamadas "rollos", refiriéndose con esto a relaciones de una noche o varios días, en las que se produce contacto sexual de algún tipo, como mínimo el beso íntimo, pero a veces incluyendo relaciones coitales. Es un proceso informal pero frecuentemente consiste en abandonar un bar o una fiesta con alguien del otro sexo e ir a un lugar privado para llevar a cabo algún tipo de actividad sexual, aunque en algunos casos el contacto sexual puede ocurrir en el mismo encuentro social (Bogle, 2004).

Antes del último tercio del siglo veinte en España, y en otros países antes de los años 60, el proceso de búsqueda de parejas íntimas estaba seriamente vigilado por las familias. La supervisión era continua y la actividad sexual se relegaba hasta que el compromiso de la relación de pareja había sido atestiguado familiarmente. Sin embargo, una serie de cambios en la estructura social terminaron afectando a la manera en la que los jóvenes intimaban sexualmente. Uno de ellos ha sido la mayor importancia que se ha otorgado a los sentimientos románticos en las sociedades occidentales, en detrimento de la posición social y la situación financiera que podía ofrecer la posible pareja a la relación. En este sentido, los sentimientos 
románticos están gravemente influidos por la atracción sexual, por lo que ésta se convierte en una parte muy importante de la búsqueda de pareja íntima.

Por otro lado, la edad de matrimonio se ha incrementado en las sociedades occidentales hasta llegar a los 25 años en las mujeres y los 27 años en los hombres (Bianchi y Casper, 2000). Como consecuencia, los jóvenes tienen mucho más tiempo para probar y experimentar antes de asentarse románticamente. Como reflejo de este incremento de la edad de matrimonio, se ha producido un descenso de la edad del primero encuentro sexual y un aumento del número de parejas sexuales (Bakker, citado en Gebhardt, Kuyper y Dusseldorf, 2006). La normalización de los métodos anticonceptivos junto a la liberalización de las actitudes sexuales han caracterizado las relaciones coitales como un signo de intimidad y placer fundamentalmente, y las han desvinculado de la procreación y del matrimonio.

Estos cambios en el área de las relaciones amorosas y la sexualidad, han sido facilitados por otros cambios en otras áreas sociales, como el mundo laboral, la educación y las comunicaciones. A medida que ha ido incrementándose la participación laboral de la mujer, lo ha hecho su independencia. Esto junto al crecimiento de la población que asiste a la universidad, hace que muchos más jóvenes vivan por su cuenta, lejos de la supervisión de sus familias.

De esta forma, unidos a los cambios que se producen en las instituciones sociales, van los cambios en los guiones que permiten a los jóvenes interaccionar íntimamente, dando lugar así a la aparición de otros tipos de relaciones y contextos sexuales legítimos, distintos de las relaciones de pareja.

\subsubsection{Estudio e importancia del contexto relacional en la adolescencia}

La mayoría de los estudios que distinguen entre relaciones y tipos de parejas, utilizan la terminología "pareja estable" y "pareja casual", pero otros estudios utilizan terminología diferente. Por ejemplo, las palabras "primaria", "exclusiva", "íntima" y "nueva" han sido utilizadas para caracterizar tipos de parejas sexuales (Bauman y Berman, 2005). Existe poca investigación sobre cómo aplican esta terminología los propios adolescentes a sus relaciones. En un estudio (Ellen, Cahn, Eyre y Boyer, 1996) encontraron que los adolescentes clasifican las parejas sexuales en tres categorías: parejas estables, parejas casuales u ocasionales y "rollos de 
una noche". Esto significa que los adolescentes distinguen sus parejas sexuales basándose en la naturaleza romántica de la relación que mantienen con ellas y que parte de las experiencias sexuales ocurren en contextos casuales.

Algunos estudios han examinado el contexto casual en el que se produce toma de decisiones sexuales en estudiantes universitarios (Maticka-Tyndale, Herold y Mewhinney, 1998; Paul, McManus y Hayes, 2000) o adultos (Cubbins y Tanfer; Hennik et al., citado en Manning et al., 2005). En cambio hay muy pocos estudios que estudien las experiencias sexuales de los adolescentes fuera de las relaciones de pareja.

Hay evidencia de que un número significativo de adolescentes se involucra en relaciones sexuales en contextos ocasionales o esporádicos. En Estados Unidos, una encuesta nacional de crecimiento familiar (1995) indicaba que un $23 \%$ de adolescentes chicas decía haber tenido su primera experiencia sexual con alguien que acababan de conocer, con amigos, o con alguien con quien habían salido una vez. (Manning, Longmore y Giordano, 2000). Sin embargo estos estudios sobre primeras relaciones sexuales pueden no ser muy indicativos de experiencias sexuales posteriores. No está muy claro si la experiencia sexual fuera de la relación de pareja es una ocurrencia aislada o si es indicativa de un patrón de comportamiento sexual.

En cualquier caso, la comprensión de la sexualidad en la adolescencia requiere tener en cuenta la naturaleza fluida y variada de las relaciones, y los estudios hasta ahora realizados no han distinguido suficientemente el contexto en el que tienen lugar las experiencias sexuales adolescentes (Manning et al., 2005).

Es importante comprender el contexto relacional de las experiencias sexuales adolescentes por varias razones. En primer lugar la corta duración y la falta de compromiso propias de las relaciones ocasionales en las que tiene lugar actividad sexual se han asociado en algunos estudios a ciertos riesgos, como exposición a mayor número de parejas sexuales, embarazos no deseados y enfermedades de transmisión sexual (Ford, Sohn y Lepkowski, 2001; Manning et al., 2000). Sin embargo otros estudios han encontrado mayor frecuencia de uso de preservativo en relaciones casuales que en relaciones de pareja (Bauman y Berman, 2005; Hynie, Lydon, Côte y Wiener, 1998; Friedman, Flor, Kottiri, Neaigus, Sandoval, Curtis, Des Jarlais y Zenilman 2001; Gebhardt, Kuyper y Greunsven, 2003). Esta falta de consistencia en los resultados puede estar reflejando la poca sistematización que existe en la investigación a la hora de controlar el contexto relacional durante el estudio de conductas sexuales en la adolescencia. 
En segundo lugar, los patrones de interacción sexual e íntima son aprendidos durante la adolescencia y es muy probable que éstos se extiendan a la adultez (Weiss, 1998). Furman y Simon (1999) argumentaron que la exposición a relaciones de pareja permite a los adolescentes desarrollar habilidades importantes que les ayudan a comprender la conducta y las motivaciones de su pareja. Así, este tipo de razonamientos más sofisticados puede estar más facilitado por las relaciones de pareja duraderas que por una serie de encuentros románticos breves y casuales.

En tercer lugar, las experiencias sexuales de los adolescentes son extremadamente complejas e involucran numerosas motivaciones, como el deseo sexual, identidad, oportunidad, características relacionales, experimentación (Giordano, Longmore y Manning, 2001; Weis, 1998). Podría argumentarse que adolescentes en particular pueden iniciar actividad sexual fuera de las relaciones de pareja, movidos por motivaciones específicas que reflejasen sus necesidades de establecer una identidad o la intensidad de los impulsos hormonales (Manning et al., 2005).

Resumiendo, el estudio del contexto en el que tiene lugar la actividad sexual en la adolescencia es importante ya que por una parte parece ser un consecuente de la existencia de determinadas motivaciones sexuales propias de la adolescencia, y por otra parte puede funcionar como antecedente que condiciona las conductas y los guiones sexuales comunicados que se llevan a cabo.

\subsubsection{Características de comunicación sexual en diferentes contextos relacionales}

Cuando comparamos la actividad sexual en dos contextos relacionales distintos como son las relaciones de pareja y las relaciones esporádicas o casuales, una de las principales características que las distingue es el diferente nivel de anticipación o preparación que suele existir en relación con la actividad sexual, y que suele llevar a diferentes tipos de comunicación sexual (Mitchell y Wellings, 1998).

En las relaciones de pareja, el hecho de planear de alguna manera o anticipar lo que puede ocurrir virtualmente, puede dar lugar a formas de comunicación más explicitas o constructivas. En este tipo de relaciones, la actividad sexual sucede simplemente como un paso más dentro de la progresión física, aunque la primera experiencia sexual tiene el potencial de producir un 
cambio cualitativo en la relación. Normalmente existe mutualidad entre ambos miembros de la pareja a la hora de iniciar la actividad sexual y se hace en gran medida a través de estrategias de comunicación directas (Seal y Ehrhardt, 2003).

Normalmente la anticipación de este paso saca a la luz las primeras discusiones sobre la parte sexual de la relación. A veces hablar sobre métodos anticonceptivos sirve para introducir el tema del sexo. Si un miembro de la pareja pregunta si compra preservativos, ambos saben que lo que realmente quiere decir es que desea tener relaciones sexuales (Mitchell y Wellings, 1998).Generalmente, haber anticipado y explicitado el hecho de tener actividad sexual, hace que la experiencia sea positiva y que haya menos probabilidades de sentir arrepentimiento (Ingham, Woodcock y Stenner, 1991).

En cambio, el nivel de anticipación de la actividad sexual en las relaciones esporádicas o de una noche es más bajo. En estas situaciones, los adolescentes son reacios a verbalizar las intenciones sexuales porque muchas veces sería inaceptable asumir que ocurrirá algo sexual, sobre todo entre adolescentes con poca experiencia sexual. Así, estas relaciones sexuales esporádicas se caracterizan por el silencio, o por una comunicación vaga y enrarecida, antes, durante y después del evento. A pesar de que existe poca anticipación, si que se disponen de ciertas pistas o señales contextuales que sugieren la posibilidad sexual. Por ejemplo, ciertos contextos como fiestas, bares o encuentros sociales en los que el alcohol está presente, pueden funcionar como señales porque en ellos, el contacto sexual se contempla como un posible resultado de la noche.

Los preservativos se utilizan en este tipo de relaciones a pesar de que la actividad sexual no está planeada. Son mayoritariamente los varones los que los lleva "por si acaso". Esto es consistente con lo que veíamos en el apartado anterior, en el que se describía a los chicos como más abiertos a la posibilidad de actividad sexual y más dispuestos a iniciarla, existiendo incluso cierta actitud negativa ante iniciaciones femeninas (Seal y Ehrhardt, 2003). Sin embargo, la introducción de los preservativos tiende a ocurrir de manera no verbal, y es sólo cuando su manipulación ocasiona dificultades que se verbaliza algo sobre ellos. Así, la falta de comunicación clara es la característica básica de la actividad sexual en este tipo de contextos relacionales. Son las estrategias indirectas y no verbales de comunicación sexual las que se utilizan y se interpretan mayoritariamente (Rosenthal y Peart, 1996; Seal y Ehrhardt, 2003). También es más frecuente en estas relaciones la existencia de ambigüedad en los mensajes o incluso contradicción entre mensajes verbales y no verbales, como veíamos también en el apartado anterior. 
Como hemos explicado antes, los guiones sexuales operan en dos dimensiones. La dimensión externa comprende los gestos, verbales y no verbales que los miembros de una cultura utilizan para indicar interés sexual, es decir, guiones comunicados. Y en la dimensión interna se encuentran los motivos que dan significado a la actividad sexual. El presente estudio examina éstos elementos de los guiones sexuales adolescentes. Por una parte, se estudian los gestos y tácticas que utilizan los adolescentes para iniciar actividad sexual, así como para limitarla, y por otra parte estudiamos las motivaciones que llevan a los adolescentes a involucrarse en relaciones sexuales. Además de analizar qué papel juegan el género y el contexto relacional en las estrategias y motivaciones sexuales, veremos qué relación existe entre estos dos elementos de los guiones sexuales. Por último dedicaremos un apartado individual a algunas prácticas relacionadas con el riesgo en la adolescencia como son el uso de la coerción sexual, del preservativo y el consentimiento de actividad sexual no deseada. Veremos ahora una revisión bibliográfica centrada en estos tres apartados específicos. 


\section{CAPITULO III}

\section{ESTRATEGIAS DE NEGOCIACIÓN SEXUAL}

Este capítulo se centra en el afrontamiento que tienen los adolescentes de la actividad sexual, es decir, cómo negocian el deseo de actividad sexual a través de estrategias de iniciación y limitación sexual. Dedicaremos en esta revisión un apartado especial a la coerción sexual como estrategia de avance sexual, por las especiales características y repercusiones psicológicas y sociales que tiene esta forma de iniciación sexual. Además examinaremos otras decisiones en el afrontamiento y la negociación de la actividad sexual en la adolescencia, como el consentimiento de actividad sexual no deseada y el uso del preservativo.

\section{ESTRATEGIAS DE AVANCE Y LIMITACIÓN SEXUAL}

\subsection{TIPOS DE ESTRATEGIAS DE AVANCE Y LIMITACIÓN SEXUAL}

La investigación sobre guiones o scripts ha estudiado estas conductas, a través del examen de la comunicación verbal y no verbal. Dentro de éste área hay varios temas en los que la investigación se ha centrado particularmente. Primero, se han descrito las tácticas concretas y 
los tipos de estrategias generales y la frecuencia con que se han utilizado para iniciar y limitar la actividad sexual. Segundo, se han examinado las diferencias de género que se encuentran en la iniciación y limitación sexual. Tercero, se ha destacado el papel de la coerción sexual como estrategia de iniciación sexual.

De manera menos sistemática, algunos estudios han explorado cómo afecta la experiencia sexual y el contexto relacional en la iniciación y limitación sexual, así como algunas variables de personalidad. Finalmente de forma puntual, se ha estudiado la eficacia y la aceptabilidad de las estrategias, la relación con el uso del preservativo y con motivaciones o metas generales. La mayoría de los estudios utilizan población adulta o universitaria y sólo unos pocos examinan el uso de estrategias sexuales en la adolescencia. También son muchos menos los estudios que examinan estrategias de limitación sexual comparados con los que estudian estrategias de iniciación sexual.

En nuestra revisión nos centraremos sobretodo en la descripción de tipos de estrategias sexuales utilizadas, de manera concreta en las coercitivas, y en las diferencias de género halladas, dando especial relevancia a aquellos estudios con población adolescente y a los que examinan el papel del contexto relacional y la experiencia sexual.

Es importante comprender las diferentes tácticas y estrategias que los individuos utilizan para iniciar actividad sexual. En primer lugar, hay que explicitar que las estrategias de iniciación sexual no son lo mismo que estrategias para iniciar una relación romántica. Las estrategias de avance sexual están destinadas a promover la actividad sexual tanto en relaciones a corto plazo como en relaciones a largo plazo (Buss y Schmitt, 1993) y su objetivo no es necesariamente desarrollar relaciones románticas. Así esta revisión se centra en los avances sexuales.

Muchos estudios han investigado con qué frecuencia las personas tienen relaciones sexuales, y sin embargo se ignora en general, los procesos individuales y diádicos que determinan si finalmente la actividad sexual ocurre. La interacción sexual es sólo el último de varios pasos que deben darse para que algún tipo de actividad sexual ocurra en una situación particular. Así, en primer lugar uno de los miembros de la pareja debe haber considerado la idea de iniciar la actividad sexual; en segundo lugar debe haber comunicado su interés o hecho algún avance sexual con su pareja; y en tercer lugar su pareja debe haber aceptado este avance sexual (Byers y Heinlein, 1989). Además diversos factores intrapersonales, interpersonales y situacionales pueden afectar en varios momentos de este proceso. En esta investigación se examina el paso 
concreto de la comunicación de interés sexual a través de estrategias de avance sexual y estrategias de limitación sexual.

Los investigadores han distinguido entre poder e influencia, a pesar de que puedan estar relacionados (Huston, citado en Christopher y Frandsen, 1990). Poder se ha entendido como el potencial de producir un cambio en un individuo, mientras que influencia es el propio intento de lograr ese cambio. En nuestro estudio nos centramos en el uso de la comunicación y la influencia. En este sentido, la mayor parte de la investigación sobre avances sexuales comienza examinando el estudio de Marwell y Schmitt (1967) sobre estrategias dirigidas convencer y estrategias dirigidas a resistir la persuasión. Propusieron, a raíz de sus estudios, que existían cinco dimensiones diferentes en las que se agrupaban las conductas dirigidas a persuadir a las personas. Estos factores eran: conducta de refuerzo, conducta de castigo, experiencia, activación de compromisos impersonales y activación de compromisos personales. Curiosamente encontraron que los factores de mayor impacto eran factores negativos como conductas de castigo y activación de compromisos impersonales. Otros estudios posteriores desarrollaron nuevas tipologías, como en el estudio de Cody, McLaughlin y Jordan (1980) que propusieron como técnicas de influencia la dirección racional, el intercambio, la manipulación, la amenaza y la declaración de competencia. Por otro lado, un estudio que investigaba el uso de tácticas para resistir los intentos de convencimiento (McLaughlin, Cody y Robey, 1980) las agrupó en cuatro tipos, la utilización de la propia identidad, la negociación, la justificación y las no negociadoras.

En el ámbito de las relaciones íntimas Falbo y Peplau (1980) encontraron dos dimensiones de técnicas utilizadas en las relaciones románticas, directa-indirecta y bilateral-unilateral.

Un considerable número de estudios se ha centrado en las tácticas de influencia asociadas con la actividad sexual, siendo de los primeros el estudio de Jesser (1978). En él, se estudia el uso que han hecho universitarios de 22 conductas dirigidas a señalizar el interés sexual a la pareja. Las conductas que más veces fueron utilizadas por la muestra fueron: "tocar", "acariciar con las manos" y "pedirlo directamente". Aunque no se categorizaron las conductas, las más utilizadas por todos fueron las estrategias directas, tanto verbales como no verbales. Hombres y mujeres utilizan por igual las estrategias directas, aunque las mujeres utilizan ligeramente más estrategias indirectas como contacto visual, cambios de apariencia física y de tono de voz. Sin embargo, es necesario tomar con precaución estos resultados ya que en este estudio, no se indicaba la frecuencia de uso de las estrategias sino si se habían utilizado alguna vez, y tampoco se discriminaba entre contextos relacionales. 
En el estudio de McCormick (1979) se investigaba la probabilidad de que estudiantes universitarios utilizasen 10 tipos de estrategias destinadas a promover la actividad sexual, así como las creencias en los estereotipos de género de ver al hombre como el incitador de la conducta sexual y a la mujer como la detractora de la misma. Las estrategias, tanto de avance como de limitación, se caracterizaron como directas o indirectas. Las directas eran refuerzo, coerción, lógica, información, moralización, conceptualización de la relación y seducción, y eran directas en la medida en la que permitían a la pareja saber que estaba siendo influenciada. El resto de estrategias, manipulación, engaño y lenguaje corporal, fueron clasificadas como indirectas porque su éxito dependía de que la pareja no supiera lo que el agente influyente estaba haciendo. Los resultados revelaron que ambos sexos utilizaban estrategias directas para evitar relaciones sexuales y estrategias indirectas para iniciar relaciones sexuales, siendo la seducción, la más frecuente en ambos sexos. Esto fue así a pesar de que en sus atribuciones se confirmaban los estereotipos de género. Estos resultados sugieren que tanto hombres como mujeres prefieren utilizar estrategias indirectas para la iniciación, probablemente para reducir su vulnerabilidad. Una limitación de este estudio era que estudiaba el uso hipotético y no real de las estrategias.

Un segundo estudio de la misma autora (LaPlante, McCormick y Brannigan, 1980) pretendía explorar de nuevo la prevalencia del guión tradicional en las atribuciones que se hacían de las estrategias de avance como propias de los hombres y las de limitación como propias de las mujeres. La intención era comprobar que ese guión cognitivo o generalizado era diferente del individual y realmente utilizado, llegando a la misma conclusión que en su anterior estudio, que no había diferencias entre hombres y mujeres en el uso real de estrategias. Los resultados confirmaron la existencia del guión generalizado tradicional, pero también confirmaron que éste guión era el que se aplicaba mayoritariamente. Así, los hombres utilizaban más estrategias directas e indirectas para iniciar relaciones sexuales y las mujeres utilizaban más estrategias tanto directas como indirectas para evitar relaciones sexuales.

La contradicción de los resultados de los dos estudios ha sido atribuida a diferencias en metodología. En el estudio original (McCormick, 1979) se situaba a los participantes en situaciones imaginarias mientras que en el siguiente se pedía que revelasen la utilización real que hacían de las estrategias. Las únicas excepciones en el estudio fueron las estrategias de avance conceptualización de la relación y lenguaje corporal, en las que no se encontraron diferencias de uso entre hombres y mujeres. La variable de personalidad locus de control, 
incluida en el estudio, no tuvo ninguna influencia sobre el uso de estrategias sexuales y los autores lo explicaron aludiendo al hecho de que el encuentro sexual hombre-mujer podría ser un baluarte en cuanto a la aplicación estricta de los roles de género.

Otro trabajo sobre situaciones hipotéticas (Peper y Weis, 1987) preguntaba a una muestra de chicas cómo iniciarían relaciones coitales con una pareja imaginaria. Las tácticas más citadas fueron "hablar", "usar señales situacionales", "tocar" y "besar". "Evitar" e "ignorar las señales" fueron las tácticas de rechazo más comunes.

Byers y Heinlein (1989) realizaron una investigación que examinaba tres aspectos de la actividad sexual en parejas casadas o que vivían juntas: la iniciación sexual, la respuesta a estas iniciaciones y considerar iniciar pero no hacerlo. Distinguieron dos dimensiones que caracterizaban la iniciación y la respuesta, que eran verbal-no verbal, y directa-indirecta, dando lugar fundamentalmente a cuatro tipos de técnicas. En el registro que llevaron a cabo las parejas, los avances fueron por igual sólo verbales, sólo no verbales y con ambos componentes, aunque la estrategia más utilizada fue el avance verbal directo, seguido de besar, una táctica no verbal directa. La respuesta negativa era más probable que se diera de manera verbal que la respuesta positiva o aceptación, y solía estar acompañada de alguna justificación. Se encontró que el rechazo era más satisfactoriamente resuelto cuando la iniciación se había producido de manera verbal. Así era más fácil decir "no" y aceptar un "no" cuando la propuesta era verbal, reflejando así, las ventajas de la comunicación sexual verbal y explícita.

Los hombres iniciaban y consideraban iniciar más frecuentemente que sus parejas, sin embargo, contrariamente a los estereotipos de género, cuando se controlaba el número de avances, hombres y mujeres no diferían en sus respuestas a las iniciaciones.

En 1992, O’Sullivan y Byers, realizaron una investigación similar pero esta vez con una muestra de estudiantes universitarios con diferentes estatus relacionales, relación estable y relación ocasional. El estudio pretendía evaluar la medida en la que estos tres aspectos de la actividad sexual se ajustaban al guión sexual tradicional, después de la abundante contradicción en este sentido hallada en estudios anteriores. En términos generales los resultados eran consistentes sólo en cuanto a la frecuencia de iniciación, que era mayor en los hombres que en las mujeres, mientras que éstos consideraban iniciar y respondían de la misma manera que ellas. Sin embargo los resultados estaban condicionados por el estatus o contexto relacional de los participantes puesto que el guión tradicional con respecto a iniciar actividad sexual parecía aplicarse más en relaciones ocasionales. Así, en relaciones de pareja, se utilizaban más tácticas 
de avance que en relaciones casuales y por parte de ambos sexos, y en relaciones casuales, era el hombre el que iniciaba con mayor frecuencia.

Hombres y mujeres no diferían tampoco en su manera de iniciar, ya que en ambos casos se hacía preferentemente a través de estrategias verbales indirectas y no verbales o físicas. En ningún caso influyeron características personales, como ideología de género, experiencia sexual o actitudes sexuales en los tres aspectos estudiados.

Christopher y Frandsen (1990) llevaron más allá el estudio de las estrategias de influencia desarrollando la escala de tácticas de influencia sexual, que examina muchas de las tácticas presentes en otros estudios. Los autores pedían a los participantes universitarios que recordasen la última cita e indicasen en qué medida habían utilizado 48 tácticas recopiladas de la literatura existente sobre intentos de influencia diádicos. Basándose en sus resultados, obtuvieron cuatro categorías generales de tácticas de influencia que eran: Actos antisociales, Cercanía física y emocional, Lógica y razón, y Manipulación. Los actos antisociales reflejaban intentos de imponer los deseos sexuales propios a la pareja de maneras socialmente inaceptables. Estas conductas fueron luego subdivididas en actos antisociales encubiertos y actos antisociales abiertos. La cercanía física y emocional comprendía las conductas tanto verbales como no verbales dirigidas a comunicar cercanía e intimidad a la pareja. La lógica y la razón consistía en la utilización de argumentos lógicos dirigidos mayoritariamente a limitar la intimidad sexual y finalmente, la presión y manipulación comprendía tácticas de presión como el uso del alcohol o la manipulación de los sentimientos y el engaño para iniciar actividad sexual. La correlación existente entre ésta categoría y los actos antisociales, sugería en la opinión de los autores que la presión y la manipulación podrían ser los precursores de actos más violentos y extremos.

Los resultados indicaban que los hombres utilizaban en mayor medida la presión y la manipulación que las mujeres. Además aquellos participantes motivados a tener mayor actividad sexual eran los que mas probabilidades tenían de utilizar los dos tipos de estrategias coercitivas. Sólo la cercanía física y emocional se relacionaba positivamente con la experiencia sexual y la lógica y la razón de manera negativa. En términos de factores asociados a las estrategias de influencia, los autores ponen de relieve que las tácticas coercitivas han sido explicadas fundamentalmente por variables de personalidad mientras que el uso de influencias positivas emocionales se ha examinado en el contexto de dinámicas de relación.

En un trabajo de Greer y Buss (1994) se examinaba las conductas específicas que los individuos utilizaban para iniciar actividad sexual, a través de un procedimiento de elicitación libre que preguntaba a los participantes que hacían para promover encuentros sexuales. Agruparon 
conceptualmente 122 actos individuales en 34 clusters homogéneos. En este estudio utilizaban una perspectiva evolutiva, sugiriendo que los hombres tenían el deseo de procrear con mujeres jóvenes y saludables. Sus resultados indicaban que las mujeres utilizaban más tácticas como potenciar su apariencia física, mientras que los hombres utilizaban más tácticas como hacer regalos y demostraciones de su fuerza física. Además los hombres también utilizaban más frecuentemente otro tipo de tácticas como emborrachar a la persona, ir a un área apartada, hacer cumplidos sobre el atractivo físico, verbalizar el deseo sexual y bailar cerca.

En un estudio posterior Schmitt y Buss (1996) recopilaron 31 tácticas para atraer a un miembro del sexo opuesto que agruparon en cuatro categorías: disponibilidad sexual, atractivo físico, dominación, y exclusividad sexual o fidelidad. Este instrumento fue también utilizado por otro estudio, en el que se estudiaba la asociación entre estrategias u objetivos de emparejamiento (largo y corto plazo) y tácticas de atracción sexual (Bleske-Rechek y Buss, 2006). Las estrategias de emparejamiento a corto plazo o una orientación sexual no restringida se asociaban con el uso de tácticas que ponían de relieve la propia disponibilidad sexual, el atractivo físico y la capacidad de dominación. En cambio, las estrategias a largo plazo o una orientación sexual restringida se asociaban con el uso de tácticas que promovían la percepción de fidelidad sexual.

Allen y Bailey (2007) llevaron a cabo un estudio para comprobar si las estrategias u objetivos de emparejamiento y las tácticas de atracción eran un mismo constructo o eran factores independientes. Plantearon que ambos factores estaban relacionados en la medida en que la utilización de las tácticas facilita la aplicación de las estrategias de emparejamiento subyacentes, pero que no podían resultar conceptos intercambiables en la investigación. Para ello, realizaron alguna modificación sobre la lista de tácticas elaborada por Greer y Buss (1994) y llegaron a 4 áreas generales con dos subtipos de tácticas cada una: Realce de las propias cualidades (higiene y actuar de manera agradable), Comunicación de interés romántico (contacto no sexual y incremento de la atención), Comunicación de interés sexual (contacto sexual y pedir actividad sexual directamente) y Realce del entorno (cena romántica y atmosfera romántica). Las estrategias u objetivos de emparejamiento se evaluaban con el Sexual Strategies Measure (SSM) de Schmitt (1996) que medía la variación en estrategias sexuales correspondiente a dos dimensiones, Arousal sexual y Compromiso sexual. Los resultados indicaron que las tácticas de atracción y las estrategias de emparejamiento eran factores independientes. Así, una orientación sexual restringida o más conservadora podía combinarse con un uso alto o bajo de tácticas de 
atracción e igualmente las estrategias no restringidas o menos conservadoras indistintamente podía coexistir con un uso alto o bajo de tácticas de atracción sexual.

En 2002, Grossman, Julián, Mathieu y Chartrand, realizaron un estudio con la intención de elaborar una escala de iniciación sexual, Sexual Initiation Scale (SIS), una medida de autoinforme que medía el uso de estrategias de iniciación sexual y así como de factores facilitadores de la iniciación en parejas casadas. Los ítems fueron clasificados a priori en directos-indirecto y verbales-no verbales, aunque el análisis factorial reflejó dos factores para la escala de iniciación sexual: Iniciación directa, que comprendía los ítems que describían estrategias físicas directas de iniciación, e Iniciación indirecta, con los ítems que describían estrategias no físicas de iniciación. Los resultados indicaban que los maridos mostraban mayores niveles de utilización de estrategias indirectas que las esposas, y que no había diferencias en el uso de estrategias directas.

Otra investigación (Dybvig-Pawelko, 2007) destinada al estudio de las estrategias de iniciación elaboró otro cuestionario, Sexual Strategies Scale, a través de listas auto-generadas o de libre elicitación, así como de ítems tomados de la investigación existente sobre el tema. Examinando la agrupación de esos 26 ítems llegaron a cinco categorías o tipos de estrategias de iniciación sexual. En primer lugar, Acciones físicas encubiertas, era considerado un factor indirecto físico, con estrategias dirigidas a cambiar la atmósfera en alguna manera. El segundo factor fue Coerción verbal, considerado de tipo directo, verbal y coercitivo, que describía una abierta persuasión o manipulación para conseguir actividad sexual. En tercer lugar apareció la Comunicación verbal indirecta, que hacía referencia a temas sexuales de manera indirecta. El cuarto factor fue Coerción no verbal siendo un factor directo, físico y coercitivo, definido por conductas de coerción física encaminadas a forzar la actividad sexual. El último factor fue Comunicación verbal directa, e incluía peticiones y frases directas en relación con el deseo de actividad sexual.

La autora de este estudio, planteó que la estructura factorial revelaba la existencia de 3 dimensiones separadas. La primera se refiere a hasta qué punto una estrategia es directa o indirecta. Comunicación verbal directa, coerción verbal y coerción no verbal estarían en el polo directo del continuo mientras que acciones físicas encubiertas y comunicación verbal indirecta se acercarían más al polo indirecto. Un segundo continuo existe en relación con el tipo de comunicación, si es verbal o no verbal. Acciones físicas encubiertas y coerción no verbal estarían en el lado no verbal del continuo, y las demás en el lado verbal. Finalmente otro 
continuo puede construirse en torno a conductas que son coercitivas o no coercitivas. Así, en un extremo se situarían la coerción verbal y no verbal, y en el otro la comunicación verbal y no verbal, y las acciones físicas encubiertas.

El tipo de estrategia más frecuentemente utilizado por los estudiantes universitarios eran las estrategias físicas encubiertas, seguidas de la comunicación directa, la indirecta, en cuarto lugar la coerción verbal y finalmente la coerción no verbal. Se encontraron diferencias significativas en función del sexo en todas las estrategias excepto en la comunicación verbal indirecta, que era utilizada por igual en ambos sexos. Los hombres utilizaban más que las mujeres la coerción verbal, mientras que las mujeres utilizaban en mayor medida el resto de estrategias (comunicación directa, acciones físicas encubiertas y coerción no verbal).

La correlación hallada en el uso de diferentes tipos de estrategia sugería que las personas se inclinan a utilizar una gran variedad de estrategias para iniciar relaciones sexuales. Según la autora, las diferentes estrategias representan componentes de los guiones sexuales. Los individuos pueden elegir utilizar una o más estrategias a la hora de poner en marcha su propio guión de iniciación sexual y las diferencias individuales en el uso de estrategias indicarían la existencia de varios guiones sexuales diferentes que se derivan en alguna medida del guión sexual general. En este estudio, una medida de agresividad sexual correlacionaba con todas las estrategias sexuales excepto con actos físicos indirectos, pero sobretodo claro, con los dos tipos de coerción. Estas asociaciones, además de apoyar la validez del continuo coercitivo-no coercitivo, proporcionan evidencia para la existencia de un guión sexual coercitivo. Las personas que son más agresivas sexualmente tienden a elegir más tácticas coercitivas para iniciar relaciones sexuales (Dybvig-Pawelko, 2007). Otro tipo de guión sexual sería aquel que combina gran variedad de estrategias al mismo tiempo, que representaría a aquellos individuos dispuestos a probar con múltiples estrategias para tener relaciones sexuales.

Otro de los objetivos de esta investigación era descubrir que variables individuales y relacionales se asociaban de manera significativa con el uso de estrategias de iniciación sexual. Los resultados mostraban que las actitudes sexuales influían en el uso de estrategias de tipo verbal no coercitivas, así las actitudes más liberales aumentaban la probabilidad de uso de las estrategias de comunicación verbales tanto directas como indirectas. La satisfacción sexual correlacionaba de manera positiva con todas las estrategias excepto con la coerción verbal, con la que no había relación significativa. La orientación comunal, es decir, la tendencia a ver las relaciones sexuales como un acto común y no de intercambio, se relacionaba positivamente con las estrategias verbales directas e indirectas y con las acciones físicas indirectas, mientras que 
no tenía relación alguna con las estrategias coercitivas. La orientación de intercambio, por otra parte se relacionaba positivamente con todas las estrategias excepto con la comunicación verbal directa.

En cuanto a las variables relacionales, se encontró que el tipo de relación era significativa sólo para el uso de las estrategias verbales directas, aunque se aproximaba a la significación en estrategias verbales indirectas y acciones físicas indirectas. Así, aquellos individuos en relaciones de matrimonio tendían a usar más el lenguaje directo para iniciar la actividad sexual que aquellos que vivían juntos. Las estrategias coercitivas fueron las menos dependientes del tipo de relación. La satisfacción con la comunicación sexual diádica se relacionaba negativamente con el uso de la coerción verbal y positivamente con las estrategias verbales. Finalmente la solidaridad interpersonal se asociaba también positivamente sólo con ambas estrategias verbales.

A la hora de analizar qué variables eran mejores predictoras del uso de estrategias de iniciación, si las individuales o las relacionales, se llevaron a cabo análisis de regresión paso a paso que demostraron que para todas las estrategias, las variables individuales superaban a las relacionales en porcentaje de varianza explicada.

Entre los pocos estudios que investigan el uso de tácticas de limitación o resistencia sexual contamos con el de Turchick, Probst, Chau, Nigoff y Gidycz (2007). En este estudio se examina como las intenciones de las mujeres, así como factores psicológicos y situacionales predicen la utilización de estrategias de resistencia en respuesta a situaciones de coerción sexual. Utilizan una escala con tres tipos de estrategias de resistencia sexual (Nurius, Norris, Young, Graham y Gaylord, 2000) que son: Asertividad verbal, que describe tácticas dirigidas a verbalizar la oposición a la actividad sexual, Asertividad física, que consiste en estrategias fisicamente defensivas como empujar o golpear, y Tácticas sin forzamiento, que son las tácticas dirigidas a convencer y apaciguar a la persona que perpetra el intento. Estudios previos manifiestan que las formas más efectivas de resistencia son el uso de táctica activas y asertivas de resistencia, como huir o golpear, mientras que se ha encontrado que las tácticas negociadoras o las excusas, incrementan la probabilidad de un asalto sexual completo.

Los resultados del estudio comprobaron que el uso de tácticas verbales asertivas estaba determinado por la intención de usar estas tácticas, preocupación por daños físicos, mayor confianza y sensación de estar aislada y controlada. El uso de tácticas físicas asertivas estaba 
determinado además por la gravedad creciente del ataque. Finalmente el uso de tácticas no forzosas, estaba determinado por la intención de utilizar este tipo de tácticas, mayor autoconciencia, conocer a la persona que perpetra el intento antes del mismo, miedo a perder la relación con esta persona y falta de historia de victimización sexual en la infancia. Los autores examinan estos resultados en función de posibles implicaciones para programas de reducción de riesgos de asaltos sexuales.

\subsubsection{Estrategias de avance y limitación sexual en adolescentes}

Como exponíamos al comienzo de este capítulo, la mayoría de la investigación realizada sobre estrategias sexuales se ha centrado en población universitaria o adulta y es como poco cuestionable, la medida en que estos resultados pueden aplicarse a la población adolescente. Una serie de factores, como el desarrollo de habilidades cognitivas asociado a la edad y la experiencia, hacen de los adolescentes una población cualitativamente diferente de otras más mayores (Eyre, Read y Millstein, 1997). Por este motivo realizamos una revisión más detallada de los estudios que han investigado la iniciación y la limitación sexual en la adolescencia.

Uno de los estudios de referencia en estrategias sexuales adolescentes es el llevado a cabo por Eyre et al., (1997). El objetivo del estudio era averiguar qué hacen los adolescentes para promover encuentros sexuales y ver si había diferencias entre chicas y chicos y para ello elaboraron un cuestionario de estrategias que habían sido elicitadas por adolescentes. Llegaron a 21 tipos de estrategias que agruparon en siete categorías que describían las estrategias como Preparativos para el sexo (pensar en ello, informarse, medidas contraceptivas), de Presentación propia (hacerse notar, presentarse de manera atractiva), de Comienzo de relación (hacer a la pareja sentirse especial, dar pasos hacia una relación, expresar amor) Aperturas o avances sexuales (insinuar interés sexual, flirtear, proponer actividad sexual, contacto sexual directo) Manipulativas (invitar o hacer regalos, llevar a un lugar oportuno, mentir, emborrachar) Coercitivas (presionar, forzar la actividad sexual) y Misceláneas (pedir ayuda a amigos, permitir que ocurra, lanzarse sin más). Entre sus hipótesis estaban la predicción de que adolescentes más jóvenes mencionarían estrategias más sencillas y homogéneas que adolescentes mayores que mencionarían estrategias más propias de la adultez y más variadas. También esperaban, desde una perspectiva evolucionista, que los chicos mencionasen más estrategias coercitivas y más estrategias dirigidas a comunicar inversión emocional y disponibilidad de recursos, en un 
intento de reflejar los intereses del sexo opuesto. Por su parte las chicas mencionarían más estrategias que señalasen disponibilidad sexual y atractivo físico. Los resultados confirmaron estas hipótesis, ya que una de las estrategias más frecuentemente mencionada era el demostrar interés emocional y las estrategias manipulativas y coercitivas por parte de los chicos. Las chicas también mencionaban los pasos hacia una relación como estrategia, así como estrategias indirectas como flirtear e insinuar interés sexual, confirmando así las expectativas formuladas desde la perspectiva evolucionista. Entre las estrategias que remencionaba por igual por ambos sexos se encontraban, hacerse notar, buscar una situación o lugar oportuno, proponer la actividad sexual y dar pasos hacia una relación.

Ni la experiencia sexual ni el número de parejas sexuales se relacionó con la mención de estrategias. Sin embargo, una serie de limitaciones importantes obliga a relativizar estos resultados, ya que no se examina el uso personal de las estrategias sino la frecuencia con la que son mencionadas por los adolescentes. Así es bastante posible que las conductas reales difieran de las normas conductuales percibidas en el grupo de iguales. Por otra parte no se examina el contexto relacional ni motivacional en el que los adolescentes sitúan sus estrategias sexuales.

Los autores concluyen que sus resultados sugieren la necesidad de prestar especial atención a las situaciones de iniciación sexual coercitivas, así como la utilidad del estudio de las estrategias sexuales como contexto para la promoción de la utilización del preservativo. Proponen que el hecho de que estas estrategias funcionen como antecedentes de la actividad sexual permite a las campañas educativas crear una asociación entre las estrategias más comunes de chicos y chicas y la intención de utilizar preservativos. Por otra parte, una mayor comprensión de las estrategias de adolescentes ofrece la posibilidad de acercarse más a las metas sociales relacionadas con esas estrategias, que en la mayor parte de los casos son más visibles para los adolescentes que las metas del bienestar y la salud.

Un segundo estudio central para el examen de estrategias sexuales en la adolescencia ha sido el de Rosenthal y Peart (1996). Su principal objetivo era clarificar las normas percibidas por los adolescentes en torno a la comunicación de interés sexual, las maneras de incitarlo y de disuadirlo. Pretendían con ello poner de relieve las creencias existentes y las dificultades en la negociación sexual que situaban a los adolescentes en una posición de vulnerabilidad en cuanto a formas sutiles de coerción sexual. La muestra de adolescentes entre 15 y 17 años puntuó tres listas de señales y estrategias dirigidas en primer lugar a transmitir en mensaje de interés sexual, en segundo lugar a incitar la ocurrencia de actividad sexual, y en tercer lugar a evitar la 
actividad sexual no deseada. Puntuaron cada estrategia en función de tres criterios: la medida en que consideraban la estrategia aceptable entre su grupo, la medida en que la consideraban útil o eficaz, y si la habían utilizado alguna vez.

Los resultados mostraban que las señales más claras de interés sexual eran "irse de fin de semana fuera" o "ir a una habitación con una persona durante una fiesta". Casi todas las estrategias para incitar a la actividad sexual fueron calificadas como aceptables, encontrándose diferencias entre chicos y chicas en "dejar que ocurra" que era más aceptada por los chicos y en "mencionar anticonceptivos" más aceptada por chicas. También se encontraron diferencias significativas en cuanto a la eficacia percibida de las estrategias. Las chicas consideraban más eficaces que los chicos estrategias directas como "sacar un condón", "hablar sexualmente", "desnudarse" y "mencionar anticonceptivos". La mayoría de las estrategias habían sido utilizadas por chicos y chicas en alguna ocasión y sólo hubo diferencias en "hablar sexualmente" siendo más probable que la hubieran utilizado las chicas que los chicos.

En cuanto a las estrategias para evitar la actividad sexual, pocas fueron calificadas como aceptables por más de la mitad de la muestra, siendo las estrategias directas las que más apoyo recibían por parte de las chicas. Se encontraron diferencias significativas en "dejar las reglas claras al principio", "decirle a la persona que está yendo demasiado lejos", "abandonar la situación" y "dar señales no verbales de que no se desea". En todos los casos las chicas veían estas estrategias como más aceptables que los chicos. Igualmente, pocas estrategias fueron calificadas como eficaces por la mayoría, y las que lo eran tendían a ser estrategias más directas. Las chicas consideraron sólo la estrategia "dejar las reglas claras al principio" más eficaz que los chicos. Sin embargo a la hora de evaluar el uso de las estrategias, los chicos manifestaron haber utilizado el total de las $1^{\circ}$ estrategias para evitar la actividad sexual, al igual que las chicas. Hubo diferencias entre los sexos en el uso de dos de las estrategias más directas: "decirle a la persona que está yendo demasiado lejos" y "dar señales no verbales de que no se desea la actividad sexual", siendo las chicas las que más probabilidades tenían de haberlas utilizado.

En resumen, chicas y chicos utilizan estrategias indirectas y no verbales, sobretodo y por igual, para iniciar actividad sexual. También utilizan sobretodo estrategias indirectas para evitar la actividad sexual aunque las chicas utilizan más estrategias directas que los chicos. En general las estrategias de incitación sexual tienen mayor apoyo y aceptación y están más claramente definidas que las estrategias de evitación, que parecen ser un área de mayor dificultad para los adolescentes. Las chicas consideran más aceptables las estrategias de evitación directas, y más eficaces las estrategias de incitación directas que los chicos, y además muestran mayor 
coherencia entre estos criterios y la medida en que utilizan las estrategias. Una explicación relacionada con las normas de género para que las chicas perciban como más eficaces estrategias de avance directas que los chicos, es que las chicas consiguen con estas estrategias directas comunicar mejor sus necesidades, mientras que los chicos pueden haber comprobado que estas estrategias directas no les funcionan precisamente porque comunican mejor sus intenciones.

Entre las conclusiones de estudio destacan un desdibujamiento de los estereotipos de género, ya que las chicas se implican activamente en todas las tareas sexuales directas y con mayor coherencia, y los chicos también experimentan la necesidad o el deseo de limitar la actividad sexual. Por otra parte, se resalta la necesidad de influir en los adolescentes para que acepten y usen aquellas reglas que son directas y explicitas a la hora de comunicar y negociar con claridad los encuentros sexuales. Una limitación relevante del estudio es la falta de control de la variable contexto relacional.

Recientemente se ha realizado una investigación sobre la asertividad percibida por chicas adolescentes en las tareas de iniciación sexual, rechazo y uso de medidas anticonceptivas (Auslander, Michelle, Perfect, Succop y Rosenthal, 2007). Además de evaluar la medida en que las adolescentes se percibían como asertivas en estas tres áreas sexuales, comprobaron si esto se relacionaba con variables de desarrollo, con la experiencia sexual y con variables interpersonales, como las características de la relación en la que se encontraban las adolescentes.

En los resultados comprobaron que aunque la asertividad en la escala de rechazo sexual, y en la de prevención sexual correlacionaba positivamente entre sí, ninguna de las dos se asociaba con la asertividad percibida en cuanto a iniciación sexual. Por otra parte sólo las variables relacionadas con la experiencia e historia sexual tenían alguna influencia en la asertividad percibida en las tres tareas sexuales. Aquellas chicas con mayor experiencia sexual tenían más probabilidades de percibirse como asertivas a la hora de iniciar encuentros sexuales que aquellas con menor experiencia sexual. En cambio, las adolescentes con mayor experiencia sexual tendían a percibirse menos asertivas en la limitación y protección de actividades sexuales, que aquellas con menor experiencia sexual. Ninguna de las características relacionales influyó en la percepción de asertividad de las adolescentes. Esto parece indicar que la asertividad sexual puede estar más condicionada por factores individuales específicos que por factores relacionales. 
En sus conclusiones, los autores destacaron el hecho de que no hubiese ninguna relación entre la percepción de las adolescentes de poder comunicar sus necesidades sexuales y su percepción de poder limitar o proteger la actividad sexual. Sugirieron la importancia de intervenir sobre los tres aspectos de asertividad sexual, y no sólo sobre la limitación o la protección sexual como se había hecho históricamente. Tal y como habían señalado estudios anteriores (Tolman; Fine, citado en Auslander et al., 2007) es potencialmente perjudicial ignorar los deseos y sentimientos de las adolescentes así como las percepciones de su cuerpo durante las experiencias sexuales. Para promover un desarrollo sexual saludable, las adolescentes tienen que ser capaces de reconocer que tienen deseos sexuales y ser conscientes de que esos deseos pueden influir en sus decisiones sexuales. Con una visión global de su sexualidad, las adolescentes pueden estar mejor equipadas y preparadas para desarrollar formas efectivas para comunicar sus deseos al mismo tiempo que se protegen.

Un estudio longitudinal (Eggermont, 2006) exploró la relación existente entre tiempo viendo la televisión y creencias de los adolescentes en torno a la expresión de deseo sexual en situaciones románticas. En tres años consecutivos los adolescentes indicaban la efectividad que consideraban que tenían dos tipos de avances sexual estudiados: el "avance sexual" y el "avance romántico". La intención era comprobar qué efecto tenían los modelos de iniciación sexual ofrecidos por la televisión en las creencias de los adolescentes. La teoría del aprendizaje social (Bandura, 1986) no predice que los observadores reproducen necesariamente las conductas observadas, sino que la información es almacenada en forma de guión conductual, que puede ser recuperado y utilizado cuando una situación lo requiera.

En un "focus group", los adolescentes proporcionaron información sobre técnicas de iniciación sexual que fueron luego factorializadas en dos grupos, el Avance sexual (desabrocharse la ropa, empezar a hablar de sexo implicito, ir a un lugar oscuro, empezar a acariciar por debajo de la ropa) y el Avance romántico (tomar algo juntos en un bar, admirar una puesta de sol, ir a un restaurante elegante, bailar).

Los resultados indicaban que en general, los adolescentes veian la estrategia de avance sexual, y no romántico, como más efectiva. A la edad de 12 años, los dos tipos de aproximaciones tenían el mismo apoyo, pero entonces comenzaban a divergir de manera que era la estrategia sexual la que alcanzaba mayor apoyo. En la muestra femenina, la televisión parecía primeramente reforzar la creencia en el avance romántico, para después debilitarla y acelerar la gradual pérdida de apoyo de éste tipo de aproximación. La pérdida de apoyo al avance romántico por parte de los varones en cambio, era menor y se veía más ralentizada por la influencia de la 
televisión. El autor concluye que los chicos parecen aprender de la televisión cómo prefieren las chicas ser seducidas, y las chicas a su vez, aprenden cómo no quieren ser seducidos los chicos.

Después de haber revisado los resultados de las investigaciones con las que contamos sobre tipos de estrategia de iniciación y limitación sexual podemos establecer tres distinciones generales en los tipos de estrategias sexuales. La distinción más clara y general es la que separa estrategias directas y estrategias indirectas, en función de la eficacia y claridad en la comunicación de intenciones y deseos sexuales. La segunda distinción, también ampliamente documentada, entre estrategias verbales y no verbales o físicas, en función del modo de comunicación. Finalmente algunos estudios han incluido la distinción entre estrategias coercitivas y no coercitivas, en función del grado de imposición de la propia voluntad sexual.

\subsection{DIFERENCIAS DE GÉNERO EN USO DE ESTRATEGIAS SEXUALES}

Utilizaremos este apartado para hacer un resumen de los estudios revisados sobre el papel del género en el uso de estrategias de avance y limitación sexual. La investigación de la que disponemos nos ofrece principalmente dos tipos de criterios para evaluar las diferencias entre chicos y chicas en la utilización de estrategias sexuales, que son por una parte la frecuencia total de iniciación y de limitación en general por parte de cada sexo, independientemente del tipo de estrategia utilizada, y por otra parte, las diferencias en la frecuencia de uso en función del tipo de estrategia sexual. La mayor parte de la discusión en torno a las diferencias de género en estrategias sexuales se centra en la medida en la que las conductas de varones y mujeres reproducen los roles de género dictados por el guión sexual tradicional. Según éste guión generalizado, se espera que sean los hombres los que inicien la actividad sexual más frecuentemente, que utilicen métodos más directos para indicar su interés sexual, y que acepten cualquier oportunidad sexual disponible (Shotland y Craig, 1988; Muehlenhard, Koralewski, Andrews, Burdick, 1986). En cambio, se espera que las mujeres controlen el acceso sexual de los hombres y que si expresan algún interés sexual, lo hagan de manera sutil e indirecta.

En este sentido y en cuanto a la frecuencia de iniciación sexual, contamos con resultados contradictorios. Los primeros estudios realizados sobre el tema demostraron que no había diferencia en la medida en hombres y mujeres iniciaba y limitaban la actividad sexual. Es decir, la frecuencia de avances, ya fueran directos o indirectos parecía ser la misma para hombres y 
mujeres (Jesser, 1978; McCormick, 1979). Sin embargo una serie de estudios posteriores ponían en duda esta evidencia con sus resultados, ya que encontraron que los hombres utilizaban más todo tipo de estrategias para iniciar la actividad sexual que las mujeres, ajustándose así al guión sexual tradicional (La Plante et al., 1980; Byers y Heinlein, 1989; O’Sullivan y Byers, 1992). Ya hemos comentado con anterioridad que había grandes diferencias metodológicas con respecto a los primeros estudios, como que en el primer estudio no se evaluó la frecuencia de uso, sino haber usado la táctica o no, y en el segundo se evaluó la probabilidad de utilizar las estrategias en situaciones hipotéticas y no su uso real.

Sin embargo estos tres estudios se contradecían entre sí en cuanto a las diferencias de género en otros aspectos como limitar o rechazar la actividad sexual y considerar la idea de iniciar la actividad sexual. Mientras que en el estudio de La Plante et al. (1980) se identificaba a las mujeres como más proclives a utilizar todo tipo de estrategias de limitación sexual que los hombres, en los otros dos estudios (Byers y Heinlein,1989; O'Sullivan y Byers, 1992) se llegó a la conclusión de que hombres y mujeres no difieren en sus respuestas a los avances sexuales de su pareja, es decir, que aceptan y rechazan la actividad sexual en la misma medida. Esto era así cuando se controlaban el número de iniciaciones efectuadas, puesto que teniendo en cuenta que los hombres son más frecuentemente los que proponen actividad sexual, ellas están necesariamente más veces en la posición de responder, haciendo que el número de rechazos (pero también de aceptaciones) en términos absolutos fuera mayor. De esta manera explicaban los autores el posible resultado engañoso de que las mujeres limiten más frecuentemente que los hombres la actividad sexual.

En este sentido y de nuevo en oposición a los últimos resultados, se halló en una investigación de O'Sullivan y Gaines (1998) que ante una situación de ambivalencia sobre el deseo de participar en actividad sexual propuesta por la pareja, hombres y mujeres respondían de manera diferente. Ante la propia ambivalencia, los hombres tendían a aceptar la iniciación y a fingir interés sexual más frecuentemente que las mujeres, y en la misma situación las mujeres tendían a rechazar la actividad sexual en mayor medida que los hombres. Además las autoras señalan que las mujeres eran más proclives a sentir ambivalencia sobre la participación sexual, quizás por una mayor predisposición en ellas a reconocer estos sentimientos cuando se enfrentan a una invitación sexual, lo que por otra parte sucede más a menudo que en los hombres

Son éstos dos últimos estudios en cambio, los que difieren en cuanto a sus resultados sobre considerar la idea de iniciar actividad sexual. En el estudio de Byers y Heinlein (1989) encontraron que los hombres consideraban iniciar la actividad sexual con mayor frecuencia que 
las mujeres. Los autores ofrecían dos posibles interpretaciones para este resultado. Una era que el resultado representaba el diferente interés que tenían hombres y mujeres sobre el sexo, siendo el hombre quién deseaba mayor actividad sexual y la otra se basaba en los diferentes roles que tenían hombres y mujeres en los guiones sexuales. Así, el guión sexual además de colocar al hombre en la posición de iniciador, le otorgaba la responsabilidad de pensar si iniciar la actividad sexual. Sin embargo, el estudio posterior de O'Sullivan y Byers (1992) desmontó estas conclusiones presentando unos resultados en los que no se mostraba diferencia en la medida en que hombres y mujeres consideraban iniciar la actividad sexual.

En cuanto al estudio sobre adolescentes (Rosenthal y Peart, 1996), en él hallaron pocas diferencias de género en cuanto a la utilización de estrategias sexuales, ya que la mayoría de chicos y chicas utilizaron la mayoría de las estrategias para incitar la actividad sexual y sólo dos estrategias para evitar la actividad sexual fueron más utilizadas por chicas que por chicos.

En relación con las diferencias de género en función del tipo de estrategia sexual utilizada, también contamos con resultados divergentes. Empezando de nuevo por el estudio de Jesser (1978), vemos que aunque la frecuencia de iniciación y de utilización de estrategias directas es la misma en ambos sexos, hay una mayor proporción de mujeres que utilizan estrategias indirectas como contacto visual o cambio de tono de voz, que hombres. En los estudios posteriores sobre iniciación, respuesta y consideración de la iniciación (Byers y Heinlein, 1989; O’Sullivan y Byers, 1992) llegaron a la conclusión común de que a pesar de que los hombres iniciaban la actividad sexual más frecuentemente, la manera de iniciar las relaciones sexuales era la misma para ambos sexos. El tipo de estrategia más frecuente es lo que difiere en los dos estudios, puesto que en el primero la estrategia más utilizada por ambos sexos es la proposición verbal directa, seguida de la conducta física y directa de besar, y en el segundo estudio, se inicia sobretodo a través de estrategias verbales indirectas y no verbales. Una posible explicación para esta diferencia es que la población del primer estudio son parejas casadas y en el segundo son estudiantes universitarios con mucho menor recorrido relacional.

En el estudio de Christopher y Frandsen (1990), sólo encontraron diferencias significativas entre hombres y mujeres en el uso de la presión y la manipulación como estrategias sexuales, teniendo los hombres más tendencia a utilizar este tipo de tácticas.

En contradicción con estos resultados que abogan por la similitud entre sexos en cuanto a maneras de iniciar la actividad sexual, en el estudio de Greer y Buss (1994) encontraron que las 
mujeres utilizaban más tácticas como resaltar su atractivo físico y disponibilidad sexual , mientras que los hombres utilizaban más tácticas como hacer regalos y demostraciones de su fuerza física. Además los hombres también utilizaban más frecuentemente otro tipo de tácticas como emborrachar a la persona, ir a un área apartada, hacer cumplidos sobre el atractivo físico, verbalizar el deseo sexual y bailar cerca de la pareja.

Estudios que reflejan diferencias entre los sexos pero en una dirección distinta a esta son los trabajos de Grossman et al. (2002) y Dybvig-Pawelko (2007). En el primero, los resultados apuntan a una mayor utilización de estrategias indirectas (que en este estudio son las estrategias que no son de contacto físico) por parte de los maridos y de una igual utilización de las estrategias directas (físicas) por parte de ambos sexos. En el segundo, las mujeres utilizan en mayor medida que los hombres las estrategias verbales directas, los actos físicos encubiertos y la coerción no verbal, mientras que éstos emplean más la coerción verbal que las mujeres.

En cuanto a las investigaciones sobre la adolescencia, las dos más representativas que estudian estrategias sexuales en ambos sexos nos ofrecen dos panoramas distintos. En el estudio de Eyre et al.(1997) hallaron diferencias significativas ya que los chicos usaban más estrategias manipulativas y coercitivas y las chicas utilizaban más estrategias indirectas como flirtear e insinuar interés sexual, confirmando así las expectativas formuladas desde la perspectiva evolucionista, así como las expectativas generadas por el guión sexual tradicional. Por el contrario, en el estudio de Rosenthal y Peart (1996) destacan un debilitamiento de los estereotipos de género, ya que las chicas se implican activamente en la iniciación y limitación sexual de manera directa, y por otra parte los chicos también experimentan la necesidad o el deseo de limitar la actividad sexual. Además las chicas no sólo utilizan más alguna estrategia directa que los chicos sino que además consideran más eficaces las estrategias directas de iniciación y más aceptables las estrategias directas de limitación sexual.

Algunos estudios sobre iniciación romántica y sexual apuntan a que es el sexo biológico y no la ideología de género lo que determina las conductas de iniciación sexual. Así, han encontrado que en general los hombres son más directos y activos, iniciando ellos los contactos físicos, mientras que las mujeres tienen un papel más pasivo (Muehlenhard et al., 1986; Clark, Shaver y Abrahams, 1999). Sin embargo otros estudios han sugerido que las mujeres pueden ser las que inician en realidad con más frecuencia a través de gestos sutiles y no verbales (sonreír, mirar) que animan a los hombres dar una respuesta más abierta y explicita, como iniciar una conversación (Moore, citado en Seal y Ehrhardt, 2003; Renninger, Wade y Grammer, 2004). 
Una posible explicación para la falta de evidencia de esta hipótesis, es que algunos gestos dirigidos a captar la atención o seducir pueden estar pasando desapercibidos por los participantes de los estudios al no ser conscientes de ellos e identificarlos como tácticas o estrategias (O’Sullivan y Byers, 1992).

Parece claro que no existe una única dirección en la que situar, si las hubiera, diferencias de género en la iniciación y limitación sexual. Hay una serie de factores cruciales que hacen difícil sacar conclusiones de los estudios, como son el amplio lapso temporal que los separa, desde los años 70 hasta ahora, con los consiguientes cambios sociales asociados, o las profundas diferencias metodológicas existentes en las investigaciones. Una conclusión que parece sin embargo más consistente que las demás es el hecho de que los varones, independientemente de su edad emplean más estrategias de coerción, tanto de presión como de manipulación para iniciar la actividad sexual que las mujeres. Esfuerzos por extraer una segunda conclusión apuntarían además a una posible mayor utilización de estrategias indirectas por parte de las mujeres para comunicar su interés sexual. Veremos en nuestra investigación si se confirman estas conclusiones.

\subsection{CONTEXTO RELACIONAL, ESTRATEGIAS Y EXPERIENCIA SEXUAL}

Contamos con muy pocos estudios que examinen el contexto relacional en el que tiene lugar la actividad sexual en general, y muchos menos que lo examinen en cuanto al uso de estrategias de iniciación y limitación sexual específicamente. Los pocos que lo hacen, además, son llevados a cabo con población de estudiantes universitarios. Aún así vamos a recordar brevemente que papel juega el contexto relacional en estos estudios.

Los resultados obtenidos en algunos estudios señalan que el contexto relacional es una variable que determina el uso de estrategias de iniciación sexual, más allá de características personales. Así, en la investigación de O’Sullivan y Byers (1992) se mostraba que aquellos estudiantes de ambos sexos en relaciones de pareja estable, utilizaban más estrategias de iniciación sexual que aquellos en relaciones casuales. Además existía una interacción con el género que indicaba que en relaciones casuales, el hombre iniciaba significativamente más que las mujeres. Así, en el estudio concluían que la actividad de iniciar actividad sexual parecía estar fuertemente influida por las oportunidades, sobre todo en el caso de los chicos puesto que la mayor oportunidad sólo 
parecía afectar en el caso de las mujeres, en contextos de relaciones de pareja. De esta forma, el guión sexual tradicional que designa al hombre como el iniciador se aplica con mayor contundencia en relaciones casuales, en las que la mujer se sitúa en roles más tradicionales. De igual manera, Miller, Bettencourt, DeBro y Hoffman (1993) encontraron que diferentes contextos relacionales (relación estable versus "rollo" de una noche) se asocian con el uso de diferentes estrategias sexuales.

Un poco más ambiguos son los resultados que se obtienen en el estudio de Dybvig-Pawelko (2007). La autora del trabajo concluye que variables relacionales como el tipo de relación no determinan significativamente la iniciación sexual más allá de características individuales. El uso de algunos tipos de estrategias como las verbales, diferían en función del tipo de relación de los participantes, pero ni la diferencia era muy amplia, ni se conseguía aportar con ella a la varianza que explicaba el uso de estrategias. Estos resultados sugieren, en la opinión de la autora, que mientras que otros aspectos de los guiones sexuales pueden depender de factores interpersonales e individuales dentro de una misma cultura, los guiones de iniciación sexual están principalmente determinados por factores individuales. Las estrategias de iniciación sexual podrían ser una forma única de comunicación sexual en el sentido de que muchas veces tienen lugar cuando la relación no está completamente formada y podrían ser las características individuales las que guiasen la decisión de utilizar ciertas tácticas. A medida que la relación progresa, es posible que está forma de iniciación sexual se arraigue y así, se haga más impermeable a las características de la relación. Una posible explicación alternativa sería que los factores relacionales o interpersonales sí influyan en los guiones de avance sexual, pero lo hagan indirectamente a través de la experiencia y la huella individual que suponen las circunstancias interpersonales. De esta manera, las variables relacionales contribuirían a la definición de características individuales relacionadas con la sexualidad que son las que finalmente condicionan el uso de estrategias de avance sexual.

Resultados más claros se obtienen en otros trabajos como el de Auslander et al. (2007) sobre asertividad en la iniciación y limitación sexual. En él se concluye que las características relacionales no determinan la percepción que tienen las adolescentes de sí mismas en cuanto a asertividad sexual. En cambio es la historia y la experiencia sexual las que influyen positivamente en la iniciación sexual y negativamente en la limitación y la protección sexual. El resultado podría explicarse, según los autores, en función de características de la muestra, puesto que eran adolescentes que participaban voluntariamente en otro estudio más amplio sobre el uso de microbicidas durante el coito. Esto podría haber sesgado la muestra en cuanto a 
que la faceta sexual en estas adolescentes podría ser un aspecto saliente de su personalidad y esto difuminase la posible influencia de las características relacionales. También es posible, nuevamente, que el tipo de relación influya sobre características individuales como la experiencia sexual, que finalmente sea lo que determina aspectos como la asertividad en iniciación, rechazo y protección de conductas sexuales.

También contamos con resultados contradictorios en cuanto a la relación entre la experiencia sexual y el uso de estrategias de avance y limitación sexual. Como acabamos de ver, existe evidencia que muestra que la experiencia sexual pueda estar positivamente relacionada con el uso de algunas estrategias de iniciación y negativamente relacionada con estrategias de limitación (Auslander et al., 2007). En concreto, en el trabajo de Christopher y Frandsen (1990) concluían que sólo el uso de la cercanía física y emocional se asociaba con una mayor experiencia sexual, así como que sólo el uso de la lógica y la razón, utilizada para limitar la actividad sexual, se asociaba a una menor experiencia sexual.

Muy al contrario, otros estudios (Eyre et al., 1997; O’Sullivan y Byers, 1992) no han encontrado relación significativa entre la experiencia sexual o el número de parejas sexuales y la iniciación sexual. Sin embargo los resultados del primer estudio, que es el que se realiza con población adolescente pueden cuestionarse, ya que no evalúan el uso real de las estrategias, sino el uso generalizado o la mención que hacen los adolescentes de las mismas.

Otras variables se han estudiado en relación con el uso de estrategias de iniciación sexual. La creencia en los estereotipos de género o ideología de género se ha visto relacionada por algunos estudios (La Plante et al., 1980) y descartada como variable asociada por otros (McCormick, 1979; O’Sullivan y Byers, 1992) y con las actitudes sexuales ha ocurrido lo mismo. Entre los estudios que han apoyado la existencia de una relación entre actitudes sexuales y uso de estrategias de limitación estén el de Dybvig-Pawelko (2007) en el que se asociaba las actitudes sexuales menos conservadoras con el empleo de estrategias de iniciación de tipo verbal. En cambio otros estudios han concluido la falta de relación entre estas dos variables (O’Sullivan y Byers, 1992).

Finalmente variables no relacionadas por algunos estudios con el uso de estrategias sexuales son la erotofilia-erotofobia y el locus de control. (LaPlante, McCormick y Brannigan, 1980; O’Sullivan y Byers, 1992).

Las variables que si han demostrado influir en el uso de determinados tipos de estrategia de iniciación sexual sexual son la motivación hacia más actividad sexual, la agresividad sexual, estrategias u objetivos de emparejamiento a largo y corto plazo, la satisfacción sexual y la 
orientación comunal-de intercambio (Christopher y Frandsen, 1990; Schmitt y Buss, 1996; Dybvig-Pawelko, 2007) Las variables implicadas en el uso de diferentes tipos de estrategias de coerción sexual las veremos con más detalle en el siguiente apartado dedicado específicamente a la coerción sexual como estrategia de iniciación sexual.

\section{NEGOCIACIÓN SEXUAL ASOCIADA AL RIESGO}

\subsection{COERCIÓN SEXUAL COMO ESTRATEGIA DE INICIACIÓN SEXUAL}

Teniendo en cuenta que la coerción sexual es desafortunadamente una forma de iniciación sexual, y debido a la particular relevancia que tienen las estrategias sexuales coercitivas a nivel individual y social, hemos considerado oportuno dedicar un apartado especial a la coerción sexual dentro de este capítulo. Puesto que no es el tema principal de este trabajo, no pretendemos ofrecer una revisión bibliográfica exhaustiva sobre coerción sexual, y por lo tanto, sólo repasaremos brevemente algunas nociones básicas que hemos extraído de la revisión realizada, que son relevantes para nuestro estudio.

\subsubsection{Definición, prevalencia e impacto}

Para entender qué lugar tiene la coerción sexual en la iniciación sexual es importante definir qué es la coerción sexual y qué consecuencias tiene. Algunos investigadores consideran que los actos de coerción forman parte de un continuo. Por ejemplo, Muehlenhard y Cook (1998) observaron que la actividad sexual se ha construido sobre un continuo de coerción que pasa de ser voluntaria, a altruista, a coaccionada verbalmente, a físicamente forzada. La definición propuesta en el estudio de Fuertes, Ramos y Fernández, (2007) considera que con coerción sexual se hace referencia a "cualquier tipo de conducta que se ejerce para forzar la voluntad sexual de otra persona, independientemente de qué estrategia coercitiva se haya empleado, de si la conducta sexual buscada tiene lugar o no, y de las características de la misma". 
Existe un elemento común y general a la mayoría de las definiciones de coerción sexual y es la necesidad de que la persona que perpetra la coerción, lo haga de una manera intencionada y consciente, reconociendo el objetivo de sus actos. Además es necesario también, que la conducta coercitiva esté produciéndose ante la no voluntariedad de la víctima, luego para que exista coerción sexual la voluntad sexual de la víctima debe ser forzada, independientemente de si la actividad es consentida o no. Al igual que el primer elemento de intencionalidad es el denominador común que unifica a todas las estrategias de avance sexual, el requisito de no voluntariedad es el que distingue la coerción de otras formas de iniciación sexual. Esta posición particular de la coerción sexual en el campo de las estrategias de avance sexual hace que las estrategias agresivas difieran de las no agresivas en prevalencia, impacto y motivación (Anderson y Newton, 2004).

Las mujeres son las victimas más frecuentes de la coerción sexual y los datos sobre su prevalencia justifican un estudio riguroso de este fenómeno. En el 2000, Sipsma, Carrobles, Montorio y Everaerd vieron que el 33\% de la muestra de 223 mujeres universitarias decía haberse visto implicadas en algún episodio de coerción sexual, y el 24\% de los 189 varones de la muestra había empleado alguna estrategia coercitiva para mantener relaciones sexuales con una chica que no las deseaba. En un trabajo sobre uso de estrategias coercitivas se observó que el 15\% de una muestra de 310 chicos afirmaba haber mantenido relaciones sexuales con una chica que no las deseaba utilizando para ello algún grado de coerción (Fuertes, Ramos, De la Orden, Del Campo y Lázaro, 2005). En diversos trabajos sobre victimización sexual, la prevalencia de este fenómeno en chicas adolescentes y jóvenes oscilaba entre el 30 y $40 \%$ (Fuertes, Ramos, Martínez, López y Tabernero, 2006; Ramos, 2004; Ramos y Fuertes, 2005; Ramos, Fuertes y De la Orden, 2006). A pesar de que son mayoritariamente las mujeres las que sufren la coerción sexual, las estrategias de coerción sexual no sólo son utilizadas por los hombres. Varios estudios coinciden en señalar que el porcentaje de mujeres que emplean estrategias sexualmente coercitivas está entre el 10\% y el 25\% (Russell y Oswald, 2001; Anderson y Newton, 2004).

Aunque los datos sobre prevalencia de la coerción sexual se muestran como suficientes a nuestro entender para examinar este fenómeno, una serie de estudios han mostrado qué impacto y qué consecuencias tienen las formas de iniciación sexual agresivas sobre la víctima. Las victimas de la coerción sexual manifiestan mayor índice de conductas de riesgo, como relaciones coitales desprotegidas, múltiples parejas sexuales, e incomodidad física (Livingston, Buddie y VanZile-Tamsen, 2004). De hecho, las victimas del abuso sexual, incluyendo la 
coerción, tienden a tener mayor índice de embarazos no deseados, y de enfermedades de transmisión sexual (Population Reports, citado en Dybvig-Pawelko, 2007). En cuanto a las consecuencias psicológicas, un estudio longitudinal reveló que las mujeres que habían experimentado relaciones sexuales verbalmente coercitivas informaban de mayores niveles de depresión, enfado y ansiedad social (Zweig, Crockett, Sayer y Vicary, 1999). En el trabajo de Livingston et al., (2004), las experiencias de coerción sexual verbal, dejaban a las victimas con sentimientos de ira y resentimiento, además de tener un impacto negativo sobre la relación con el perpetrador, y con otras relaciones, siendo más negativo si no había precedentes sexuales con esta persona. En general, haber sufrido coerción sexual representa un elemento moderador de la valoración y de la experiencia sexual femenina (Felson, 2002; Gaston et al. 1995, citado en Savin-Williams y Diamond, 2004).

Los preocupantes datos en torno a la prevalencia e impacto de la conducta sexual coercitiva en jóvenes y adolescentes han promovido la aparición de diversas investigaciones dirigidas a la identificación de posibles factores desencadenantes y de riesgo de la coerción sexual. Expondremos una breve relación de aquellos que pueden tener alguna relevancia en nuestra investigación.

\subsubsection{Factores de riesgo socioculturales}

El contexto sociocultural contribuye de varias maneras al desarrollo de patrones de comportamiento correctivos. Una de ellas es a través de las definiciones de masculinidad y feminidad de los estereotipos de género, que asocian la masculinidad al poder, el dominio, la fortaleza, la superioridad económica, y la feminidad a la vulnerabilidad, emocionalidad, dependencia, etc. La existencia de los mitos sobre la agresión desarrollados en los procesos de socialización es otro mecanismo, puesto que además de dificultar la identificación de situaciones coercitivas no prototípicas, otras veces justifican la agresión con creencias del tipo de que a la mujer le gusta o lo desea, que la mujer es la que provoca de algún modo, o que la mujer miente o exagera sobre lo que le haya podido ocurrir. Además el contexto sociocultural actual favorece la creación de unas expectativas sobre el alcohol, y en situaciones en las que se da un consumo normativo de alcohol en la adolescencia, este puede ser utilizado como excusa para la desinhibición del agresor, para reducir la resistencia de la víctima, y como estímulo sexual para la misma (Fuertes et al., 2007) 
Dentro de los factores socioculturales se sitúa el propio guión sexual tradicional y las normas y expectativas acerca de lo que han de hacer los varones y las mujeres en sus relaciones sexuales. Se asume un alto impulso sexual masculino, mientras que la mujer debe ser sexy pero contener al varón (La Plante, McCormick y Brannigan, 1980; Metz y Spitzberg, 1996; Byers, 1996). Además mientras que tener múltiples parejas sexuales es algo positivo para el hombre, esto devalúa el estatus social de la mujer. Diversos aspectos de los guiones sexuales tradicionales pueden contribuir a la coerción sexual, como ya veíamos anteriormente en el apartado de los guiones sexuales y género. Por ejemplo la idea de que el hombre debería iniciar las relaciones sexuales y a menudo tendrá que utilizar múltiples estrategias para superar las resistencias de la mujer, puede conducir al hombre a justificar las medidas coercitivas para obtener actividad sexual (Metts y Spitzberg, 1996; Garcia, 1998). De hecho, en una investigación se encontró que los hombres calificaban de "un poco justificable" el hecho de tener relaciones sexuales con una mujer que no las deseaba y las había rechazado por dos veces (Muehlenhard, Andrews y Beal, 1996). El papel de la mujer como limitadora de la actividad sexual y la devaluación que para una mujer supone tener muchas parejas sexuales, puede llevar al hombre a pensar que su resistencia no es genuina, que sólo es token resistance, fenómeno del que también hemos hablado ya en el apartado de comunicación de intenciones sexuales.

\subsubsection{Factores de riesgo individuales}

El siguiente grupo de factores que veremos son los factores de carácter individual o variables que afectan a nivel individual. El género vuelve a ser una de ellas, puesto que los varones generalmente perciben mayor interés sexual por parte de los demás, especialmente por parte de las mujeres, que las mujeres (Abbey, citado en Littleton y Axsom, 2003; Shotland y Craig, 1988) lo que además se convierte en una de las razones por las que en general, ante escenarios de violación los hombres atribuyen mayor responsabilidad a la víctimas femenina y justifican en mayor medida la conducta coercitiva del agresor masculino (Kowalski, 1992; Muehlenhard, 1988).

Algunas características de personalidad están también asociadas al uso de la coerción sexual. Según el modelo de confluencia elaborado y contrastado por Malamuth, Sockloskie, Koss y Tanaka (1991), la posibilidad de que un varón emplee estrategias sexualmente coercitivas se ve 
incrementada en la medida en que converjan en él ciertas actitudes de hostilidad y deseos de dominar y controlar a las mujeres, o masculinidad hostil y una mayor predisposición hacia las relaciones sexuales sin compromiso, o sexo impersonal. Diversos estudios han respaldado el planteamiento de este modelo, entre ellos el de Fuertes et al. (2005) que confirmaba que la necesidad de control y dominio, la preocupación por el sexo y la predisposición hacia el sexo impersonal se relacionaban de forma positiva con el uso de estrategias sexualmente coercitivas. Además los autores de este estudio comprobaron que la capacidad empática no sólo se asociaba de forma negativa con las conductas coercitivas, sino que jugaba un papel moderador en tanto que el efecto de las variables predictoras comentadas sobre la conducta coercitiva se veía muy atenuado en aquellos chicos que presentaban una alta capacidad empática.

En el estudio de Dybvig-Pawelko (2007), introdujeron una medida de agresividad sexual que correlacionaba positivamente con casi todos los tipos de estrategias sexuales pero sobretodo claro, con los dos tipos de coerción, verbal y no verbal. Estas asociaciones apoyan la validez del continuo coercitivo-no coercitivo ya que las personas que son más agresivas sexualmente tienden a elegir más tácticas coercitivas para iniciar relaciones sexuales, pero también utilizan en mayor medida estrategias de iniciación no coercitivas que otras personas menos agresivas. Algunos estudios también han observado una relación significativa entre la experiencia sexual y el número de parejas sexuales, y el uso de estrategias sexualmente coercitivas en mujeres (Anderson et al., 2004; Anderson, Kontos, Tanigoshi y Struckman-Johnson, 2005).

\subsubsection{Factores de riesgo interpersonales}

El último grupo de factores de riesgo los hemos considerado factores interpersonales, puesto que se derivan de la relación o de la interacción entre la persona que perpetra la coerción sexual y la víctima. A pesar de que estos factores no implican en sí mismos un mayor riesgo de que la coerción sexual ocurra, si conllevan mayor riesgo de que la situación coercitiva no se identifique como tal, o tenga unas características determinadas. De esta manera, parte del problema de la coerción es el hecho de considerar una situación coercitiva como una situación normativa, y que así se facilite si no su origen, su perpetuación. Las atribuciones y valoraciones sobre un episodio coercitivo, se ha visto que se hacen en función de la existencia de una relación previa entre agresor y víctima (Regan, 1997; Littleton y Axsom, 2003), de la existencia de precedentes sexuales consensuados entre ambos (L'Armand y Pepitone, citado en Regan, 1997), 
del uso que haga la víctima de conductas no verbales "sugerentes", y del grado de resistencia o tipo de respuesta que ofrezca a la iniciación sexual masculina (Kowalski, 1992).

En el estudio de Littleton y Axsom (2003) identificaron varios elementos del guión interpersonal sexual comunes que estaban presentes tanto en situaciones de seducción como en situaciones de violación, y que contribuían a confundir los dos tipos de guiones. Estos elementos eran que en ambas situaciones iniciaba la actividad sexual el hombre, se trataba de dos conocidos, se daba un episodio consensuado de besos, se empleaban estrategias de presión o manipulación como presión verbal e intoxicación, y se hacía uso del alcohol. Regan (1997) observó que algunas características del guión sexual interpersonal, como el estilo de iniciación de tipo romántico, la existencia de relación previa y el menor grado de resistencia ofrecida ante la iniciación masculina, tenían significado psicológico, y afectaban a las asunciones que se hacían sobre la naturaleza consensuada de la interacción sexual. Según la autora, la creencia de que la sexualidad femenina está ligada a factores emocionales lleva a que, ante un estilo de iniciación romántico, se presuponga un mayor deseo sexual en la mujer, y sea más probable que el acto sea percibido como consensuado.

En cuanto al papel del contexto relacional, contamos con una investigación que examina el papel de la precedencia sexual en la coerción sexual (Livingstone, Buddie y VanZile-Tamsen, 2004). Se ha observado que el hecho de que existan precedentes sexuales o no, además de alterar la valoración que se haga de la situación coercitiva, puede afectar a otras características del encuentro sexual, como la táctica utilizada, la resistencia de la víctima, y los motivos para capitular de la víctima. En primer lugar cuando existían precedentes sexuales, normalmente en el contexto de una relación de pareja, el tipo de estrategia coercitiva más utilizada era la persuasión verbal negativa, para suscitar sentimientos de culpa, obligación, o deseo de evitar el conflicto, mientras que en relaciones sin precedentes sexuales, normalmente relaciones ocasionales, las estrategias más empleadas eran también de persuasión verbal pero positiva, para seducir a la pareja mientras se ponía en marcha algún tipo de contacto físico (besar, etc.). Cleveland, Koss y Lyons (1999) encontraron que el uso de fuerza y de sustancias de intoxicación decrecía cuando había mayores niveles de intimidad entre la víctima y el perpetrador, puesto que la existencia de la relación hacía que hubiese mayor facilidad de acceso a la mujer, y que la presión verbal fuese suficiente para convencerla.

Livingstone et al. (2004) señalaban que en ambos contextos la táctica de limitación era la misma, el uso de resistencia verbal directa, aunque no lo eran las razones para ceder al 
encuentro sexual. En la situación de relación previa, la mujer suele ceder para escapar de la situación de presión, y en el caso de la relación ocasional, la mujer tiende a sentir mayor ambivalencia ante el encuentro sexual, y termina cediendo por temor a que el rechazo ofenda al hombre, y pueda arruinar la posible relación. Aunque es también en esta situación en la que hay más probabilidades de que la coerción tenga un impacto más negativo en la relación con el perpetrador.

Algunos estudios sobre coerción sexual en la adolescencia (Krahé, Bieneck y ScheinbergerOlwig, 2006; Krahé, Bieneck y Scheinberger-Olwig, 2007) señalan que algunos elementos o carácterísticas del encuentro sexual asociados a mayor riesgo de agresión y victimización sexual son el uso del alcohol, la comunicación ambigua de intenciones sexuales como token resistance y consentimiento de actividad sexual no deseada, y un alto índice de actividad sexual, entendido como un alto número de parejas sexuales, encuentros sexuales casuales, y un inicio temprano de las relaciones sexuales. De esta manera en la medida en que los guiones sexuales de los adolescentes contengan estos elementos como elementos normativos, será más probable que se involucren o experimenten situaciones sexualmente coercitivas.

Estos autores proponen desafiar en intervenciones educativas la aceptación normativa del alcohol, la comunicación sexual ambigua y la disposición al sexo con personas apenas conocidas, en los guiones sexuales de los adolescentes, puesto que es en la adolescencia cuando se desarrollan los patrones de comportamiento sexual y las normas relacionadas con la sexualidad.

\subsection{CONSENTIMIENTO DE ACTIVIDAD SEXUAL NO DESEADA}

El consentimiento de la actividad sexual no deseada ha sido definida como la decisión positiva de involucrarse en cualquier tipo de actividad sexual, a pesar del hecho de que la persona no desee llevar a cabo tal actividad sexual (Reneau, 2004). A primera vista parece que es un fenómeno incongruente y poco probable, y sin embargo, las pocas y recientes investigaciones que hay sobre el tema reflejan que la mayoría de hombres y mujeres han consentido alguna vez en tener actividad sexual no deseada, sobretodo en relaciones de pareja estables (Impett y Peplau, 2002; O’Sullivan y Allegeir, 1998; Reneau, 2004; Shotland y Hunter, 1995). En este apartado examinaremos las diversas definiciones conceptuales del consentimiento sexual (a 
veces lo denominaremos así de manera abreviada), su prevalencia en ambos sexos, así como las motivaciones que lo subyacen y las consecuencias que lo siguen.

\subsubsection{Definición, prevalencia e impacto}

La asunción lógica, y tal vez demasiado simplista, en relación con el deseo sexual y el consentimiento sexual era que la actividad sexual consentida era siempre actividad sexual deseada. Sin embargo Muehlenhard y Peterson (2005) propusieron un modelo en el que las experiencias de querer y no querer actividad sexual podían concurrir simultáneamente, sugiriendo que el modelo de querer y consentir era más complicado de lo que se había asumido. El modelo multi-dimensional de Muehlenhard distingue entre querer y no querer actividad sexual, y querer y no querer las consecuencias asociadas con tal actividad sexual. Por ejemplo, una persona puede querer una relación sexual por sí misma (por el placer que supone), pero puede no querer las consecuencias percibidas con esa relación sexual (miedo al embarazo o enfermendades). Contrariamente una persona puede no desear actividad sexual por no estar de humor en el momento, pero puede querer obtener las consecuencias asociadas a ella, como el cimentar la intimidad en la relación.

Este modelo también distingue entre querer y no querer cierta actividad sexual, y consentir o no consentir tal actividad sexual. Una mujer puede querer una relación sexual con un hombre pero no consentirla por no tener medidas anticonceptivas. Contrariamente, una persona puede no desear actividad sexual pero consentirla de todas formas por no herir a su pareja por ejemplo, que sería la situación que examinamos en este apartado.

El consentimiento está considerado como una parte integral de las interacciones sexuales, sin embargo las mujeres parecen ser más capaces de nombrar y explicar conductas que indican consentimiento que los hombres (Verberg, Wood, Desmarais, Kalra y Senn, 2000). La investigación sobre interacciones sexuales ha mostrado que el consentimiento tiende a ser ambiguo y que los guiones sexuales no incluyen la necesidad de un consentimiento verbal explícito (Bartels, 2007; O’Sullivan y Byers, 1992; Fuertes et al., 2007). La ambigüedad parece ser el resultado de las diferentes maneras de comunicar el consentimiento sexual, y de las diversas maneras en que puede ser interpretado. 
La investigación normalmente ha definido esta conducta como una conducta caracterizada por la decisión de un individuo de involucrarse voluntariamente en alguna actividad sexual que no es deseada. Sin embargo existen algunas diferencias entre estudios.

La definición que proponía O'Sullivan y Allgeier (1998) y Shotland y Hunter (1995) incluía sólo actividad sexual que fuese iniciada por la pareja, así como que la persona que consentía debía ocultar o disimular su falta de deseo para que esto se considerase consentimiento sexual. La definición de Reneau (2004) era más inclusiva pues comprendía cualquier actividad sexual no deseada (besar, sexo oral etc.) en la que se involucraba o incluso iniciaba una persona, y que podía ocultar o no la falta de deseo sexual (es decir, podía fingir o no deseo sexual durante la actividad). La definición que utilizaremos en nuestra investigación incluye también cualquier actividad sexual, la posibilidad de fingir o no el deseo sexual, pero no incluye la posibilidad de que la persona que consiente sea la que haya iniciado la actividad sexual no deseada. Es decir, para considerar en nuestro estudio que se ha dado un consentimiento de actividad sexual no deseada será necesario que la actividad la haya iniciado el otro miembro de la pareja.

La prevalencia del consentimiento sexual varía bastante de estudio a estudio, debido principalmente a diferencias en las técnicas de metodología y en las definiciones conceptuales. En las definiciones más exclusivas (Sprecher et al., 1994; O’Sullivan y Allgeier, 1998; Impett y Peplau, 2003) coincidían en una prevalencia de entre 38 y 50\% de participantes que habían consentido alguna vez sexualmente, mientras que en definiciones más inclusivas (Reneau, 2004) la prevalencia se incrementaba hasta el punto de que casi todos los participantes habían consentido alguna vez en tener actividad sexual no deseada (83\%).

Los resultados de la investigación de que disponemos sugieren que consentir actividad sexual no deseada, tiene consecuencias tanto positivas como negativas, y estas consecuencias pueden afectar tanto al individuo que consiente como a la relación.

Varios estudios muestran que consentir actividad sexual no deseada produce resultados positivos. De hecho, las personas que consienten sexualmente suelen calificar la experiencia de agradable (O'Sullivan y Allgeier, 1998). En el trabajo sobre ambivalencia sexual de O'Sullivan y Gaines (1998) encontraron que los participantes que finalmente habían decidido tener relaciones sexuales a pesar de la ambivalencia, experimentaron más consecuencias positivas que los que habían rechazado la invitación sexual. O’Sullivan y Allgeier (1998) descubrieron que las consecuencias positivas más frecuentes eran la satisfacción de la pareja, la promoción de la 
intimidad en la relación y la prevención del conflicto relacional. No encontraron diferencias en estas consecuencias positivas entre hombres y mujeres. Impett y Peplau (2003) también señalaban que el consentimiento sexual podía tener como resultado emociones positivas. En el estudio de Reneau (2004) se encontró que las consecuencias más comunes de las experiencias de consentimiento positivas eran la fortaleza de la relación, establecer una imagen positiva de uno mismo, y compromiso-reciprocidad en la relación.

También se han documentado consecuencias negativas del consentimiento sexual. En su revisión, Impett y Peplau (2003) señalaban que consentir sexualmente podía conllevar un mayor índice de riesgos sexuales, y que se asociaba a un mayor riesgo de victimización. De hecho, Krahe, Scheinberger-Olwig y Kolpin (2000) descubrieron que las mujeres que habían consentido en tener actividad sexual no deseada alguna vez, tenían tres veces más probabilidades de sufrir algún tipo de coerción o asalto sexual con uso de la fuerza o bajo la influencia del alcohol, que las mujeres que nunca habían consentido sexualmente. Reneau (2004) señalaba que las consecuencias más comunes de las experiencias negativas de consentimiento eran comprometer los propios valores, y la tensión en la relación. En el estudio de O'Sulliavan y Allgeier (1998) vieron que consentir actividad sexual no deseada por motivos que no fueran por el bien de la relación tenía consecuencias como malestar emocional tras la experiencia, tensión en la relación, y auto-evaluaciones negativas.

Las consecuencias pueden ser más negativas aún entre aquellos que dan su consentimiento sexual, tras experimentar presión o coerción sexual. En el estudio de Livingstone et al. (2004) la mayoría de las mujeres que consintieron sexualmente tras un episodio de presión verbal, manifestaban que haber consentido la relación sexual no deseada había impactado negativamente la relación y les había provocado sentimientos de enfado, resentimiento, y desconfianza. Sólo el 13\% de la muestra indicó que la experiencia de consentimiento no había tenido consecuencias, mientras que el $2 \%$ dijo que la relación había mejorado tras el episodio de consentimiento.

Las mujeres que consintieron en relaciones ocasionales o sin precedentes sexuales, manifestaban un mayor impacto negativo en la relación y más sentimientos de culpabilidad y arrepentimiento tras el consentimiento sexual, que las mujeres en relaciones de pareja, especialmente si habían bebido alcohol antes del encuentro sexual.

Como ya hemos visto, el consentimiento sexual aumenta el riesgo de victimización (Krahe et al., 2000) y a su vez, las consecuencias del consentimiento sexual producido en una situación de 
coerción sexual son más negativas que las producidas ante iniciaciones sexuales no coercitivas. Además algunos estudios han visto conexiones entre sufrir la presión sexual en pareja y el empleo de presión sexual por parte de la misma persona que la sufre en otras ocasiones (Brassard, Shaver y Lussier, 2007). En este sentido, parece que la comunicación sexual inconsistente, como es el consentimiento sexual, puede llevar a actitudes más permisivas ante el uso de la fuerza o la coerción con fines sexuales. Esto ocurriría no sólo a través de un mayor índice de victimización y tolerancia de los que consienten, sino también a través de un posible moldeamiento en las propias tácticas de avance sexual de las personas que dan el consentimiento, hacia estilos más coercitivos.

De esta manera, el consentimiento sexual y la aceptación y normalización de la coerción y la fuerza en las relaciones, pueden ser vistos como elementos conectados, de una representación de la sexualidad más amplia. Estas conclusiones cuentan con el apoyo del estudio de Krahe et al. (2006) quienes observaron que los adolescentes sexualmente agresivos describían mayores índices de comunicación sexual inconsistente (como el consentimiento sexual) en sus guiones sexuales consensuados, que los adolescentes menos agresivos. Los autores proponen que la manera en la que los individuos conceptualizan las interacciones sexuales consensuadas, juega un papel importante en su disposición y tendencia a utilizar la agresión sexual.

En cuanto a la explicación que se ofrece para comprender la existencia de consecuencias tan dispares tras el consentimiento sexual, varios estudios coinciden en señalar que, el que las consecuencias del consentimiento sean positivas o negativas depende de la motivación que ha impulsado tal consentimiento, algo sobre lo que volveremos en el capítulo de motivaciones sexuales. Otro factor que parece tener un papel determinante, es el contexto relacional en el que se produce el consentimiento sexual, puesto que es más probable que en una relación de pareja estable haya mayor confianza, más deseos de proteger la relación y los sentimientos de la otra persona, y que cuente con un patrón establecido para el consentimiento sexual. Por tanto se espera que el consentimiento sexual en relaciones de pareja tenga consecuencias más positivas o menos negativas, que en relaciones ocasionales, y que por lo tanto sea más frecuente en este contexto relacional (O'Sullivan y Gaines, 1998; Livingstone et al., 2004). 


\subsubsection{Género y guiones sexuales en el consentimiento sexual}

Un punto de coincidencia en los estudios que examinan la prevalencia del consentimiento de actividad sexual no deseada es la diferencia encontrada entre la frecuencia del consentimiento sexual en mujeres y en hombres. Los estudios de Sprecher et al. (1994) y O'Sullivan y Allgeier (1998) coincidían en señalar que mientras la mitad de la muestra femenina había consentido sexualmente, sólo un tercio de la masculina lo había hecho alguna vez en su vida. Reneau (2004) encontró que el 92\% de las mujeres y el 77\% de los hombres habían consentido en algún momento de su relación actual.

Las diferencias encontradas entre los sexos en materia de consentimiento sexual son un tanto paradójicas vistas desde un punto de vista del guión sexual tradicional. Los roles de género y el guión sexual tradicional sitúan al hombre en la posición de agente iniciador de las relaciones sexuales y a la mujer en la posición de agente limitador. Es evidente que estas normas culturales pueden afectar los sentimientos y conductas de hombres y mujeres, en relación con la actividad sexual. En un estudio (Grauerholz y Serpe, 1985) se encontró que los hombres se sentían más cómodos que las mujeres iniciando actividad sexual, y que lo contrario era cierto para la tarea de rechazar actividad sexual no deseada.

Parece que esto supusiese un salto en la lógica cuando nos fijamos en la prevalencia del consentimiento sexual: ¿Por qué el consentimiento sexual en la mujer es mayor si las mujeres se sienten más cómodas rechazando actividad sexual no deseada? Lewin (1985) sugirió que la existencia de una relación romántica enfatiza otro aspecto de las expectativas culturales para las mujeres: la expectativa de la mujer como cuidadora de la relación de pareja. Así, se asume que la mujer adopta la responsabilidad de la armonía en sus relaciones, y por lo tanto accede a determinadas actividades para complacer a su pareja, como ocurre con el consentimiento sexual. En este sentido tanto la investigación de Shotland y Hunter (1995) como la de O'Sullivan y Allgeier (1998) señalan que la mayoría de las mujeres que manifiestan consentimiento sexual, lo hacen en relaciones de pareja establecidas.

La relación entre el consentimiento sexual y la adherencia al guión sexual tradicional no está muy clara. Mientras que en el estudio de O'Sullivan y Allgeier (1998) no encontraron diferencias significativas en consentimiento sexual en función de la adherencia a roles de género tradicionales, en el trabajo de Bartels (2007) descubrieron que el ajuste al guión sexual 
tradicional predecía el consentimiento sexual. Sin embargo en este estudio se puso de manifiesto que la habilidad para comunicar las propias preferencias sexuales moderaba esta asociación, y que en presencia de esta capacidad comunicativa, la adherencia al guión tradicional ya no predecía el consentimiento de actividad no deseada.

Algunos estudios apuntan con sus resultados a un posible mayor consentimiento sexual por parte de los hombres, aunque no evalúan este concepto como tal. Por ejemplo en el estudio de O’Sullivan y Gaines (1998) sobre ambivalencia sexual señalaban que ante la ambivalencia, los hombres tenían mayor probabilidad de fingir interés sexual y participar en el encuentro que las mujeres, lo que supone una forma de comunicación inconsistente. Además era menos probable que los hombres comunicasen sus sentimientos de ambivalencia a la pareja, que las mujeres. Esto sugiere que existe cierta resistencia en algunos hombres a aparecer como alejados del ideal masculinos de "siempre a punto" para un encuentro sexual. En el guión sexual tradicional, se espera que el hombre esté disponible para cada oportunidad sexual (Shotland y Craig, 1988), así que si éste no expresa un claro interés sexual, podría haber dudas sobre su masculinidad, su potencia sexual, etc. (O’Sullivan y Allgeier, 1998; Gilbert et al., 1999). También podemos entenderlo bajo la luz del mayor interés sexual documentado en varones que en mujeres (Baumeister, 2000), lo que apuntaría a que no dejar pasar una oportunidad sexual puede actuar como otro elemento importante de motivación sexual masculina (Eyre y Millstein, 1999), en situaciones de ambivalencia sexual.

Por otra parte ante la ambivalencia sexual, las mujeres tenían más probabilidades que los hombres de rechazar el avance sexual, una respuesta consistente con su papel tradicional. En este sentido las autoras señalan que las mujeres eran además más proclives a sentir ambivalencia sobre la participación sexual quizás por una mayor predisposición en ellas a reconocer estos sentimientos cuando se enfrentan a una invitación sexual, lo que por otra parte sucede más a menudo que en los hombres. En otro estudio con adolescentes (Kvalem y Traeen, 2000), encontraron que las chicas de su estudio mostraban mayor autoeficacia a la hora de prevenir relaciones sexuales no deseadas que los adolescentes chicos, lo que se puede interpretar como un apoyo a la explicación basada en las expectativas y roles de género en la interacción sexual.

A modo de resumen concluimos que, en la relación entre género, guiones sexuales y consentimiento sexual, la presencia de una relación romántica, y de habilidades de comunicación sexual tiene un papel determinante: la primera para incrementar el consentimiento sexual en las mujeres, y la segunda para disminuir el consentimiento sexual. 
Concluimos además, que la mayoría de las personas, ya sean hombres o mujeres, han consentido alguna vez en tener actividad sexual no deseada.

\subsection{USO DEL PRESERVATIVO}

\subsubsection{Prevalencia e impacto}

El interés por la prevención del SIDA y otras enfermedades de transmisión sexual, así como del embarazo no deseado entre adolescentes ha incrementado notablemente la investigación psicosocial acerca del comportamiento sexual en este grupo de edad (Ramos et al., 2003; Navarro-Pertusa, Barberá y Reig, 2003; Diz, Sueiro, Chas y Diéguez, 2003; Planes, Gras, Cunnill, Gómez, Romero, Font-Mayolas y Vieta, 2004; Sánchez y Muñoz, 2001). En Estados Unidos, se estimó que ocurrían 19 millones de infecciones de transmisión sexual al año (Centers For Disease Control and Prevention, 2004) y la mitad de las personas infectadas tenían menos de 24 años, tendencia que parece ir en aumento puesto que en el año 2000, la misma estimación era de 15 millones de infecciones al año. En Europa, concretamente en Holanda, la estimación es de 100.000 casos de infección al año, siendo la población total de 16 millones (Gebhardt et al., 2006) y el $40 \%$ de los infectados son menores de 25 años. Una conclusión que parece clara, es que los adolescentes y adultos jóvenes tienen más riesgo de adquirir enfermedades de transmisión sexual que aquellos mayores de 25 años.

Experimentar con las relaciones y con las conductas íntimas es cada vez más un patrón de desarrollo adolescente normativo, pero como hemos visto, los adolescentes no cuentan con un repertorio consistente de normas o conductas, que hagan de la experiencia sexual una experiencia satisfactoria y saludable. Como resultado, los encuentros sexuales de los adolescentes son muchas veces imprevistos, esporádicos y a veces son el resultado de presión social o coerción sexual (Kelly y Kalichman, 1995), y es muy frecuente que los adolescentes no sean suficientemente conscientes de los riesgos que suponen las relaciones coitales (Gebhardt et al., 2006).

Como ya hemos comentado, durante las últimas décadas se ha producido en los países occidentales un descenso en la edad de inicio de relaciones sexuales y un aumento en el número 
de parejas sexuales y muchos de estos adolescentes no utilizan el preservativo de manera sistemática. Según un estudio de Bakker y Vanwesenbeeck (citado en Gebhardt, 2006) dos tercios de su muestra utilizaban el preservativo con parejas casuales, mientras que sólo el $17 \%$ de los adolescentes lo usaban de manera consistente con parejas estables. En general entre el 42 y el 63\% de adolescentes sexualmente activos manifiestan haber utilizado el condón en su última relación sexual, pero muchos menos lo utilizan en todas las ocasiones (Kann, Kinchen y Williams, 2000; Tschann, Adler, Millstein, Gurvey y Ellen, 2002; CDC, 2003; Ford y Norris, Marin, citado en Bauman y Berman, 2005; Gebhardt et al., 2006).

En España contamos con un índice de uso del preservativo algo mayor, pero aún así lejos de ser óptimo. Diversos estudios realizados con adolescentes coinciden en que el porcentaje de utilización del preservativo se sitúa entre el 75 y el $85 \%$ en la primera o en la última relación sexual (Ramos, Fuertes, Martínez y Hernández, 2003; Diz et al., 2003; Planes et al., 2004; Espadalé, Planes y Gras, 2005; Cerqueira-Santos, Koller y Wilcox, 2008).

La investigación psicológica ha identificado algunos determinantes de las conductas sexuales de riesgo, que en su mayor parte son factores cognitivos y se han aplicado en un marco de toma de decisiones, utilizando modelos teóricos como la teoría de la acción razonada (Fishbein y Ajzen, 1975), la teoría de la conducta planeada (Ajzen, 1985) o la teoría cognitivo social (Bandura, 1994). En este marco, se asume que las personas estarán motivadas a utilizar los preservativos una vez que estén convencidos de los beneficios de hacerlo en oposición a los costes, y de que son capaces de hacerlo. La intención de utilizar condones se considera así el determinante más próximo de tener relaciones sexuales protegidas. Sin embargo, la investigación indica que sólo alrededor de un 19\% de la varianza en la utilización del preservativo se explica a través de las intenciones (Sheeran y Orbell, citado en Gebhardt, 2006) por lo que existe un salto sustancial entre la intención de tener sexo seguro y la utilización real del preservativo.

\subsubsection{Contexto y guiones sexuales en el uso del preservativo}

Una de las razones de porqué las actitudes individuales y las normas sociales percibidas fracasan a la hora de predecir el uso del preservativo puede residir en el concepto de los guiones interpersonales (Hynie, Lydon, Côté y Wiener, 1998). Los guiones interpersonales pueden actuar de eslabón entre las actitudes y las normas percibidas puesto que la puesta en marcha, a nivel interno y conductual, de estos guiones da como resultado una internalización de los 
significados y valores adquiridos. Tal y como sugieren las teorías de la autoeficacia (Ajzen, 1991; Bandura, 1977), la influencia de las normas sociales y las actitudes está limitada por el conocimiento de los individuos sobre como llevar a la acción estas normas y actitudes, o en otras palabras, por el conocimiento de los guiones apropiados. Cuando hay un salto entre actitudes hacia el uso del preservativo, y el conocimiento de cómo poner en práctica el uso del condón en las propias interacciones, es menos probable que las personas actúen de manera acorde a sus actitudes (Hynie et al., 1998). En su estudio Edgar y Fitzpatrick (1993) observaron que estudiantes universitarios podían presentar guiones detallados sobre cómo transmitir interés sexual, pero apenas contaban con guiones para prácticas sexuales seguras, como discutir el uso del condón.

En esta línea Gebhardt et al. (2006) demostraron que la preparación cognitiva era un aspecto determinante a la hora de utilizar el preservativo. La utilización del preservativo es una tarea compleja ya que involucra múltiples pasos preparativos como el comprarlos, negociar su uso, colocarlos correctamente etc., y un paso que resulta crucial es pararse a pensar cuándo sacar el tema con la pareja. Así los guiones sexuales parecen vitales para el análisis de la conducta sexual saludable ya que la comunicación, la toma de decisiones, y la habilidad para moldear el propio comportamiento y el de la pareja, resultan centrales en las negociaciones sexuales. En la investigación de Dworkin, Beckford y Ehrhardt (2007) se examinó cualitativamente la iniciación sexual, el ritmo, la toma de decisiones sexuales, la comunicación de necesidades sexuales, y el momento de introducción del condón, en una muestra de mujeres que participaron en una intervención sobre la prevención del VIH. Las participantes que habían participado en el programa reflejaron un cambio en el guión sexual ya que, de una iniciación y toma de decisiones controlada por el hombre, pasaron a un guión más controlado por la mujer, y el momento de introducción del condón pasó de ser tardío, a ser previo incluso a la intimidad sexual.

Este y otros estudios (Navarro-Pertusa et al., 2003) sugieren que la adherencia a guiones de iniciación tradicionales, pueden dificultar la toma de precauciones y poner en peligro la salud tanto del hombre como de la mujer. Las características potencialmente dañinas son por una parte el hecho de que el hombre se sienta presionado para perseguir todo tipo de oportunidades sexuales, ya sean seguras o arriesgadas, y por otra, el hecho de que la mujer se distancie de sus propias necesidades sexuales, y le resulte difícil negociar el uso de preservativo ante la insistencia masculina, (Seal y Ehrhardt, 2003; Wagner, Seal y Ehrhardt, 2001) bien por la 
creencia en el alto drive sexual masculino esencial, o por la interdependencia entre aspectos sexuales y amorosos.

El guión sexual tradicional podría explicar en parte por qué muchas chicas bien informadas sobre los riesgos sexuales no llevan a la práctica lo que conocen para prevenir daños potenciales para su salud. A pesar de no haber encontrado estudios que relacionasen el uso del preservativo, con el empleo de determinadas estrategias de iniciación o limitación sexual, hay alguna evidencia que sugiere cierta relación positiva entre la coerción sexual y mayor riesgo de contraer enfermedades de transmisión sexual. En el caso de las chicas haber sufrido coerción sexual se relaciona positivamente con conductas sexuales de riesgo, mientras que los hombres que han sufrido coerción sexual utilizan el condón de manera más sistemática que hombres que nunca han sufrido coerción sexual (Choi, Binson, Adelson y Catania, 1998). Parece probable que la violencia ejercida principalmente por el hombre juegue un papel importante a la hora de disuadir a la mujer para que intente negociar el uso del preservativo. Así, se asume que el miedo de las mujeres hacia la coerción sexual masculina es un factor que contribuye al mayor riesgo de infección de enfermedades de transmisión sexual en mujeres (Doll y Carballo-Diéguez, 1998).

En este sentido, Breakwell y Millward (1997) observaron en su investigación una relación positiva entre asertividad sexual y uso del preservativo en su muestra femenina. Sin embargo, en otro estudio realizado sobre asertividad sexual en chicas adolescentes (Auslander et al., 2007) se observó que la asertividad percibida a la hora de iniciar encuentros sexuales no correlacionaba con la asertividad en el uso de anticonceptivos o en el rechazo de actividad sexual, mientras que la asertividad en estas dos conductas correlacionaban positivamente. Esto parece apuntar a que la asertividad sexual puede no aplicarse por igual a diferentes ámbitos de la conducta sexual femenina. Además, sabemos que a pesar de que algunos estudios señalan que las adolescentes tienen mayor nivel de autoeficacia en el uso de anticonceptivos y en prevenir relaciones coitales no deseadas que los adolescentes chicos (Kvalem y Traeen, 2000), diversos trabajos señalan que en realidad las chicas utilizan menos el preservativo que los varones (Robinson, Holmbeck y Paikoff, 2007; Vogels et al., citado en Gebhardt et al., 2003; Bauman y Berman, 2005).

Este salto entre asertividad y autoeficacia, y uso real del preservativo en chicas adolescentes pueden tener su explicación en el hecho de que la utilización del preservativo está finalmente bajo el control físico del varón, explicación que se ve confirmada por el hecho de que la autoeficacia en contracepción femenina se asocia más coherentemente con el uso adecuado de la 
píldora anticonceptiva, método controlado por la mujer (Tschann et al., 2002; Kvalem y Traeen, 2000).

A pesar de que la investigación ha demostrado que la adherencia a roles de género en sexualidad es mayor en las relaciones casuales que en las relaciones de pareja, y que algunas circunstancias propias del guión sexual tradicional dificultan el uso del preservativo, en numerosas investigaciones se ha documentado que existe un mayor uso del preservativo en relaciones ocasionales o esporádicas, que en relaciones de pareja estables (Bauman y Berman, 2005; Rosenthal, Gifford y Moore, 1998; Hynie et al., 1998; Friedman, Flor, Kottiri, Neaigus, Sandoval, Curtis, Des Jarlais y Zenilman, 2001; Gebhardt et al., 2003). Según Bauman y Berman (2005) en relaciones de pareja se utiliza el condón hasta que se alcanza mayor compromiso y confianza y entonces el uso se hace intermitente hasta que finalmente se sustituye por la píldora anticonceptiva. En el estudio de Fortenberry, Harezlak, Katz y Orr (2002) observaron además que una relación de pareja nueva en la adolescencia requería sólo de un mes para que el uso del preservativo descendiese hasta niveles similares al uso que hacían de él parejas establecidas.

Sin embargo, en el estudio de Bauman y Berman (2005) llegaron a la conclusión de que no era concretamente la duración de la relación lo que determinaba la utilización del preservativo sino otros criterios, a veces derivados de la duración como el compromiso, el carácter público de la relación, la exclusividad sentimental o monogamia, y el afecto entre los miembros de la pareja. Otra variable relacionada también con el contexto relacional, como es la experiencia sexual en adolescentes, se ha visto asociada negativamente al uso del preservativo. Así los adolescentes que más experiencia sexual tienen, utilizan menos el preservativo que aquellos con menos experiencia sexual (Auslander, Perfect, Succop y Rosenthal, 2007; Kvalem y Traeen, 2000).

Así, ni las relaciones de una noche u ocasionales, ni las cualidades asociadas a una relación de pareja estable parecen facilitar un mayor uso del preservativo. Es posible que haya un momento intermedio, quizas en los comienzos de una relación de pareja, en el que se de un equilibrio entre la incipiente flexibilidad de roles y la cautela, que favorezca en los adolescentes la toma de precauciones sexuales. 


\section{CAPITULO IV}

\section{MOTIVACIONES SEXUALES}

El porqué hombres y mujeres tienen relaciones sexuales suele parecer una cuestión evidente para muchas personas, ya que se asume que el sexo es una motivación en sí misma. Sin embargo, si rascamos suavemente sobre la superficie de esta explicación, rápidamente aparece un complejo conjunto de posibilidades motivacionales para la actividad sexual. Algunos individuos buscan actividad sexual por motivos de placer, otros para aliviar tensión y estrés. En otros casos, como sucede en gran medida en la adolescencia, la conducta sexual, al igual que las demás conductas, se sustenta en motivos sociales, como complacer a otras personas, ajustarse a las normas del grupo, expresar afecto, o adquirir estatus. Así, responder a la cuestión de porqué las personas tienen relaciones sexuales se convierte en un asunto de notable complejidad e interés.

El interés por examinar el campo de las motivaciones sexuales, además de estar justificado en sí mismo, como un reflejo de las características de la sexualidad humana, es importante por los múltiples correlatos o repercusiones que puede tener sobre la experiencia sexual subjetiva y la conducta sexual. La investigación ha demostrado que la conducta sexual sustentada por diferentes motivos tiene implicaciones importantes para el bienestar personal e interpersonal 
(Snyder y Cantor, 1997; Impett, citado en Impett, Peplau y Gable, 2005). Así la psicología clínica puede beneficiarse de una mayor comprensión de porqué hombres y mujeres deciden mantener relaciones sexuales ya que esto afecta a aspectos de la relación de pareja como la intimidad y la sexualidad, temas que frecuentemente son objeto de consulta.

También fuera de las relaciones de pareja existen importantes razones para atender a la motivación sexual, ya que en múltiples estudios se ha visto que algunas motivaciones sexuales se relacionan con la puesta en marcha de conductas sexuales de riesgo, que pueden conducir a embarazos no deseados, y a contagio de enfermedades de transmisión sexual (Sanderson y Cantor, 1995; Cooper, Powers y Shapiro, 1998; Gebhardt et al., 2003; Gebhardt, Kuyper y Dusseldorp, 2006; Navarro-Pertusa, Barberá y Reig, 2003). Además, el conocimiento de las motivaciones sexuales puede facilitar el análisis de factores que afectan a disfunciones sexuales, violencia de género, coerción y abuso sexual (Hill y Preston, 1996).

Teniendo en cuenta la importancia de la motivación sexual, este es un tema sorprendentemente poco estudiado (Meston y Buss, 2007; Impett, Peplau y Gable, 2005). Los primero estudios de la sexualidad humana ignoraron los aspectos motivacionales de la conducta sexual (Kinsey, Pomeroy y Martin, 1948; Kinsey, Pomeroy, Martin y Gebhard, 1953). Los que sí afrontaron el papel de la motivación sexual presentaron mayoritariamente una perspectiva reduccionista centrada en el impulso sexual biológico y el alivio del orgasmo (Master y Johnson, 1966), una posición que era coherente con las teorías de la época. Más recientemente los teóricos motivacionales han ampliado el foco de atención para incluir diversos incentivos sexuales que son externos al individuo, como factores específicos de las relaciones íntimas (Basson, 2000).

Las motivaciones sexuales varían en función del tipo de relación deseada, relaciones a corto o largo plazo (Meston y Buss, 2007). Un ejemplo de motivaciones sexuales para relaciones casuales o relaciones extramaritales sería el deseo de experimentar variedad sexual o la intención de mejorar las propias habilidades sexuales (Symons, citado en Meston y Buss, 2007; Greiling y Buss, 2000). También las motivaciones sexuales son númerosas en contextos de relaciones de pareja estables, como el querer recompensar a la pareja por algo o como un favor o intercambio, para intensificar la relación o aumentar el nivel de compromiso (Buss, 2003). En un estudio se describía cómo algunas mujeres buscaban en las relaciones sexuales los efectos colaterales de cercanía emocional, afecto, amor etc. (Basson, 2000). 
Desde otra perspectiva, algunas personas pueden utilizar las relaciones sexuales como una manera de "mantener la pareja" o de "competencia de esperma" (Shackelford, Pound, Goetz y LaMunyon, 2005). Popularmente se concibe el sexo como un recurso consumible que alguien puede ofrecer y otra persona puede desear. Como recurso, la actividad sexual puede intercambiarse por otros recursos como el dinero, como es el caso de la prostitución (Burley y Symanski, citado en Meston y Buss, 2007).

La psicología del sexo además, no se da sólo entre los miembros de la pareja involucrada sino que ocurre en un contexto social y cultural más amplio, con implicaciones para el prestigio, el estatus, y la reputación (Buss, 2003). Así, como la actividad sexual tiene consecuencias para el estatus y la reputación que pueden funcionar como incentivos (o elementos de disuasión), una persona puede estar motivada hacia la actividad sexual por razones sociales que nada tienen que ver con la relación interpersonal en la que ocurre. La conclusión que nos ofrece este panorama es que los motivos que las personas tienen para tener relaciones sexuales son mucho más numerosos y complejos psicológicamente de lo que se había creído en los inicios de la investigación.

Pasaremos a continuación a hacer una revisión de las perspectivas teóricas desde las que se ha estudiado la motivación sexual y de la investigación que existe sobre el tema, centrándonos finalmente en el modelo de motivación sexual en adolescentes que utilizaremos en el presente estudio.

\section{PERSPECTIVAS TEÓRICAS EN MOTIVACION SEXUAL}

\subsection{Modelos del "drive” o impulso sexual de la motivación sexual}

La perspectiva más reconocida y fundamental sobre la motivación sexual es quizás la que se basa en la teoría del impulso o "drive theory". Tanto la teoría psicoanalítica como las teorías conductuales del drive han acudido al concepto de impulso sexual para explicar la motivación sexual y a pesar de sus diferencias teoréticas, mantienen ideas parecidas sobre la naturaleza de los impulsos y sus relaciones con la conducta. 
Freud veía la sexualidad como una fuerza fundamental en la conducta individual y en la sociedad. Esta fuerza vital básica llamada Eros la comprendía como un impulso instintivo que cuando no era satisfecho daba lugar a tensiones internas que construían una energía erótica o libido. La conducta individual está dirigida y motivada hacia una vuelta a la homeostasis fisiológica a través de la descarga de energía, normalmente con el orgasmo. Así, el único objetivo del instinto sexual es su propia gratificación que puede conseguirse unicamente eliminando las tensiones estimulantes internas (Freud, 1923-1990) y cuyo resultado placentero invita a la futura repetición o incluso compulsión del acto. Desde esta perspectiva por tanto, la motivación sexual es una propensión interna independiente de su objeto de apego, que normalmente puede quedar fijado en una edad temprana a través de su asociación con un momento de excitación sexual agudo (Freud, 1905-1953). Freud también describía el instinto sexual como altamente moldeable y constreñido por imperativos culturales. A través del mecanismo defensivo de la sublimación, las energías libidinales son canalizadas en otro tipo de actividades socialmente deseables.

De esta manera Freud concebía el sexo como un motivo básico que conduce al organismo hacia actividades que reducen la tensión, actividades que pueden ser sexuales o no sexuales, y para el psicoanálisis son los correlatos y las vicisitudes del impulso sexual lo que constituyen el tema sometido a análisis, en vez de la motivación sexual por sí misma.

Las teorías conductuales del drive, aunque diferían en su enfoque, compartían con la teoría psicoanalítica la concepción del sexo como un impulso innato dirigido a la reducción del estado fisiológico de tensión. El ejemplo más prominente es la teoría del drive de Hull (1943) que mantenía que toda conducta está directa o indirectamente motivada por la necesidad de resolver deprivaciones fisiológicas como el hambre o la sed a través de actos consumatorios. En el caso del sexo, la consumación es proporcionada por el orgasmo, que tras comprobar su eficacia en la reducción de la tensión, activa y refuerza las asociaciones estímulo-respuesta.

En la literatura clásica del drive la distinción entre motivación sexual masculina y femenina apenas tiene lugar, posiblemente porque estas teorías se apoyan de forma desproporcionada sobre la fisiología y el funcionamiento sexual del sujeto masculino y había por tanto una comprensión muy pobre de la sexualidad femenina (Singer y Toates, citado en Jenkins, 2004). Aún así la investigación indica que el sustrato fisiológico de la motivación sexual depende en parte de los diferentes niveles hormonales (andrógenos, estrógenos y progesterona) que existen para hombres y mujeres (Legar, 1992). Estos mecanismos corporales podrían por lo tanto tener un papel importante en la intensidad del impulso sexual biológico de las personas. 
Existen evidencias de que los hombres atribuyen la motivación sexual al impulso sexual en mayor medida que las mujeres (Leigh, 1989; Baumeister y Tice, 2001). Sin embargo contamos con otro tipo de resultados como que el $83 \%$ de los hombres y el $97 \%$ de las mujeres valoran la sexualidad más allá del orgasmo (Carroll, Volk y Hyde, 1985) y que dos tercios de hombres y el 90\% de las mujeres atribuían la motivación a algo diferente de estar excitado. Además en otro estudio se demostró que el alivio de la tensión sexual era la quinta de ocho posibles razones para la actividad sexual en ambos sexos (Jenkins, 2004).

La conclusión es que no todo se reduce a la reducción del impulso sexual y de hecho desde la mitad del pasado siglo se ha criticado estas teorías como simplistas en incapaces de explicar las complejidades de la sexualidad humana. Una crítica concreta recae sobre la imposibilidad de explicar la tendencia del organismo a inducir en vez de reducir estados de tensión psicológica y fisiológica, a través de la búsqueda de la estimulación proporcionada por la novedad y el desafío (Deci, citado en Jenkins, 2004). Además en algunos trabajos, el placer como motivo aparece diferenciado de la reducción del impulso sexual o la excitación. En los estudios de White (1959) con animales demostraron que la excitación sexual en ausencia de orgasmo o eyaculación tenía igualmente un efecto reforzador en ratones, lo que sugería que la tensión sexual sin reducción puede ser la propia recompensa. La implicación de estos resultados es que además de un aparente impulso por reducir la tensión fisiológica a través del orgasmo, la motivación sexual incluye una fuerza interna dirigida a conseguir la estimulación y excitación propia de la sexualidad.

\subsection{Perspectiva evolucionista de la motivación sexual}

En opinión de la sociobiología (Wilson, 1975) y de sus herederos contemporáneos, los psicólogos evolucionistas (Buss, 1989, 1999), la conducta humana se organiza en torno a la capacidad de fomentar el éxito reproductivo. La conducta sexual en particular, está considerablemente influida por las estrategias asociadas al éxito reproductivo a lo largo de la evolución de la especie. Así, las preferencias por algunas parejas o la búsqueda de placer y excitación son algunos aspectos que equivocadamente relacionamos con decisiones o intenciones razonadas, cuando en realidad son el resultado de patrones de conducta que han incrementado la prosperidad genética a lo largo de la historia de la evolución humana. 
Una implicación para las diferencias de género en motivación sexual se encuentra en la teoría de la inversión parental de Trivers (1972). Esta teoría predice que la motivación sexual aparece de acuerdo al nivel de recursos que se requieren de alguien para invertir en la supervivencia de los descendientes. La mujer debe invertir más recursos y correr más riesgos que los hombres en cada etapa de la gestación, nacimiento y crecimiento de la descendencia, por lo que el éxito reproductivo está más asegurado si la motivación sexual femenina se da en contextos de relaciones estables. Así, las mujeres están más motivadas por la conexión emocional, que fomenta el apego y las relaciones duraderas, en las que hay más probabilidad de que el hombre se quede y proporcione recursos más allá de la contribución genética de su esperma.

Según este enfoque, la inversión del hombre consiste en una distribución promiscua del material genético entre tantas mujeres como sean capaces, e invertir los recursos mínimos necesarios para ayudar a cada madre a criar a los hijos. Así, la motivación sexual masculina es la búsqueda de la gratificación o placer físico del acceso sexual a diversas parejas en la medida de lo posible saludables y atractivas. Según Buss (1995), los hombres deben hacer esto porque nunca pueden estar cien por cien seguros de su paternidad.

En un trabajo de Townsend (1995) sobre sexo sin involucración emocional se apoya la perspectiva evolucionista. En una muestra de estudiantes universitarios que habían manifestado no sentir ningún deseo de involucración emocional, se examinaron las reacciones de los participantes ante el coito. Los resultados revelaron que las relaciones coitales habían dejado a la mayoría de las mujeres con un sentimiento de vulnerabilidad, a pesar de no querer una relación con su pareja sexual. Las relaciones sexuales parecían elicitar sentimientos de unión y deseo de involucración independientemente del número de parejas sexuales. En cambio, los hombres con mayor número de parejas sexuales encontraban cada vez más sencillo desvincular el sexo de la emoción y la inversión parental. Las mujeres con múltiples parejas desarrollaron técnicas para manejar sus reacciones negativas ante el sexo de baja involucración valorando en sus parejas signos de posible inversión emocional. La conclusión sugiere que las intenciones conscientes femeninas de no querer involucrarse emocionalmente eran superadas por la función evolutiva de evaluar la inversión parental.

Por otra parte, dado que los hombres son conscientes de la existencia de competidores masculinos, están motivados hacia conductas y estrategias que fomentan su sensación de poder y control, demostrando sus habilidades sexuales o incrementando sus recursos, reputación o prestigio en su comunidad. La violación se entendería en este escenario como la estrategia de los hombres de bajo estatus para acceder sexual y reproductivamente a parejas a las que de otra 
manera no podrían acceder. Gangestad (1991) sugiere que por otra parte, algunos hombres adoptan de una manera genuina la estrategia de una sexualidad conservadora y restrictiva como una forma de atraer a mujeres que buscan el compromiso. Así, la sexualidad masculina no es enteramente uniforme, sino que una mezcla de conductas altamente reactivas a la excitación, conductas agresivas y conductas amorosas conforman el variado vocabulario que utilizan los hombres para describir al "hombre sexual", tal y como expusieron Andersen, Cyranowski y Espindle (1999).

Tal y como señala Kilmartin (2000) existen una serie de críticas y limitaciones teóricas y metodológicas contra la psicología evolucionista, como su tendencia hacia explicaciones simplistas, una presentación selectiva de los datos, un fracaso a la hora de explicar algunas conductas sexuales humanas y animales que no fomentan la reproducción, como la homosexualidad y la masturbación (Oliver y Hyde, 1993) y una sobrevaloración de las contribuciones biológicas sobre las sociales a la conducta.

\subsection{Perspectiva del construccionismo social de la motivación social.}

Aunque las teorías evolucionistas y las teorías del impulso se centran en tendencias naturales e innatas que subyacen a la sexualidad, la mayor parte de la investigación psicológica sugiere que hay multitud de factores que constituyen el aprendizaje social (Mischel, 1966), adherencia a guiones sexuales (Gagnon y Simon, 1973) e ideologías y roles de género (Pleck, citado en Jenkins, 2004). Estos enfoques varían en el nivel de importancia que asignan a la biología y al entorno, pero en general comparten una visión en la que conciben la conducta como construida dentro de un contexto de dinámicas y acuerdos sociales, que incluye relaciones interpersonales, economía, historia, cultura, refuerzos y castigos (Kilmartin, 2000).

La naturaleza de las preferencias sexuales, formas de expresión, y experiencia de la motivación son entendidas como parte de una negociación cambiante y continua entre el individuo, que imita, se resiste, se compromete o internaliza, y su entorno. La manera en la que el entorno determina es a través de costumbres parentales, normas y expectativas institucionales y culturales, presión de grupo, medios de comunicación, lenguaje etc. 
Existen dos consecuencias significativas de la perspectiva construccionista. La primera es que en estas teorías, el sexo pierde su potencial para explicar tanto la motivación sexual como para explicarse a sí mismo. Así, el sexo se hace dependiente de las fuerzas sociales que le dan significado y dirección. El resultado es que la actividad sexual está motivada frecuentemente por otra cosa que no es el sexo en sí mismo (Jenkins, 2004).

La segunda consecuencia es que la sexualidad y sus motivos quedan subsumidos bajo el proceso de la construcción social del género (Oliver y Hyde, 1993). Así, para entender lo que significa estar sexualmente motivado como hombre o como mujer, hay que entender la construcción social de masculinidad y feminidad respectivamente.

Las raíces de la comprensión del género y la sexualidad que hace el construccionismo social se encuentran en la teoría del aprendizaje social de la adquisición de identidad de género (Mischel, 1966) que propone que niños y niñas aprenden las lecciones sobre la pertinencia de la conducta para cada género, a través de la observación de los refuerzos y castigos impuestos a otros. Mas tarde, se elaboró un papel más activo para el individuo, como agente activo constructor de identidad y significado, más que como un mero observador pasivo.

Además de la observación y el aprendizaje vicario, hombres y mujeres aprenden de sus experiencias sexuales e incorporan ese aprendizaje a sus conductas y actitudes sexuales. Por ejemplo, el hombre experimenta más placer durante la primera relación coital que las mujeres, lo que constituye un refuerzo positivo a la hora de repetir la conducta (Horowitz, 2000). Como explicábamos en el apartado del género en los guiones sexuales, la mayor frecuencia de la conducta de masturbación en los chicos hace que sea más probable que los chicos aprendan a pensar en la actividad sexual en términos de placer físico, que normalmente requiere poco esfuerzo o compromiso social (García y Carrigan, 1998; Regan y Berscheid, 1996). El aprendizaje social se refuerza también a un nivel social más amplio, en el que los hombres reciben mayor refuerzo por las relaciones sexuales casuales y las mujeres lo reciben por restringir su actividad sexual a relaciones amorosas comprometidas (Regan y Dreyer, 1999).

De esta manera, se entiende que son las normas socioculturales las que influyen y determinan las diferencias de género en la motivación sexual. De acuerdo con las normas socioculturales la sexualidad femenina está más intensamente asociada a la calidad de la relación que la de los hombres y en la medida en que las mujeres asocian cualidades interpersonales a la sexualidad, enfatizarán los motivos interpersonales como el compromiso o el mejorar la relación, en su actividad sexual (Regan y Dreyer, 1999). 


\subsection{Perspectiva funcional de la motivación sexual: Modelo propuesto}

Esta perspectiva se basa en la asunción, derivada del construccionismo, de que la sexualidad o la actividad sexual en las personas sirve para conseguir determinados objetivos o cubrir determinadas necesidades, diferentes de las propiamente sexuales. Es decir, la conducta sexual, al igual que el resto de conductas, puede tener un amplio rango de funciones psicológicas, que cubren determinadas necesidades personales y sociales en las personas. Estas funciones serían por lo tanto lo que buscan las personas cuando deciden tener actividad sexual, o dicho de otro modo, las razones o motivaciones que tienen para la conducta sexual.

Este enfoque defiende que examinando las funciones psicológicas a las que sirve la conducta se facilitará la comprensión de la actividad sexual en general y en especial de algunos patrones de conducta sexual que pueden resultar problemáticos. Esta premisa de que tener actividad sexual para cubrir determinadas necesidades se asocia a diferentes patrones de conducta se apoya en un análisis funcional de la conducta (Snynder y Cantor, 1997). De acuerdo a esta perspectiva, la conducta se entiende mejor atendiendo a las metas o necesidades a las que sirve. Si las personas ponen en marcha diferentes conductas para lograr un mismo objetivo o si ponen en marcha la misma conducta para lograr diferentes objetivos, la clave para la comprensión de la conducta se encuentra en los propósitos y motivos que subyacen a tal conducta. Así, no importa cuanto se parezcan externamente las conductas, pues si sirven a diferentes necesidades, son consideradas como fenomenologicamente distintas: responden a antecedentes disposicionales y situacionales diferentes, están caracterizadas por correlatos distintos, y llevan en muchos casos, a consecuencias diferentes (Cooper et al., 1998).

Diversos estudios apoyan la utilidad de esta perspectiva para comprender la conducta romántica y sexual concretamente (Miller et al., 1993; Sanderson y Cantor, 1995). Los resultados obtenidos son consistentes con la idea de que las personas pueden utilizar y de hecho utilizan la actividad sexual de manera estratégica para cubrir determinadas necesidades psicológicas, que la naturaleza de las experiencias sexuales difiere en función de las necesidades a las que sirve, y que los factores que mantienen o promueven la conducta también dependen de las necesidades subyacentes. Este razonamiento sugiere que un estudio directo de las motivaciones sexuales debería conllevar insights importantes sobre las causas y consecuencias probables de la 
conducta sexual, al igual que una mejor comprensión de la mejor manera de intervenir y cambiar conductas sexuales problemáticas o asociadas al riesgo.

Según Cooper et al. (1998) la crucial tarea de modificar estos patrones asociados al riesgo ha sido afrontada en su mayor parte por modelos centrados en el cambio de actitudes, creencias y conocimientos relacionadas con la sexualidad y con sus riesgos. Así su objetivo era evitar la enfermedad y otras consecuencias no deseadas convenciendo a las personas de las conductas sexuales que tenían que evitar y medidas preventivas que tenían que tomar. Esta aproximación ha tenido un éxito limitado (Kelly y Kalichman, 1995) debido a que en ella se ignora que la conducta sexual sirve a determinadas funciones psicológicas que nada tienen que ver con la salud o la prevención de enfermedades. El hecho de que algunos patrones de conducta sean tan resistentes al cambio indica que hay determinadas fuerzas sociales que dan significado, que mantienen y promueven estas conductas, y que tal y como exponen Cooper et al. (1998), puede ser útil entender en términos motivacionales.

Estos autores proponen que tener diferentes motivaciones sexuales estará asociado con diferentes patrones de conducta sexual, no sólo porque diferentes conductas satisfacen a personas motivadas por diferentes objetivos, sino porque personas con unos motivos dados, buscan circunstancias interpersonales concretas que facilitan la consecución de estas metas, y son estas circunstancias las que en última instancia determinan la conducta sexual.

\subsubsection{Fuentes de diferencias individuales en motivación sexual}

Para el análisis de las motivaciones sexuales Cooper et al., (1998) señalaron la necesidad de disponer de dimensiones motivacionales que fuesen relevantes desde un punto de vista teórico, $\mathrm{y}$ de instrumentos validos y fiables que las midieran en muestras representativas. Aunque muchos teóricos de la personalidad han indagado sobre las necesidades o motivos humanos básicos que energizan y dirigen la conducta humana, no existe consenso en cuanto a la naturaleza o número de estos motivos. Sin embargo, según los autores, hay dos distinciones que generalmente se utilizan en todas las teorías motivacionales y que además parecen especialmente útiles para explicar conductas interpersonales emocionales como la conducta sexual. Las distinciones se centran en si la conducta está motivada por un deseo de evitar una consecuencia negativa o de perseguir una positiva, y si la conducta está originalmente centrada 
en uno mismo, autodirigida, y controlada por uno mismo, o si está externa y socialmente centrada y controlada.

Las conductas dirigidas a conseguir experiencias positivas o placenteras también son llamadas conductas aproximativas y las dirigidas a evitar experiencia negativas o dolorosas san también llamadas conductas aversivas. Estos dos tipos de conductas, aproximativa y aversiva están reguladas por dos sistemas motivacionales que son neurológicamente distintos (Gray, citado en Cooper et al., 1998). El sistema de inhibición de conducta o BIS (behavior inhibition system) regula la motivación aversiva y controla la experiencia de emociones negativas, mientras que el sistema de activación de conducta o BAS (behavior activation system) provoca el movimiento hacia los objetivos o conductas de aproximación. Gray hipotetizó que las personas difieren, como si de un rasgo estable se tratara, en la sensibilidad que tienen ante los sistemas de activación o inhibición. Así, las personas que son muy sensibles al sistema de inhibición son especialmente reactivas a las señales de amenaza y castigo y consecuentemente están predispuestos a experimentar emociones negativas y a responder de una manera evitativa y miedosa. Por el contrario, las personas con alta sensibilidad al sistema de activación, son especialmente reactivas a las señales de recompensa y están predispuestas a experimentar emociones positivas y a involucrarse en conductas de búsqueda del refuerzo (Carver, Sutton y Scheier, 2000; Carver y White, Fowless, Larssen y Ketelaar, citado en Cooper et al., 1998).

Aplicado a la sexualidad, la distinción sugiere que algunas personas o algunas veces, se puede utilizar la conducta sexual para conseguir consecuencias placenteras como la gratificación física o para evitar consecuencias negativas como el rechazo de la pareja. También la teoría de la regulación de Higgins (1998) apuntaba a la distinción entre dos formas independientes de autorregulación, una centrada en la promoción o consecución de estados positivos y otra centrada en la prevención de estados negativos. Elliot y Sheldon (1997) igualmente diferenciaban entre metas de aproximación y de evitación en cuanto a logros personales.

La segunda distinción tiene que ver con la medida en la que se persigue un objetivo individual versus un objetivo social. Esta dicotomía se parece aunque no es idéntica a la distinción entre agency y communion de Bakan (1966), exploración versus apego (Bowlby, 1970) y autonomía versus pertenencia (Skinner y Wellborn, 1994). En el trabajo de Cooper et al., se asume que los objetivos o metas centrados en uno mismo están primeramente motivados por necesidades de identidad, de autonomía y de competencia, e incluyen la utilización del sexo para obtener gratificación física o para autoafirmarse en términos de identidad o atractivo y para manejar la 
experiencia emocional interna. En cambio, se asume que los objetivos centrados en los demás están motivados por necesidades comunales y de apego, como utilizar el sexo para lograr mayor intimidad en una relación o ganarse la aprobación de un individuo o grupo significativo. Aunque algunos teóricos han considerado los motivos de búsqueda de aprobación como individuales con la asunción de que derivan de una preocupación por mantener el propio estatus, en el trabajo de Cooper et al., clasifican este motivo como centrado en los demás porque el primer objetivo de la conducta es elicitar una respuesta de otra persona o grupo de personas. Así, aunque ambos tipos de motivos se persiguen en un contexto interpersonal y ambos pueden considerarse finalmente como originados por el deseo de manejar las propias emociones, estos tipos de motivos difieren en la medida en que el resultado buscado se da primeramente en un nivel interno o individual, o en un nivel social.

Estas dos dimensiones expuestas pueden cruzarse y dar lugar a cuatro categorías de motivos: a) motivaciones de aproximación o positivas centradas en uno mismo, como tener actividad sexual para obtener placer físico (motivación de placer); b) motivaciones aversivas o negativas centradas en uno mismo, como tener actividad sexual para afrontar emociones negativas o amenazas a la autoestima (motivación de afrontamiento); c) motivaciones de aproximación centradas en los demás, como tener relaciones sexuales para lograr mayor intimidad con la pareja (motivación de intimidad) y d) motivaciones aversivas centradas en los demás o sociales, como tener relaciones sexuales para evitar críticas de otros o ganarse la aprobación de los demás (motivación de aprobación). La estructura factorial hallada en la escala Sex Motives desarrollada en 1998 por Cooper et al., en una muestra de adolescentes, reveló la existencia de 6 tipos de motivaciones en lugar de cuatro. Las motivaciones de afrontamiento se dividieron en dos tipos (autoafirmación y afrontamiento) y las motivaciones de aprobación se dividieron en otras dos categorías (aprobación de la pareja y aprobación de los amigos).

La revisión de la investigación existente sobre motivación sexual muestra un enorme consenso sobre la importancia de dos de las motivaciones expuestas, las que en el estudio de Cooper et al., llamaron motivación de placer y de intimidad. Se entienden como las razones principales para tener actividad sexual (Leigh, 1989; Sprague y Quadagno, 1989; Brigman y Knox, 1992). Algunos estudios también proporcionan apoyo para los motivos de afrontamiento y de aprobación (Christopher y Cate, 1984; Brigman y Knox, 1992; Leigh, 1989). Tanto la teoría como los datos sugieren que esta tipología proporciona un marco conceptual para las principales dimensiones motivacionales que subyacen a la conducta. En nuestra investigación hemos adoptado este modelo para el estudio de las motivaciones sexuales en la adolescencia. 


\subsubsection{Implicaciones para el bienestar de los tipos de motivaciones sexuales.}

La distinción entre motivaciones positivas o negativas (de aproximación y de evitación) ha demostrado tener implicaciones en el bienestar personal e interpersonal de las personas. En términos de emociones, Carver y Scheier (1998) señalaron dos dimensiones de la experiencia afectiva independientes, una que manejaba la conducta de aproximación (que iba desde la euforia a la depresión) y otra que manejaba la conducta evitativa (desde el miedo al alivio). Gable, Reiss y Elliot (2000) encontraron que participantes con una alta sensibilidad al sistema de activación de la conducta, mostraban mayores índices diarios de afectos emociones positivas, aunque no menor índice de afectos negativos que aquellos con baja sensibilidad al sistema de activación. En cambio, aquellos con alta sensibilidad al sistema de inhibición indicaban mayores índices de emociones negativas diarias, aunque no menor índice de emociones positivas que aquellos con baja sensibilidad al sistema de inhibición.

En términos de salud, la motivación de aproximación o positiva se asocia con mayores niveles de optimismo vital, mayor bienestar subjetivo y menor depresión. La motivación de evitación en cambio de asocia con más muestras de síntomas físicos (Elliot y Sheldon, 1997). En términos de bienestar interpersonal, los motivos de aproximación estaban vinculados a resultados caracterizados por la presencia o ausencia de cualidades sociales positivas, como mayor satisfacción con lazos sociales, y los motivos de evitación se relacionaban con la presencia o ausencia de cualidades sociales negativas, como mayor inseguridad en las relaciones (Impett, Peplau y Gable, 2005).

En cuanto a la aplicación de este enfoque a la sexualidad, existen diversos modos por los que la motivación de aproximación y de evitación puede influir en el bienestar personal e interpersonal. En primer lugar, involucrarse en relaciones sexuales por motivaciones positivas como acceder al placer físico puede ser experimentado como inherentemente recompensante, así como tener relaciones sexuales para acercarse emocionalmente a la pareja o para la gratificación física de la misma, puede llevar a la satisfacción por sí mismo, y también por un proceso de identificación empática. En cambio, tener relaciones sexuales por evitar un conflicto, una decepción o un malestar emocional, puede en el mejor de los casos conducir al alivio y en el peor producir la ansiedad y la tensión que se estaba intentando evitar (Downey et al., citado en Impett, Peplau y Gable, 2005). En un estudio de Impett (citado en Impett et al., 2005) se 
asociaba la motivación positiva en sexualidad con sentimientos posteriores de excitación, amor y pasión, mientras que tener relaciones sexuales por motivos negativos se asociaba a sentimientos posteriores de enfado, vergüenza y miedo.

En relación con las implicaciones para el bienestar interpersonal, en el mismo trabajo de Impett, se vinculaba la motivación sexual positiva con mayor satisfacción relaciona y la motivación sexual negativa con menor satisfacción relacional. La explicación podría estar en que una persona que tiene actividad sexual para lograr el placer de su pareja, puede sentirse posteriormente más cercana a ella y más satisfecha, mientras que una persona que tiene actividad sexual para evitar el castigo o decepción de su pareja, puede sentir resentimiento u otras emociones negativas que la alejan de la satisfacción.

En el estudio de Impett et al., (2005) se proponía un mecanismo alternativo o complementario en realidad, en el que se consideraba un posible mediador entre la motivación y el bienestar a las conductas específicas puestas en marcha en la interacción sexual. Los autores sugerían que cuando un individuo se involucra en actividad sexual por motivos de aproximación, como el placer o la intimidad, puede expresar de una manera más clara y explícita, verbal o fisicamente, su deseo y su placer, lo que tendría un efecto directo sobre la percepción de la pareja y la satisfacción general de ambos miembros. En cambio, la conducta sexual motivada por la evitación, puede ser manifestada con mayor reticencia y ambigüedad y menor entusiasmo, lo que puede ser percibido por la pareja y afectar negativamente a la satisfacción de ambos miembros.

En nuestra investigación hemos adoptado una perspectiva acorde con lo expuesto en el párrafo anterior, en relación con la posible relación entre motivaciones sexuales y la comunicación de interés sexual a través de estrategias de avance y limitación sexual. De la misma manera que las motivaciones influyen en el bienestar personal e interpersonal por las repercusiones que éstas pueden tener sobre la expresión de la conducta y sentimientos durante la interacción sexual, creemos que las motivaciones pueden afectar a la manera en la que se inicia un encuentro sexual o se expresa el interés sexual. Así, las motivaciones positivas pueden determinar una expresión más clara e inequívoca del interés sexual a través del uso de estrategias de avance o de limitación sexual más directas y explicitas, mientras que las motivaciones negativas podrían determinar una forma de comunicación más ambigua y confusa con el empleo de estrategias de avance o de limitación indirectas, implícitas, o incluso coercitivas. 
También existen implicaciones para la conducta romántica y sexual en función de si los objetivos o motivaciones están centradas en uno mismo o en los demás. La investigación en los estilos de apego sugiere que los individuos con un estilo de apego seguro tienen mayor probabilidad de tener motivaciones relacionadas con la intimidad con los demás, porque cuentan con una base segura sobre la que construir una relación cercana (Bartholomew y Horowitz, 1991; Hazan y Shaver, 1987). Aunque muchos adolescentes tienen una serie de relaciones exclusivas pero bastante cortas (2-3 meses) tales relaciones pueden aún así facilitar las revelaciones íntimas de pensamientos y sentimientos, el cuidado de la pareja, afecto, confianza y respeto (Weinstein y Rosen, 1991). Sin embargo no todos los adolescentes están preparados para intimar de una manera exclusiva con otra persona. La teoría de las etapas vitales de Erikson (1950) propone que la capacidad de intimidad de un individuo depende en parte de la resolución de algunas tareas como la formación de la identidad. Para estos adolescentes, cuya motivación sexual está más centrada en sí mismos, tener múltiples relaciones casuales les permite realizar una exploración de aspectos de sí mismos, conocer a diferentes tipos de personas, desarrollar habilidades sociales nuevas y explorar de una manera hedonista la actividad sexual con diferentes tipos de parejas.

Así, según Miller, Bettencourt, DeBro y Hoffman (1993) los adolescentes con motivaciones sexuales centradas en sí mismos enfatizan la exploración hedonista y la búsqueda de la autoafirmación y poder en sus relaciones sexuales, mientras que aquellos con motivaciones más centradas en la intimidad con los demás enfatizan la comunicación abierta, la negociación y la dependencia mutua con sus parejas. También pueden extraerse implicaciones prácticas para mensajes educativos sobre prevención de riesgos ya que los mensajes podrían adecuarse al tipo de motivación sexual. Por ejemplo, los adolescentes con motivaciones de intimidad tienen más probabilidades de beneficiarse de intervenciones educativas que enfatizan la comunicación efectiva con la pareja (Sanderson y Cantor, 1995).

\section{TIPOS DE MOTIVACIONES SEXUALES}

Aunque hay un considerable número de estudios que han examinado las motivaciones sexuales, existe poco acuerdo, más allá de las dos motivaciones de placer e intimidad, sobre sobre la naturaleza y el número del resto de motivaciones que subyacen a la conducta sexual. 
Nelson (1978) fue el primero en desarrollar una escala que midiese los motivos sexuales. Su análisis factorial dio lugar a cinco motivos para tener actividad sexual: 1) Amor, 2) Placer, 3) Conformismo, 4) Reconocimiento y 5) Poder (dominación y sumisión). Los motivos de conformismo, amor y placer fueron los mejores predictores de diez tipos de variables sexuales en su estudio, desde la frecuencia de sexo casual a la frecuencia de orgasmo coital. En el año 2000, Browning, Hatfield, Kessler y Levine, llevaron a cabo un estudio utilizando éstas mismas motivaciones en estudiantes universitarios y examinaron su relación con variables sexuales como iniciar conductas sexuales usuales e inusuales, realizar conductas sexuales usuales e inusuales y utilización del preservativo.

En sus resultados hallaron que los hombres tenían mayores índices de motivación de placer y de conformismo que las mujeres y menores índices de motivación de amor que ellas, tal y como habían encontrado en otros estudios (Nelson, 1978; Leigh, 1989) y consistente con la evidencia que las mujeres tienen más probabilidades de hacer del amor un prerrequisito para la actividad sexual (Reiss, 1960). Los motivos de placer, amor y reconocimiento se asociaban positivamente a realizar actividad sexual usual y el conformismo lo hacía negativamente. En cuanto a iniciar actividad sexual usual, los motivos de amor y placer aumentaban la iniciación significativamente pero sólo en la muestra femenina, mientras que el motivo de reconocimiento sólo incrementaba la posibilidad de la iniciación sexual en los varones. La motivación de placer era la única que se asociaba en ambos sexos y negativamente al uso del preservativo. En los varones también el reconocimiento se relacionaba de manera inversa con el uso del preservativo.

Los autores concluyen que tanto el conformismo como en reconocimiento son motivaciones importantes en muestras jóvenes, ya que las normas de grupo contribuyen a predecir la involucración en relaciones sexuales casuales en adolescentes (Maticka-Tyndale et al., 1998) y la necesidad de reconocimiento parece ser el mejor predictor del número de parejas sexuales en el estudio de Nelson (1978). Además descubren un interesante papel del contexto relacional en tanto que sólo las chicas en relaciones casuales mostraban un asociación directa entre la motivación de dominación e involucrarse en actividad sexual, lo que los autores explican a través de la posibilidad de que las mujeres utilicen el sexo para ganar poder en sus relaciones esporádicas. Sin embargo, esta submuestra concreta resultaba demasiado pequeña como para asentar este resultado como conclusión. 
En 1989, Leigh que examinó tanto razones para tener como para no tener actividad sexual, documentó siete motivaciones para la actividad sexual: placer, expresión de cercanía emocional, reproducción, complacer a la pareja, porque la pareja lo desea, para hacer una conquista, para aliviar tensión sexual. El mejor predictor de la frecuencia de actividad sexual fue la motivación de placer en este estudio.

La taxonomía más completa que existía sobre motivación sexual encuadrada en una perspectiva teórica de disposiciones sexuales motivacionales fue la de Hill y Preston (1996) que construyó las siguientes ocho escalas: 1) valoración de la pareja, 2) valoración por la pareja, 3) alivio de estrés, 4) proporcionar cuidados, 5) enfatizar el propio poder, 6) enfatizar el poder de la pareja, 7) placer y 8) procreación. Los autores descubrieron que la procreación no era una motivación ni un correlato de la actividad sexual de los estudiantes universitarios con los que realizó el estudio. El alivio del estrés en cambio resultó ser la única motivación que predecía la frecuencia masturbatoria.

En relación con los adolescentes, Cohen (1995) sugiere que los motivos para la actividad sexual representan necesidades no sexuales, como obtener la aprobación de los amigos, rebelión, expresión de hostilidad hacia los padres, escapar de la propia situación vital, un grito de socorro, tendencias autodestructivas o búsqueda del amor. Cohen diferencia las motivaciones no sexuales de las sexuales porque están iniciadas por otro tipo de factores diferentes de la curiosidad sexual, el placer erótico o la intimidad relacional. Las motivaciones no sexuales reflejan conflictos y necesidades sociales y psicológicas subyacentes, y tienen más probabilidades de conducir a complicaciones sociales, médicas y psicológicas.

Como ya hemos expuesto, Cooper et al., (1998) desarrollaron una tipología de motivaciones sexuales: a) motivaciones de aproximación o positivas centradas en uno mismo, (motivación de placer); b) motivaciones aversivas o negativas centradas en uno mismo, (motivación de afrontamiento); c) motivaciones de aproximación centradas en los demás, (motivación de intimidad) y d) motivaciones aversivas centradas en los demás o sociales, (motivación de aprobación). Sin embargo en el análisis factorial obtuvieron 6 factores y no cuatro, ya que los dos factores de motivación de evitación se dividieron en otros dos cada uno de ellos. La motivación concebida como de afrontamiento distinguía entre motivación de autoafirmación y de afrontamiento, y la concebida como motivación de aprobación se dividía en motivación de aprobación de la pareja y aprobación de los amigos. 
En sus análisis de validez, encontraron que el patrón de relación entre las motivaciones de intimidad y placer y otras medidas de sexualidad sugería una orientación positiva y hedonista de éstas motivaciones hacia el sexo, y que ambas diferían unicamente en el grado en el que se centraban en uno mismo o en los demás. En cambio, los motivos de autoafirmación y afrontamiento mostraban una orientación ambivalente hacia el sexo en la que existían relaciones positivas con medidas generales de sexualidad pero también con neuroticismo. La motivación de autoafirmación además correlacionaba de manera más intensa con la necesidad general de aprobación social. Finalmente, los patrones de asociación de las motivaciones de aprobación de la pareja y de los amigos se caracterizaban por una ausencia de incentivos positivos para el sexo, con ambos motivos mostrando relaciones casi insignificantes con la necesidad de sexo, de intimidad, búsqueda de sensaciones y erotofilia. De hecho las relaciones más importantes las mostraban con erotofobia, neuroticismo y necesidad general de aprobación. Así el miedo al rechazo parece ser lo único que motivaría hacia el sexo a los individuos que muestran este tipo de necesidades.

Los autores llegaron a la conclusión de que las motivaciones de afrontamiento, autoafirmación, aprobación de la pareja y de los amigos, nacen principalmente de procesos de motivación aversiva y que la clave distintiva tiene menos que ver con el grado en el que están centrados en uno o en los demás, que con la valencia positiva o negativa de los incentivos que las caracterizan.

Los resultados del estudio reflejaban una mayor frecuencia de las motivaciones de placer e intimidad sobre las motivaciones aversivas, especialmente sobre las motivaciones de aprobación de la pareja y los amigos. Los chicos tenían más frecuentemente todas las motivaciones sexuales excepto la motivación de intimidad en la que no se observaban diferencias de género. La edad se relacionaba positivamente con la motivación de intimidad, de placer y negativamente relacionada con la motivación de aprobación de la pareja y amigos, aunque la asociación con la motivación de placer desaparecía al controlar la experiencia sexual.

En un estudio de O'Sullivan y Gaines (1998) se estudiaron las razones que tenían estudiantes universitarios para sentir ambivalencia o indecisión sobre mantener relaciones sexuales, así como para tener finalmente actividad sexual y para rechazar la actividad sexual. Las razones más frecuentes para la ambivalencia estaban relacionadas en este orden con: factores sobre la intimidad de la relación, factores circunstanciales, factores de excitación sexual, factores morales y otro tipo de factores. Entre las razones más citadas para tener actividad sexual finalmente se encontraban: "excitarse más durante el proceso", "no querer decepcionar" o 
"enfadar a la pareja", "satisfacer sexualmente a la pareja", "mostrar afecto o cariño", y "recibir confort y seguridad de la pareja". Las razones más frecuentes para decidir no tener actividad sexual fueron "preocupación por embarazos o contagios", "razones morales", "asociar el sexo con mayor compromiso", "no estar suficientemente atraído por la pareja" y "no estar preparado". En el caso sólo de las chicas también citaron frecuentemente "estar demasiado nerviosa".

La excitación sexual sobrevenida es la primera razón para decidir involucrarse en actividad sexual y los autores lo explican a través de unos resultados de Hunter y Shotland (1996) quienes indicaron que el deseo y las intenciones varían a lo largo del curso de un encuentro sexual y que los que no inician la actividad pueden necesitar tiempo para reconocer si están excitados o no. Vemos que las razones asociadas con la relación y la intención de mantenerla, son las que predominan sobre las otras, en los tres tipos de motivaciones, si bien es cierto que la mayoría de los participantes contestaron pensando en relaciones de pareja estables, con lo que la generalización de los resultados a otros contextos relacionales es dudosa.

En un trabajo de Navarro-Pertusa et al. (2003) expusieron a 505 adolescentes un escenario de una relación casual en la que podía ocurrir una relación coital y pidieron a los participantes que atribuyeran una serie de motivos por los que tener actividad sexual desprotegida o no tenerla, a los personajes del escenario. Presentaron los posibles motivos en forma de dilemas siendo el primero complacer a la pareja / complacer al grupo, el segundo excitación sexual / alcohol, y el tercero placer sexual / ser como los demás. Tan sólo la mitad de los participantes pronosticó que el personaje se implicaría en una relación desprotegida lo que puede indicar que el mensaje de la prevención ha calado especialmente entre los varones. Además encontraron que la mitad de las chicas sí se implicarían en un encuentro casual no coital y lo interpretan en términos del cambio experimentado en los roles femeninos en los últimos años.

Los resultados sobre motivación se ajustaban más a creencias tradicionales ya que indicaron que el comportamiento sexual del chico del escenario era más atribuido por ambos sexos a motivos intrínsecos como el impulso sexual o el cortejo, revelando una creencia en el mayor "drive" masculino, mientras que el origen del comportamiento de la chica se ubica en otras circunstancias como el consumo de alcohol y el estatus. En cuanto a los motivos para no tener actividad sexual, los chicos señalan con mayor frecuencia el temor al sida y ellas señalan más la ausencia de vinculación amorosa, lo que indica que la prevención es menor cuanto mayor es la vinculación amorosa. Los varones indicaron que aunque les gustaría que les sucediera una historia similar veían poco probable que les ocurriera, lo que sugiere que no dejar pasar una 
oportunidad sexual puede actuar como otro elemento importante de motivación sexual masculina (Eyre y Millstein, 1999).

Un inconveniente de esta investigación es que no valora las motivaciones personales de los participantes sino las atribuciones que hacen a unos personajes, lo que bien puede estar reflejando estereotipos de género dentro del guión sexual tradicional.

En el estudio de Horowitz (2000) en el que se examinaban diferencias de género en motivación sexual y relaciones de ésta con conductas sexuales de riesgo, elaboraron una medida de motivación sexual con seis factores: Expresión de amor, Placer, Pragmatismo, Control, Obligación y Reproducción. Los resultados indicaron que las universitarias chicas estaban más motivadas por la expresión de amor, y los chicos más por el placer, aunque ambos resultados estaban mediados por otros factores psicosociales como el conformismo, el apoyo social y la auto-aceptación, que resultaron mejores predictores de la motivación sexual que el género. Por otra parte el pragmatismo, el control y la obligación como motivos estaban más asociados a las conductas de riesgo y consecuencias negativas, mientras que la expresión de amor y placer se asociaban inversamente al malestar emocional. Según la autora, algunos motivos para la actividad sexual pueden estar representando algún tipo de malestar psicológico o dificultades interpersonales subyacentes, por las que las personas se inclinan a llevar a cabo más conductas sexuales de riesgo.

Ott, Millstein, Ofner y Halpern-Felsher (2006) llevaron a cabo un estudio sobre motivaciones y expectativas sexuales en la adolescencia. Los participantes valoraron en primer lugar la motivación de intimidad, en segundo lugar el estatus social y en tercer lugar el placer, aunque estas relaciones variaban en función del género y la experiencia sexual. Las chicas valoraban significativamente más la intimidad y significativamente menos el placer que los chicos y los adolescentes experimentados valoraban más tanto el placer como la intimidad que los inexperimentados. En términos de expectativas, los adolescentes pensaban que la actividad sexual les conduciría más probablemente al placer, en segundo lugar a la intimidad y finalmente al estatus social. Sin embargo, las chicas y los adolescentes inexperimentados manifestaban expectativas más bajas de que el sexo llevase a estos objetivos, que los varones y los participantes experimentados.

Los autores concluyen que sus resultados desafían las creencias convencionales sobre la sexualidad masculina y sugieren que las relaciones interpersonales son importantes para los varones en tanto que han valorado la intimidad por encima del placer o el estatus. Una limitación propuesta por los autores es que, a pesar de las importantes diferencias encontradas 
en la motivación sexual y en las expectativas en función de la experiencia sexual, no se puede establecer una dirección de influencias por falta de causalidad. Concluyen sin embargo que la evidencia de los estudios longitudinales en adolescentes sugiere que la experiencia y las actitudes pueden influirse mutuamente.

Finalmente en el año 2007, Meston y Buss elaboraron una escala de motivos sexuales en la que se encontraron cuatro factores generales de los que surgían 13 subfactores. En el factor de razones Físicas se encontraban la reducción de tensión, el placer, el deseo físico y la búsqueda de experiencias. El factor de Logro de objetivos incluía recursos, estatus social, venganza, y razones utilitarias. El factor Emocional incluía amor y compromiso, y expresión y finalmente en el factor de Inseguridad se encontraban la subida de autoestima, la obligación o presión, y mantenimiento de la pareja. Los resultados mostraron que todos los factores eran más frecuentes en hombres que en mujeres excepto el factor emocional, en el que no se encontraban diferencias, y de la misma manera todos los factores excepto el emocional se asociaban positivamente a la orientación sociosexual liberal (SOI) que los autores entienden como estrategias de emparejamiento a corto plazo. Concluyen que si el hombre es el que inicia mayoritariamente las relaciones sexuales, esto debe reflejarse en el orden y frecuencia de las motivaciones sexuales femeninas. Además indican la conveniencia de estudiar las motivaciones sexuales en rangos de edad concretos y de incluir el contexto relacional como variable.

\section{MOTIVACIONES SEXUALES Y GÉNERO}

A la hora de recopilar las conclusiones sobre diferencias de género en motivaciones sexuales hemos decidido hacer tres grupos de estudios en función del tipo de resultado que obtienen. Por una parte hay estudios que sostienen que los hombres sostienen mayores índices en todas las motivaciones excepto la motivación de intimidad, para la que no se encuentran diferencias de género (Clark, Shaver y Abrahams, 1999; Cooper et al., 1998; Meston y Buss, 2007). En este sentido Ott el al. (2006) descubrieron que los chicos tenían mayores expectativas de que la actividad sexual les condujese hacia las metas que perseguían en mayor medida que las chicas, que tenían unas expectativas más bajas de que esto sucediera.

Por otra parte la conclusión más extendida en el campo de la motivación sexual es que en general los hombres aducen mas motivaciones relacionadas con la gratificación física y el placer 
a la hora de tener relaciones sexuales, mientras que las mujeres tienden a estar más motivadas por le necesidad o el deseo de expresar su amor o experimentar intimidad emocional. En este sentido hay multitud de estudios que parecen coincidir entre sí (Carroll, Volk y Hyde, 1985; Leigh, 1989; Nelson, 1978; Browning, Hatfield y Kessler, 2000; Murstein y Tuerkheimer, 1998; Sprague y Quadragno, 1989; Seal y Ehrhardt, 2003; Patrick et al., 2007). Estas diferencias se han entendido como motivaciones centradas en el cuerpo versus motivaciones centradas en la persona y es consistente con los múltiples resultados que indican un mayor número de parejas sexuales en los hombres.

También existen otros estudios que a pesar de haber obtenido estos mismos resultados ofrecen una serie de matizaciones que relativizan la medida en que puede simplificarse las conclusiones sobre el tema. Por ejemplo, Navarro-Pertusa et al. (2003) encontraron que las motivaciones atribuidas al personaje ,masculino estaban basadas en el impulso sexual en mayor medida que las chicas, pero al ser atribuciones esto podría reflejar estereotipos de género. Horowitz (2000) descubrió que factores como el conformismo y la auto-acepetación mediaban los resultados situándose así como predictores de la motivación sexual por encima del género. Ott el al. (2006) encontraron que a pesar de que comparativamente los chicos daban más importancia al placer y menos a la intimidad que las chicas, en términos generales valoraban la intimidad por encima del placer, con lo que concluían la necesidad de revisar las asunciones tradicionales sobre la sexualidad masculina.

En el estudio de Sprague y Quadragno (1989) encontraron interacciones entre el género y la edad, en el sentido de que a medida que los participantes avanzaban en edad, los dos sexos se aproximaban a las motivaciones sexuales propias del sexo opuesto. Así, los hombres mayores que tendían a mostrar motivaciones emocionales eran más y la proporción de mujeres con motivaciones físicas también se incrementaba con la edad. Estos estudios, introducen variables que cuestionan y matizan unas asunciones tremendamente extendidas sobre las diferencias de género en motivación sexual, otorgando al tema una mayor complejidad e interés.

Además de estos resultados un tanto ambiguos contamos con otra serie de estudios que han mostrado de una manera más clara la falta de diferencias entre los dos sexos en términos de tipos de motivaciones sexuales (O’Sullivan y Gaines, 1998; Impett et al., 2005; Gebhardt et al., 2003) aunque este último estudio observó la falta de diferencias sólo en relaciones estables. En su trabajo, Peplau (2003) concluye que las diferencias en motivación sexual entre hombres y 
mujeres no son absolutas sino una cuestión de grado, y que puede existir mayor variación dentro del mismo género que entre los dos géneros.

Además contamos con evidencia que sugiere que la motivación de intimidad y de placer físico no son mutuamente excluyentes, a diferencia de como se conceptualizan normalmente (Horowitz, 2000). En su estudio cualitativo Seal, Smith, Coley, Perry y Gamez (2008) concluyeron que estos dos discursos motivacionales se entrelazaban y que esto sucedía especialmente en la experiencia de los participantes masculinos, lo que resulta sorprendente dada la evidencia que apunta a que son las mujeres las que más frecuentemente entrelazan estas dos motivaciones. Los autores especulan que la experiencia contra-normativa de un episodio de alta excitación fisiológica en ausencia de intimidad emocional puede contribuir a que las mujeres tiendan a elegir esta experiencia como la más fisicamente excitante, y así sea más probable que la diferencien de otras experiencias excitantes en contextos emocionales.

Aunque no es exactamente lo mismo, Sanderson y Cantor (1995) en su estudio sobre motivaciones para tener relaciones románticas, tampoco encontraron diferencias entre chicas y chicos en la medida en que perseguían metas relacionadas con su identidad o con la intimidad, a la hora de tener relaciones románticas. Todos estos resultados pueden estar reflejando una faceta de cambio en los roles sexuales y el los intereses de las nuevas generaciones.

La motivación de aprobación de los amigos es una motivación concreta que suele general diferentes resultados para chicas y chicos. En el trabajo de Browning et al. (2000) observaron que la motivación de conformismo era mayor en chicos que en chicas, lo que era coherente con lo hallado por Nelson (1978), y con la creencia de que es más probable que los chicos experimenten presión de su grupo para tener relaciones sexuales que las chicas. En este sentido en la investigación de Navarro-Pertusa et al. (2003) también hallaron que las chicas atribuían en mayor medida la influencia del grupo de iguales como motivación sexual al personaje masculino que al femenino. Además Ott et al. (2006) encontraron que las chicas con experiencia sexual valoraban menos el objetivo de estatus social que las inexperimentadas, mientras que en los chicos no se encontraba relación entre experiencia sexual y la motivación de estatus social. Los autores concluyen que debido al doble estándar, la actividad sexual puede representar una dificultad para el estatus social de las chicas, pero no de los chicos. 


\section{MOTIVACIONES SEXUALES Y ESTRATEGIAS DE NEGOCIACIÓN SEXUAL}

\subsection{Motivaciones sexuales y estrategias de avance y limitación sexual}

Como ya hemos expuesto en apartados anteriores, uno de nuestros objetivos en esta investigación será examinar la relación existente entre las motivaciones sexuales y las estrategias de iniciación y limitación sexual. Según la teoría de los guiones sexuales (Gagnon y Simon, 1973) los guiones se mantienen en tres niveles. El nivel cultural especifica los objetos de deseo, la hora y el lugar y en general, las normas sociales que rodean un encuentro sexual. El nivel intrapsíquico que son los elementos motivacionales que producen excitación sexual o al menos compromiso con una secuencia de conductas, y que dan significado a estas conductas. Finalmente el nivel interpersonal es la aplicación del guión intrapsíquico a las secuencias de conducta compartidas socialmente, en un contexto determinado dentro de un escenario cultural específico.

Pretendemos pues, estudiar que conexiones pueden estar produciéndose entre algunos elementos de los guiones intrapsíquico e interpersonal en los adolescentes, como son las motivaciones y las estrategias de iniciación sexual respectivamente.

Seibold, Cantrill y Meyers (1994) han propuesto que las estrategias que las personas utilizan, reflejan sus intenciones, sus elecciones y su conducta, al servicio de objetivos específicos. Además de la teoría de los guiones sexuales, hay otras teorías que respaldan esta afirmación como la teoría de los estilos de apego adulto (Hazan y Shaver, 1994; Bartholomew y Horowitz, 1991) que señala que las necesidades en términos de apego serán las que guíen las conductas destinadas a favorecer o dificultar el establecimiento de relaciones románticas. Las teorías evolucionistas (Buss y Schmitt, 1993; Gangestad y Simpson, 1990) argumentan que hombres y mujeres se enfrentan a necesidades evolutivas diferentes en lo que a éxito reproductivo se refiere, y las estrategias sexuales y de emparejamiento son intentos por cubrirlas, por lo que son también diferentes. El modelo de intimidad interpersonal (Reis y Shaver, 1988) propone que las estrategias utilizadas en la búsqueda de la intimidad emocional pueden ser diferentes de aquellas utilizadas al servicio de la intimidad sexual. Específicamente estos autores encontraron que las conductas de comunicación directa y la revelación de información personal son las principales maneras de incrementar la intimidad emocional, mientras que Greer y Buss (1994) indicaron 
que la estrategia de emborrachar a la persona objetivo era mejor puntuada que la revelación de información personal para la promoción de un encuentro exclusivamente sexual.

Desafortunadamente apenas contamos con estudios que examinan la relación entre motivaciones sexuales y tipos de estrategias de iniciación sexual, tal y como se estudia en esta investigación. Algunos trabajos sin embargo, ofrecen resultados que apuntan en direcciones determinadas en este tema. En términos de objetivos relacionados con la identidad (centrados en uno mismo) y con la intimidad (centrados en los demás) en las relaciones románticas, Sanderson y Cantor (1995) encontraron que estos dos objetivos o metas, se relacionaban con patrones de comportamiento sexual diferentes. Los adolescentes con objetivos centrados en su identidad tenían más relaciones casuales y parejas sexuales, y aquellos con objetivos centrados en la intimidad tenían relaciones a más largo plazo. Aunque ambos objetivos están asociados con la búsqueda activa de las relaciones, lo hacen en contextos relacionales diferentes.

En el trabajo de Clark et al. (1999) sobre iniciación de relaciones románticas hallaron que en general los chicos iniciaban más frecuentemente y lo hacían directa y activamente, mientras que las chicas eran más indirectas. En cuanto a la relación con objetivos o motivaciones, la motivación de amor se perseguía a través de estrategias directas verbales y activas, mientras que la motivación del placer sexual se buscaba a través del contacto físico, estrategias indirectas, flirteo y manipulación. Tanto el tipo de objetivos como las estrategias utilizadas se relacionaban más en este estudio con ser chico o chica que con la masculinidad o feminidad. Browning y Hatfield (2000) encontraron evidencias en su trabajo sobre motivos sexuales y conducta sexual que indicaban que las mujeres con mayores índices de motivación de intimidad y placer iniciaban actividad sexual con más frecuencia que aquellas con menores índices de estas motivaciones. Lo mismo sucedía para la motivación de reconocimiento en los hombres. Aquellos con mayor motivación de reconocimiento, iniciaban actividad sexual más frecuentemente que aquellos menos motivados por el reconocimiento social.

Según las narrativas masculinas analizadas por Seal y Ehrhardt (2003), las motivaciones sexuales variaban en función del contexto relacional, puesto que en relaciones estables, la intimidad y la cercanía emocional era la principal motivación y en relaciones casuales era la motivación por el placer la que estaba más presente. Las estrategias de iniciación también variaban en función del contexto relacional. En parejas estables existía mutualidad a la hora de iniciar los encuentros sexuales, o era la mujer quien iniciaba a través de estrategias directas, mientras que en relaciones casuales, iniciaba sobretodo el hombre a través de estrategias de 
contacto físico directo o estrategias indirectas. Además, en sus discursos, los hombres tendían a evaluar de manera negativa la iniciación femenina, especialmente cuando la propuesta era puramente sexual.

En el 2007, Seal et al. Realizaron otra investigación cualitativa con el objetivo de estudiar el guión intrapsíquico e interpersonal para tres momentos sexuales concretos, la primera vez, el encuentro más fisicamente excitante, y el encuentro sexual más intenso emocionalmente. Descubrieron que los guiones intrapsíquicos se alineaban con las dos conceptualizaciones tradicionales de motivos sexuales: placer físico e intimidad emocional. En la primera experiencia sexual el motivo predominante era la excitación física para ambos sexos y en este caso, el guión interpersonal consistía en iniciaciones masculinas, ritmo controlado por el varón y limitaciones propuestas por la mujer. A medida que la relación iba progresando y el guión intrapsiquico se ajustaba más a la intimidad emocional, los guiones interpersonales se hacían más igualitarios y la iniciación se realizaba con mayor mutualidad entre los sexos.

Como podemos observar, en el juego que hay entre motivos y estrategias de iniciación sexual, un elemento crucial es la relación interpersonal o contexto relacional. Parece que motivos sexuales y contexto relacional están profundamente relacionados, en tanto que en contextos de pareja la motivación fundamental es la de intimidad emocional y ambos factores parecen determinar un tipo concreto de guión interpersonal de iniciación sexual, caracterizado por el uso de estrategias directas y comunicación explicita o verbal, así como por la igualdad entre los sexos. En cambio las relaciones esporádicas suelen contener motivaciones de placer físico que se asocian a guiones interpersonales caracterizados por una iniciación indirecta, física y predominantemente masculina.

En cuanto a otro tipo de motivaciones sexuales y la coerción sexual como forma de avance sexual, consideramos que determinadas motivaciones sexuales podrían facilitar el uso de conductas coercitivas para iniciar relaciones sexuales, sin embargo hemos hallado pocas investigaciones que examinen la relación entre estos dos fenómenos, tal y como los entendemos en esta investigación. En los estudios que hay sobre motivaciones sexuales y agresión sexual se han observado resultados heterogéneos. En la investigación llevada a cabo por Christopher y Frandsen (1990) observaron que aquellos participantes motivados a tener mayor actividad sexual eran los que mas probabilidades tenían de utilizar los dos tipos de estrategias coercitivas, presión y manipulación y actos antisociales. Por otra parte Hall (citado en Fuertes, 2000) no encontró en su trabajo diferencias entre hombres agresores y no agresores respecto a la 
excitación sexual provocada por escenas de violencia sexual, mientras que en otros estudios se ha observado que los agresores tenían mayores niveles de excitación ante estímulos sexuales de cualquier tipo, y tenían más fantasías agresivas y sádicas (Greenlinger y Byrne; Rapaport y Posey, citado en Fuertes, 2000). Por su parte Lisak y Roth (1988) llegaron a la conclusión de que motivos como el poder o la cólera eran más fuertes que la motivación sexual entre el grupo de agresores que estudiaron. Sin embargo, estos resultados se obtuvieron fundamentalmente para muestras de población adulta y en pareja. Además en muchas ocasiones se equipara la motivación sexual con la excitación sexual, y se dejan fuera otras motivaciones diferentes para tener actividad sexual.

Otra línea de investigación que puede resultar de utilidad es la que examina el estilo de apego y la conducta sexual, incluyendo la coerción sexual. En su estudio, Cooper et al. (1998) señalan que una fuente de diferencias individuales en la motivación sexual puede ser el estilo de apego derivado de las experiencias tempranas con las figuras de apego (Bowlby, 1970). De esta manera resulta probable que las motivaciones sexuales aproximativas como la motivación de placer e intimidad sean más frecuentes o más importantes para personas con estilos de apego seguro, con una base afectiva positiva y estable, que se buscan y se sienten cómodos con la cercanía interpersonal. Alternativamente se puede esperar que las motivaciones sexuales evitativas como el afrontamiento de estados negativos o el miedo al rechazo de los demás sean más propias de personas con apego inseguro. El afrontamiento emocional sería una motivación más importante para personas con apego evitativo ya que estos individuos niegan sus necesidades de intimidad, y el miedo al rechazo de la pareja por ejemplo sería una motivación más frecuente en individuos con apego ansioso que desean la cercanía pero temen el abandono simultáneamente. Así, los autores concluyen que parte de las diferencias en conducta sexual atribuidas a diferencias en estilos de apego, podrían en realidad atribuirse a las diferencias en motivación sexual derivadas del apego (Cooper, Shaver y Collins, 1998).

En este sentido se ha asociado el apego ansioso y evitativo a la coerción sexual perpetrada por estudiantes universitarios masculinos. Específicamente Davis (2006) sugirió que las personas de apego ansioso tienen más probabilidades de ser insistentes sexualmente o coercitivos cuando sienten que la relación o la intimidad están amenazadas, mientras que las personas de apego evitativo tienen más probabilidades de emplear la coerción sexual con extraños en relaciones nuevas, influidos por su grupo de amigos o con la intención de impresionarles. En el estudio de Brassard, Shaver y Lussier (2007) examinaban cómo el estilo de apego seguro o inseguro afectaba en el empleo de la presión sexual en parejas comprometidas, y hallaron que los 
hombres con apego ansioso tendían a utilizar en mayor medida la presión sexual, como una manera de incrementar la intimidad o cuando creen que la relación está amenazada, que los hombres de apego seguro. Por otra parte, las mujeres con apego evitativo tendían a utilizar más la limitación para evitar encuentros sexuales que aquellas con estilo de apego ansioso o seguro.

A pesar de que somos conscientes del pequeño salto, pero salto al fin y al cabo, entre el estilo de apego y las motivaciones sexuales, consideramos que estos resultados pueden arrojar cierta luz sobre las posibles relaciones entre motivaciones sexuales y empleo de la coerción sexual, asunto que abordaremos en nuestra investigación.

\subsection{Motivaciones sexuales y consentimiento de actividad sexual no deseada}

Hemos de puntualizar que las motivaciones para tener actividad sexual cuando no se desea, examinadas en investigaciones sobre el consentimiento sexual, son más específicas que las motivaciones generales para tener actividad sexual deseada, que es lo que evaluaremos en este trabajo. Sin embargo, pueden existir ciertos lazos que vinculen a unas con otras, por lo que consideramos relevante revisar este aspecto del consentimiento sexual no deseado.

En el trabajo de O’Sullivan y Allgeier (1998) encontraron que las razones más comunes para el consentimiento sexual eran querer satisfacer las necesidades de la pareja, promover la intimidad y evitar tensión en la relación. En otro estudio de O'Sullivan y Gaines (1998) sobre ambivalencia sexual, indicaron que las razones para decidir involucrarse finalmente en una relación sexual por la que sentían ambivalencia (no clara falta de deseo en este caso) eran un aumento del deseo sexual posterior, no querer decepcionar o molestar a la pareja, satisfacer la excitación sexual de la pareja y mostrar afecto o cariño. Reneau (2004) proporcionó a los participantes de su estudio una lista con posibles motivaciones para el consentimiento y tras la puntuación se obtuvieron cinco factores interpretables: Evitar herir sentimientos, Transigir con la presión de la pareja, Sentimientos de obligación relacionados con la relación, Intercambio o reciprocidad, e Imagen y experiencia sexual (sentirse mejor pareja sexual). Las motivaciones consideradas positivas más frecuentes fueron fortalecer la relación y ganar experiencia sexual, y las negativas más frecuentes fueron ceder a la presión de la pareja. 
Como hemos visto la mayoría de los estudios coinciden en señalar que las motivaciones relacionadas con la relación romántica son las más frecuentes. La motivación pro-relacional consiste en que el individuo tiene el objetivo de beneficiar a su pareja o a la relación considerando lo que es mejor para éstas, por encima de su propios deseos personales (Impett y Peplau, 2003). Las personas que consienten actividad sexual no deseada por razones prorelacionales, tienden a manifestar que lo hacen para evitar herir los sentimientos de su pareja, para evitar tensión, para potenciar la intimidad o para hacer a la pareja sentirse atractiva y querida, y como hemos visto, son la mayoría. Sin embargo la motivación pro-relacional varía de persona a persona y de situación a situación y la conducta por-relacional puede ser afrontada con actitud de sacrificio, de reciprocidad, de obligación o de miedo al abandono.

En el estudio de Livingstone et al. (2004) sobre mujeres verbalmente presionadas por sus parejas, hallaron diferencias significativas en las razones por las que éstas consentían sexualmente, en función de si existían precedentes sexuales con esas parejas. Las mujeres en situaciones de precedente sexual (que solían ser relaciones de pareja) consentían actividad sexual no deseada para mantener la calma en la relación y conseguir que el hombre la dejara en paz. Las transcripciones de las mujeres en situaciones de no precedente sexual (normalmente relaciones ocasionales) sugerían que éstas consentían sexualmente por temor a que el hombre las dejara, o por no querer decepcionarle.

En términos de diferencias de género en consentimiento sexual, aunque las motivaciones prorelacionales son las más frecuentemente citadas entre hombres y mujeres, la investigación sugiere que es más probable que las mujeres se involucren en relaciones sexuales por razones pro-relacionales (Impett y Peplau, 2003), y esto parece particularmente cierto cuando esta motivación se deriva de sentimientos de obligación. Shotland y Goodstein (1992) sugirieron que una vez que se ha experimentado el sexo en una relación, la mujer tiende a sentirse obligada a continuar proporcionando relaciones sexuales, y el hombre tiende a sentirse en derecho de continuar recibiendo sexo. Los resultados de Reneau (2004) proporcionaron apoyo para esta afirmación puesto que más mujeres (67\%) que hombres (23\%) citaron sentimientos de obligación relacional como una razón para el consentimiento sexual.

Por otra parte, tanto en el estudio de O’Sullivan y Allgeier (1998) como en el de Bartels (2007), observaron que los hombres exponían la motivación de evitar tensión u otras consecuencias negativas en la relación, con mayor frecuencia que las mujeres. Además en el trabajo de Reneau 
(2004) mientras que las mujeres consideraban la motivación de evitar el conflicto como una motivación negativa, los hombres la calificaban de positiva.

Finalmente concluiremos apuntando que las razones que tiene una persona para consentir actividad sexual cuando no lo desea son importantes, como ya hemos visto, de cara a las consecuencias e impacto que tiene la decisión de consentir sobre el individuo o sobre la relación. Varios estudios coinciden en señalar que, el que las consecuencias del consentimiento sean positivas o negativas depende de la motivación que ha impulsado tal consentimiento. Así, del consentimiento sexual motivado por razones positivas o pro-relacionales como expresar amor y apoyo, se esperan consecuencias positivas para la relación, mientras que el consentimiento motivado por razones negativas como evitar enfados o abandonos, o bajo presión sexual, es más probable que produzca diversas consecuencias perjudiciales, como las que hemos visto en el anterior apartado de consentimiento de actividad sexual no deseada (Impett y Peplau, 2003; Reneau, 2004; Livingstone et al., 2004).

\subsection{Motivaciones sexuales, uso del preservativo y experiencia sexual}

Un factor que se ha tenido poco en cuenta dentro del marco de toma de precauciones sexuales es el hecho de que muchos adolescentes tienen relaciones sexuales, a veces desprotegidas, que están motivadas por razones ajenas a la salud o la prevención de riesgos. Así, conocer cómo usar el preservativo y estar convencido de la necesidad de hacerlo, no implica necesariamente la toma de precauciones, ya que los adolescentes pueden tener otras prioridades más allá de la prevención de la enfermedad. En primer lugar expondremos con mayor atención las conclusiones sobre la relación entre las motivaciones sexuales y la conducta sexual y uso del preservativo en los estudios que, cómo nosotros, han utilizado una perspectiva funcional a través de la utilización de la escala de Cooper et al., (1998) o versiones similares en adolescentes. Posteriormente haremos un breve resumen de las conclusiones obtenidas por otros estudios ya comentados.

En el trabajo de Cooper se observaron diferentes patrones conductuales asociados a las diferentes motivaciones sexuales. La experiencia sexual se asociaba positiva $\mathrm{y}$ significativamente a las motivaciones positivas de placer e intimidad y negativamente a las motivaciones de auto-afirmación y aprobación de los amigos. El número de parejas sexuales 
aumentaba a medida que lo hacían las motivaciones de placer y de afrontamiento, mientras que decrecía con la motivación de intimidad. La frecuencia de uso del preservativo sólo parecía asociarse negativamente a la motivación de intimidad aunque las demás conductas de riesgo estudiadas como sexo anal, sexo casual, o sexo con desconocidos o prostitutas, se asociaba negativamente a la motivación de intimidad y positivamente a la motivación de placer y de afrontamiento.

El análisis del papel del estatus relacional resultó ser de especial relevancia en la asociación que se daba entre las motivaciones sexuales y la conducta sexual. La motivación de placer dificultaba el mantenimiento de relaciones estables y aumentaba tanto la frecuencia de la actividad sexual, como la probabilidad de contraer enfermedades, y sin embargo, el efecto de esta motivación sobre el uso del preservativo dependía del contexto relacional. Mientras que la motivación de placer incrementaba el uso del preservativo en relaciones casuales, disminuía su uso en relaciones de pareja estables. La motivación de intimidad se relacionaba con la búsqueda y mantenimiento de parejas estables y exclusivas, y aumentaba la utilización del preservativo y la contracepción en contextos de pareja estables, mientras que esta motivación parecía impedir estas conductas preventivas en otros contextos relacionales. Este resultado apoya las expectativas formuladas por Sanderson y Cantor (1995) de que hay más probabilidades de que se produzca sexo seguro en contextos que son congruentes con las motivaciones más importantes de la persona. En este sentido, señalaban que la búsqueda de intimidad en relaciones no congruentes como las relaciones sexuales ocasionales puede resultar en situaciones de tensión y frustración, que dificultan la puesta en marcha de medidas preventivas, a través por ejemplo de una pérdida de asertividad sexual.

Así mismo la motivación de afrontamiento se asociaba a un aumento de las conductas promiscuas entre los que no tenían relaciones estables, pero no se asociaba a fracasos en la toma de precauciones ya que éstos mantienen la actividad sexual de una manera premeditada, por lo que son capaces de tomar precauciones. La motivación de aprobación de la pareja predecía una disminución en conductas de riesgo en aquellos en relaciones de pareja, pero se relacionaban positivamente a un aumento de conductas de riesgo en aquellos que no tenían relaciones de pareja. La motivación de auto-afirmación conseguía aumentar la eficacia de medidas de contracepción en relaciones estables pero no fuera de las relaciones estables. Finalmente, no se pudo sacar ninguna conclusión sobre el papel del contexto relacional en el efecto de la motivación de aprobación de los amigos por el pequeño tamaño del subgrupo que tenía esta motivación en relaciones de pareja. 
Así los autores concluyeron que parte del efecto que producen las motivaciones sexuales sobre la conducta sexual está moderado por el contexto relacional en algunas ocasiones, y en otras, mediado por la probabilidad de encontrarse en un contexto relacional, determinado por las propias necesidades y motivaciones sexuales, al igual que lo que vimos que ocurría entre las motivaciones y los estilos de iniciación sexual.

En 2003, un estudio que utilizaba la misma medida de motivación sexual (Gebhardt et al.) descubrieron que las relaciones sexuales protegidas en relaciones estables se caracterizaban por niveles bajos de motivación de intimidad. En cambio en relaciones casuales el sexo protegido se relacionaba con mayor necesidad de intimidad, al contrario de lo que sucedía en el trabajo original. En este estudio observaron además una relación positiva entre las relaciones sexuales casuales y las motivaciones negativas o la motivación de placer, mientras que se asociaba negativamente a la motivación de intimidad. Así mismo las motivaciones de aprobación y de afrontamiento incrementaban el número de parejas sexuales casuales.

En cuanto al género, concluyeron que aunque en relaciones estables no se observaban grandes diferencias entre los sexos, en relaciones esporádicas parecía que para el uso del preservativo los chicos utilizaban un modelo de toma de decisiones basado en las creencias y la autoeficacia, mientras que las chicas parecían utilizar más factores contextuales, como el significado que atribuyen al encuentro sexual y a la relación, para tomar una decisión.

Estos mismos autores en 2006 sobre el uso del preservativo en la primera relación sexual en chicas adolescentes en función de la preparación cognitiva y las motivaciones sexuales. La motivación más frecuente fue la de intimidad, seguida de la motivación de placer. Los resultados indicaban igualmente una relación inversa entre el uso del preservativo y la motivación de afrontamiento y de intimidad, así como que las adolescentes más motivadas por la intimidad eran las que menos se beneficiaban de la preparación cognitiva dirigida al uso del preservativo. Los autores concluyeron que sacar el tema del preservativo puede ser visto por las adolescentes con alta motivación de intimidad como una amenaza potencial a la relación que desean iniciar.

La explicación para este resultado la ofrecen en su trabajo sobre el poder relativo Tschann et al. (2002), quienes señalan que el miembro de la pareja que tiene menor deseo de intimidad emocional es el que tiene mayor poder en esa relación y que aquellos adolescentes que tienen mayor poder que sus parejas en el ámbito de la intimidad emocional, tienen mayores probabilidades de salirse con la suya en términos de uso del preservativo. Además se observó 
que los chicos solían tener mayor poder relativo en el ámbito de la intimidad emocional que las chicas. Así parece probable que las chicas que desean mayor nivel de intimidad no se atrevan a insistir en llevar a cabo sus deseos sexuales (como el uso del condón) y prefieran no emprender ninguna acción que ponga en peligro la relación en la que desean invertir emocionalmente.

Una línea de investigación diferente es la de Impett et al. (2005) e Impett y Tolman, (2006) en la que se centran en el estudio de motivaciones sexuales de aproximación y motivaciones sexuales de evitación en general. En el primer trabajo concluyeron que las motivaciones sexuales de aproximación se relacionaban positivamente con la actividad sexual y con el bienestar relacional, mientras que las motivaciones de evitación se asociaban a menor actividad sexual y menor bienestar relacional. Estos motivos parecían ser perjudiciales también para el mantenimiento de la relación en el tiempo. No encontraron diferencias de género en la importancia otorgada a motivaciones de evitación versus motivaciones de aproximación, aunque hay que tener en cuenta que todos los participantes tenían relaciones de pareja en el momento del estudio. Los autores concluyeron que las conductas realizadas con el objetivo de mejorar la relación eran más efectivas para la pareja que las conductas destinadas a prevenir o evitar el conflicto interpersonal.

En el segundo estudio con chicas adolescentes, los resultados señalaban que las motivaciones de aproximación se asociaban positivamente con la experiencia sexual, aunque la relación con el número de parejas sexuales era negativa. Además estas motivaciones positivas se asociaban a mayor satisfacción sexual durante la última experiencia sexual, aunque en este estudio no se controlaba el contexto relacional, siendo muy probable que la satisfacción derivada de la experiencia sexual viniese explicada por el hecho de que la interacción hubiera ocurrido en el contexto de una relación significativa y no en relaciones casuales.

En el trabajo de Patrick, Maggs y Abar (2007) emplearon los ítems de Sex Motives (Cooper el al., 1998) basándose en su distinción entre motivos centrados en uno mismo y centrados en los demás. Los hombres calificaron las motivaciones centradas en uno mismo como más importantes y las motivaciones centradas en la pareja como menos importantes que las mujeres. Los resultados indicaron que aquellos universitarios con motivaciones centradas en la pareja tendían a tener mayor frecuencia de actividad sexual y menor número de parejas sexuales, lo que sugería que la motivación centrada en la pareja refleja un deseo de intimidad en relaciones a largo plazo. Una limitación señalado por los autores era que no habían medido el estatus relacional de los participantes. 
A modo de resumen podemos concluir que en la mayor parte de los estudios se obtienen resultados similares en cuanto a la posible relación entre motivaciones sexuales y experiencia sexual. En términos de frecuencia de actividad sexual las motivaciones que han mostrado incrementar la frecuencia sexual son las motivaciones positivas de placer e intimidad o amor (Leigh, 1989; Browning, Hatfield, Kessler y Levine, 2000; Cooper, Powers y Shapiro, 1998; Impett et al., 2005, 2006; Ott et al., 2006; Patrick, Maggs y Abar, 2007) así como que generalmente las motivaciones negativas se han relacionado con menores niveles de experiencia sexual (Cooper et al., 1998; Impett, Peplau y Gable, 2005).

Sin embargo cuando nos centramos en una medida de número de parejas sexuales y de relaciones casuales, vemos que en muchas ocasiones el patrón de relaciones cambia, siendo las motivaciones negativas y el placer las que se asocian a mayor número de parejas sexuales y la intimidad la que predice menor número de parejas (Cooper et al., 1998; Gebhardt, Kuyper y Greunsven, 2003; Meston y Buss, 2007; Patrick et al., 2007).

Esto parece indicar que las motivaciones positivas de intimidad y placer se asocian a la experiencia sexual de dos maneras positivas pero distintas. La motivación de intimidad parece suscitar la búsqueda de relaciones significativas en las que se incrementa la experiencia sexual en cuanto a frecuencia de actividad, mientras que la motivación de placer puede suscitar la búsqueda tanto de relaciones estables como de relaciones casuales, incrementando tanto la frecuencia de actividad como el número de parejas sexuales. En cambio, las motivaciones negativas parecen no facilitar el establecimiento de relaciones románticas por lo que se accede a actividad sexual de manera mucho más infrecuente y generalmente a través de mayor número de parejas sexuales esporádicas.

En cuanto a la utilización del preservativo, la motivación de intimidad es la que ha generado mayor controversia. En todos los estudios se ha observado en general una relación inversa entre la motivación de intimidad y la utilización del preservativo, aunque este resultado dependía en buena medida del contexto relacional en el que se utilizase el preservativo. En el trabajo de Cooper et al. (1998) observaron que en relaciones estables la intimidad como motivación sexual favorecía el uso del preservativo, mientras que en relaciones casuales lo dificultaba, resultado consistente con otros estudios (Gebhardt et al., 2006). Otro estudio anterior en cambio (Gebhardt et al., 2003), obtenía el resultado contrario, ya que la utilización del preservativo en relaciones estables era menor cuanto mayor era la motivación de intimidad, y viceversa para las relaciones casuales. 
Con relación a otras motivaciones se ha observado que tanto chicas como chicos utilizan menos el preservativo cuanto mayor es su motivación de placer (Browning et al., 2000), lo que es consistente con otros resultados que señalan que la motivación de placer promueve las conductas de riesgo (Cooper et al., 1998). Sin embargo estos autores matizan que aunque inhibe el uso del preservativo en relaciones estables a favor de la píldora anticonceptiva, la motivación de placer lo incrementa en relaciones esporádicas. La motivación de afrontamiento también se ha asociado positivamente a conductas de riesgo en los trabajos de Gebhardt et al. (2006) y Cooper et al. (1998), aunque estos últimos matizan sin embargo, que esta motivación no se ha asociado a fracasos a la hora de tomar precauciones. La motivación de autoafirmación o de autoestima han sido igualmente asociada a un menor uso del preservativo (Robinson et al., 2007; Gebhardt et al., 2006), así como la motivación de tener relaciones sexuales con una pareja considerada altamente deseable también se ha relacionado inversamente con la intención de utilizar precauciones, principalmente a través de una menor percepción de riesgo (Agocha, 2002; Pilkington et al., citado en Gebhardt, Kuyper y Dusserdorp, 2006).

Una conclusión que parece clara es que los factores que influyen en la decisión de tener o no relaciones sexuales protegidas dependen del tipo de relación que existe entre los miembros de la pareja, de la comunicación sexual que se establece entre ambos, y de las motivaciones que subyacen a la decisión de tener tales relaciones sexuales. De hecho, en la revisión de la literatura realizada por East, Jackson, O’Brian y Peters (2007) se concluía que además de la falta de conocimiento sobre ETS, y la ambigüedad sobre el uso de métodos anticonceptivos, el tercer factor que obstaculizaba la toma de precauciones en adolescentes era la dificultad de negociar relaciones sexuales protegidas. Estos autores señalan que el concepto de amor romántico obstaculiza la valoración del riesgo y puede inhabilitar a los adolescentes, especialmente a las chicas, para la negociación de prácticas sexuales seguras. Concluyen que los adolescentes son una población particularmente vulnerable a los riesgos sexuales y que es necesario que los mensajes educativos de prevención recojan el importante papel que el amor romántico juega en la toma de decisiones sexuales. 


\section{PARTE II}

Desarrollo de

la investigación 


\section{PLANTEAMIENTO DEL PROBLEMA}

Este apartado pretende, a modo de puente, resumir las conclusiones más destacadas a las que hemos llegado tras la revisión bibliográfica y establecer, en función de estas conclusiones, nuestras expectativas e intenciones con relación a la presente investigación. La Teoría de los Guiones Sexuales (Gagnon y Simon, 1973) plantea que los diferentes niveles en los que se construyen guiones sexuales (nivel cultural, interpersonal e individual) se influencian entre sí para dar lugar a la conducta final. La conducta final examinada en esta investigación son determinadas estrategias de negociación sexual, en concreto estrategias de avance y limitación sexual, uso del preservativo, y consentimiento de actividad sexual no deseada en la adolescencia. La investigación llevada a cabo sobre estrategias de avance y limitación sexual, sobre todo en la adolescencia y en España, es muy escasa, casi inexistente, y esto es todavía más notable cuando hablamos de factores relacionados con el uso de estrategias sexuales.

Entre los aspectos que estudiaremos y que esperamos que determinen las estrategias de negociación sexual se encuentran, en el nivel interpersonal, el contexto relacional, y en nivel individual, el género, el grado de experiencia sexual y las motivaciones sexuales de los 
adolescentes. En este sentido, además de la investigación sobre guiones sexuales, contamos con otros estudios sobre apego en la adolescencia que destacan la influencia de las características de la persona y de la relación romántica, por encima de otros factores como las caracteristicas de la pareja o de la familia (Buist, Dekovic, Meeus y van Aken, 2004).

Después de la revisión de la investigación que hay sobre estrategias de avance y limitación sexual, sabemos que los tipos de estrategias se han clasificado de una manera relativamente consistente en estrategias directas e indirectas, estrategias verbales y no verbales, y estrategias coercitivas y no coercitivas, aunque esta última dimensión no se ha aplicado a las estrategias de limitación sexual. Sin embargo, no hemos hallado acuerdo en cuáles de estas categorías son las más utilizadas, excepto para el caso de las estrategias coercitivas, siendo significativamente menos utilizadas que el resto. Así, establecer una relación de las estrategias sexuales más frecuentes en la adolescencia será uno de nuestros principales objetivos.

También existen contradicciones y falta de acuerdo en torno a las posibles diferencias de género, en la utilización de algunas estrategias sexuales, lo que también esperamos clarificar. Sí parece más claro sin embargo, que los varones de cualquier edad utilizan con mayor frecuencia las estrategias sexuales de tipo coercitivo para iniciar actividad sexual que las mujeres, y que éstas emplean a su vez las estrategias de tipo indirecto más frecuentemente que los varones (Renninger, Wade y Grammer, 2004; Greer y Buss, 1994; Eyre et al., 1997: Christopher y Frandsen, 1990)

Si son muy pocos los estudios que examinan el uso de estrategias sexuales en la adolescencia, son muchos menos los que lo hacen discriminando entre diferentes contextos relacionales. Los que hemos hallado sostienen que en relaciones de pareja se tiende a utilizar estrategias de comunicación directa y verbal, mientras que las relaciones ocasionales se caracterizan por el empleo de estrategias de comunicación indirecta y no verbal (Seal y Ehrhardt, 2003; O'Sullivan y Byers, 1992). Aunque estos estudios no se realizaron con población adolescente, los que sí han estudiado la comunicación sexual en adolescentes, apuntan en esta misma dirección (Mitchell y Wellings, 1998).

Por lo tanto, una de nuestras pretensiones es examinar el uso de estrategias de avance y limitación sexual en la adolescencia, y ver si se reproducen las categorías mayoritariamente resultantes en otras investigaciones, y en qué orden de frecuencia son utilizadas por ambos sexos. Además comprobaremos si existen diferencias en el uso de estrategias sexuales en 
función del contexto relacional, puesto que consideramos que en la puesta en marcha de guiones de iniciación y limitación sexual, el tipo de relación interpersonal que exista entre los adolescentes resultará decisiva. Nuestras expectativas en este sentido están en sintonía con lo que nos expone la escasa investigación previa, ya que esperamos replicar aquellos resultados que sitúan la comunicación sexual más clara y efectiva en relaciones de pareja estables, y la comunicación más ambigua o incierta, en aquellas relaciones que los adolescentes mantienen de manera imprevista o esporádica.

La experiencia sexual como posible factor determinante en el uso de estrategias de negociación sexual, no en todos los estudios ha mostrado un papel claro en relación con las estrategias de iniciación y limitación sexual, puesto que entre los pocos estudios que han examinado esta relación, algunos han mostrado una asociación positiva y otros no han hallado relación alguna (Christopher y Frandsen, 1990; Auslander et al., 2007; Eyre et al., 1997; O’Sullivan y Byers, 1992). Así, con nuestro estudio pretendemos averiguar qué estrategias sexuales están más directamente vinculadas con el nivel de experiencia sexual de los adolescentes, si esque lo están.

En cuanto a las motivaciones sexuales hemos visto que las motivaciones que han aparecido en la investigación como fundamentales a la hora de mantener relaciones sexuales son la motivación de obtener placer sexual y la motivación de acercamiento emocional o intimidad con la pareja sexual. Sin embargo, estudios que han examinado la motivación sexual en población adolescente señalan la existencia de otras motivaciones diferentes, basadas en la búsqueda de aprobación o evitación del rechazo social, y en el afrontamiento o evitación de estados emocionales negativos, consideradas ambas como motivaciones de carácter evitativo o negativo. Estas motivaciones para la evitación de consecuencias negativas, son mucho menos frecuentes que las motivaciones positivas anteriormente mencionadas, pero aún así han demostrado tener un papel importante en los guiones y conductas sexuales de los adolescentes (Cooper et al., 1998; Christopher y Cate, 1984; Brigman y Knox, 1992; Caffray y Schneider, 2000). Aunque no es unánime, la investigación sobre sexualidad en general expone la existencia de diferencias de género en la adolescencia en las motivaciones que subyacen a la conducta sexual. Tal y cómo muestran algunos estudios, esperamos que los adolescentes varones otorguen mayor importancia a la motivación de placer que las chicas adolescentes, y que éstas concedan mayor importancia que ellos a la motivación de intimidad emocional a la hora de mantener relaciones sexuales (Seal y Ehrhardt, 2003; Patrick et al., 2007 Browning, Hatfield, Kessler y Levine, 2000; Murstein y Tuerkheimer, 1998). 
En general, los estudios revisados señalan que la conducta sexual que se pone en marcha depende en gran medida de las motivaciones que subyacen a esa conducta, o dicho de otra manera, de los objetivos que se pretende conseguir con la conducta sexual (Browning et al., 2000; Clark et al., 1999; Seal y Ehrhardt, 2003; Cooper et al., 1998; Sanderson y Cantor, 1994). Nosotros pretendemos confirmar algunos indicios en la investigación previa, que sugieren que las personas con motivaciones positivas tienden a emplear estrategias de comunicación más efectivas y directas, y que las personas con motivaciones evitativas suelen utilizar estrategias de comunicación más indirectas o incluso más coercitivas. En este sentido existe una laguna en términos empíricos, en torno a la relación que pudieran haber entre motivaciones sexuales y estrategias de comunicación sexual, tal y como las entendemos en nuestro trabajo.

De la misma manera, esperamos replicar algunos resultados previos, que establecen que las motivaciones de evitación se asocian en mayor medida a algunas prácticas sexuales asociadas al riesgo, que las motivaciones positivas (Cooper et al., 1998; Schachner y Shaver, 2004; Paul, MacManus y Hayes, 2000; Brassard et al., 2007). Sin embargo, hemos observado en nuestra revisión que existe cierta falta de acuerdo en torno a la relación de las motivaciones sexuales con el uso del preservativo, y esperamos contribuir con nuestro estudio a esclarecer este aspecto. Además introduciremos en nuestro estudio la variable contexto relacional con la expectativa de que la diferente relación interpersonal suponga la existencia de diferentes motivaciones sexuales en adolescentes, y que estas motivaciones por su parte, se asocien diferentemente a las estrategias y conductas de riesgo en cada contexto relacional, algo indocumentado en investigaciones previas.

Finalmente, en nuestro estudio pretendemos examinar como se asocian las conductas de iniciación y limitación sexual con otras prácticas de negociación sexual que se han visto asociadas al riesgo, ya que, aunque algunos estudios subrayan la utilidad del estudio de las estrategias sexuales como contexto para la promoción de la utilización del preservativo (Eyre, Read y Millstein, 1997), no hemos hallado investigaciones que examinen esta asociación. 


\section{OBJETIVOS E HIPÓTESIS DE LA INVESTIGACIÓN}

\section{OBJETIVOS}

\section{OBJETIVO GENERAL}

Examinar las estrategias de negociación sexual y las motivaciones sexuales, como elementos de los guiones sexuales en la adolescencia.

\section{OBJETIVOS CONCRETOS}

1. Explorar el uso de estrategias de avance y limitación sexual en la adolescencia para diferentes contextos relacionales (contexto de relación de pareja y contexto de relación esporádica), teniendo en cuenta el género de los adolescentes. 
2. Analizar la experiencia sexual y las motivaciones sexuales en la adolescencia, teniendo en cuenta el género y la experiencia relacional de los adolescentes, y explorar cómo se asocian con las estrategias sexuales en diferentes contextos relacionales.

3. Explorar algunas conductas asociadas al riesgo en las prácticas sexuales de los adolescentes, en función del contexto relacional y el género, y su relación con motivaciones y estrategias sexuales. Estas conductas serán la coerción sexual, el consentimiento de actividad sexual no deseada y el uso del preservativo.

\section{HIPÓTESIS}

1. Basándonos en los resultados obtenidos en estudios anteriores esperamos que las tácticas de avance sexual se agrupen en: estrategias directas, estrategias indirectas y estrategias coercitivas. Así mismo, las tácticas de limitación sexual se agruparán presumiblemente en estrategias de limitación directas e indirectas (McCormick, 1979; Byers y Heinlein, 1989; O’Sullivan y Byers, 1992; Grossman et al., 2002; Dybvig-Pawelko, 2007; Rosenthal y Peart, 1996).

2. Según estudios previos (Mitchell y Wellings, 1998; Seal y Ehrhardt, 2003; Byers y Heinlein, 1998) podemos esperar que los adolescentes utilicen más frecuentemente estrategias de avance y de limitación sexual directas en sus relaciones de pareja que en sus relaciones esporádicas. Así mismo esperamos, que los adolescentes utilicen más frecuentemente estrategias sexuales indirectas en sus relaciones esporádicas, que en sus relaciones de pareja.

3. Diversos estudios sugieren que a medida que transcurre una relación, los roles de género van flexibilizándose en cuanto a inicitivas sexuales (O’Sullivan y Byers, 1992; Seal et al., 2007; Gebhardt et al., 2003), y que en general el desarrollo de la sexualidad femenina está más asociado al contexto de relaciones de pareja que la masculina (Oliva et al., 1992; NavarroPertusa, 2006; Carroll et al., 1985; Ramos, Fuertes, Martínez y Hernández, 2003; Papadopoulos, 2000). En este sentido es esperable que en el contexto de relaciones de pareja no haya diferencias en la puesta en marcha de estrategias de avance sexual entre chicos y chicas, pero que en el contexto de relaciones esporádicas, las chicas utilicen significativamente menos estrategias de avance sexual que los chicos. 
4. Esperamos, de acuerdo a los resultados obtenidos en previas investigaciones, que los chicos utilicen en general más estrategias coercitivas que las chicas, y que estas utilicen más estrategias de avance de tipo indirecto y más estrategias de limitación que los chicos (Renninger, Wade y Grammer, 2004; Greer y Buss, 1994; Eyre et al., 1997: Christopher y Frandsen, 1990; Felson, 2002; Fuertes et al., 2006; Ramos, Fuertes y De la Orden, 2006).

5. Se espera que los adolescentes con experiencia en relaciones de pareja, tengan más experiencia sexual que los adolescentes que sólo han experimentado relaciones esporádicas, ya que las relaciones de pareja son un contexto especialmente facilitador del desarrollo sexual de los adolescentes.

6. Se podría anticipar en función de resultados previos, que las chicas tengan una mayor motivación sexual de intimidad que los chicos, y que ellos tengan una mayor motivación de placer que las chicas (Seal y Ehrhardt, 2003; Patrick et al., 2007 Browning, Hatfield y Kessler, 2000).

7. Esperamos, basándonos en previas investigaciones, que las motivaciones sexuales positivas o de aproximación se relacionen positivamente con la experiencia sexual, y que las motivaciones sexuales negativas o de evitación de consecuencias negativas se relacionen negativamente con la experiencia sexual (Browning, Hatfield, Kessler y Levine, 2000; Impett et al., 2005, 2006; Ott et al., 2006; Patrick, Maggs y Abar, 2007; Gebhardt, Kuyper y Greunsven, 2003; Meston y Buss, 2007).

8. Se espera que los adolescentes que han tenido relaciones de pareja, den más importancia a las motivaciones positivas y menos importancia a las motivaciones negativas que los adolescentes que sólo han experimentado relaciones esporádicas (Sanderson y Cantor, 1995; Cooper et al., 1998; Schachner y Shaver, 2004; Paul, MacManus y Hayes, 2000; Cooper, Shaver y Collins, 1998), ya que las necesidades suyacentes a las motivaciones aproximativas parecen ser más satisfactoriamente resueltas en contextos de pareja y las motivaciones sexuales para evitar consecuencias negativas, podrían dificultar en alguna medida el mantenimiento de relaciones duraderas.

9. Esperamos que las motivaciones de evitación de consencuencias negativas se asocien positivamente con el uso de estrategias coercitivas e indirectas, y que las motivaciones 
aproximativas se asocien positivamente a las estrategias no coercitivas y directas. A pesar de que no contamos con estudios que ofrezcan evidencias en cuanto a la relación entre estrategias y motivaciones sexuales (tal y como las estudiamos en esta investigación) existen algunos trabajos cuyos resultados apuntan en la misma dirección de nuestra hipótesis (Impett ; Downey et al., citado en Impett, Peplau y Gable, 2005; Gable, Reiss y Elliot, 2000; Brassard et al., 2007; Feeney, Peterson, Gallois y Terri, 2000).

10. En cuanto al uso del preservativo, algunas investigaciones han documentado que en relaciones de pareja se utiliza el condón hasta que se alcanza mayor compromiso y confianza, y entonces el uso se hace intermitente hasta que finalmente se sustituye por la píldora anticonceptiva (Bauman y Berman, 2005; Rosenthal et al., 1998; Hynie et al., 1998; Friedman et al., 2001; Gebhardt et al., 2003). De esta manera, es previsible una mayor utilización del preservativo en las relaciones esporádicas que en las relaciones de pareja.

11. Además esperamos que el uso del preservativo presente una relación inversa con la motivación de placer y con la motivación de intimidad, aunque esta última sólo para la muestra de chicas, tal y como sostienen estudios previos (Browning, 2000; Cooper et al., 1998; Gebhardt et al., 2006)

12. Con relación al consentimiento de actividad sexual no deseada, se espera que éste sea más frecuente en las relaciones de pareja, que en las relaciones esporádicas. Las pocas y recientes investigaciones que hay sobre el tema apuntan en esta dirección, a pesar de que no examinan específicamente el papel del contexto, ya que reflejan que la mayoría de hombres y mujeres que han consentido alguna vez en tener actividad sexual lo hacen en relaciones de pareja estables (Impett y Peplau, 2002; O’Sullivan y Allegeir, 1998; Reneau, 2004; Shotland y Hunter, 1995).

13. También esperamos que el consentimiento de actividad sexual no deseada sea más frecuente en las chicas que en los chicos en relaciones de pareja, y lo contrario en relaciones ocasionales. Esperamos esta interacción porque la prevalencia del consentimiento sexual en los estudios realizados es mayor en las chicas que en los chicos, pero esto sucede principalmente en relaciones de pareja. Además resultados en otras investigaciones sugieren que, en contextos en los que se da mayor adherencia a los roles de género, el consentimiento sexual podría ser un fenómeno más frecuente y propio de los varones (O’Sullivan y Gaines, 1998; Impett y Peplau, 2002; Reneau, 2004). 
14. Por último esperamos que el consentimiento de actividad sexual no deseada se asocie positivamente con las motivaciones sexuales de evitación de consecuencias negativas, ya que algunos estudios sugieren que el deseo intenso de aprobación y de seguridad emocional puede conllevar cierta ineficiencia en las negociaciones sexuales, a la hora por ejemplo, de expresar la falta de deseo de actividad sexual (Feeney, Peterson, Gallois y Terri, 2000). 



\section{METODOLOGIA DE LA INVESTIGACIÓN}

\section{SELECCIÓN Y OPERACIONALIZACIÓN DE LAS VARIABLES DE ESTUDIO}

En este estudio trabajamos con 6 grupos de variables que definimos como: variables sociodemográficas, variables relacionales, estrategias de avance y de limitación sexual, motivaciones sexuales, experiencia sexual y conductas de negociación sexual asociadas al riesgo.

\subsection{Variables sociodemográficas}

La edad y el sexo constituyen importantes puntos de referencia a la hora de realizar cualquier análisis, y más tratándose de un estudio sobre sexualidad adolescente.

En nuestro estudio se formulaba una pregunta abierta sobre la edad de los participantes del estudio en el momento de la recogida de datos, y se ofrecían dos casillas para especificar el sexo. 


\subsection{Variables relacionales}

Con variables relacionales nos estamos refiriendo a aquellas que describen algún aspecto de las relaciones, en nuestro caso de las relaciones de pareja de los adolescentes y su historia romántica. Concretamente solicitábamos que los participantes especificasen:

- Número de relaciones románticas esporádicas

- Número de relaciones de pareja serias que habían mantenido

- Duración más larga entre las relaciones de pareja pasadas (en meses)

- Si tenían o no una relación de pareja en la actualidad

- Duración de esta relación de pareja actual (en meses)

Todas eran respuestas abiertas excepto la cuarta, que era un ítem dicotómico. Nosotros creamos una nueva variable de duración de las relaciones de pareja, sumando la duración de relación pasada y la actual, para poder disponer de una única medida que reflejase el número total de meses que un adolescente había mantenido una relación de pareja.

\subsection{Estrategias de avance y de limitación sexual}

Por estrategias de avance sexual entendemos el conjunto de tácticas ya sean verbales o no verbales, que se ponen en marcha para conseguir tener actividad sexual con otra persona, ya sea la pareja habitual o alguien desconocido. Pueden ser estrategias comunicativas, en tanto que son conductas que transmiten el mensaje de que se desea tener actividad sexual, y también pueden ser estrategias de influencia, en la medida en que su puesta en marcha tiene como objetivo influir o modificar las actitudes o intenciones de la otra persona hacia el hecho de tener actividad sexual. De la misma manera, las estrategias de limitación sexual son el conjunto de tácticas destinadas a rechazar o limitar la actividad sexual con otra persona que lo demanda.

La elaboración del cuestionario utilizado en el estudio sobre tácticas sexuales tanto de avance como de limitación sexual se hizo en base a una recopilación de tácticas sexuales de otros instrumentos de medida encontrados en estudios previos. De entre éstos, dimos relevancia a aquellos estudios que evaluaban el uso de estrategias en adolescentes sobre aquellos que 
estudiaban a adultos (Eyre, Read y Millstein, 1996; Rosenthal y Peart, 1996) y confeccionamos una lista con las tácticas sexuales que mejor se adecuaban a nuestra muestra. Llevamos a cabo un "focus group" con la intención de que se generasen tácticas sexuales que no hubiéramos contemplado en nuestra primera lista, y un estudio piloto, para evaluar cómo funcionaba cada táctica dentro del cuestionario. Tanto el "focus group", como el estudio piloto se llevaron a cabo con muestra estadounidense, durante una estancia de investigación, por lo que tuvimos precaución a la hora de interpretar los resultados, y diseñar la lista final de tácticas sexuales.

En la lista final, los adolescentes debían puntuar cada táctica en función de la frecuencia con la que la utilizaban, bien para mantener actividad sexual, bien para limitar la actividad sexual con otra persona. Dado el carácter ambiguo de algunas tácticas que podían entenderse tanto como medios o estrategias, como fines en sí mismos, puntualizamos que no contaban las veces que habían realizado las conductas de la lista sin pretender tener o limitar la actividad sexual. La escala de respuesta en ambos cuestionarios era tipo Likert con cinco opciones de respuesta: (1) Nunca; (2) Una vez; (3) De 2 a 4 veces; (4) De 5 a 10 veces y (5) Más de 10 veces.

El cuestionario de estrategias de avance sexual estaba compuesto por 29 tácticas y el de limitación sexual por 14. Algunos ejemplos de ítems de avance sexual son: "Acercarte e incrementar el contacto físico", "Hablar sobre sexo (temas sexuales, anticonceptivos)", "Emborrachar o aprovecharse de la borrachera de otra persona para tener actividad sexual". Algunos ejemplos de ítems de limitación sexual son: "Inventarte una excusa desde el principio", "Decir directamente que no quieres seguir en el momento", "Utilizar tácticas para retrasarlo (proponer una actividad no sexual)".

\subsection{Motivaciones sexuales}

Las motivaciones sexuales son las diferentes razones por las que las personas mantienen relaciones sexuales. Algo que no siempre se tiene en cuenta es el hecho de que la conducta sexual puede satisfacer un amplio rango de funciones psicológicas, además de la satisfacción del deseo sexual. De esta manera parece inevitable que las motivaciones sexuales sean en realidad, numerosas y diversas en su naturaleza. 
El cuestionario de motivaciones sexuales que utilizamos fue una adaptación de Sex Motives (Cooper, Shapiro y Powers, 1998). La escala consiste en una lista de 29 motivos que las personas pueden tener para mantener relaciones sexuales. Los participantes deben puntuar cada uno según la frecuencia con la que tienen relaciones sexuales por cada motivo en una escala tipo Likert con 5 opciones de respuesta (1=Nunca, 5=Siempre). En nuestra adaptación, sustituimos el criterio de "frecuencia" por el de "importancia", así los adolescentes en nuestro estudio debían puntuar cada motivo en función de la importancia que ese motivo tenia para ellos a la hora de tener experiencias sexuales con otra persona, entendiendo por experiencias sexuales "toda conducta con significado sexual". De esta manera todos los adolescentes de la muestra, incluidos los que tuvieran poca experiencia sexual, podían responder en base al mismo criterio cualitativo y no cuantitativo de respuesta, tal y como proponían los propios autores de las escala original: (1) Nada importante, (2) Poco importante, (3) Algo importante, (4) Muy importante, (5) Extremadamente importante.

El cuestionario original agrupa los 29 ítems en 6 subescalas de motivos sexuales: Placer, Intimidad, Afrontar emociones negativas, Autoafirmación, Evitar rechazo de pareja, Evitar rechazo de amigos. Los ítems se distribuyen en las subescalas en grupos de 4 o 5. Si recordamos la exposición del instrumento en la revisión teórica, las 6 subescalas se sitúan en dos dimensiones: Motivación de aproximación a eventos positivos vs. Motivación de evitación de eventos negativos y Motivaciones centradas en uno mismo vs. Motivaciones centradas en los demás. Estas dos dimensiones independientes, se pueden combinar formando 4 categorías: Motivaciones positivas centradas en uno mismo, en la que se incluiría la motivación de placer; Motivaciones positivas centradas en los demás, en la que se incluiría la motivación de intimidad; Motivaciones negativas centradas en uno mismo, donde se situaría las motivaciones de afrontamiento y autoafirmación (y en nuestro estudio la autorregulación emocional) y por último Motivaciones negativas centradas en los demás, como la motivación de evitación del rechazo de la pareja y la motivación de la evitación del rechazo de los amigos.

Todas las subescalas muestran una alta consistencia interna, con un alfa de Crohnbach igual o superior a .83. Algunos ejemplos de ítems son: "Para obtener placer sexual", "Para sentirme más cerca de mi pareja","Para afrontar alguna decepción" "Para sentirme mejor conmigo mismo/a", "Para no disgustar o decepcionar a mi pareja", "Para no parecer un pringado delante de mis amigos". 


\subsection{Experiencia sexual}

La experiencia sexual es la acumulación de vivencias sexuales, emocionales y conductuales, a las que han tenido acceso las personas a lo largo de su vida. En este estudio nos centramos en el nivel de experiencia sexual en términos exclusivamente conductuales, es decir, la frecuencia con la que los adolescentes han practicado las diferentes conductas sexuales a lo largo de su vida.

Para evaluar la experiencia sexual de los adolescentes utilizamos la escala "Heterosexual Behavior Assesment" (Bentler, 1967) adaptada a nuestra población. Este cuestionario consta de 21 conductas sexuales diferentes, ordenadas de forma ascendente, según su aparición progresiva y normativa en la vida de los adolescentes, desde los besos y caricias hasta el coito y el sexo oral.

En nuestro estudio hemos utilizado la versión reducida que consiste en 10 conductas sexuales que los participantes puntuan en función de si han realizado o no esa conducta alguna vez. Aparte de esta información, considerábamos interesante que se puntuaran las conductas también atendiendo al número de veces que habían realizado cada una, para obtener una medida cuantitativa de experiencia sexual. Así nuestra escala de respuesta era de tipo Likert con 5 opciones de respuesta distribuidas de la siguiente manera: (1) Nunca, (2) Una o 2 veces, (3) De 3 a 5 veces, (4) De 6 a 10 veces, (5) Más de 10 veces.

En nuestra adaptación suprimimos uno de los ítems que reflejaba una conducta coital en una postura determinada, dejando un único ítem representativo de la conducta coital, y añadimos un ítem de caricias a senos femeninos por encima de la ropa. Consideramos que dada la poca experiencia sexual de los adolescentes, la medida así era más discriminativa. Además prescindimos del item 10 (Sexo oral mutuo hasta orgasmo mutuo) por no ser pertinente para nuestros objetivos.

Puesto que algunas experiencias sexuales consisten en que otra persona realice una conducta sobre el adolescente que contesta el cuestionario, siendo éste la parte pasiva, insistimos en puntualizar en las instrucciones, que debían responder también cuántas veces habían recibido, y no realizado, algunas de éstas conductas (ej: una adolescente debía responder cuántas veces había recibido caricias en los senos por parte de su pareja)

La consistencia interna de la escala según el índice de Kuder-Richardson es de .89 , la escala es por lo tanto muy satisfactoria en términos de fiabilidad. 


\subsection{Conductas de negociación sexual asociadas al riesgo}

Las variables relacionadas con el riesgo, son en este estudio conductas de negociación o decisiones sexuales que toman las personas, y que pueden tener consecuencias negativas en términos de salud mental y física.

En el cuaderno del cuestionario incluimos algunas variables que han mostrado estar relacionadas con conductas de riesgo, en forma de una única pregunta, duplicada en dos versiones: una para contestar pensando en las relaciones de pareja, y otra para contestar pensando en las relaciones esporádicas.

Uso de la coerción sexual: Variable obtenida a través del cuestionario de estrategias de avance sexual.

Uso del preservativo: Indica en qué medida sueles utilizar preservativo en tus relaciones sexuales (con tu pareja vs. con tus relaciones esporádicas). Si no has tenido relaciones sexuales coitales, no contestes.

Consentimiento de actividad sexual no deseada: Cuando es la otra persona (pareja vs. relación esporádica) la que utiliza estrategias de avance sexual para tener actividad sexual contigo ¿En qué medida aceptas tener actividad sexual cuando en realidad no lo deseas? Si nunca han intentado tener actividad sexual contigo, no contestes a esta pregunta.

Para la segunda y tercer pregunta propusimos una escala de respuesta tipo Likert con cinco opciones de respuesta: (1) Nunca, (2) La minoría de las veces (3) La mitad de las veces, (4) La mayoría de las veces, (5) Siempre. La escala es de tipo porcentual, para poder interpretar mejor la respuesta en función del total de veces sobre las que el adolescente había decidido practicar las conductas que se evaluaban.

\section{PROCEDIMIENTO DE RECOGIDA DE DATOS}

Los instrumentos de medida empleados son de autoinforme y por lo tanto la mejor forma de recogida de datos entendíamos que fuese por grupos, especialmente tratándose de adolescentes cuyo acceso en grupos viene facilitado a través de las clases de tutoría en los institutos. 
Contactamos con los orientadores de los centros para explicarles las características de nuestro estudio y proponerles su participación en él, después de haber solicitado los correspondientes permisos a los jefes de estudios.

Con ellos, convinimos la selección de los cursos y el horario para la recogida de datos. Esta se realizo durante clases normales en cada centro, es decir, en cada aula estaban los mismos alumnos que solían estar normalmente, de 20 a 30 alumnos. Esto nos pareció adecuado porque reunir a más participantes no nos hubiera permitido atender y solventar sus dudas acerca del vocabulario o forma de respuesta, adecuadamente. Las instrucciones eran las mismas para todos evidentemente, y en ellas nos preocupamos de dejar claro el carácter voluntario de la tarea, y la importancia de la veracidad de sus respuestas asegurando el tratamiento confidencial que daríamos a los datos.

Debido a los objetivos de nuestro estudio decidimos incluir en el cuaderno de cuestionarios 2 versiones de cada escala de estrategias de negociación sexual: Una versión a la que contestarían adolescentes que hubiesen tenido una relación de pareja de más de 3 meses, pensando en esa relación, y otra versión que contestarían adolescentes que hubiesen tenido relaciones esporádicas (de días o semanas) con personas a las que no consideraban su pareja, de tal manera que diese lugar a varias submuestras: los adolescentes que habían contestado a una u otra versión y los que hubiesen contestado a ambas versiones. La única diferencia entre las dos versiones era la denominación en la redacción de los ítems de la persona objeto de las estrategias: "tu pareja" u "otra persona".

Dispusimos así los cuestionarios, a pesar de que entrañaba cierta complicación a la hora de ser entendidos, por varios motivos. En primer lugar, nos parecía importante que los adolescentes respondieran a nuestras preguntas sobre su afrontamiento de la actividad sexual (iniciación, rechazo, uso del preservativo y consentimiento de actividad sexual no deseada) sabiendo claramente en qué relación y contexto debían situarse para ofrecer una respuesta lo más precisa posible. No queríamos una generalización o una media estadística improvisada por ellos mismos sobre lo que ellos hacen en general, en el mejor de los casos, ni que se ubicasen arbitrariamente en diferentes contextos románticos para cada respuesta, en el peor de los casos.

En segundo lugar, conscientes de la variedad de tipos de relaciones románticas que tienen los adolescentes y que muchos de ellos ya tienen experiencia en todos estos tipo de relación (en las características de la muestra veremos qué porcentaje respondió a ambas versiones), no 
queríamos perder la valiosa información que pueden ofrecer aquellos que han tenido las dos experiencias, relación de pareja y esporádicas, obligándoles a responder a sólo una versión. Por otra parte tampoco queríamos tener una muestra de datos sobre la versión 2, sesgada por autoselección. Es decir, si solo iban a responder a ésta versión los que no hubiesen tenido una relación de pareja, no tendríamos información sobre qué hacen los adolescentes en general en sus relaciones esporádicas, sino sobre qué hacen los adolescentes sin experiencia en relaciones de pareja, en sus relaciones esporádicas. Creemos, que ambas informaciones podrían ser en alguna medida diferentes.

Les pedimos que separasen sus mesas con el fin de conseguir la máxima intimidad posible a la hora de responder y de preguntar dudas sobre el cuestionario. Convinimos en que la forma de hacer las preguntas sería alzando la mano para que acudiéramos nosotros a cada mesa, manteniendo el aula lo más tranquila y silenciosa posible. Una vez separados, repartimos los cuadernillos de respuesta y comenzamos a explicar el cuestionario y la forma de respuesta. Explicamos con especial atención cómo debían responder al cuestionario de estrategias sexuales, por contar con dos versiones del mismo.

El tiempo medio en responder fue de 35 minutos. En esos últimos minutos, nos comprometíamos, una vez finalizados el estudio a ofrecerles un dossier con los resultados y conclusiones más relevantes y agradecíamos su colaboración. El periodo de recogida de datos se llevo a cabo en un mes y medio, desde mediados de Enero hasta Marzo.

\section{SELECCIÓN Y CARACTERISTICAS DE LA MUESTRA}

La muestra la componían 392 adolescentes después de desechar los datos de 30 de ellos bien por no haber rellenado el cuaderno completo de cuestionarios, bien por salirse del rango de edad que nos interesaba: adolescencia media y tardía. La adolescencia temprana la excluimos del estudio por la alta probabilidad de que esa parte de la muestra careciese de manera generalizada de experiencia relacional y sexual.

La selección de los centros de Enseñanza Secundaria Obligatoria se llevó a cabo de forma libre y conseguimos la colaboración de 4 de ellos, situados en distintos puntos de Salamanca capital: "Mateo Hernández", "Francisco Salinas"'Rodriguez Fabrés" y "Venancio Blanco". De estos 
cuatro, tres eran institutos públicos y uno concertado. Los cursos que participaron en el estudio fueron desde $4^{\circ}$ de la ESO hasta Ciclos Formativos.

En relación con las características sociodemográficas de la muestra, contábamos con 190 adolescentes varones y 202 mujeres, es decir 48,5 \% y 51,5\% respectivamente. El rango de edad iba de los 15 años a los 19. La media de edad era de 16,74 años (DT=1,13) y había la siguiente distribución de la muestra para cada edad: 15 años (14,2\%) 16 años (29,8\%) 17 años $(32,3 \%) 18$ años $(15,3 \%)$ y 19 años $(8,4 \%)$.

La distribución de la muestra en función de la versión del cuestionario de estrategias sexuales a la que habían contestado (contexto de pareja vs. contexto de relación esporádica) quedaba así: A la versión de uso de estrategias sexuales en pareja habían contestado 230 adolescentes $(58,5 \%)$, 101 chicos y 129 chicas, con una media de edad de 16, 87 años. A la versión de uso de estrategias sexuales en relaciones esporádicas habían contestado 328 adolescentes (83,7\%), 169 varones y 159 mujeres, con una media de edad de 16, 74 años. Finalmente aquellos que había contestado a ambas versiones por hacer uso de las estrategias sexuales en los dos contextos sumaban 178 adolescentes (45,3\%), 85 chicos y 93 chicas con una media de 16, 89 años. Se observa grosso modo, que la muestra que ha tenido experiencias de pareja tienen una media de edad ligeramente mayor que los que nunca han tenido experiencias de pareja y que el sexo femenino está también ligeramente en mayoría entre los que han tenido una relación de pareja en comparación con los varones, que son mayoría en relaciones esporádicas.

Los que sólo tuvieron relaciones de pareja, sin ninguna relación casual eran el 13,2\% y los que al contrario no tuvieron más que experiencia en relaciones casuales, nunca duraderas, eran el $38,4 \%$.

Tabla 1. Total de adolescentes en cada contexto relacional

\begin{tabular}{|l|c|c|c|}
\hline \multirow{2}{*}{ Relaciones esporádicas } & \multicolumn{2}{|c|}{ Relaciones de pareja } \\
\hline $\mathrm{Si}$ & $\mathrm{Si}$ & No & Total \\
\hline No & 178 & 151 & 328 \\
& $45,3 \%$ & $38,4 \%$ & $83,7 \%$ \\
\hline \multirow{2}{*}{ Total } & 52 & 12 & 64 \\
& $13,2 \%$ & $3,1 \%$ & $16,3 \%$ \\
\hline
\end{tabular}


En cuanto a las características de cada contexto relacional en esta muestra de adolescentes, las relaciones de parejas de los adolescentes se entendían en este estudio como relaciones de más de tres meses de duración. La media de número de relaciones de pareja es de 3,62 relaciones (véase Tabla 2).

Tabla 2. Estadísticos descriptivos de las variables relacionales

\begin{tabular}{lccc}
\hline Variable & $\mathrm{N}$ & Media & Desviación Típica \\
\hline $\mathrm{N}^{\circ}$ relaciones de pareja & 222 & 3.62 & 3.31 \\
$\mathrm{~N}^{\mathrm{o}}$ relaciones esporádicas & 293 & 8.30 & 7.61 \\
Duración más larga pasada & 209 & 8.00 & 8.21 \\
Duración relación actual & 142 & 11.14 & 10.43 \\
Duración total en relación & 224 & 14.68 & 11.71 \\
\hline
\end{tabular}

La duración media más larga de estas relaciones pasadas es de 8 meses y la duración media de las relaciones existentes durante el momento de la recogida de datos está en torno a los 11 meses. Son duraciones medias relativamente altas teniendo en cuenta que la muestra la componen adolescentes. Sin embargo en ambos casos la variabilidad es grande, ya que las desviaciones típicas son 8,21 y 10,43 respectivamente y además debemos tener en cuenta que hablamos de la adolescencia media y tardía.

Como ya hemos comentado en el apartado de variables de estudio, creamos una nueva variable que sumaba la duración de las relaciones pasadas con la duración de la relación actual, para tener una medida única y total del número de meses que los adolescentes habían "vivido" una relación de pareja. La duración total media en relaciones de pareja estaba entre 14 y 15 meses. Del 58,5\% que tenían experiencia en contextos de relación de pareja, 142 adolescentes tenían pareja en el momento de la recogida de datos, es decir, un $36,1 \%$ de la muestra total.

En cuanto a las relaciones esporádicas o casuales, el número medio de relaciones esporádicas, entendidas como relaciones de un día/noche o varios, con alguien a quien no consideraban su pareja, era de 8,3 relaciones esporádicas. La desviación típica era de 7,6, y el máximo de relaciones esporádicas era de 50, dato llamativo. 


\section{DISEÑO BASICO Y ANALISIS ESTADISTICOS}

\subsection{Diseño Básico}

El diseño que hemos utilizado en nuestro estudio es de tipo correlacional y multivariado ya que, el número de variables predictoras y criterios requiere de análisis estadísticos multivariados. A causa de nuestro propósito de explorar las relaciones de asociación entre las principales variables del estudio y no la causalidad, hemos utilizado un diseño transversal en el procedimiento y recogida de datos, limitando éstos a una sola toma de información. También hemos utilizado el modelo de efectos univariado.

En nuestro estudio, las variables predictoras serán: Variables sociodemográficas (2 variables), Variables relacionales (5), Motivaciones sexuales (5), Experiencia sexual (1) y las variables criterio serán: Estrategias de avance sexual (6), Estrategias de limitación sexual (2) y Prácticas sexuales asociadas al riesgo (2).

Sin embargo tenemos que tener en cuenta que algunas de las variables son evaluadas para dos contextos relacionales diferentes: relaciones de pareja y relaciones esporádicas. Este es el caso de las estrategias de avance y de limitación sexual, y de las prácticas relacionadas con el riesgo (uso del preservativo y consentimiento de actividad sexual no deseada).

Hemos utilizado instrumentos de medida de tipo autoinforme para todas nuestras variables. Esto, como es sabido, cuenta con determinadas ventajas como es el que sean un medio de acceso a variables introspectivas y que este acceso se realice con relativa facilidad. Entre las desventajas, también conocemos la a veces dudosa fiabilidad de los recuerdos o una posible falta de sinceridad de los participantes, especialmente tratándose de temas sobre sexualidad como el presente estudio. En cualquier caso, hemos intentado que el propio formato y redacción de los cuestionarios esquiven en lo posible estos riesgos. 


\subsection{Análisis estadísticos}

En primer lugar, hemos hecho análisis factoriales y análisis de fiabilidad en todos los instrumentos, por dos motivos. El idioma original de todos los cuestionarios es el inglés y, en unos más que en otros pero en todos, se debería suponer cierta pérdida de validez y fiabilidad. Así al adaptar las escalas hemos intentados que permaneciese lo máximo posible del espíritu de cada una, modificando solo el vocabulario que pudiese resultar desconocido o problemático para los adolescentes, pero aún así, los análisis de validez y fiabilidad eran obligados. Por otra parte, era de nuestro máximo interés descubrir en qué tipos de estrategias se agrupaban las tácticas sexuales que hemos ido recopilando, y con las que hemos elaborado nuestro cuestionario, por lo que en algún caso el análisis factorial formaba parte de nuestros objetivos de estudio.

El segundo grupo de técnicas estadísticas consistían en análisis descriptivos destinados a exponer el estado de la situación para nuestras principales variables en la muestra seleccionada, en términos de medias, desviaciones típicas y porcentajes. Aunque la sexualidad adolescente es un tema explorado, somos conscientes del carácter reciente e inexperimentado de algunas metodologías en el terreno de la sexualidad, por eso consideramos de evidente utilidad el continuar añadiendo esfuerzos y matices que contribuyan a describir de forma nítida los rasgos de la sexualidad adolescente.

Con el propósito de hallar diferencias del efecto de unas variables sobre otras realizamos una serie de análisis inferenciales, utilizando en concreto anovas, anovas de medidas repetidas y ancovas.

El modo de explorar las relaciones entre nuestras variables predictoras y criterios consistió en el análisis con las técnicas basadas en la correlación, como el coeficiente de correlación de Pearson. El hecho de que la mayor parte de nuestras variables fuesen cuantitativas nos facilitó el análisis del grado en el que dos constructos varían conjuntamente, y la dirección de este cambio, pudiendo así dar respuesta a algunas de nuestras principales hipótesis. 


\section{RESULTADOS}

Esta sección está organizada en cuatro apartados. En el primero expondremos el análisis factorial llevado a cabo con las tácticas de avance y limitación sexual en cada contexto relacional, y veremos en qué tipo de estrategias se agrupan estas tácticas, así como el resto de las propiedades psicométricas y resultados despcriptivos del cuestionario de estrategias sexuales. Después examinaremos cómo se interrelaciona el uso de estrategias sexuales en los dos contextos relacionales, así como su asociación con algunas variables relacionales.

En el segundo apartado mostraremos los resultados sobre el efecto que tiene el contexto relacional y el género, en la utilización de estrategias de avance y limitación sexual en la adolescencia, y el efecto conjunto de estas variables. Hemos de puntualizar que, a pesar que somos conscientes del diferente significado que las palabras "género" y "sexo" tienen en investigación, en algún momento en este estudio las hemos podido utilizar de manera indistinta, sin que esto conlleve a priori la adherencia ni a una perspectiva sociocultural, ni biológica respectivamente. 
En tercer lugar estudiaremos las estrategias sexuales en relación con variables psicológicas individuales, como la motivación y la experiencia sexual de los adolescentes. Se expondrán los resultados psicométricos y descriptivos de los cuestionarios sobre motivaciones sexuales y experiencia sexual, así como los resultados sobre la relación entre éstas variables y las estrategias de avance y limitación sexual para cada contexto relacional.

En el cuarto apartado expondremos los resultados relativos a la prevalencia en adolescentes de algunas conductas de negociación sexual relacionadas con el riesgo, como el uso de la coerción sexual, el uso del preservativo y el consentimiento de actividad sexual no deseada, así como su relación con estrategias y motivaciones sexuales. Aunque el uso de la coerción sexual es una variable que forma parte de las estrategias de avance sexual, hemos considerado oportuno ofrecer una atención especial a este tipo de estrategia, dentro de un apartado dedicado a variables sexuales asociadas al riesgo. 


\section{USO DE ESTRATEgIAS DE AVANCE Y LIMITACIÓN SEXUAL EN DIFERENTES CONTEXTOS RELACIONALES: RELACIÓN DE PAREJA Y RELACIÓN ESPORÁDICA.}

\subsection{Análisis factorial y propiedades psicométricas del cuestionario de estrategias sexuales.}

Para analizar las propiedades psicométricas de nuestro cuestionario de estrategias sexuales, llevamos a cabo análisis factoriales y de fiabilidad para las estrategias de avance sexual por un lado y para las estrategias de limitación sexual por otro. Además hicimos un análisis separado para cada versión del cuestionario o contexto relacional en el que se habían llevado a cabo las estrategias sexuales: versión 1 o relaciones de pareja, y versión 2 o relaciones esporádicas. A la primera versión contestaron 230 adolescentes y a la segunda 328 .

\subsubsection{Estrategias de avance sexual}

Como ya se ha comentado en la sección dedicada a la metodología de la investigación, la elaboración del cuestionario sobre tácticas sexuales tanto de avance como de limitación sexual se hizo en base a una recopilación de tácticas sexuales de otros instrumentos de medida sobre los que se seleccionaban las tácticas más adecuadas a nuestra población. En la lista de tácticas sexuales resultantes, los adolescentes debían puntuar cada táctica en función de la frecuencia con la que la utilizaban para mantener actividad sexual con otra persona.

Nos interesaba principalmente descubrir si existía una estructura subyacente que organizase las tácticas sexuales en grupos determinados, por lo que llevamos a cabo un análisis factorial.

Realizamos primero el análisis factorial de la versión de relaciones de pareja del cuestionario, es decir, de la versión a la que habían contestado adolescentes que habían tenido relaciones de pareja más largas de 3 meses, que eran 230 participantes.

A la hora de valorar la pertinencia de esta técnica, nos fijamos en varios indicios que indicasen que existía multicolinealidad entre los ítems. Tras una inspección de la matriz de correlaciones vimos que había correlaciones moderadas entre los elementos y comprobamos la medida de adecuación muestral de Kaiser-Meyer-Olkin (KMO), que resultó ser aceptable, concretamente 
de .76. La prueba de esfericidad da .000 , con lo que se rechaza la hipótesis nula de que haya esfericidad, y por tanto podemos asegurar que existe multicolinealidad.

En la Tabla 3 se puede observar el resultado del análisis factorial. Por motivos de validez de contenido o invalidez, mejor dicho, tuvimos que prescindir de varios ítems, cuyo peso factorial era poco claro y de difícil interpretación. Los ítems 5, 11 y 15 fueron eliminados por ser tácticas pasivas, luego no realmente estrategias de iniciación. El ítem 6 se eliminó por ser casi igual al 7 y no añadir ningún matíz al modelo; los ítems 23, 14 y 22 se eliminaron por su bajo peso factorial, mala adecuación conceptual a los factores y porque su eliminación aumentaba tanto la fiablidad, como la varianza explicada de la solución factorial.

Finalmente se eliminaron los ítems 10 y 28 porque, aunque en la versión de estrategias de avance en pareja formaban un factor coherente (Verbal Directo), su fiabilidad era muy baja, y en la versión de relaciones esporádicas no se adecuaban conceptualmente. Aunque no se consideraron en el análisis factorial, seguimos teniendo en cuenta el ítem 10 en solitario ("Decir directamente que deseas tener una relación sexual"), como representante de estrategias verbales directas, por su relevancia en el estudio y sencillez de interpretación.

Tabla 3. Matrices de factoriales rotados del cuestionario de estrategias de avance sexual para relaciones de pareja

\begin{tabular}{cccccc}
\hline Ítem & Factor & Factor & Factor & Factor & 4 \\
& 1 & 2 & 3 & & \\
\hline Item 3 & 0.76 & & & \\
Item 4 & 0.72 & & & \\
Item 1 & 0.66 & & & \\
Item 7 & 0.63 & & & \\
Item 13 & 0.61 & & & \\
Item 2 & 0.56 & 0.79 & & \\
Item 21 & & 0.77 & & \\
Item 9 & & 0.66 & & \\
Item 27 & & 0.60 & 0.78 & \\
Item 17 & & & 0.73 & \\
Item 19 & & 0.69 & \\
Item 20 & & & & \\
Item 24 & & & & \\
Item 18 & & & 0.38 & \\
Item 12 & & & 0.69 & \\
Item 29 & & & & \\
Item 16 & & & & \\
Item 8 & & & & \\
Item 25 & & & & \\
Item 26 & & & & \\
\hline
\end{tabular}

1) Avance Físico Directo

2) Estrategias de Presión

3) Gestos de Seducción

4) Insinuación Verbal

5) Estrategias de fuerza 
Finalmente obtuvimos una estructura factorial de 5 componentes, con un total de 20 ítems. La varianza explicada era de $57,2 \%$ (véase Tabla 4). Seis ítems integraron el primer factor llamado Avance físico directo. Este factor representa las tácticas de avance que se basan en el acercamiento y contacto físico, y que inequivocamente demuestran el deseo de la persona que las pone en practica, de realizar alguna actividad sexual.

El segundo factor estaba compuesto por 5 ítems y lo denominamos Estrategias coercitivas de presión o Estrategias de presión. Las tácticas que componen este factor son coercitivas en el sentido de que ejercen presión sobre una persona que no desea mantener actividad sexual, para que cambie de opinión. El tercer factor lo integraban 4 ítems y lo llamamos Gestos de seducción, entendiendo así estrategias de carácter físico e indirecto, tales como roces, miradas, movimientos y posturas provocativas, que sin dejar claro su significado, abren camino e insinúan un posible interés sexual.

El cuarto factor, al que llamamos Insinuación verbal, estaba compuesto por tres tácticas de carácter verbal que tratan de transmitir, a través de una conversación íntima e indirectamente, un interés por mantener actividad sexual con la otra persona. El quinto factor está integrado por 2 ítems y lo denominamos Estrategias coercitivas de fuerza, o Estrategias de fuerza, cuyas características residen en el uso o la amenaza de la fuerza, para conseguir mantener relaciones sexuales con la otra persona. El último "factor", como comentábamos antes no incluido en al análisis factorial, era el ítem 10 "Decir directamente que se desea una relación sexual" Sería el representante de las estrategias verbales directas y lo denominamos Avance verbal directo.

Tabla 4. Varianza explicada por cada uno de los factores del cuestionario de estrategias de avance sexual en pareja

\begin{tabular}{c|ccc} 
Factor & Autovalor & \% de la Varianza & \% Acumulado \\
\hline 1 & 4.67 & 23.36 & 23.36 \\
2 & 2.54 & 12.70 & 36.07 \\
3 & 1.56 & 7.80 & 43.87 \\
4 & 1.43 & 7.17 & 51.05 \\
5 & 1.23 & 6.17 & 57.22
\end{tabular}

Así, las tácticas se habían agrupado en función de si eran directas o indirectas, y a sí utilizaban la coerción o no, pero también atendiendo a su contenido, verbal o de contacto físico. Así, contábamos con dos tipos de estrategias directas: avance físico directo y avance verbal directo; dos tipos de estrategias indirectas: gestos de seducción e insinuación verbal; y dos tipos de estrategias coercitivas: estrategias de presión y de fuerza. Por otro lado también se podrían dividir en dos tipos de estrategias físicas: avance físico directo y gestos de seducción; dos tipos 
de estrategias verbales: insinuación verbal y avance verbal directo; y dos tipos de estrategias coercitivas: estrategias de presión y de fuerza.

Llevamos a cabo también el análisis factorial de la versión en relaciones esporádicas, del cuestionario de tácticas de avance sexual. Esta era la versión a la que habían contestado adolescentes que habían tenido relaciones esporádicas, que constituían 328 participantes. Hicimos dos análisis factoriales independientes porque parecía lógico pensar que las tácticas pudieran agruparse en diferentes factores, dando lugar a diferentes modelos para cada contexto relacional. Sin embargo, tras eliminar los ítems con poco peso factorial o inadecuados para ambos análisis, llegamos a la misma solución factorial en los dos contextos. En ambos aparecían 5 factores integrados por los mismos ítems en cada uno.

Desde luego, este resultado tiene importantes implicaciones para nuestro estudio, ya que esto nos permite hacer una comparación legítima entre la frecuencia de uso de los tipos de estrategia en un contexto relacional y otro contexto relacional y ver si existen diferencias entre ambos, otro objetivo de nuestra investigación.

Tabla 5. Matrices de factoriales rotados del cuestionario de estrategias de avance sexual para relaciones esporádicas

\begin{tabular}{lccccc}
\hline Ítem & Factor & Factor & Factor & Factor & Factor \\
& 1 & 2 & 3 & & \\
\hline Item 3 & 0.83 & & & & \\
Item 13 & 0.70 & & & \\
Item 4 & 0.67 & & & \\
Item 7 & 0.63 & & & \\
Item 2 & 0.61 & & & \\
Item 1 & 0.55 & 0.80 & & \\
Item 21 & & 0.74 & & \\
Item 19 & & 0.64 & & \\
Item 27 & & 0.62 & 0.83 & \\
Item 17 & & & 0.76 & \\
Item 9 & & & 0.75 & \\
Item 18 & & & & \\
Item 24 & & & & \\
Item 20 & & & & \\
Item 12 & & & & \\
Item 25 & & & & \\
Item 26 & & & & \\
Item 29 & & & & \\
Item 16 & & & & \\
Item 8 & & & & \\
\hline
\end{tabular}

1) Avance Físico Directo

2) Estrategias de Presión

3) Gestos de Seducción

4) Estrategias de Fuerza

5) Insinuación Verbal 
Volviendo al análisis factorial de las estrategias sexuales en relaciones esporádicas, podemos ver en la Tabla 5 que fueron también 20 ítems agrupados en 5 factores. El KMO fue algo más alto esta vez, de .83 y la prueba de esfericidad de Bartlett significativa. La varianza explicada del modelo ascendió también al 61,3\% (véase Tabla 6). Ya que los factores estaban integrados por los mismos ítems, les pusimos las mismas etiquetas que a la versión en relaciones de pareja: Avance físico directo, Avance verbal directo, Gestos de seducción, Insinuación verbal, Estrategias de presión y Estrategias de fuerza.

Tabla 6. Varianza explicada por cada uno de los factores del cuestionario de estrategias de avance sexual en $\mathrm{r}$. esporádicas

\begin{tabular}{c|ccc} 
Factor & Autovalor & \% de la Varianza & \% Acumulado \\
\hline 1 & 5.56 & 27.80 & 27.80 \\
2 & 2.74 & 13.74 & 41.54 \\
3 & 1.50 & 7.50 & 49.05 \\
4 & 1.35 & 6.75 & 55.81 \\
5 & 1.11 & 5.56 & 61.37
\end{tabular}

Haciendo una rápida comparación entre los resultados de ambos análisis, vemos que los pesos factoriales de los ítems de los factores gestos de seducción y estrategias de presión, llegan a ser más bajos en el análisis factorial de las relaciones de pareja que en el otro análisis. Parece que tanto la táctica 12 como la 19 ("Chocar 'accidentalmente' con la otra persona para acercarte" "Emborrachar o aprovecharse de la borrachera de la otra persona para tener actividad sexual") encajasen menos en el contexto de relaciones de pareja que en el de relaciones esporádicas, y eso se viese reflejado en sus pesos factoriales. Mirando las medias de frecuencia de uso, vemos que dentro de sus factores correspondientes, las tácticas 12 y 19 son las menos utilizadas por los adolescentes en sus relaciones de pareja, y sin embargo son las segundas más utilizadas, dentro de su factor, en las relaciones esporádicas.

Los coeficientes de fiabilidad medido a través del alfa de Cronbach de los tipos de estrategia para las relaciones de pareja fueron los siguientes: avance físico .78, gestos de seducción .74, insinuación verbal .62, estrategias de presión .69 y estrategias de fuerza .77. El factor avance verbal no cuenta con índice de fiabilidad puesto que se compone de un solo ítem.

Los coeficientes de fiabilidad de los grupos de estrategias en las relaciones esporádicas, enumerados en el mismo orden en que se han expuesto previamente, son los siguientes: .82, .77, 
.63, .76 y .82. Cómo vemos, exceptuando en ambos casos el factor insinuación verbal, que tiene un alfa de Cronbach sólo aceptable (.62 y .63), el resto de los coeficientes de fiabilidad son satisfactorios o buenos.

En cuanto a la frecuencia de uso de los tipos de estrategias de avance sexual por parte de los adolescentes, las estrategias de avance sexual más frecuentes en relaciones de pareja son las siguientes: $1^{\circ}$ Avance físico, $2^{\circ}$ Insinuación verbal, $3^{\circ}$ Gestos de seducción, $4^{\circ}$ Avance verbal, $5^{\circ}$ Estrategias de presión y $6^{\circ}$ Estrategias de fuerza. En las relaciones esporádicas, el orden es prácticamente el mismo, excepto que los gestos de seducción son las segundas estrategias más utilizadas, y la insinuación verbal pasan al tercer puesto (véase Tabla 8).

Tabla 7. Estadísticos descriptivos en frecuencia de uso de tipo de estrategia de avance sexual en pareja

\begin{tabular}{lccc}
\hline Tipo de estrategia & $\mathrm{N}$ & Media & Desviación Típica \\
\hline Avance físico directo & 230 & 3.98 & 0.84 \\
Insinuación verbal & 230 & 3.68 & 1.03 \\
Gestos de seducción & 230 & 2.95 & 1.02 \\
Avance verbal directo & 230 & 2.53 & 1.42 \\
Estrategias de presión & 230 & 1.31 & 0.48 \\
Estrategias de fuerza & 230 & 1.02 & 0.16 \\
\hline
\end{tabular}

Tabla 8. Estadísticos descriptivos en frecuencia de uso de tipo de estrategia de avance sexual en r. esporádicas

\begin{tabular}{lccc}
\hline Tipo de estrategia & $\mathrm{N}$ & Media & Desviación Típica \\
\hline Avance físico directo & 328 & 3.13 & 0.98 \\
Gestos de seducción & 328 & 2.78 & 1.04 \\
Insinuación verbal & 328 & 2.73 & 1.06 \\
Avance verbal directo & 328 & 1.75 & 1.17 \\
Estrategias de presión & 328 & 1.33 & 0.58 \\
Estrategias de fuerza & 328 & 1.06 & 0.33 \\
\hline
\end{tabular}

\subsubsection{Estrategias de limitación sexual}

Como ya hemos dicho en la sección metodológica, la elaboración del cuestionario de estrategias de limitación sexual fue paralela a la elaboración del cuestionario de avance sexual, se siguieron los mismos pasos, por lo que el análisis psicométrico se expondrá de la misma manera. 
Hicimos dos análisis factoriales independientes, uno para cada versión del cuestionario; versión 1, para relaciones de pareja y versión 2, para relaciones esporádicas. Eliminamos 3 ítems del análisis $(3,9$ y 13$)$ por resultar poco adecuados, bien por no ser verdaderamente una estrategia de limitación como en el caso del ítem 13, o bien por disminuir la varianza explicada del modelo. Después comprobamos que una vez más, las soluciones factoriales se revelaban idénticas en su estructura y composición.

Tabla 9

Tabla 10

Matrices de factoriales rotados de estrategias

Matrices de factoriales rotados de estrategias de limitación sexual para relaciones de pareja de limitación sexual para relaciones esporádicas

\begin{tabular}{lcc|ccc}
\hline Ítems & Factor & Factor & Ítems & Factor & Factor \\
2
\end{tabular}

1) Estrategias de Limitación Indirectas

2) Estrategias de Limitación Directas
1) Estrategias de Limitación Indirectas

2) Estrategias de Limitación Directas

En las Tablas 9 y 10 vemos que en ambas versiones, resultaban 2 factores de 7 ítems y 4 ítems cada uno. En el análisis practicado con la versión de limitación sexual en pareja, el KMO era bueno, de .84 y la prueba de Bartlett era significativa lo que asegura la pertinencia del análisis factorial. El porcentaje de varianza explicada es del 51, 5\%. Muy similares eran los índices en el análisis de la versión de relaciones esporádicas, ya que el KMO era de .87, el coeficiente de Bartlett era .000 y la varianza explicada sumaba $53,4 \%$ (véase Tablas 11 y 12). 
Tabla 11. Varianza explicada por los factores del cuestionario de estrategias de limitación sexual en relaciones de pareja.

\begin{tabular}{c|ccc} 
Factor & Autovalor & \% de la Varianza & \% Acumulado \\
\hline 1 & 4.14 & 37.07 & 37.07 \\
2 & 1.52 & 13.87 & 51.58
\end{tabular}

Tabla 12. Varianza explicada por los factores del cuestionario de estrategias de limitación sexual en relaciones esporádicas.

\begin{tabular}{c|ccc} 
Factor & Autovalor & \% de la Varianza & \% Acumulado \\
\hline 1 & 4.51 & 41.01 & 41.01 \\
2 & 1.36 & 12.37 & 53.39
\end{tabular}

La denominación de los factores era clara, Estrategias de limitación directas y Estrategias de limitación indirectas. En el factor directo se integraban tácticas de limitación sexual destinadas a transmitir un mensaje claro: el mensaje de que no se desea mantener la actividad sexual propuesta. Las tácticas difieren en su estilo, más o menos diplomático, pero todas coinciden en ser tácticas directas, y no encubiertas.

En el factor indirecto al contrario, se integran diversas tácticas que intentan disimular su objetivo, que no transmiten un mensaje claro, y que utilizan otros asuntos o excusas para disuadir a la persona interesada de sus avances sexuales y que todo transcurra de forma implícita.

Los coeficientes de fiablidad medido a través del alfa de Chronbach de los tipos de estrategia de limitación sexual para las relaciones de pareja fueron los siguientes: estrategias directas .70 y estrategias indirectas .80. Los coeficientes de fiabilidad de los grupos de estrategias en las relaciones esporádicasson los siguientes: estrategias directas $.77 \mathrm{y}$ estrategias indirectas .81 . Son todos pues, satisfactoriamente fiables.

En cuanto a la frecuencia de las estrategias de limitación sexual, vemos que las estrategias más utilizadas son las estrategias directas y las menos utilizadas las indirectas en ambos contextos relacionales (véase Tabla 13 y 14).

Tabla 13. Estadísticos descriptivos en frecuencia de uso de tipo de estrategias de limitación sexual en pareja

\begin{tabular}{lccc}
\hline Tipo de estrategia & $\mathrm{N}$ & Media & Desviación Típica \\
\hline Estrategias directas & 225 & 2.45 & 0.97 \\
Estrategias indirectas & 225 & 1.62 & 0.69 \\
\hline
\end{tabular}


Tabla 14. Estadísticos descriptivos en frecuencia de uso de tipo de estrategias de limitación sexual en r. esporádicas

\begin{tabular}{lccc} 
Tipo de estrategia & $\mathrm{N}$ & Media & Desviación Típica \\
\hline Estrategias directas & 318 & 2.54 & 1.07 \\
Estrategias indirectas & 318 & 1.81 & 0.76 \\
\hline
\end{tabular}

\subsection{Correlación entre estrategias sexuales y variables relacionales}

Realizamos un análisis de correlación con el uso de estrategias sexuales en relaciones de pareja, y el uso de estrategias sexuales en relaciones esporádicas, para examinar qué interrelaciones existían entre los tipos de estrategias sexuales, tanto dentro del mismo contexto, como entre contextos. Esto nos permitiría explorar la variabilidad en el uso de estrategias sexuales en los adolescentes. Por otra parte, pretendíamos explorar, cómo se asociaban las variables relacionales "duración total relación de pareja" y "número de relaciones esporádicas", con la frecuencia de uso de estrategias sexuales en cada contexto. Así se podría anticipar a grandes rasgos, qué papel van a jugar el contexto y las variables relacionales en el uso de estrategias sexuales.

El análisis de correlación lo realizamos sobre aquellos adolescentes que habían tenido ambas experiencias, relación de pareja y relación esporádica, ya que sería en esta submuestra en la que podríamos examinar ambas variables relacionales y su relación con el uso de estrategias en ambos contextos. Además es en esta muestra en la que pueden derivarse conclusiones de las correlaciones entre tipos de estrategia entre contextos relacionales diferentes. Constituían el $45,3 \%$ de la muestra, es decir, 160 participantes.

Como vemos en la Tabla de correlaciones 15, la duración de la relación de pareja, afecta significativamente sólo al uso de estrategias de avance sexual en contextos de pareja, y concretamente a las estrategias directas: avance físico y avance verbal. La variable número de relaciones esporádicas afecta sólo al uso de estrategias de avance en contextos esporádicos, y concretamente a las estrategias físicas: avance físico y gestos de seducción. 
Tabla 15. Matriz de correlaciones de variables relacionales y estrategias sexuales en ambos contextos relacionales para ambos sexos.

\begin{tabular}{|c|c|c|c|c|c|c|c|c|c|c|c|c|c|c|c|c|c|c|c|}
\hline & & 1 & 2 & 3 & 4 & 5 & 6 & 7 & 8 & 9 & 10 & 11 & 12 & 13 & 14 & 15 & 16 & 17 & 18 \\
\hline 1 & $\mathrm{~N}^{\circ}$ r. esporádicas & 1 & & & & & & & & & & & & & & & & & \\
\hline 2 & Duración r. de pareja & .030 & 1 & & & & & & & & & & & & & & & & \\
\hline 3 & Avance físico pareja & .059 & $.222^{* *}$ & 1 & & & & & & & & & & & & & & & \\
\hline 4 & Gestos seducción pareja & .067 & .058 & $.488^{\star *}$ & 1 & & & & & & & & & & & & & & \\
\hline 5 & Insinuación verbal pareja & -.149 & .086 & $.269^{\star \star}$ & $286^{* *}$ & 1 & & & & & & & & & & & & & \\
\hline 6 & Avance verbal pareja & .105 & $.297^{\star *}$ & $.317^{* *}$ & $.168^{*}$ & .139 & 1 & & & & & & & & & & & & \\
\hline 7 & E. de presión pareja & .080 & .107 & .144 & $.199^{*}$ & $.170^{*}$ & $302^{* *}$ & 1 & & & & & & & & & & & \\
\hline 8 & E. de fuerza pareja & .015 & -.075 & -.121 & .034 & -.041 & .041 & $.247^{\star *}$ & 1 & & & & & & & & & & \\
\hline 9 & Avance físico esporádicas & $.307^{* *}$ & -.091 & $.417^{\star \star}$ & $.281^{* *}$ & .008 & $.189^{*}$ & $.301^{* *}$ & -.019 & 1 & & & & & & & & & \\
\hline 10 & Gestos seducción esporád. & $.258^{\star *}$ & -.049 & $.309^{\star *}$ & $.588^{* \star}$ & $.194^{*}$ & $.181^{*}$ & $.252^{\star *}$ & .062 & $.523^{\star \star}$ & 1 & & & & & & & & \\
\hline 11 & Insinuación verbal espor. & .055 & -.090 & .053 & $.213^{*}$ & $.336^{* \star}$ & .074 & $.293^{\star *}$ & .060 & $.406^{* *}$ & $411^{* *}$ & 1 & & & & & & & \\
\hline 12 & Avance verbal esporád. & $.156^{*}$ & -.050 & .100 & .092 & $.179^{*}$ & $.402^{\star *}$ & $.452^{* *}$ & .132 & $.371^{* *}$ & $.264^{\star *}$ & $.394^{* *}$ & 1 & & & & & & \\
\hline 13 & E. de presión esporádicas & .123 & -.037 & .092 & .128 & .116 & .143 & $.667^{\star *}$ & $.242^{* *}$ & $.319^{* *}$ & $.258^{* *}$ & $.327^{\star *}$ & $.461^{* *}$ & 1 & & & & & \\
\hline 14 & E. de fuerza esporádicas & -.029 & -.084 & -.018 & .080 & .013 & .071 & $.290^{* *}$ & $.512^{* *}$ & .045 & .113 & $.164^{*}$ & $.228^{\star *}$ & $.528^{\star *}$ & 1 & & & & \\
\hline 15 & E. limitación directa p. & -.032 & -.014 & -.030 & .072 & -.013 & -.104 & -.080 & .068 & -.072 & .064 & .050 & -.077 & -.157 & .100 & 1 & & & \\
\hline 16 & E. limitación indirecta p. & -.082 & -.115 & .044 & $.223^{*}$ & .073 & -.131 & .101 & $.190^{*}$ & -.003 & .141 & $.204^{*}$ & .060 & .120 & $.277^{\star *}$ & $.474^{\star \star}$ & 1 & & \\
\hline 17 & E. limitación directa e. & .128 & .004 & .029 & .134 & .059 & -.089 & -.036 & .095 & .073 & .105 & .088 & .056 & .090 & .106 & $.410^{\star \star}$ & $.159^{\star}$ & 1 & \\
\hline 18 & E. limitación indirecta e. & .096 & -.108 & -.068 & $.174^{\star}$ & .057 & -.138 & .106 & $.222^{*}$ & .079 & .121 & $.175^{\star}$ & .123 & $.286^{\star *}$ & $.368^{\star \star}$ & $.269^{* *}$ & $.533^{\star *}$ & $.588^{\star *}$ & 1 \\
\hline
\end{tabular}


Vemos también, que las correlaciones entre tipos de estrategias en contextos de relaciones esporádicas son más abundantes y más altas que en contextos de pareja. Esto nos hace pensar que los adolescentes cuando están en una relación esporádica utilizan más variedad de estrategias sexuales que en sus relaciones de pareja. Por otra parte, la comparación del mismo tipo de estrategia entre contextos, nos muestra que las estrategias coercitivas y los gestos de seducción son los que presentan correlaciones más altas. Esto significa que los adolescentes que más utilizan estas estrategias en un contexto utilizarán más probablemente estas estrategias en el otro contexto, siendo menos importante la diferencia que supone el cambio de contexto relacional. Por el contrario, las correlaciones más bajas indican una mayor dependencia del contexto relacional, puesto que el uso en uno y otro contexto está menos relacionado. Estas estrategias más frecuentes en uno que en otro contexto son las estrategias directas y la insinuación verbal. Más adelante veremos en qué contexto se muestran más frecuentes estas estrategias.

Con relación a las estrategias de limitación sexual, en las relaciones de pareja el uso de estrategias indirectas se asocia positivamente al uso de gestos de seducción y de estrategias de fuerza más levemente. En relaciones esporádicas, el uso de estrategias de limitación indirectas se asocia positivamente al empleo de estrategias coercitivas de fuerza y de presión y a la insinuación verbal más levemente.

Así, vemos que mientras las estrategias de limitación sexual de tipo directo no correlacionan con ningún tipo de estrategia de avance, el uso de estrategias de tipo indirecto se asocia al uso de estrategias de avance indirectas y coercitivas en ambos contextos relacionales.

En cuanto a las correlaciones que muestran entre sí el uso de tipos de estrategias de limitación sexual entre contextos relacionales, vemos que en el contexto de relaciones esporádicas existe una correlación algo mayor en el uso de ambas estrategias directas e indirectas $(\mathrm{r}=.58, \mathrm{p}<.01)$ que en el contexto de pareja $(r=.47, \mathrm{p}<.01)$ luego parece que los adolescentes emplean algo más variablemente uno u otro tipo de estrategias de limitación en relaciones esporádicas. Por otra parte, la comparación del mismo tipo de estrategia entre contextos, indica que el uso de estrategias directas tiene una correlación más baja entre contextos $(r=.41, \mathrm{p}<.01)$ que el uso de estrategias indirectas $(\mathrm{r}=.53, \mathrm{p}<.01)$. Esto sugiere que, aunque levemente, la utilización de estrategias de limitación directa dependen más del contexto relacional que las indirectas. 


\section{DIFERENCIAS EN EL USO DE ESTRATEGIAS DE AVANCE Y LIMITACIÓN SEXUAL EN FUNCIÓN DEL CONTEXTO RELACIONAL Y EL GÉNERO.}

En este apartado de los resultados, nuestra intención es examinar qué relevancia tiene el contexto relacional (relación de pareja o esporádica) y el género a la hora de emplear unas u otras estrategia sexuales. Esto lo haremos a través de dos tipos de análisis diferentes pero complementarios.

Por una parte, haremos un análisis en el que compararemos a aquellos adolescentes que han tenido experiencia en ambos contextos relacionales, utilizando las dos puntuaciones que tienen para las estrategias sexuales en los dos contextos, y comparándolas entre sí. Esto se hará a través de un ANOVA de medidas repetidas, lo que nos permitirá poder atribuir, en el caso de que hubiera, las diferencias encontradas únicamente al contexto relacional, y no a diferencias individuales entre los sujetos. Además en este análisis podemos incluir covariables que resulten relevantes en el uso de estrategias sexuales, como la duración de la relación de pareja o el número de relaciones esporádicas, con la intención de eliminar la contribución que puedan estar haciendo al efecto que nos interesa. Los detalles de este análisis los expondremos más adelante.

Por otra parte compararemos a dos grupos de adolescentes con dos experiencias relacionales diferentes: experiencia sólo en contextos de pareja y experiencia sólo en contextos esporádicos y veremos si existen diferencias significativas en el uso de estrategias sexuales en función del contexto relacional. Este análisis además de ofrecer concluisiones relevantes per se, servirá como referencia para el análisis en adolescentes con ambas experiencias relacionales, en el sentido de que permitirá comprobar si las diferencias halladas en el análisis de medidas repetidas podrían ser fruto de la transferencia de una primera experiencia relacional sobre una experiencia relacional posterior, o por el contrario, al verse reproducidas las mismas diferencias en ambos análisis, serían fruto del efecto del contexto relacional. Además veremos sí el género de los adolescentes influye a su vez, en el efecto que pueda tener el contexto sobre la puesta en marcha de estrategias sexuales. Para ello, en este análisis, se realizarán comparaciones entre grupos de chicos y chicas, con diferentes experiencias relacionales. En la Tabla 16 vemos la composición de estos grupos. 
Tabla 16. Composición de grupos en función de su experiencia relacional y del sexo.

\begin{tabular}{cl|c|c|c|c}
\hline & & \multicolumn{3}{|c|}{ Experiencia relacional } & \\
\hline \multirow{2}{*}{ Sexo } & Sólo r. de pareja & Sólo r. esporádicas & Ambas experiencias & Total \\
\hline \multirow{2}{*}{ Chicos } & Recuento & 16 & 84 & 85 & 185 \\
& Porcentaje & $4,2 \%$ & $22,1 \%$ & $22,4 \%$ & $48,7 \%$ \\
\hline \multirow{2}{*}{ Chicas } & Recuento & 36 & 66 & 93 & 195 \\
& Porcentaje & $9,5 \%$ & $17,4 \%$ & $24,5 \%$ & $51,3 \%$ \\
\hline \multirow{2}{*}{ Total } & Recuento & 52 & 150 & 178 & 380 \\
& Porcentaje & $13,7 \%$ & $39,5 \%$ & $46,8 \%$ & $100 \%$ \\
\hline
\end{tabular}

2.1. Diferencias en el uso de estrategias sexuales en función del contexto relacional y el género, en un grupo de adolescentes con ambas experiencias relacionales.

\subsubsection{Estrategias de avance sexual}

Con el objetivo de analizar el papel que juega el contexto relacional y el género en el uso de estrategias de avance y de limitación sexual en la adolescencia, decidimos comparar en primer lugar, al grupo de adolescentes que habían tenido experiencias tanto de pareja como de relaciones esporádicas y que por tanto, había rellenado ambas versiones del cuestionario de estrategias sexuales. Esta submuestra, de 178 adolescentes, nos ofrecía la ventaja de que siendo los mismos individuos los que habían contestado a una y otra versión del cuestionario, podíamos confiar en que si se hallaban diferencias en el uso de estrategias en función del contexto, éstas no podrían ser debidas a diferencias individuales, y serían más probablemente atribuibles al contexto relacional. Así llevamos a cabo un análisis de la varianza de medidas repetidas, con los factores contexto relacional, tipo de estrategia, y género, este último como factor inter-sujetos.

A la hora de examinar el papel del contexto relacional en el uso de estrategias sexuales, nos planteamos que al ser la medida de frecuencia de uso de las estrategias, una medida de frecuencia objetiva, necesitaríamos tener en cuenta variables de referencia que estableciesen un marco en el que situar a cada adolescentes en cuanto a la frecuencia total con la que llevaban a 
cabo estrategias sexuales en cada contexto. Estas variables eran "duración total en relación de pareja" y "número de relaciones esporádicas" y las consideramos como covariables, puesto que, como comprobamos en en apartado anterior, mostraban ciertas correlaciones con el uso de estrategias sexuales.

En primer lugar, decidimos comprobar qué porcentaje de efecto sobre la frecuencia de uso de estrategias sexuales eliminábamos de cada covariable. Después las incluiríamos juntas en el análisis con el propósito de obtener un efecto subjetivo atribuible unicamente al contexto relacional. De no hacerlo así, se podría confundir el efecto subjetivo de estar en diferentes contextos relacionales, que es lo que nos interesa en este estudio, con el efecto objetivo de la cantidad de oportunidades en el tiempo que se han tenido, para poner en marcha las estrategias sexuales.

En primer lugar realizamos un ANOVA de medidas repetidas para examinar las diferencias en el uso de estrategias de avance sexual para los dos tipos de contexto relacional, y relacionarlo con el género. Así, era un diseño factorial de 6 (tipo de estrategia) x 2 (contexto relacional) x 2 (género), de medidas repetidas en los dos primeros factores. Se halló un efecto significativo del contexto relacional $[\mathrm{F}(1,175)=92,995, \mathrm{p}=.000, \eta 2=.34]$. Así, había diferencias significativas en la frecuencia de uso de estrategias sexuales en función del contexto relacional, siendo el contexto de pareja en el que más frecuentemente se utilizaban estrategias de avance sexual.

En segundo lugar, introdujimos la covariable "duración de la relación de pareja" para eliminar el efecto objetivo del tiempo que los adolescentes han pasado en sus relaciones de pareja, ya que las oportunidades de poner en marcha estrategias sexuales dependen en gran parte de tiempo físico del que disponen. El ANCOVA tenía por tanto el mismo diseño arriba descrito, más la covariable "duración de la relación". El efecto del contexto relacional resulto significativo igualmente $[\mathrm{F}(1,171)=7,911, \mathrm{p}=.005, \eta 2=.04]$. El tamaño del efecto pasó del $34 \%$ al 4\%, con lo que podemos deducir que el efecto que eliminamos de la duración de la relación de pareja contribuía intensamente al total del efecto del contexto relacional: un $30 \%$.

En tercer lugar, llevamos a cabo otro ANCOVA, pero esta vez, sacando la covariable "duración de la relación de pareja" y sustituyéndola por otra covariable "número de relaciones esporádicas" que igualmente suponía una variable contaminante, que determina fisicamente las oportunidades de poner en marcha estrategias de avance sexual en relaciones esporádicas, y que puede confundirse con el efecto del contexto relacional. El efecto del contexto relacional resultó 
significativo $[\mathrm{F}(1,160)=60,957, \mathrm{p}=.000, \eta 2=.27]$. Del $34 \%$ como efecto del contexto sin covariables, pasó al 27\%, con lo que podemos deducir que el efecto que eliminamos del número de relaciones esporádicas a las diferencias entre contextos relacionales es un 7\%, bastante más bajo que el porcentaje eliminado de la duración de la relación de pareja.

Finalmente llevamos a cabo un ANCOVA para examinar las diferencias en el uso de los tipos de estrategias de avance sexual en los dos tipos de contexto relacional, y relacionarlo con el género. Así, era un diseño factorial de 6 (tipo de estrategia) x 2 (contexto relacional) x 2 (género), de medidas repetidas en los dos primeros factores. Esta vez introdujimos las 2 covariables "Duración total de la relación" y "Número de relaciones esporádicas" para controlar su efecto sobre la frecuencia de uso de estrategias sexuales en relaciones de pareja y en relaciones esporádicas respectivamente, y conseguir así que no fuese el número de meses en una relación de pareja o el número de relaciones esporádicas lo que estuviese afectando a la frecuencia con la que los adolescentes llevaban a cabo sus estrategias sexuales. La introducción de las dos covariabales redujo ligeramente el tamaño de la muestra a 160 sujetos, ya que no disponíamos de la información sobre variables relacionales de los otros 18 participantes. De esta forma, utilizamos este análisis como análisis final, del que extrajimos los resultados correspondientes a los efectos principales del contexto, el tipo de estrategia y el género, así como las respectivas interacciones entre estos factores.

Se halló un efecto significativo del factor contexto relacional sobre el uso de estrategias de avance sexual, para sus dos niveles: relación de pareja y relación esporádica $[F(1,156)=13,993$, $\mathrm{p}=.000, \eta 2=.08]$ suponiendo este efecto del 8\%, ahora sí, libre de otras influencias, y representativo del efecto subjetivo y psicológico de estar en uno u otro contexto relacional.

Observando las medias de frecuencia de uso de las estrategias de avance sexual en cada contexto relacional concluimos, que las relaciones de pareja en la adolescencia constituyen un contexto relacional que favorece en mayor medida la frecuencia de utilización de estrategias de avance sexual, que un contexto relacional esporádico (véase Tabla 17).

Tabla 17. Estadísticos descriptivos en frecuencia de uso de estrategias de avance sexual en dos contextos relacionales

\begin{tabular}{lccc}
\hline Contexto relacional & $\mathrm{N}$ & Media & Desviación Típica \\
\hline Relación de pareja & 160 & 2.65 & 0.50 \\
Relación esporádica & 160 & 2.23 & 0.64 \\
\hline
\end{tabular}


El efecto del tipo de estrategia era también significativo $[F(5,152)=97,106, p=.000, \eta 2=.76] \mathrm{Se}$ utilizaron en este caso los contrastes multivariados, ya que la prueba de esfericidad de Mauchly sobre la variable "tipo de estrategia" es significativa y por tanto rechaza la hipótesis nula de que existe esfericidad. Por tanto, no hay igualdad de varianzas de las diferencias entre cada dos niveles del "factor tipo de estrategia". En este caso se recomienda acudir a los contrastes multivariados (Pallant, 2001; SPSS 10 Guía para el análisis de datos) en lugar de los contrastes univariados. Los contrastes a posteriori reflejaron que existen diferencias entre todas las estrategias excepto entre los dos tipos de estrategias indirectas: Gestos de seducción e Insinuación verbal, entre las que no hay diferencias de frecuencia de uso. De esta prueba podemos concluir que el uso de estrategias de avance sexual no coercitivas es significativamente más frecuente que el de estrategias coercitivas, y que el uso de estrategias físicas de iniciación sexual, es más frecuente que el de estrategias verbales, en la adolescencia y en ambos contextos relacionales (véase Tabla 18).

Tabla 18. Estadísticos descriptivos en frecuencia de uso de estrategias de avance sexual según el tipo de estrategia

\begin{tabular}{lccc}
\hline Tipo de estrategia & $\mathrm{N}$ & Media & Desviación Típica \\
\hline Avance físico directo & 160 & 3.69 & 0.77 \\
Gestos de seducción & 160 & 2.98 & 0.92 \\
Insinuación verbal & 160 & 3.19 & 0.88 \\
Avance verbal directo & 160 & 2.26 & 1.17 \\
Estrategias de presión & 160 & 1.38 & 0.56 \\
Estrategias de fuerza & 160 & 1.05 & 0.28 \\
\hline
\end{tabular}

También se han hallado diferencias significativas en función del género $[\mathrm{F}(1,156)=6.225$, $\mathrm{p}<.05, \eta 2=.04]$, aunque la significación en este caso es moderada. Efectivamente vemos que la diferencia en el uso de estrategias de avance sexual, a favor de los chicos, es muy leve. Sin embargo, esta conclusión habría que matizarla mediante la interpretación de interacción hallada entre contexto relacional y género.

Tabla 19. Estadísticos descriptivos en frecuencia de uso de estrategias de avance sexual en varones y mujeres

\begin{tabular}{lccc}
\hline Sexo & $\mathrm{N}$ & Media & Desviación Típica \\
\hline Chicos & 77 & 2.54 & 0.56 \\
Chicas & 83 & 2.35 & 0.54 \\
\hline
\end{tabular}


El efecto de la interacción entre el contexto relacional y el género se ha mostrado significativo $[\mathrm{F}(1,156)=14,336, \mathrm{p}=.000, \eta 2=.08]$. En este sentido los contrastes realizados a posteriori con el ajuste de Bonferroni indican que, mientras que en las relaciones de pareja no se encuentran diferencias significativas entre chicos y chicas en el uso de estrategias, en las relaciones esporádicas los varones ponen en marcha estrategias de avance sexual con mayor frecuencia que las adolescentes mujeres $(\mathrm{p}=.000)$. Desde el punto de vista del contexto relacional, los resultados también indican que ambos sexos utilizan significativamente más las estrategias de avance sexual en relaciones de pareja que en relaciones esporádicas $(\mathrm{p}=.000)$, aunque esta diferencia es mucho más acusada en la muestra femenina, a juzgar por el tamaño del efecto del contraste (véase Figura 1).

Figura 1: Frecuencia de uso de estrategias de avance sexual en chicos y chicas y en diferentes contextos relacionales

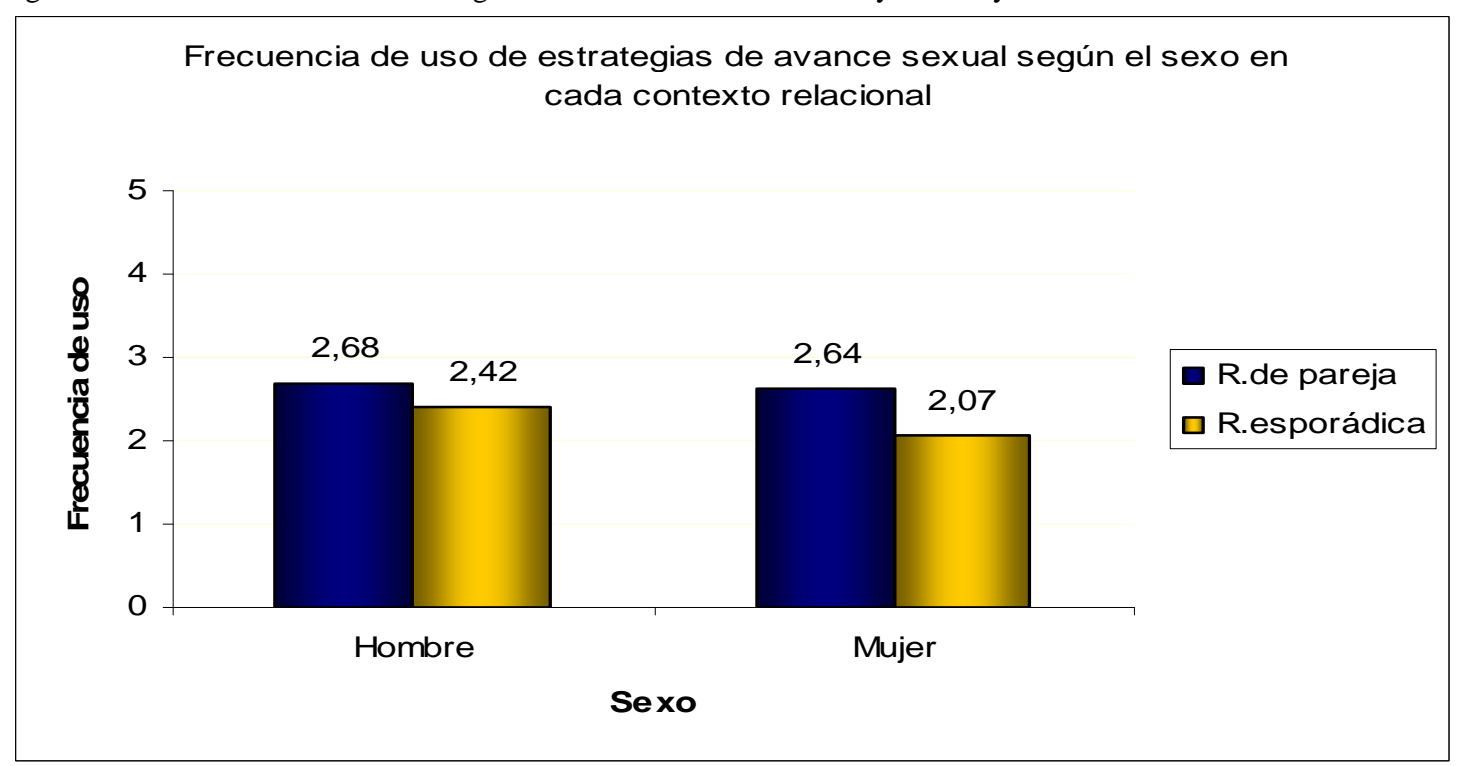

El efecto de la interacción entre el tipo de estrategia sexual y el sexo de los adolescentes también se ha mostrado significativa $[F(5,152)=7,527, p=.000, \eta 2=.19]$. Nuevamente para analizar el significado de esta interacción, se realizaron los contrastes pertinentes con el ajuste Bonferroni. Los adolescentes varones utilizan significativamente más que las mujeres, las estrategias de presión $(\mathrm{p}=.000)$ y el avance verbal directo $(\mathrm{p}=.000)$ para iniciar encuentros sexuales (véase Figura 2). 
Figura 2: Frecuencia de uso de los tipos de estrategias de avance sexual en chicos y chicas

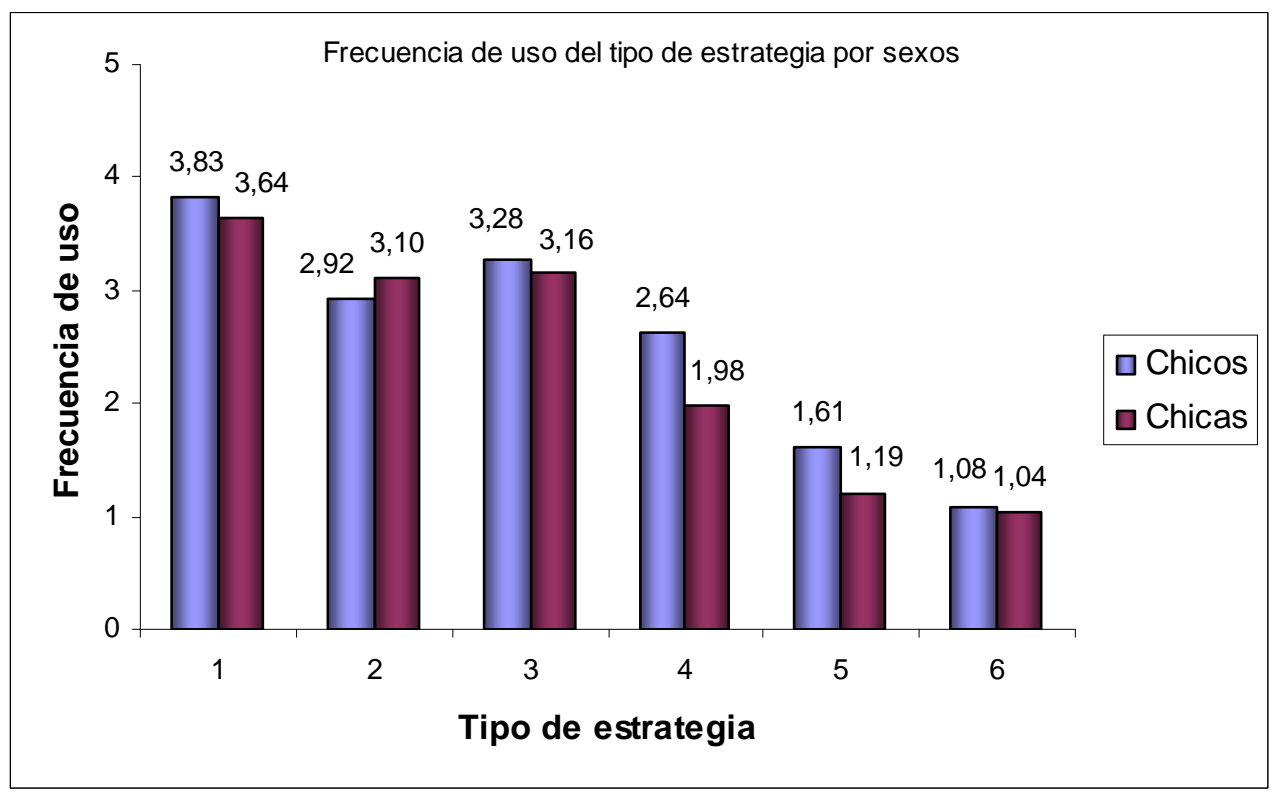

1. Avance físico directo

2. Gestos de seducción

3. Insinuación verbal

4. Avance verbal directo

5. Estrategias de presión

6. Estrategias de fuerza

El efecto de la interacción entre el tipo de estrategia y el contexto relacional es significativo [F $(5,152)=9.742, \mathrm{p}=.000, \eta 2=.24]$. La frecuencia de uso de los tipos de estrategia insinuación verbal, avance físico directo y avance verbal directo es significativamente mayor en el contexto de pareja, que en el contexto esporádico. Es decir, los adolescentes utilizan más a menudo las estrategias de avance sexual directas y verbales en sus relaciones de pareja, que en sus relaciones esporádicas. Esta conclusión se vería completada por último, por la interpretación de la interacción de los tres efectos principales a continuación presentada. 
Figura 3: Frecuencia de uso de los tipos de estrategia de avance sexual en cada contexto relacional

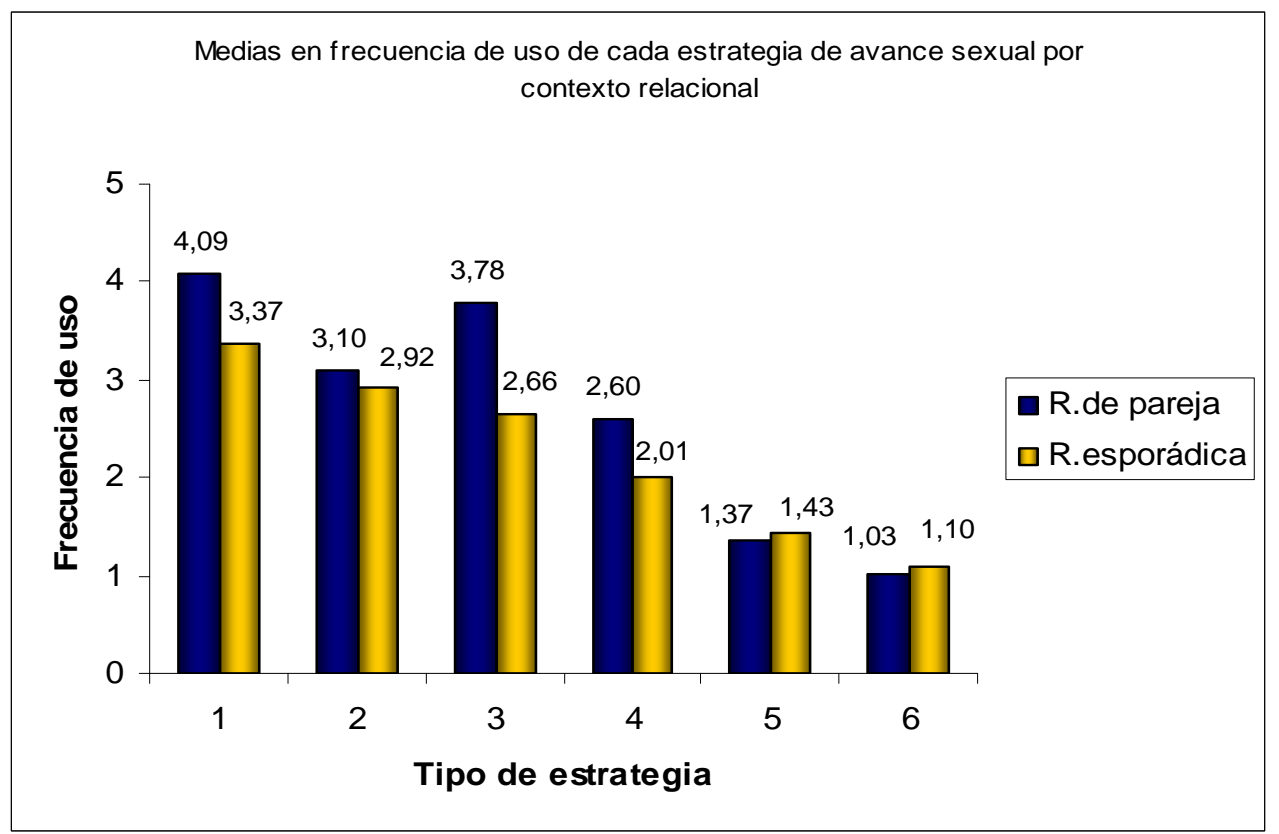

1. Avance físico directo

2. Gestos de seducción

3. Insinuación verbal

4. Avance verbal directo

5. Estrategias de presión

6. Estrategias de fuerza

Por último, la interacción entre el contexto, el tipo de estrategia y el género, ha resultado significativa $[\mathrm{F}(5,152)=.2,999, \mathrm{p}=.013, \eta 2=.09]$. En la muestra de varones, el contexto influye en el uso de determinadas estrategias de avance sexual. Utilizan más la insinuación verbal ( $\mathrm{p}=.000)$, el avance físico ( $\mathrm{p}=.000)$, y el avance verbal $(\mathrm{p}=.001)$ en relaciones de pareja que en relaciones esporádicas. En cambio las estrategias coercitivas de presión y de fuerza, las utilizan más en contextos de relaciones esporádicas que en pareja, aunque con una significación leve $(\mathrm{p}<.05)$.

En la muestra de chicas, el contexto relacional influye de manera más intensa en el uso de estrategias de avance sexual, que en la muestra de varones. Utilizan significativamente más la insinuación verbal $(\mathrm{p}=.000)$, el avance físico $(\mathrm{p}=.000)$, el avance verbal $(\mathrm{p}=.000)$ y los gestos de seducción $(\mathrm{p}=.001)$ en contextos de pareja que en relaciones ocasionales. Observando las medias en frecuencia de uso, vemos que aunque hay diferencias en función del contexto en ambos sexos, esta diferencia es más acusada en la muestra femenina que en la masculina, siendo mucho mayor la frecuencia de empleo de estrategias en relaciones de pareja sobre las relaciones ocasionales (véase Figura 4). 
Figura 4: Frecuencia de uso de tipos de estrategia sexual en chicos y chicas y en diferentes contextos relacionales

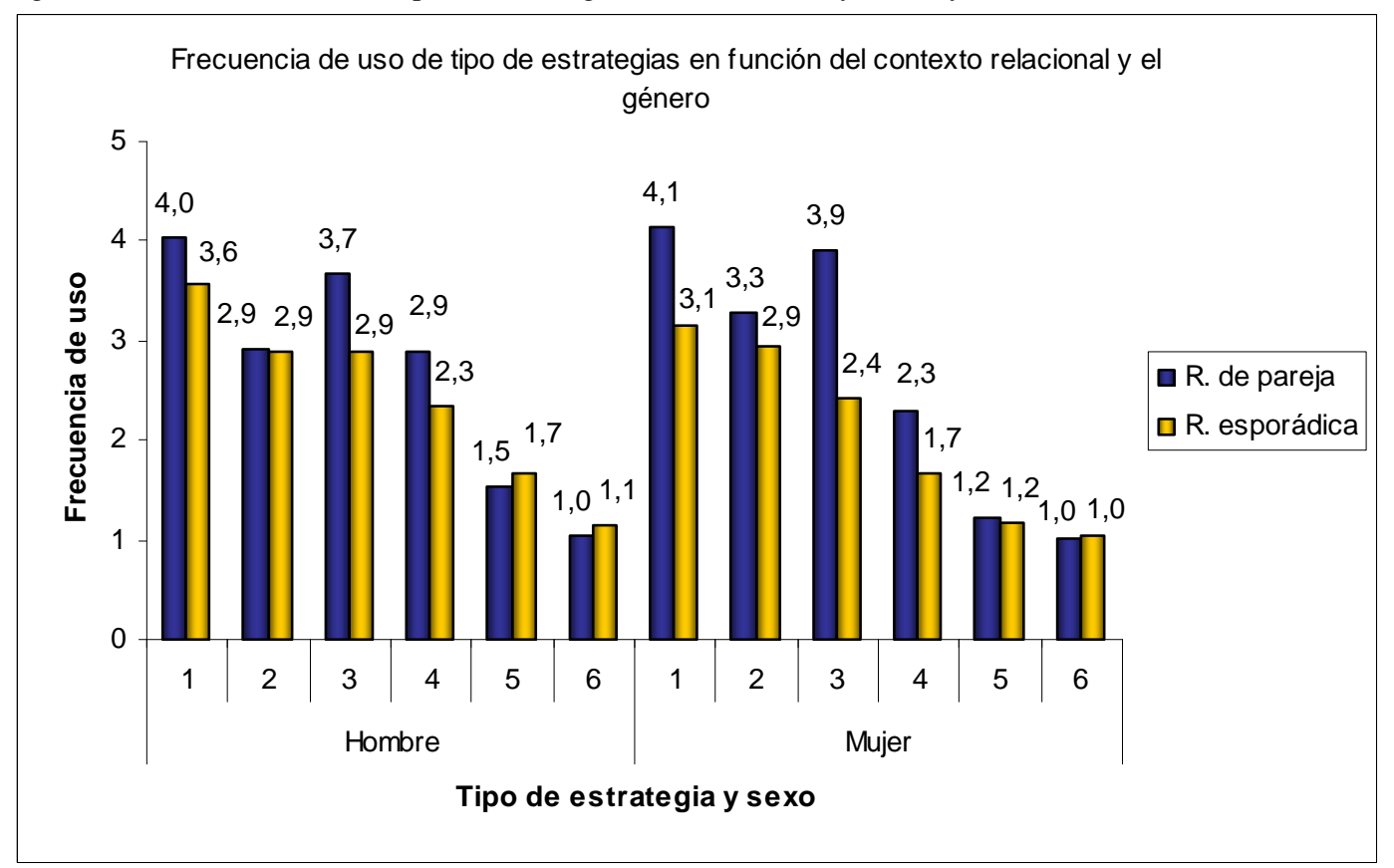

1. Avance físico directo

2. Gestos de seducción

3. Insinuación verbal

4. Avance verbal directo

5. Estrategias de presión

6. Estrategias de fuerza

Resumiendo, el contexto relacional parece que sí afecta a la forma en que los adolescentes emplean estrategias de avance sexual. Concretamente afecta al uso de estrategias de avance de tipo directo y verbal, que son más empleadas en contextos de pareja frente a contextos esporádicos. Aunque esta diferencia se ve en ambos sexos, es la muestra de chicas la que se ve más intensamente afectada por el contexto relacional en el que se encuentran, a la hora de utilizar estrategias de iniciación sexual.

Por otra parte, el género influye en el uso de las estrategias de presión y de avance verbal directo fundamentalmente, puesto que los chicos las utilizan más frecuentemente que las chicas en ambos contextos relacionales. 
Tabla 20. Estadísticos descriptivos en frecuencia de uso de estrategias de avance sexual: Género x Contexto relacional x Tipo de estrategia

\begin{tabular}{|c|c|c|c|c|c|}
\hline Sexo & Contexto relacional & Tipo de estrategia & $\mathrm{N}$ & Media & DT \\
\hline \multirow{12}{*}{ Chicos } & \multirow[t]{6}{*}{ Relación de pareja } & Avance físico directo & 77 & 4.02 & 0.73 \\
\hline & & Gestos de seducción & 77 & 2.90 & 0.92 \\
\hline & & Insinuación verbal & 77 & 3.66 & 1.03 \\
\hline & & Avance verbal directo & 77 & 2.90 & 1.38 \\
\hline & & Estrategias de presión & 77 & 1.53 & 0.61 \\
\hline & & Estrategias de fuerza & 77 & 1.03 & 0.23 \\
\hline & \multirow[t]{6}{*}{ Relación esporádica } & Avance físico directo & 77 & 3.58 & 0.92 \\
\hline & & Gestos de seducción & 77 & 2.89 & 1.00 \\
\hline & & Insinuación verbal & 77 & 2.88 & 1,18 \\
\hline & & Avance verbal directo & 77 & 2.34 & 1.48 \\
\hline & & Estrategias de presión & 77 & 1.66 & 0.89 \\
\hline & & Estrategias de fuerza & 77 & 1.14 & 0.59 \\
\hline \multirow[t]{12}{*}{ Chicas } & \multirow[t]{6}{*}{ Relación de pareja } & Avance físico directo & 83 & 4.14 & 0.77 \\
\hline & & Gestos de seducción & 83 & 3.27 & 0.99 \\
\hline & & Insinuación verbal & 83 & 3.89 & 0.91 \\
\hline & & Avance verbal directo & 83 & 2.29 & 1.39 \\
\hline & & Estrategias de presión & 83 & 1.21 & 0.37 \\
\hline & & Estrategias de fuerza & 83 & 1.01 & 0.09 \\
\hline & \multirow[t]{6}{*}{ Relación esporádica } & Avance físico directo & 83 & 3.14 & 1.00 \\
\hline & & Gestos de seducción & 83 & 2.94 & 1.11 \\
\hline & & Insinuación verbal & 83 & 2.42 & 1.05 \\
\hline & & Avance verbal directo & 83 & 1.67 & 1.14 \\
\hline & & Estrategias de presión & 83 & 1.18 & 0.36 \\
\hline & & Estrategias de fuerza & 83 & 1.04 & 0.22 \\
\hline
\end{tabular}

Tabla 21. Resumen de efectos significativos del ANCOVA (contexto relacional x tipo de estrategia x género) en uso de estrategias de avance sexual en adolescentes

\begin{tabular}{lcccc}
\hline \multicolumn{1}{c}{ Anova } & & & \\
\hline \multicolumn{1}{c}{ Factores principales / interacciones } & $\mathrm{F}$ & $\mathrm{gl}$ & $\mathrm{p}$ & $\eta 2$ \\
Contexto relacional & 13,993 & 1,156 & .000 & .08 \\
Tipo de estrategia & 97,106 & 5,152 & .000 & .76 \\
Género & 6,225 & 1,156 & .014 & .04 \\
Tipo de estrategia x Contexto relacional & 9,742 & 1,152 & .000 & .24 \\
Tipo de estrategia x Sexo & 7,527 & 5,152 & .000 & .19 \\
Contexto relacional x Sexo & 14,336 & 1,156 & .000 & .08 \\
Sexo x Contexto x Tipo de estrategia & 2,999 & 5,152 & .013 & .09 \\
\hline
\end{tabular}




\subsubsection{Estrategias de limitación sexual}

Para comprobar el segundo objetivo en las estrategias de limitación sexual, llevamos a cabo el mismo análisis que en el caso de el avance sexual: ANCOVA de medidas repetidas con un diseño de 2 (tipo de estrategia) x 2 (contexto relacional) x 2 (género), con el último factor intersujetos y los dos primeros intra-sujetos. Así, de nuevo contestaban los mismos adolescentes y se comparaban sus puntuaciones en ambas versiones del cuestionario, para conocer el efecto del tipo de estrategia y del contexto relacional, y se comparaban las puntuaciones de diferentes grupos (chicos y chicas), para conocer el efecto del sexo.

Nuevamente hicimos un análisis sin covariables y otro con covariables para ver la influencia de la duración de la relación y el número de relaciones esporádicas en las posibles diferencias en el uso de estrategias de limitación sexual entre contextos relacionales.

En el ANOVA de medidas repetidas, el efecto del contexto relacional era significativo [F (1, $165)=12,713, \mathrm{p}=.000, \eta 2=.07]$, mientras que en el ANCOVA, introduciendo las covariables, el efecto del contexto relacional no era significativo $[\mathrm{F}(1,151)=0,151, \mathrm{p}=.699]$.

Así vemos que el leve efecto del contexto que existe en el ANOVA, en el que el contexto esporádico favorece levemente el uso de estrategias de limitación sexual, sobre el contexto de pareja, es debido a las covariables duración de la relación y número de relaciones esporádicas, principalmente debido al número de relaciones esporádicas, ya que éste interacciona con la variable contexto relacional, aumentando la frecuencia de uso de estrategias sexuales en relaciones esporádicas sobre relaciones de pareja, mientras que la duración de la relación no parece tener influencia en la frecuencia de uso de la limitación sexual. De esta manera decidimos que el resto de los resultados que forman parte del segundo objetivo, se extrajeran de este análisis de la covarianza.

Por lo tanto concluimos como resultado que el contexto relacional no tiene un efecto significativo en el empleo de tácticas de limitación sexual en los adolescentes $[\mathrm{F}(1,151)=$ $0,151, \mathrm{p}=.699]$.

En cuanto al tipo de estrategia, sí se muestran diferencias significativas en el uso de uno u otro tipo de estrategias de limitación sexual $[\mathrm{F}(1,151)=22,445, \mathrm{p}=.000, \eta 2=.13]$. Los adolescentes 
hacen un uso más frecuente de las estrategias de limitación directas que de las indirectas (véase Tabla 22).

Tabla 22. Estadísticos descriptivos en frecuencia de uso de estrategias de limitación sexual según tipo de estrategia

\begin{tabular}{lccc}
\hline Tipo de estrategia & $\mathrm{N}$ & Media & Desviación Típica \\
\hline Estrategias directas & 155 & 2.55 & 0.91 \\
Estrategias indirectas & 155 & 1.77 & 0.70 \\
\hline
\end{tabular}

El género de los adolescentes tiene también un efecto significativo en las pruebas inter-sujetos $[\mathrm{F}(1,151)=.23,717, \mathrm{p}=.000, \eta 2=.13]$. Concluimos observando las medias de la Tabla 23, que las adolescentes chicas utilizan más las estrategias de limitación sexual que los varones.

Tabla 23. Estadísticos descriptivos en frecuencia de uso de estrategias de limitación sexual según el género

\begin{tabular}{lccc}
\hline Sexo & N & Media & Desviación Típica \\
\hline Chicos & 75 & 1.91 & 0.73 \\
Chicas & 80 & 2.41 & 0.71 \\
\hline
\end{tabular}

La interacción entre el tipo de estrategia y el género se ha mostrado significativa $[\mathrm{F}(1,151)=$ $.14,914, \mathrm{p}=.000, \eta 2=.09]$. Los contrastes realizados a posteriori con el ajuste de Bonferroni indican que mientras que la diferencia entre ambos sexos en el empleo de las tácticas de limitación indirectas es muy leve $(\mathrm{p}=.019)$, la diferencia en el empleo de las estrategias de limitación directas es bastante más intensa a favor de las chicas ( $\mathrm{p}=.000)$. (véase Figura 5) 
Figura 5: Frecuencia de uso de tipos de estrategia de limitación en chicos y chicas

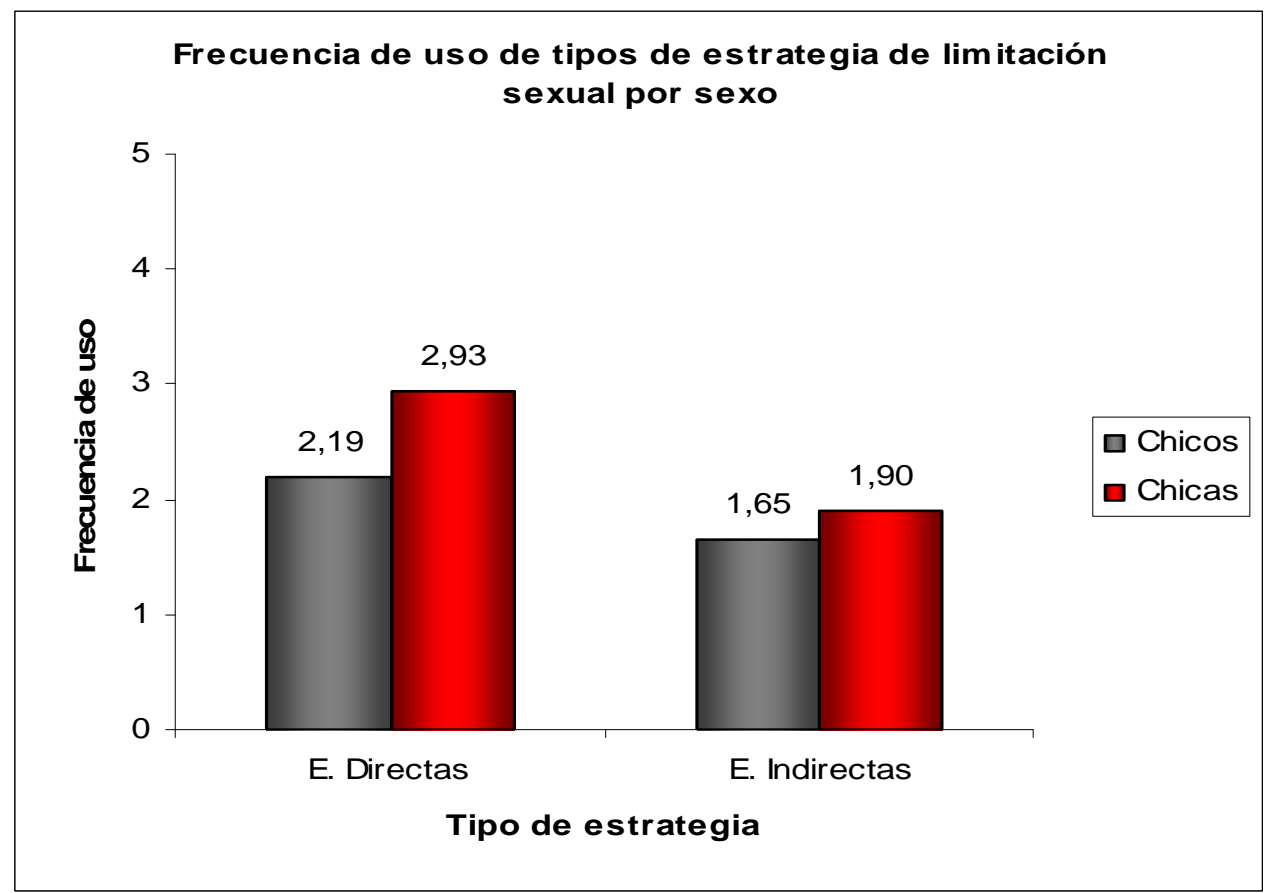

Existe también una interacción significativa aunque leve entre género, contexto y tipo de estrategia $[\mathrm{F}(1,151)=5,872, \mathrm{p}=.017, \eta 2=.04]$. Es en el contexto esporádico dónde más diferencias existen entre chicos y chicas, a favor de las chicas, en el uso de estrategias de limitación sexual. Concretamente es en el uso de estrategias de limitación directas donde se producen las mayores diferencias $(\mathrm{p}=.000)$. También existen diferencias, aunque menos acusadas, en el uso de la limitación directa en relaciones de pareja a favor de las adolescentes chicas $(\mathrm{p}=.001)$ 
Figura 6: Frecuencia de uso de tipos de estrategia de limitación en chicos y chicas en diferentes contextos relacionales.

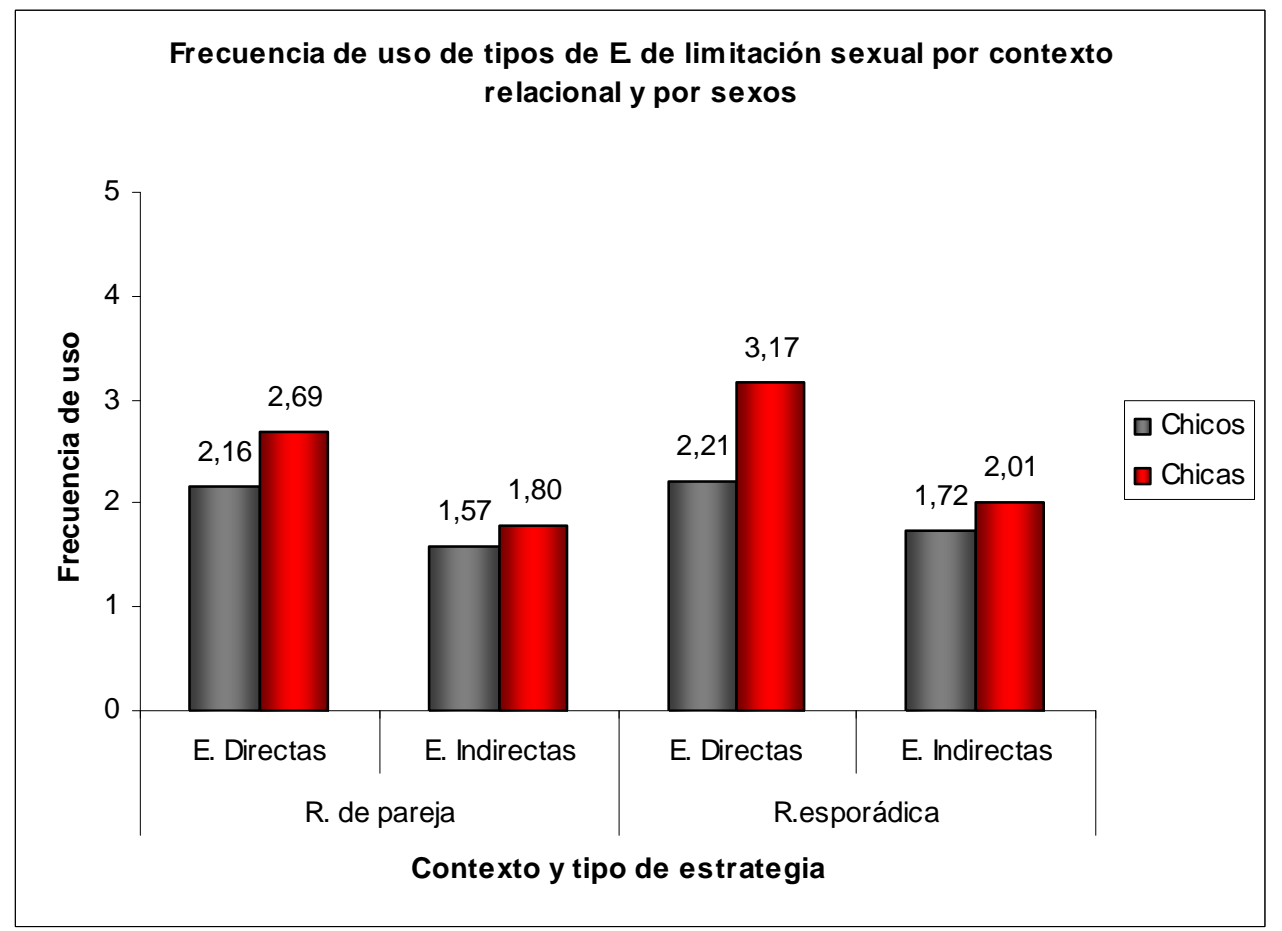

Tabla 24. Estadísticos descriptivos en frecuencia de uso de tipos de estrategias de limitación sexual según contexto relacional y género

\begin{tabular}{llllll}
\hline Contexto relacional & Tipo de estrategia & Sexo & $\mathrm{N}$ & Media & DT \\
\hline Relación de pareja & Directas & Chicos & 75 & 2.16 & 0.86 \\
& & Chicas & 80 & 2.69 & 0.96 \\
\cline { 2 - 6 } & Indirectas & Chicos & 75 & 1.57 & 0.71 \\
& & Chicas & 80 & 1.80 & 0.73 \\
\hline \multirow{2}{*}{ Relación esporádica } & \multirow{2}{*}{ Directas } & Chicos & 75 & 2.21 & 1.04 \\
& & Chicas & 80 & 3.17 & 1.10 \\
\cline { 2 - 6 } & \multirow{2}{*}{ Indirectas } & Chicos & 75 & 1.72 & 0.85 \\
& & Chicas & 80 & 2.01 & 0.77 \\
\hline
\end{tabular}

Tabla 25. Resumen de efectos significativos del ANCOVA (contexto relacional x tipo de estrategia x sexo) en uso de estrategias de limitación sexual en adolescentes.

\begin{tabular}{lcccc}
\hline \multicolumn{1}{c}{ Ancova } & & & \\
\hline \multicolumn{1}{c}{ Factores principales / interacciones } & $\mathrm{F}$ & $\mathrm{gl}$ & $\mathrm{p}$ & $\eta 2$ \\
Contexto relacional & 0,151 & 1,151 & .699 & .01 \\
Tipo de estrategia & 22,445 & 1,151 & .000 & .13 \\
Sexo & 23,717 & 1,151 & .000 & .13 \\
Tipo de estrategia x Sexo & 14,914 & 1,151 & .000 & .09 \\
Sexo x Contexto x Tipo de estrategia & 5,872 & 1,151 & .017 & .06 \\
\hline
\end{tabular}




\subsection{Diferencias en el uso de estrategias sexuales entre adolescentes con experiencia sólo en contextos de pareja y adolescentes con experiencia sólo en contextos de relaciones esporádicas.}

En este segundo apartado, expondremos qué diferencias existen en el uso de estrategias sexuales, tanto de avance como de limitación sexual entre dos grupos de adolescentes: los que sólo han tenido experiencia en contextos de relaciones de pareja y los que sólo han tenido experiencia en contextos de relaciones esporádicas, como análisis complementario al primer apartado de resultados. En la Tabla 16 podemos ver la composición de estos grupos. Tal y cómo exponíamos en las hipótesis, esperamos encontrar diferencias significativas en el empleo de estrategias sexuales, en función del contexto relacional en el que se pongan en marcha. También comprobaremos si el sexo tiene un efecto significativo en el uso de estrategias, y si éste interacciona con el efecto del contexto relacional.

Para ello, llevamos a cabo un ANOVA para cada tipo de estrategia sexual, es decir, seis para las estrategias de avance y otros dos, para las estrategias de limitación. Todos los ANOVAs se llevaran a cabo con el mismo diseño: contexto relacional (adolescentes en relaciones de pareja vs. adolescentes en relaciones casuales) x sexo (chico vs. chica) como factores fijos.

\subsubsection{Estrategias de avance sexual}

El primer ANOVA lo realizamos sobre el uso de estrategias de avance físico directo, introduciendo como factores fijos el contexto relacional y el género de los adolescentes. Los resultados revelaron un efecto significativo del contexto relacional $[F(1,198)=16,710, p=.000$, $\eta 2=.08]$. Los adolescentes que tienen experiencia en contextos de pareja utilizan más el avance físico directo para tener relaciones sexuales que aquellos con experiencia en contextos esporádicos (véase Tabla 26). 
Tabla 26. Estadísticos descriptivos de uso del avance físico en dos grupos de adolescentes en diferentes contextos.

\begin{tabular}{lccc} 
Contexto relacional & $\mathrm{N}$ & Media & Desviación Típica \\
\hline Relación de pareja & 52 & 3.72 & 1.01 \\
Relación esporádica & 150 & 2.90 & 0.90 \\
\hline
\end{tabular}

El efecto del género también resultó significativo $[\mathrm{F}(1,198)=10,057, \mathrm{p}=.002, \eta 2=.05]$. Las chicas adolescentes utilizan este tipo de estrategia física directa ligeramente más que los chicos.

Tabla 27. Estadísticos descriptivos en frecuencia de uso del avance físico directo en varones y mujeres

\begin{tabular}{lccc}
\hline Sexo & $\mathrm{N}$ & Media & Desviación Típica \\
\hline Chicos & 100 & 2.93 & 0.92 \\
Chicas & 102 & 3.28 & 1.04 \\
\hline
\end{tabular}

Por ultimo, la interacción entre los dos factores también resultó significativa $[\mathrm{F}(1,198)=$ $11,666, p=.001, \eta 2=.05]$. Mientras que en la muestra masculina el contexto relacional no influye en el uso del avance físico, si influye en la muestra femenina ( $\mathrm{p}=.000)$. Así, las chicas en relaciones de pareja utilizan más este tipo de estrategias físicas directas que en relaciones esporádicas.

Figura 7: Frecuencia de uso del avance físico directo en chicos y chicas según el contexto relacional

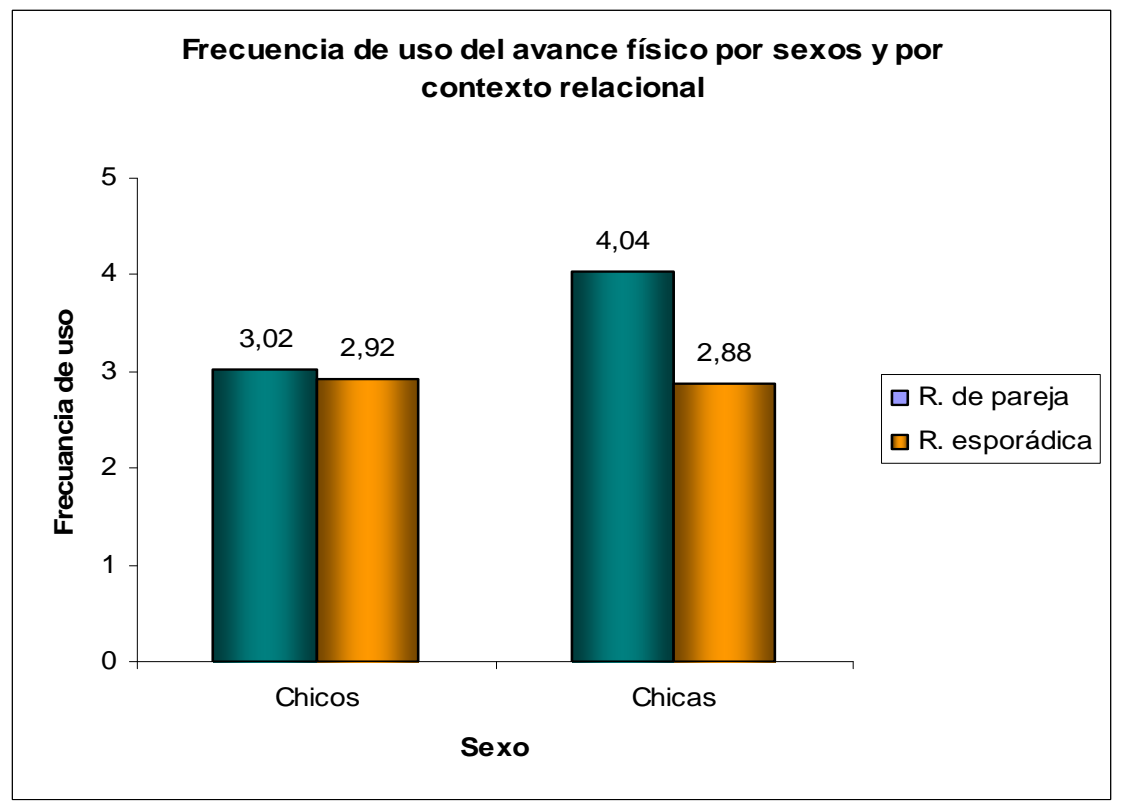


El segundo ANOVA, se realizó sobre el uso de gestos de seducción. El efecto del contexto relacional no resultó significativo $[\mathrm{F}(1,198)=2,955, \mathrm{p}=.087]$. Sólo el efecto del género resultó significativo en este tipo de estrategia $[\mathrm{F}(1,198)=9,094, \mathrm{p}=.003, \eta 2=.04]$. Las chicas utilizan más los gestos de seducción que los chicos, independientemente del contexto relacional en el que se encuentren. La interacción entre sexo y contexto relacional tampoco resultó significativa $[\mathrm{F}(1,198)=3,417, \mathrm{p}=.066]$

Tabla 28. Estadísticos descriptivos en frecuencia de uso de gestos de seducción en varones y mujeres

\begin{tabular}{lccc}
\hline Sexo & $\mathrm{N}$ & Media & Desviación Típica \\
\hline Chicos & 100 & 2.48 & 1.02 \\
Chicas & 102 & 2.78 & 0.97 \\
\hline
\end{tabular}

En el análisis de la insinuación verbal, encontramos que sólo el efecto del contexto relacional resulto significativo $[\mathrm{F}(1,198)=10,004, \mathrm{p}=.002, \eta 2=.05]$. Los adolescentes de ambos sexos en contextos de pareja utilizan más la insinuación verbal que los adolescentes en contextos de relaciones esporádicas. El efecto del género y la interacción del género y el contexto no resultaron significativos $[\mathrm{F}(1,198)=2,033, \mathrm{p}=.155]$ y $[\mathrm{F}(1,198)=1,464, \mathrm{p}=.228]$

Tabla 29. Estadísticos descriptivos de uso de la insinuación verbal en dos grupos de adolescentes en diferentes contextos.

\begin{tabular}{lccc}
\hline Contexto relacional & $\mathrm{N}$ & Media & Desviación Típica \\
\hline Relación de pareja & 52 & 3.47 & 0.94 \\
Relación esporádica & 150 & 2.85 & 1.09 \\
\hline
\end{tabular}

El cuarto ANOVA lo realizamos sobre el uso de estrategias de avance verbal directo. Los resultados revelaron un efecto significativo del contexto relacional $[\mathrm{F}(1,198)=22,817, \mathrm{p}=.000$, $\eta 2=.10]$. Los adolescentes que tienen experiencia en contextos de pareja utilizan más el avance verbal directo para tener relaciones sexuales que aquellos con experiencia en contextos esporádicos (véase Tabla 30). 
Tabla 30. Estadísticos descriptivos de uso del avance verbal en dos grupos de adolescentes en diferentes contextos.

\begin{tabular}{lccc} 
Contexto relacional & $\mathrm{N}$ & Media & Desviación Típica \\
\hline Relación de pareja & 52 & 2.42 & 1.41 \\
Relación esporádica & 150 & 1.46 & 0.86 \\
\hline
\end{tabular}

El género no tuvo efectos significativos $[\mathrm{F}(1,198)=1,374, \mathrm{p}=.243]$. Sin embargo, este resultado hay que matizarlo puesto que la interacción entre el género y el contexto relacional sí resultó significativa $[\mathrm{F}(1,198)=15,939, \mathrm{p}=.000, \eta 2=.07]$. Mientras que en la muestra masculina el contexto relacional no influye en el uso del avance verbal, si influye en la muestra femenina $(\mathrm{p}=.000)$. Así, las chicas en contextos de pareja utilizan más este tipo de estrategias verbales directas, que las chicas en relaciones esporádicas. Visto desde la perspectiva del género, en relaciones esporádicas, los varones utilizan más el avance verbal directo que las chicas, mientras que en relaciones de pareja, las chicas superan significativamente a los chicos en el uso de este tipo de estrategia verbal directa (véase Figura 8).

Figura 8: Frecuencia de uso del avance verbal directo en chicos y chicas según el contexto relacional

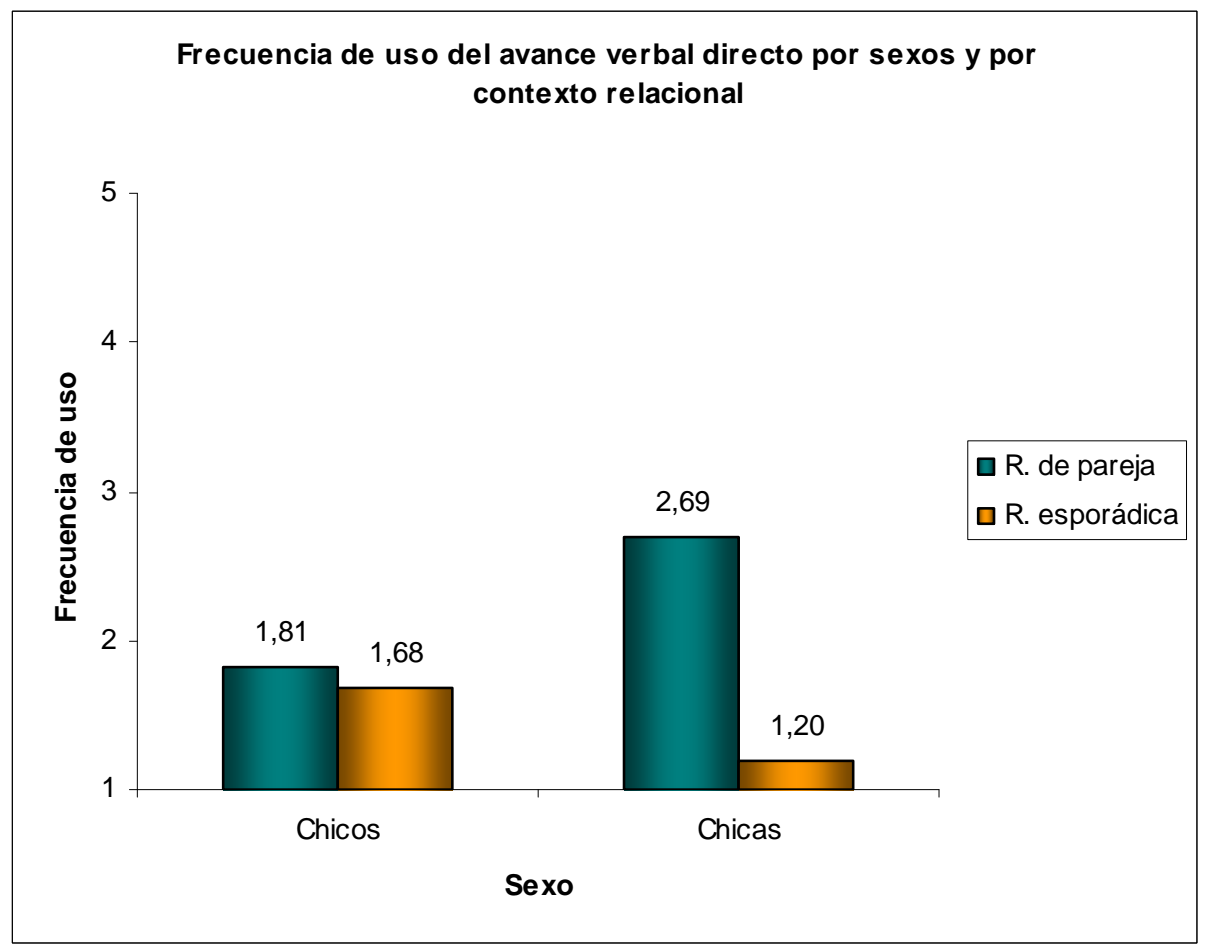


El quinto anova, se realizó sobre el uso de las estrategias de presión sexual. Sólo el efecto del género resultó significativo en este tipo de estrategia, aunque con un tamaño del efecto muy pequeño $[\mathrm{F}(1,198)=5,855, \mathrm{p}=.016, \eta 2=.03]$. Los chicos utilizan más la presión sexual como estrategia de iniciación sexual que las chicas. El efecto del contexto y la interacción del género y el contexto no resultaron significativos $[\mathrm{F}(1,198)=0,753, \mathrm{p}=.387]$ y $[\mathrm{F}(1,198)=0,056$, $\mathrm{p}=.814]$.

Tabla 31. Estadísticos descriptivos en frecuencia de uso de estrategias de presión sexual en varones y mujeres

\begin{tabular}{lccc}
\hline Sexo & N & Media & Desviación Típica \\
\hline Chicos & 100 & 1.31 & 0.44 \\
Chicas & 102 & 1.14 & 0.31 \\
\hline
\end{tabular}

Finalmente en el análisis sobre las estrategias de fuerza ni el efecto del contexto relacional [F $(1,198)=1,371, \mathrm{p}=.243]$, ni el género $[\mathrm{F}(1,198)=0,025, \mathrm{p}=.875]$, ni la interacción resultaron significativas $[\mathrm{F}(1,198)=0,025, \mathrm{p}=.875]$.

\subsubsection{Estrategias de limitación sexual}

En el análisis que comparaba a dos grupos de adolescentes con experiencia en diferentes contextos relacionales en el uso de estrategias de limitación sexual directa, introdujimos igualmente el contexto relacional y el sexo de los adolescentes como factores fijos. Se observó que sólo el género tuvo un efecto significativo $[\mathrm{F}(1,192)=15,238, \mathrm{p}=.000, \eta 2=.07]$. Las chicas utilizan significativamente más las estrategias de limitación directas que los chicos (véase Tabla 32). El efecto del contexto relacional $[\mathrm{F}(1,192)=2,162, \mathrm{p}=.143]$ y de la interacción $[\mathrm{F}$ $(1,192)=1,314, \mathrm{p}=.253]$ no resultaron significativos.

Tabla 32. Estadísticos descriptivos en frecuencia de uso de estrategias de limitación directas en varones y mujeres

\begin{tabular}{lccc}
\hline Sexo & N & Media & Desviación Típica \\
\hline Chicos & 97 & 2.09 & 0.89 \\
Chicas & 99 & 2.85 & 0.92 \\
\hline
\end{tabular}


En el caso de las estrategias indirectas, ningún efecto resultó significativo, ni el contexto relacional $[\mathrm{F}(1,192)=0,414, \mathrm{p}=.521]$, ni el género $[\mathrm{F}(1,192)=0,006, \mathrm{p}=.938]$, ni la interacción $[\mathrm{F}(1,192)=0,682, \mathrm{p}=.938]$.

Tabla 33. Resumen de efectos significativos de los ANOVAs (contexto relacional x sexo) en tipos de estrategias de avance y limitación sexual en adolescentes con experiencia en relaciones de pareja vs.experiencia en relaciones casuales

\begin{tabular}{llcccc}
\hline \multicolumn{1}{c}{ Tipo de estrategia } & \multicolumn{1}{c}{ Factores / interacciones } & \multicolumn{2}{c}{ Anovas } \\
\hline \multirow{2}{*}{ Avance físico directo } & Contexto relacional & 16,710 & 1,198 & .000 & .08 \\
& Sexo & 10,057 & 1,198 & .002 & .05 \\
& Contexto relaciona x Sexo & 11,666 & 1,198 & .001 & .05 \\
Gestos de seducción & Sexo & & & & \\
& & 9,094 & 1,198 & .003 & .04 \\
Insinuación verbal & Contexto relacional & 10,004 & 1,198 & .002 & .05 \\
Avance verbal directo & Contexto relacional & 22,817 & 1,198 & .000 & .10 \\
& Contexto relacional x Sexo & 15,939 & 1,198 & .000 & .07 \\
Estrategias de presión & Sexo & & & & .03 \\
E. limitación directa & Sexo & 5,855 & 1,198 & .016 & .07 \\
\hline
\end{tabular}

Concluimos a modo de resumen que el contexto relacional ha resultado significativo en el uso de 3 tipos de estrategias de avance sexual: las estrategias directas (físicas y verbales) y la insinuación verbal. En todas, el contexto en el que mayor uso hacen de ellas los adolescentes es el contexto de pareja, sobre el contexto esporádico. El uso de los otros tres tipos de estrategias de avance, coercitivas y gestos de seducción, parece que no se ve influido significativamente por el contexto relacional.

El género ha revelado un efecto significativo para las estrategias de avance físicas (directas e indirectas) y las estrategias de presión, así como para las estrategias de limitación directas. Las chicas han mostrado un mayor uso de todas éstas estrategias, excepto en las de presión, en las que los varones superan a las chicas. 
Sólo en el análisis de las estrategias directas se ha encontrado un interacción significativa entre contexto relacional y género y en ambos casos en la misma dirección: mientras que el contexto relacional no influye en la medida en que los varones utilizan estrategias de avance directas, el contexto sí tiene un efecto significativo y grande, en el uso que las chicas hacen de las estrategias directas, siendo mayor en contextos de relaciones de pareja.

Podemos concluir por tanto que el efecto del contexto relacional es significativo en el uso de algunas estrategias sexuales directas y verbales, sobre todo en la muestra femenina, y a favor del contexto de pareja. Por otra parte, que el género tiene un efecto significativo en el uso de algunas estrategias sexuales, como el uso de gestos de seducción y estrategias de limitación directas a favor de las chicas, o el uso de estrategias de presión a favor de los chicos. 


\section{EXPERIENCIA Y LAS MOTIVACIONES SEXUALES TENIENDO EN CUENTA EL GÉNERO Y LA EXPERIENCIA RELACIONAL, Y SU ASOCIACIÓN CON LAS ESTRATEGIAS SEXUALES EN CADA CONTEXTO.}

\subsection{Experiencia sexual en la adolescencia}

\subsubsection{Análisis descriptivo}

En este apartado hablaremos de cómo puntúa nuestra muestra en la escala de experiencia sexual, tanto cualitativa como cuantitativa y de las diferencias que existen en función de la edad, el sexo y la experiencia relacional.

Como ya hemos expuesto en el apartado metodológico, contábamos con 9 conductas sexuales a las que los participantes debían puntuar en función de la cantidad de veces que habían hecho cada una. Esto también permitía claro, obtener una medida puramente cualitativa de si habían realizado o no, cada conducta. Es decir una medida de nivel de experiencia sexual, con 9 niveles.

Tabla 34. Porcentaje de adolescentes que han realizado al menos una vez, y más de 10 veces cada conducta sexual

\begin{tabular}{ccccc}
\hline Niveles & \% Han realizado alguna vez & $\mathrm{N}$ & \% Han realizado más de 10 veces & $\mathrm{N}$ \\
\hline 1 & 95.2 & 374 & 73.5 & 289 \\
2 & 81.9 & 322 & 42.7 & 168 \\
3 & 72.0 & 283 & 33.8 & 133 \\
4 & 63.6 & 250 & 26.0 & 102 \\
5 & 60.6 & 238 & 26.7 & 105 \\
6 & 63.4 & 249 & 30.8 & 121 \\
7 & 56.5 & 222 & 27.5 & 108 \\
8 & 33.8 & 157 & 14.2 & 56 \\
9 & 29.9 & 133 & 13.7 & 54 \\
\hline
\end{tabular}

Atendiendo a esta medida de nivel, hemos expuesto en la Tabla 34, el porcentaje de la muestra que había llegado a realizar alguna vez cada una de las 9 conductas o niveles. Vemos, que de acuerdo a la secuencia normativa en la adquisición de la experiencia sexual aceptada en la investigación sobre sexualidad adolescente, el porcentaje va disminuyendo a medida que las conductas aumentan en intimidad. Así, mientras que un 95,2\% de la muestra ha experimentado besos, "solo" un $29,9 \%$ ha practicado o recibido sexo oral a genitales femeninos. Un dato a 
remarcar es que el 56,5\% de la muestra han realizado el coito alguna vez, es decir, algo más de la mitad de los participantes. Este dato es algo superior a otros estudios realizados por nosotros o por otros investigadores de la sexualidad en la adolescencia, pero hay que tener en cuenta que nuestra muestra abarcaba sólo la adolescencia media y tardía, dejando fuera a los adolescentes de 13 a 15 años. Por otra parte, hicimos un análisis de correlación entre la experiencia sexual y la edad y la correlación era significativa $(\mathrm{r}=.36, \mathrm{p}<.01)$. La experiencia sexual de los adolescentes aumenta a medida que lo hace la edad de éstos.

También exponemos en la Tabla 34 qué porcentaje de la muestra que ha realizado cada conducta en más de 10 ocasiones, para comprobar la diferencia con el porcentaje que lo han realizado al menos una vez. Vemos que el porcentaje de los que han realizado cada conducta en más de 10 ocasiones, desciende a, más o menos, la mitad del porcentaje que habían realizado cada conducta al menos una vez.

La media del nivel de experiencia sexual cualitativa es 5,6 y se sitúa entre la conducta 5 y 6 , por lo tanto (caricias a genitales masculinos y femeninos respectivamente). La puntuación media de experiencia sexual cuantitativa es 25,9 y la desviación típica es 11,4 . Teniendo en cuenta que la mínima puntuación es 9 (no haber hecho ninguna conducta) y la máxima son 45 (haber hecho cada conducta más de 10 veces), la puntuación media de 25,9, sitúa el nivel medio en el mismo lugar de la secuencia que la medida cualitativa.

Teniendo en cuenta que los estadísticos descriptivos centrales no siempre representan adecuadamente la variabilidad de los datos, expondremos la media de número de veces que se ha llevado a cabo cada conducta en la Tabla 35.

Tabla 35. Estadísticos descriptivos de frecuencia de realización de cada conducta sexual en adolescentes.

\begin{tabular}{cccc}
\hline Conducta sexual & N & Media & Desviación Típica \\
\hline 1 & 393 & 4.39 & 1.16 \\
2 & 393 & 3.50 & 1.56 \\
3 & 393 & 3.15 & 1.65 \\
4 & 393 & 2.75 & 1.64 \\
5 & 393 & 2.74 & 1.67 \\
6 & 393 & 2.87 & 1.70 \\
7 & 393 & 2.63 & 1.70 \\
8 & 393 & 1.92 & 1.47 \\
9 & 393 & 1.99 & 1.45 \\
\hline
\end{tabular}


Las medias expuestas reflejan las medias en las puntuaciones obtenidas en el cuestionario y tienen la siguiente equivalencia en cuanto a frecuencia: $1=$ Nunca; $2=$ Una 02 veces; $3=$ De 3 a 5 veces; $4=$ De 6 a 10 veces; 5= Más de 10 veces. En cuanto a la experiencia coital, aunque hemos visto que el $56 \%$ de la muestra total tiene experiencia coital, nos interesan porcentajes específicos relativos a la experiencia relacional de los adolescentes. Así, dentro de los 52 adolescentes que sólo han tenido relaciones de pareja, un $75 \%$ tiene experiencia coital. De los 150 que sólo han experimentado relaciones esporádicas, un 30,5\% llegó a tener experiencia coital, y de aquellos que han tenido ambas experiencia relacionales (178 adolescentes), un $76,4 \%$ han realizado el coito alguna vez.

Comprobando que la medida cualitativa y cuantitativa ofrecen la misma representación de la experiencia sexual de los adolescentes y se relacionan idénticamente con las demás variables, optamos por utilizar la medida cuantitativa en el resto del estudio, como medida única de experiencia sexual.

\subsubsection{Diferencias en experiencia sexual en función del género y la experiencia relacional.}

Queríamos comprobar además si las conductas sexuales de la escala se diferenciaban entre sí en cuanto a la frecuencia con las que los adolescentes las experimentan, además de las diferencias en función del sexo y de la experiencia relacional. Para ello, Realizamos un ANOVA de medidas repetidas con un diseño de 9 (conductas sexuales) x 3 (nivel experiencia relacional) x 2 (sexo) con medidas repetidas en el primer factor. Para configurar en segundo factor, nivel de experiencia relacional dividimos a los sujetos en 3 grupos en función de su experiencia relacional: 1) aquellos que sólo habían tenido relaciones de pareja, 2) aquellos que sólo habían tenido relaciones esporádicas y 3) aquellos que habían tenido ambas experiencias relacionales.

El análisis revela diferencias significativas en la frecuencia de realización de cada conducta sexual $[\mathrm{F}(8,367)=92,734, \mathrm{p}=.000, \eta 2=.67]$. En la comparación por pares, vimos que había diferencias entre la conducta 1 (beso íntimo) y las demás, la 2 (caricias a senos femeninos) y las demás, la 3 (caricias a senos femeninos bajo la ropa) y el resto. Las conductas 4, 5, 6, y 7, sin embargo no revelaban diferencias entre sí, en cuanto al número de veces que los adolescentes 
habían realizado estas conductas, pero sí se diferenciaban de las anteriores y de las posteriores. Por último las conductas 8 y 9 (sexo oral) tampoco se diferenciaban entre sí, pero si del resto.

Podemos decir, por lo tanto que las conductas se pueden agrupar de una manera determinada en esta muestra, en cuanto a la intimidad que suponen para los adolescentes, y el cambio cualitativo que puede suponer el iniciar el siguiente "grupo de conductas sexuales", en la adquisición de experiencia sexual. Por una parte, tenemos la conducta de besar, después vendrían las caricias por encima de la ropa, posteriormente aparecen las caricias de los senos por debajo de la ropa, el siguiente grupo serían aquellas conductas entendidas generalmente como relaciones sexuales, que se desarrollan sin ropa, en un espacio apropiado, y dirigidas a la consecución del orgasmo, como la masturbación o el coito. Finalmente están las conductas de sexo oral, como el último escalón en cuanto a experiencia e intimidad sexual en esta muestra de adolescentes.

Por otra parte el efecto de la experiencia relacional también resultó ampliamente significativo [F $(2,374)=76,627, p=.000, \eta 2=.29]$. En las comparaciones por pares vimos que los 3 grupos diferían entre sí en su nivel de experiencia sexual. Los adolescentes que habían tenido ambas experiencias relacionales, tenían significativamente más experiencia sexual que los otros dos grupos. En segundo lugar se situaban los que sólo habían tenido pareja, y en tercer lugar los que sólo habían tenido relaciones esporádicas, que eran los que menos experiencia sexual tenían significativamente (véase Tabla 36).

Tabla 36. Estadísticos descriptivos en frecuencia de conductas sexuales en función de la experiencia relacional

\begin{tabular}{lccc}
\hline Experiencia relacional & $\mathrm{N}$ & Media & Desviación Típica \\
\hline Sólo relación de pareja & 52 & 3.06 & 1.59 \\
Sólo relación esporádica & 150 & 2.09 & 1,19 \\
Ambas experiencias relacionales & 178 & 3.52 & 1.63 \\
\hline
\end{tabular}

Concluimos que los adolescentes que han tenido ambas experiencias relacionales tienen más experiencia sexual que los que han tenido sólo un tipo de experiencia relacional, y que la experiencia de haber tenido una relación de pareja contribuye a la adquisición de experiencia sexual en mayor medida, que la experiencia de haber tenido relaciones esporádicas. 
El efecto del sexo, no resultó significativo en la experiencia sexual de los adolescentes, [F $(1,374)=2,115, \mathrm{p}=.147]$ por lo que concluimos que no había diferencias en el nivel de experiencia sexual entre chicos y chicas.

Sí había en cambio, interacción significativa entre el sexo y la experiencia relacional [F $(2,374)$ $=9,521, \mathrm{p}=.000, \eta 2=.05]$. Para analizar el resultado de esta interacción, se realizaron los contrastes pertinentes con el ajuste Bonferroni. La experiencia relacional tiene un efecto significativo sobre la experiencia sexual en ambos sexos, pero vemos que en la muestra masculina, el grupo con mayor experiencia sexual son aquellos con ambas experiencias relacionales, que son los que se diferencian significativamente de los otros dos grupos. En la muestra femenina en cambio, el grupo con mayor experiencia sexual es el que sólo ha tenido relaciones de pareja, por encima de los otros dos. En este caso, las que menos experiencia tienen son las que sólo han tenido relaciones esporádicas y son las que se diferencian significativamente de los otros dos grupos.

Figura 9: Experiencia sexual de los adolescentes en función de la experiencia relacional y el sexo

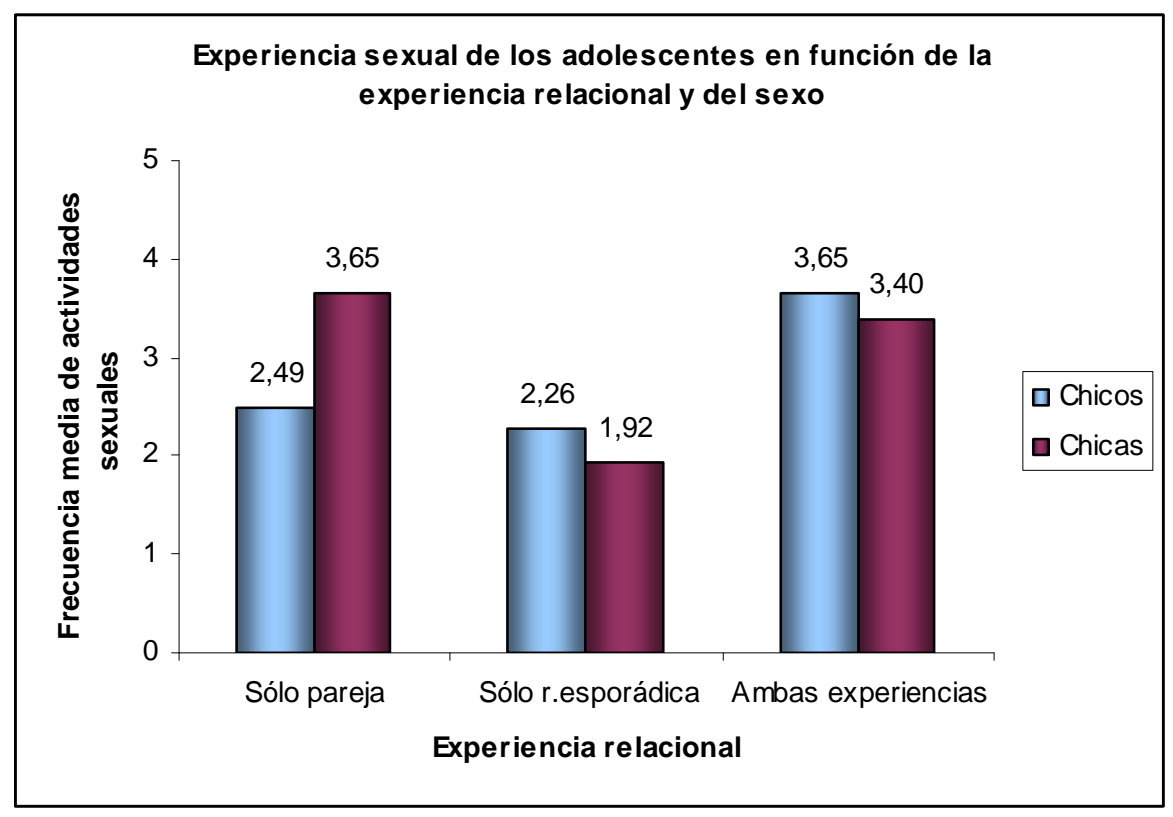

Podemos concluir por tanto, que la experiencia relacional tiene diferentes efectos sobre la experiencia sexual para cada sexo. La experiencia relacional en los chicos parece influir de manera acumulativa, ya que a mayor número de relaciones de cualquier tipo, mayor incremento 
en la experiencia sexual. Las relaciones de pareja y las relaciones casuales como contextos relacionales, parecen contribuir por igual, y es la suma de ambas lo que supone un cambio diferencial en la experiencia sexual de los adolescentes varones. En las chicas en cambio, parece que es fundamentalmente la relación de pareja, la que contribuye a la adquisición de experiencia sexual, ya que los grupos que han tenido relaciones de pareja se igualan en experiencia sexual, o incluso las que sólo han tenido pareja superan a las que han tenido ambas experiencias, y es el grupo que sólo ha tenido relaciones esporádicas el que se diferencia significativamente por su baja experiencia sexual. Con estos datos concluimos que aunque chicos y chicas adolescentes no difieren en su nivel de experiencia sexual, si difieren en cuanto al tipo de relaciones a través de las que adquieren esa experiencia sexual.

Tabla 37. Resumen de efectos significativos del ANOVA (conducta sexual x experiencia relacional x sexo).

\begin{tabular}{lcccc}
\hline \multicolumn{5}{c}{ Anova } \\
Factores principales / interacciones & $\mathrm{F}$ & $\mathrm{gl}$ & $\mathrm{p}$ & $\eta 2$ \\
Tipo de conducta sexual & 92,734 & 2,374 & .000 & .67 \\
Experiencia relacional & 76,627 & 2,374 & .000 & .29 \\
Sexo & 2,115 & 1,374 & .147 & \\
Experiencia relacional x Sexo & 9,521 & 2,374 & .000 & .05 \\
\hline
\end{tabular}

\subsection{Motivaciones sexuales en la adolescencia}

\subsubsection{Análisis descriptivo de las motivaciones sexuales}

En primer lugar, para examinar las motivaciones sexuales en adolescentes españoles, debemos llevar a cabo un análisis factorial que revele si la estructura factorial y los tipos de motivación sexual son los mismos que propusieron los autores del cuestionario "Sex Motives" (Cooper, Shapiro y Powers, 1998), para adolescentes estadounidenses.

Para comprobar que la aplicación de esta técnica era pertinente, nos fijamos en señales que indicasen que existe multicolinealidad entre los ítems. Una inspección de la matriz de correlaciones nos indicó que había correlaciones moderadas entre los elementos y comprobamos la medida de adecuación muestral de Kaiser-Meyer-Olkin (KMO), que era muy buena, de .91. 
La prueba de esfericidad es significativa, con lo que se rechaza la hipótesis nula de que haya esfericidad, y por tanto podemos asegurar que existe multicolinealidad. La varianza total explicada por el modelo factorial llega al 64,4\%, (véase Tabla 38).

Tabla 38. Varianza explicada por cada uno de los factores del cuestionario de motivaciones sexuales en la adolescencia.

\begin{tabular}{c|ccc} 
Factor & Autovalor & \% de la Varianza & \% Acumulado \\
\hline 1 & 9.56 & 32.9 & 32.9 \\
2 & 4.54 & 15.6 & 48.6 \\
3 & 2.01 & 6.9 & 55.5 \\
4 & 1.48 & 5.1 & 60.6 \\
5 & 1.09 & 3.7 & 64.4
\end{tabular}

En la Tabla 39, se puede observar el resultado del análisis factorial. Seis factores resultaron del análisis, aunque el último factor estaba formado por un solo ítem (ítem 3) y lo desechamos por no estar justificado conceptualmente.

En el estudio utilizamos por tanto cinco factores. Dos de los factores originales se agruparon en uno de 9 ítems, en nuestro análisis. Si recordamos la sección metodológica, el cuestionario original agrupa los 29 ítems en 6 subescalas de motivos sexuales: Placer, Intimidad, Afrontar emociones negativas, Autoafirmación, Evitar rechazo de pareja, Evitar rechazo de amigos, y los ítems se distribuyen en las subescalas en grupos de 4 o 5 . En nuestro análisis, los ítems en principio pertenecientes a los factores Afrontar emociones negativas y Autoafirmación, se agruparon conjuntamente formando un solo factor al que nosotros llamamos Autorregulación emocional. El resto de los factores resultaron idénticos a los originales.

El factor Placer, comprende aquellos ítems que aluden al placer sexual como motivo para tener actividad sexual. Es una motivación que busca conseguir algo, es por tanto de aproximación o positiva y está centrada en uno mismo, ya que el placer que se busca, es el propio.

El factor Intimidad agrupa aquellos ítems que proponen la intimidad o cercanía emocional con la pareja, como motivo para tener relaciones sexuales. Es también una motivación de aproximación, ya que busca conseguir o aumentar la intimidad, pero está centrada en los demás, concretamente en la pareja, ya que la cercanía emocional que se busca es entre dos personas. 
Tabla 39. Matrices de factoriales rotados del cuestionario de motivaciones sexuales en adolescentes

\begin{tabular}{|c|c|c|c|c|c|c|}
\hline Ítem & $\begin{array}{c}\text { Factor } \\
1\end{array}$ & $\begin{array}{c}\text { Factor } \\
2\end{array}$ & $\begin{array}{c}\text { Factor } \\
3\end{array}$ & $\begin{array}{c}\text { Factor } \\
4\end{array}$ & $\begin{array}{c}\text { Factor } \\
5\end{array}$ & $\begin{array}{c}\text { Factor } \\
6\end{array}$ \\
\hline Item 12 & 0.85 & & & & & \\
\hline Item 24 & 0.85 & & & & & \\
\hline Item 29 & 0.81 & & & & & \\
\hline Item 18 & 0.79 & & & & & \\
\hline Item 6 & 0.77 & & & & & \\
\hline Item 9 & & 0.70 & & & & \\
\hline Item 10 & & 0.68 & & & & \\
\hline Item 16 & & 0.66 & & & & \\
\hline Item 21 & & 0.65 & & & & \\
\hline Item 28 & & 0.64 & & & & \\
\hline Item 4 & & 0.63 & & & & \\
\hline Item 22 & & 0.61 & & & & \\
\hline Item 15 & & 0.49 & & & & \\
\hline Item 27 & & 0.45 & & & & \\
\hline Item 13 & & & 0.83 & & & \\
\hline Item 19 & & & 0.80 & & & \\
\hline Item 1 & & & 0.73 & & & \\
\hline Item 25 & & & 0.73 & & & \\
\hline Item 7 & & & 0.68 & & & \\
\hline Item 20 & & & & 0.81 & & \\
\hline Item 8 & & & & 0.81 & & \\
\hline Item 14 & & & & 0.81 & & \\
\hline Item 26 & & & & 0.72 & & \\
\hline Item 2 & & & & 0.57 & & \\
\hline Item 23 & & & & & 0.60 & \\
\hline Item 17 & & & & & 0.58 & \\
\hline Item 5 & & & & & 0.55 & \\
\hline Item 11 & & & & & 0.54 & \\
\hline Item 3 & & & & & & 0.76 \\
\hline
\end{tabular}

Factores de Motivación Sexual:
1) Evitar rechazo de amigos
2) Autorregulación emocional
3) Placer sexual
4) Intimidad
5) Evitar rechazo de pareja
6) Item $n^{\circ} 3$

El factor Autorregulación emocional, como ya hemos comentado, agrupa dos categorias originales (Afrontar emociones negativas y Autoafirmación) que representan la motivación de evitación o negativa, porque se pretende evitar algo, en este caso estados emocionales negativos o baja autoestima, a través de la actividad sexual. Se sitúa en la categoría de motivación centrada en uno mismo, ya que lo que se evita son estados negativos originados en uno mismo. Las categorías originales, eran de hecho una sola en la primera conceptualización de los autores sobre categorías de motivación sexual. Así, los ítems agrupados por la autorregulación emocional hacen referencia a la actividad sexual como forma de escape o mejora a estados de 
ánimo aversivos, como una forma de reducir sentimientos negativos o de equilibrar una autoestima baja.

El factor Evitar rechazo de la pareja, integra a los ítems que aluden a evitar posibles enfados o castigos por parte de la pareja como motivo para acceder a la actividad sexual.

El factor Evitar rechazo de los amigos, agrupa aquellos ítems que conciben la actividad sexual como un medio para dar una imagen deseada dentro del grupo de iguales, impidiendo así el rechazo del adolescente por el grupo social. Estos dos últimos factores pertenecen al grupo de motivaciones de evitación o negativas y centradas en los demás, puesto que buscan evitar castigos impuestos por su entorno social.

Los valores de alfa de Cronbach de las subescalas de motivos sexuales en nuestro estudio son las siguientes: Motivación de placer, con 5 ítems: .85; Motivación de intimidad, con 5 ítems: .83; Motivación de autorregulación emocional, con 9 ítems: .89; Motivación para evitar el rechazo de la pareja, con 4 ítems: .87 y la Motivación para evitar el rechazo de los amigos: .91. Podemos por tanto decir, que nuestra adaptación del cuestionario tiene una alta fiabilidad.

La motivación que más importancia ha tenido para los adolescentes a la hora de tener actividad sexual es la motivación de intimidad, con una puntuación media de 4 , es decir, una motivación considerada "muy importante". La segunda en puntuación era la motivación de placer con 3,5 puntos, la tercera era la motivación de autorregulación emocional con un puntuación de 2,3, seguida de la motivación para evitar el rechazo de la pareja con 1,9 y por último la motivación para evitar el rechazo de los amigos con 1,6 puntos. Estas dos últimas consideradas por lo tanto "poco importantes".

En cuanto a la edad, solo tenía una relación significativa con la motivación de placer, pero esta desaparecía cuando se controlaba la experiencia sexual. La edad no tenía efecto pues sobre ninguna motivación sexual. 


\subsubsection{Diferencias en motivaciones sexuales en función del sexo y la experiencia sexual y} $\underline{\text { relacional de los adolescentes }}$

Para ver la relación que existía entre las motivaciones sexuales, la experiencia sexual y relacional y el sexo, hicimos un ANOVA de 5 (motivaciones sexuales) x 2 (nivel de experiencia sexual) x 3 (experiencia relacional) x 2 (sexo) con medidas repetidas en el primer factor.

Este análisis nos permitiría en primer lugar saber si hay diferencias significativas en la importancia que han tenido las diferentes motivaciones sexuales en la vida sexual de los adolescentes. La variable experiencia sexual la hicimos dicotómica utilizando la mediana como punto de corte. Esto daba lugar a una variable con dos niveles, que podíamos introducir en el análisis como factor inter-sujetos y utilizar para comprobar si había diferencias en las motivaciones sexuales en función del nivel de experiencia sexual: adolescentes con experiencia sexual alta y con experiencia sexual baja. La variable experiencia relacional la construimos dividiendo a los adolescentes en tres grupos: 1) aquellos que sólo habían tenido la experiencia de relación de pareja, 2) aquellos que sólo habían tenido la experiencia de relaciones esporádicas y 3) aquellos que habían tenido las dos experiencias. Así comprobaríamos si había diferencias en las motivaciones sexuales de los adolescentes en función de su experiencia relacional. Por último examinaríamos si hay diferencias en las motivaciones sexuales adolescentes en función del sexo.

El efecto principal del tipo de motivación resultó significativo $[\mathrm{F}(4,365)=266,414, \mathrm{p}=.000$, $\eta 2=.74]$. En las comparaciones por pares vimos que había diferencias significativas entre todas las motivaciones sexuales. Así pues podemos concluir que las motivaciones de intimidad con la pareja y placer sexual, motivaciones positivas, son significativamente más importantes para los adolescentes a la hora de tener actividad sexual, que el resto de motivaciones de evitación de consecuencias negativas (véase Tabla 40). 
Tabla 40. Estadísticos descriptivos en importancia concedida a tipos de motivación sexual

\begin{tabular}{lccc}
\hline Tipo de motivación sexual & $\mathrm{N}$ & Media & Desviación Típica \\
\hline Motivación de placer & 380 & 3.49 & 0.78 \\
Motivación de intimidad & 380 & 4.00 & 0.69 \\
Motivación de autorregulación e. & 380 & 2.37 & 0.83 \\
Motivación a evitar rechazo pareja & 380 & 1.99 & 0.94 \\
Motivación a evitar rechazo amigos & 380 & 1.61 & 0.80 \\
\hline
\end{tabular}

El efecto principal del sexo no tuvo un efecto significativo en las motivaciones sexuales [F (1, $368)=3,858, \mathrm{p}=.050]$, y tampoco el efecto de la interacción entre sexo y el tipo de motivación sexual fue significativo $[\mathrm{F}(4,365)=1,710, \mathrm{p}=.147]$, por lo que concluimos que no hay diferencias significativas entre los sexos en motivaciones sexuales. El efecto principal del nivel de experiencia sexual $[\mathrm{F}(1,368)=1,114, \mathrm{p}=.292]$ y de la experiencia relacional $[\mathrm{F}(2,368)=$ $0,931, \mathrm{p}=.395$ ] tampoco fueron significativos. Sin embargo estas conclusiones hay que matizarlas mediante la interpretación de las interacciones de la experiencia sexual y relacional y el tipo de motivación sexual.

El efecto de la interacción entre los tipos de motivación sexual y el nivel de experiencia sexual resultó significativo $[\mathrm{F}(4,365)=6,978, \mathrm{p}=.000, \eta 2=.07]$. En los contrastes a posteriori vimos que había diferencias significativas en la motivación de placer e intimidad ( $\mathrm{p}=.006$ y p=.014), a favor de los que tenían una experiencia sexual alta y que había diferencias significativas en las motivaciones de evitar el rechazo de pareja y amigos, a favor de los que tenían baja experiencia sexual ( $\mathrm{p}=.001$ y $\mathrm{p}=.010$ ). Concluimos por tanto que aquellos adolescentes que dan más importancia a motivaciones sexuales de aproximación o positivas tienen más experiencia sexual que los que dan menos importancia a estas motivaciones. Por otro lado, los adolescentes que dan más importancia a las motivaciones de evitación del rechazo de los demás, tienen menos experiencia sexual que aquellos que dan menos importancia a estas motivaciones (véase Figura $10)$. 
Figura 10: Motivaciones sexuales de los adolescentes según el nivel de experiencia sexual

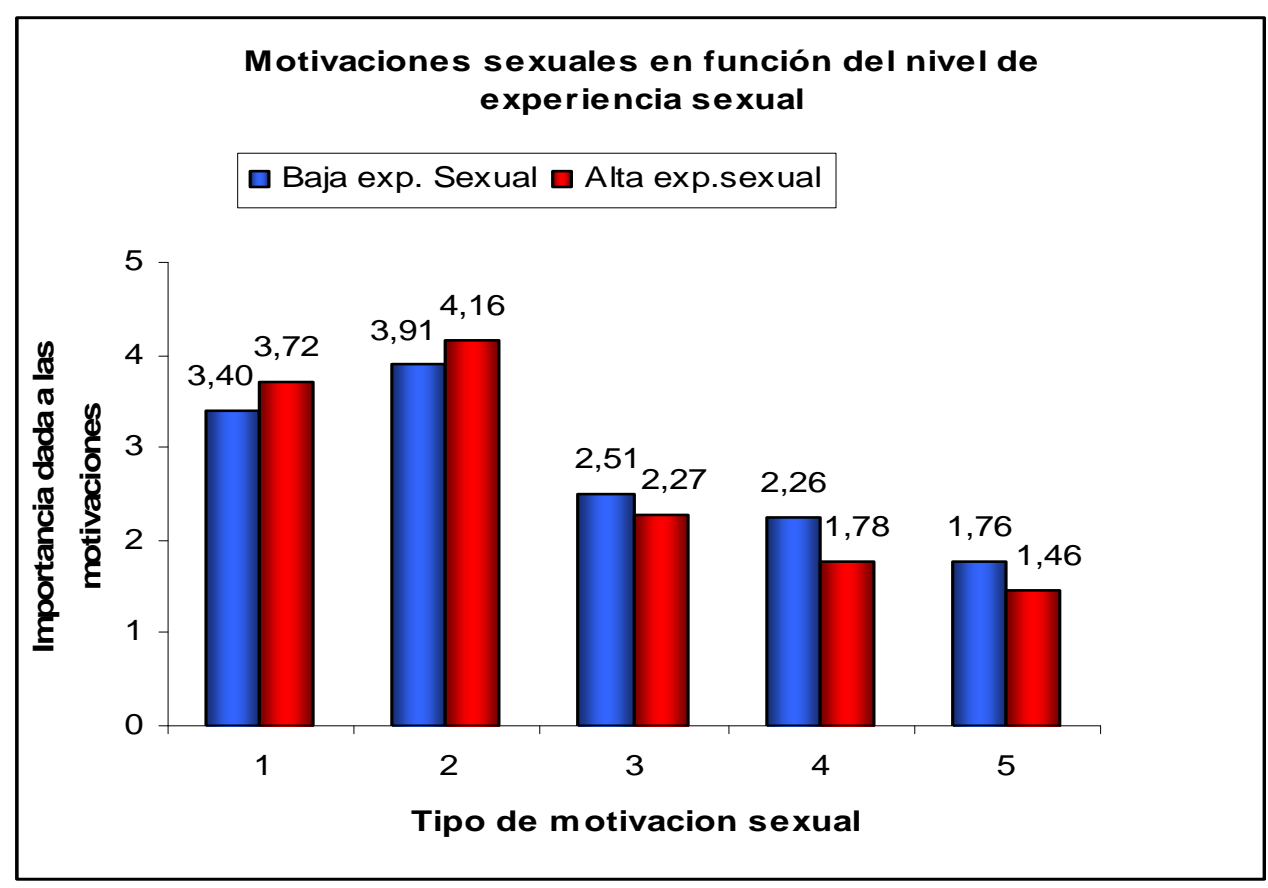

1. Motivación de placer

2. Motivación de intimidad

3. Motivación de autorregulación

4. Motivación de evitar rechazo pareja

5. Motivación de evitar rechazo amigos

También encontramos una interacción significativa entre tipo de motivaciones y experiencia relacional $[\mathrm{F}(8,732)=3,476, \mathrm{p}=.001, \eta 2=.03]$, aunque con un tamaño del efecto pequeño. En los contrastes vimos que había diferencias significativas en la motivación de intimidad a favor de los que habían tenido ambas experiencias o sólo pareja. Estos dos grupos se diferenciaban significativamente de aquellos que sólo tuvieron relaciones esporádicas (que nunca habían tenido pareja), que eran los que tenían puntuaciones más bajas en la motivación sexual de intimidad ( $\mathrm{p}=.006$ ). También había diferencias significativas en la motivación de evitar el rechazo de los amigos, a favor de los que sólo habían tenido relaciones esporádicas. Este grupo se diferenciaba de nuevo de los otros dos; aquellos que sólo habían tenido pareja y los que habían tenido las dos experiencias ( $\mathrm{p}=.002)$. 
Figura 11. Motivaciones sexuales de los adolescentes en función de la experiencia relacional

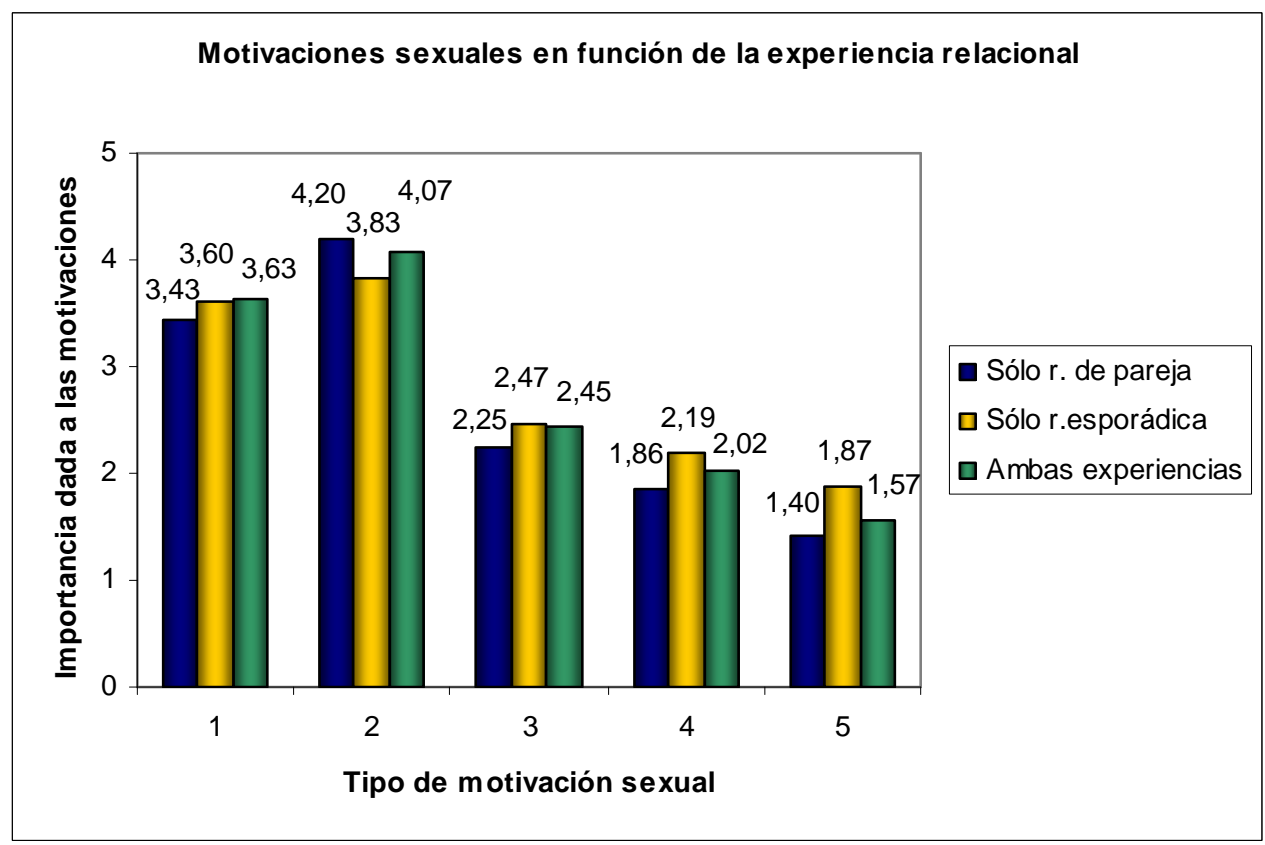

1. Motivación de placer

2. Motivación de intimidad

3. Motivación de autorregulación

4. Motivación de evitar rechazo pareja

5. Motivación de evitar rechazo amigos

Podemos concluir por tanto, que los adolescentes que dan más importancia a la intimidad como motivación sexual, tienen más probabilidades de tener relaciones de pareja que aquellos que dan menos importancia a la motivación de intimidad. Por otro lado, los adolescentes que otorgan más importancia a la aprobación de sus amigos, como motivación sexual tienen menos probabilidades de tener relaciones de pareja estables, que los que dan menos importancia a esta motivación.

Tabla 41. Resumen de efectos significativos del ANOVA (tipo motivación sexual x experiencia sexual x experiencia relacional x sexo).

\begin{tabular}{lcccc}
\hline \multicolumn{5}{c}{ Anova } \\
\multicolumn{1}{c}{ Factores principales / interacciones } & $\mathrm{F}$ & $\mathrm{gl}$ & $\mathrm{p}$ & $\eta 2$ \\
Tipo de motivación sexual & 266,414 & 4,365 & .000 & .74 \\
Tipo de motivación x Experiencia sexual & 6,978 & 4,365 & .000 & .07 \\
Tipo de motivación x Experiencia relacional & 3,476 & 8,732 & .001 & .03 \\
\hline
\end{tabular}




\subsection{Experiencia sexual, motivaciones sexuales y estrategias de avance y limitación sexual}

Hemos realizado análisis de correlación para cada contexto relacional por separado, por un lado para examinar las asociaciones entre las motivaciones sexuales y experiencia sexual y el uso de estrategias sexuales en relaciones de pareja, y por otro para observar estas mismas relaciones para las estrategias empleadas en relaciones casuales. También hemos separado los análisis para chicos y chicas. Vemos los resultados en las Tablas 42 y 43 para el contexto de pareja, y Tablas 44 y 45 para el contexto de relaciones casuales. .

\subsubsection{Experiencia sexual y estrategias de avance y limitación sexual}

En este apartado expondremos qué relaciones significativas existen entre el nivel de experiencia sexual de los adolescentes y el empleo de estrategias de avance y limitación sexual. Para ver si la experiencia sexual influye de manera diferente a chicos y a chicas en la iniciación sexual, realizamos los análisis por separado.

En las Tablas 42 y 43, podemos observar que tanto chicos como chicas aumentan significativamente el empleo de estrategias de avance directas en sus relaciones de pareja, como el avance físico y el verbal, a medida que aumenta su nivel de experiencia sexual. En las chicas la experiencia sexual tiene una correlación muy alta con al avance verbal directo sobre todo, con el avance físico después y finalmente tiene una correlación algo más baja con los gestos de seducción. En los chicos la experiencia sexual se relaciona sobretodo con el al avance físico directo, después con el verbal directo. Así, en las relaciones de pareja, los adolescentes con mayor experiencia sexual serán los que más estrategias de avance sexual directas utilicen, por encima de aquellos menos experimentados.

En las relaciones esporádicas, la experiencia sexual parece tener un papel un poco más diferente para cada sexo, como podemos ver en las Tablas 44 y 45 . En las chicas la experiencia sexual se asocia nuevamente a las estrategias de avance directas sobre todo. También hay una relación inversa, pero leve con la insinuación verbal. En los chicos, la experiencia sexual parece aumentar el uso de casi todas las estrategias de avance sexual en relaciones esporádicas, en este 
orden: avance físico, gestos de seducción, estrategias de presión y avance verbal. Así, en las relaciones esporádicas, las chicas experimentadas utilizarán más estrategias directas, que las no experimentadas, y los varones experimentados, utilizarán además todo tipo de estrategias de iniciación sexual en mayor medida que los no experimentados, sobre todo estrategias físicas y de presión.

En resumen, hemos visto que en las chicas, la experiencia sexual juega un papel similar en ambos contextos, aumentando la frecuencia de la iniciación directa, aunque la intensidad de la asociación en el contexto esporádico es algo más baja que en las relaciones de pareja. La experiencia sexual también parece incrementar los gestos de seducción indirectos en la pareja y disminuir la insinuación verbal indirecta, con una significatividad moderada en este caso, en relaciones casuales.

$\mathrm{Al}$ contrario, en los adolescentes varones, la experiencia sexual tiene más influencia en la iniciación sexual en relaciones casuales que en las relaciones de pareja. La asociación aparece con más tipos de estrategias y con mayor intensidad, aunque en ambos casos la estrategia más potenciada es el avance físico directo.

En cuanto a las estrategias de limitación, solo existe relación entre éstas y la experiencia sexual para la muestra de varones. Vemos en la Tabla 44 que la experiencia sexual se ha mostrado asociada al uso de estrategias de limitación directa en relaciones esporádicas únicamente. La experiencia sexual no parece influir en la medida en la que las chicas utilizan la limitación sexual. Los adolescentes varones con más experiencia sexual emplearán estrategias de limitación directa en sus relaciones esporádicas con más frecuencia que los adolescentes con menos experiencia sexual. 
Tabla 42. Matriz de correlaciones de motivaciones sexuales, experiencia sexual y estrategias sexuales en pareja en muestra masculina

\begin{tabular}{|c|c|c|c|c|c|c|c|c|c|c|c|c|c|c|c|c|c|}
\hline & & 1 & 2 & 3 & 4 & 5 & 6 & 7 & 8 & 9 & 10 & 11 & 12 & 13 & 14 & 15 & 16 \\
\hline 1 & M. de placer & 1 & & & & & & & & & & & & & & & \\
\hline 2 & M. de intimidad & $.361^{* *}$ & 1 & & & & & & & & & & & & & & \\
\hline 3 & M. autorregulación & $.279^{* *}$ & $.161^{*}$ & 1 & & & & & & & & & & & & & \\
\hline 4 & M. evitar rechazo p. & $.161^{*}$ & .077 & $.668^{\star \star}$ & 1 & & & & & & & & & & & & \\
\hline 5 & M. evitar rechazo a. & .124 & -.090 & $.616^{\star *}$ & $.679^{\star *}$ & 1 & & & & & & & & & & & \\
\hline 6 & Experiencia sexual & $.266^{\star *}$ & $.255^{\star *}$ & $-.168^{*}$ & $-.219^{\star \star}$ & $-.201^{* *}$ & 1 & & & & & & & & & & \\
\hline 7 & Avance físico & $.362^{* *}$ & $.293^{\star *}$ & -.025 & -.105 & -.021 & $.487^{\star *}$ & 1 & & & & & & & & & \\
\hline 8 & Gestos de seducción & $.268^{* *}$ & .179 & $.224^{*}$ & .062 & .114 & .148 & $.463^{\star *}$ & 1 & & & & & & & & \\
\hline 9 & Insinuación verbal & .151 & $.321^{* *}$ & $.255^{*}$ & .150 & .177 & -.069 & $.263^{\star *}$ & $.455^{\star *}$ & 1 & & & & & & & \\
\hline 10 & Avance verbal & $.452^{* *}$ & $.273^{\star \star}$ & .006 & -.156 & -.046 & $.274^{\star *}$ & $.467^{\star \star}$ & $.343^{\star *}$ & $.258^{\star *}$ & 1 & & & & & & \\
\hline 11 & E. de presión & $.283^{* *}$ & .050 & $.299^{\star *}$ & $.280^{* *}$ & $.386^{\star \star}$ & .063 & $.224^{*}$ & $.410^{\star *}$ & $.343^{* *}$ & $.288^{\star *}$ & 1 & & & & & \\
\hline 12 & E. de fuerza & -.022 & -.184 & .039 & .030 & .143 & -.066 & -.106 & .088 & -.017 & .062 & $.300^{* *}$ & 1 & & & & \\
\hline 13 & E. limitación directa & .144 & .028 & .043 & .054 & .045 & .092 & .064 & -.086 & -.090 & .069 & -.035 & .099 & 1 & & & \\
\hline 14 & E. limitac. indirecta & .020 & -.077 & $.342^{\star \star}$ & $.381^{* *}$ & $.378^{\star \star}$ & -.148 & -.042 & .049 & .003 & -.144 & .142 & $.234^{*}$ & $.575^{\star *}$ & 1 & & \\
\hline 15 & Uso preservativo & -.201 & -.077 & -.078 & -.081 & -.169 & $-.325^{\star *}$ & $-.361^{\star *}$ & $-.289^{* *}$ & -.036 & -.130 & $-.404^{\star *}$ & -.201 & .103 & .079 & 1 & \\
\hline 16 & Consentimiento sexual & .091 & .127 & $.257^{*}$ & .170 & .137 & -.068 & .190 & .207 & .187 & .105 & $.252^{*}$ & .057 & -.176 & -.129 & -.215 & 1 \\
\hline
\end{tabular}


Tabla 43. Matriz de correlaciones de motivaciones sexuales, experiencia sexual y estrategias sexuales en pareja en muestra femenina

\begin{tabular}{|c|c|c|c|c|c|c|c|c|c|c|c|c|c|c|c|c|c|}
\hline & & 1 & 2 & 3 & 4 & 5 & 6 & 7 & 8 & 9 & 10 & 11 & 12 & 13 & 14 & 15 & 16 \\
\hline 1 & M. de placer & 1 & & & & & & & & & & & & & & & \\
\hline 2 & M. de intimidad & $.454^{\star *}$ & 1 & & & & & & & & & & & & & & \\
\hline 3 & M. autorregulación & $.297^{\star *}$ & $.296^{\star *}$ & 1 & & & & & & & & & & & & & \\
\hline 4 & M. evitar rechazo p. & $.106^{\star *}$ & .104 & $.731^{\star *}$ & 1 & & & & & & & & & & & & \\
\hline 5 & M. evitar rechazo a. & $.058^{* *}$ & -.012 & $.621^{* *}$ & $.769^{* *}$ & 1 & & & & & & & & & & & \\
\hline 6 & Experiencia sexual & $.351^{* *}$ & $.211^{* *}$ & $-.171^{*}$ & $-.256^{* *}$ & $-.260^{* *}$ & 1 & & & & & & & & & & \\
\hline 7 & Avance físico & $.332^{* *}$ & .123 & -.037 & $-.188^{*}$ & -.049 & $.408^{\star \star}$ & 1 & & & & & & & & & \\
\hline 8 & Gestos de seducción & $.352^{\star *}$ & -.002 & -.042 & -.054 & -.007 & $.229^{* \star}$ & $.600^{\star *}$ & 1 & & & & & & & & \\
\hline 9 & Insinuación verbal & .130 & .063 & .051 & .072 & .106 & -.100 & $.354^{* *}$ & $.327^{\star *}$ & 1 & & & & & & & \\
\hline 10 & Avance verbal & $.213^{*}$ & .122 & -.138 & $-.233^{\star *}$ & -.171 & $.529^{\star *}$ & $.377^{\star *}$ & $.283^{\star *}$ & .130 & 1 & & & & & & \\
\hline 11 & E. de presión & $.225^{\star}$ & .120 & $.383^{\star *}$ & $.369^{* *}$ & $.390^{\star *}$ & .022 & .093 & $.202^{*}$ & .151 & .089 & 1 & & & & & \\
\hline 12 & E. de fuerza & .109 & .100 & $.317^{\star \star}$ & $.216^{*}$ & .135 & -.023 & .009 & -.008 & .012 & .014 & .037 & 1 & & & & \\
\hline 13 & E. limitación directa & .039 & -.017 & .079 & -.023 & -.053 & -.166 & -.006 & .217 & .022 & .048 & .127 & .026 & 1 & & & \\
\hline 14 & E. limitac. indirecta & .156 & -.063 & $.198^{\star}$ & .117 & .093 & -.031 & .087 & $.345^{\star *}$ & .056 & -.023 & $.327^{* *}$ & .130 & $.393^{\star \star}$ & 1 & & \\
\hline 15 & Uso preservativo & -.185 & -.039 & .043 & .051 & .093 & $-.318^{\star *}$ & -.045 & -.006 & .097 & -.067 & .037 & -.194 & .120 & .058 & 1 & \\
\hline 16 & Consentimiento sexual & .073 & .105 & .172 & $.189^{\star}$ & .142 & -.050 & .031 & .090 & .075 & .083 & $.245^{\star *}$ & .054 & .125 & $.245^{\star *}$ & -.032 & 1 \\
\hline
\end{tabular}


Tabla 44. Matriz de correlaciones de motivaciones sexuales, experiencia sexual y estrategias sexuales en r. esporádicas en muestra masculina

\begin{tabular}{|c|c|c|c|c|c|c|c|c|c|c|c|c|c|c|c|c|c|}
\hline & & 1 & 2 & 3 & 4 & 5 & 6 & 7 & 8 & 9 & 10 & 11 & 12 & 13 & 14 & 15 & 16 \\
\hline 1 & M. de placer & 1 & & & & & & & & & & & & & & & \\
\hline 2 & M. de intimidad & $.361^{* *}$ & 1 & & & & & & & & & & & & & & \\
\hline 3 & M. autorregulación & $.279^{* *}$ & $.161^{*}$ & 1 & & & & & & & & & & & & & \\
\hline 4 & M. evitar rechazo p. & $.161^{*}$ & .077 & $.668^{\star *}$ & 1 & & & & & & & & & & & & \\
\hline 5 & M. evitar rechazo a. & .124 & -.090 & $.616^{*}$ & $.679^{* *}$ & 1 & & & & & & & & & & & \\
\hline 6 & Experiencia sexual & $.266^{* *}$ & $.255^{* *}$ & $-.168^{*}$ & $-.219^{* *}$ & -.210 & 1 & & & & & & & & & & \\
\hline 7 & Avance físico & $.390^{\star *}$ & $.250^{* *}$ & .107 & .054 & .046 & $.563^{* *}$ & 1 & & & & & & & & & \\
\hline 8 & Gestos de seducción & $.304^{\star *}$ & $.217^{\star *}$ & $.255^{\star *}$ & $.189^{*}$ & .108 & $.329^{* *}$ & $.536^{\star *}$ & 1 & & & & & & & & \\
\hline 9 & Insinuación verbal & $.161^{*}$ & $.186^{*}$ & $.267^{\star *}$ & $.210^{\star *}$ & .148 & .104 & $.303^{*}$ & $.449^{* *}$ & 1 & & & & & & & \\
\hline 10 & Avance verbal & $.272^{* *}$ & $.191^{*}$ & .121 & .045 & .026 & $.226^{* *}$ & $.398^{\star *}$ & $.291^{* *}$ & $.358^{*}$ & 1 & & & & & & \\
\hline 11 & E. de presión & $.173^{*}$ & $.159^{*}$ & $.176^{*}$ & $.194^{*}$ & $.195^{\star}$ & $.251^{* *}$ & $.390^{* *}$ & $.358^{* *}$ & $.374^{\star *}$ & $.478^{* *}$ & 1 & & & & & \\
\hline 12 & E. de fuerza & .135 & .041 & .117 & .128 & $.163^{*}$ & .117 & .142 & $.190^{*}$ & $.180^{*}$ & $.216^{* *}$ & $.527^{\star *}$ & 1 & & & & \\
\hline 13 & E. limitación directa & -.066 & .096 & -.075 & -.111 & -.197 & $.203^{* *}$ & .066 & .094 & $.161^{*}$ & $.213^{* *}$ & $.240^{* *}$ & $.199^{*}$ & 1 & & & \\
\hline 14 & E. limitac. indirecta & -.006 & .067 & .145 & .105 & .084 & .052 & .016 & $.212^{\star *}$ & $.241^{* *}$ & .153 & $.344^{* *}$ & $.395^{\star *}$ & $.593^{\star *}$ & 1 & & \\
\hline 15 & Uso preservativo & .080 & .042 & -.155 & -.057 & -.105 & $.338^{* *}$ & .118 & .049 & .001 & .065 & -.118 & -.134 & -.173 & -.104 & 1 & \\
\hline 16 & Consentimiento sexual & $.272^{\star *}$ & .149 & .159 & .155 & .112 & $.162^{*}$ & $.305^{\star *}$ & $.293^{\star *}$ & $.175^{\star}$ & .155 & $.318^{* *}$ & $.189^{*}$ & $-.166^{*}$ & -.084 & -.015 & 1 \\
\hline
\end{tabular}


Tabla 45. Matriz de correlaciones de motivaciones sexuales, experiencia sexual y estrategias sexuales en r. esporádicas en muestra femenina

\begin{tabular}{|c|c|c|c|c|c|c|c|c|c|c|c|c|c|c|c|c|c|}
\hline & & 1 & 2 & 3 & 4 & 5 & 6 & 7 & 8 & 9 & 10 & 11 & 12 & 13 & 14 & 15 & 16 \\
\hline 1 & M. de placer & 1 & & & & & & & & & & & & & & & \\
\hline 2 & M. de intimidad & $.454^{* *}$ & 1 & & & & & & & & & & & & & & \\
\hline 3 & M. autorregulación & $.297^{\star *}$ & $.296^{* *}$ & 1 & & & & & & & & & & & & & \\
\hline 4 & M. evitar rechazo p. & .106 & .104 & $.731^{\star *}$ & 1 & & & & & & & & & & & & \\
\hline 5 & M. evitar rechazo a. & .058 & -.012 & $.621^{\star *}$ & $.769^{* *}$ & 1 & & & & & & & & & & & \\
\hline 6 & Experiencia sexual & $.351^{* *}$ & $.211^{* *}$ & $-.171^{*}$ & $-.256^{\star *}$ & $-.260^{* *}$ & 1 & & & & & & & & & & \\
\hline 7 & Avance físico & $.313^{* *}$ & .093 & .022 & -.010 & .017 & $.322^{* *}$ & 1 & & & & & & & & & \\
\hline 8 & Gestos de seducción & $.339^{\star *}$ & .059 & .067 & .036 & .039 & .154 & $.579^{\star *}$ & 1 & & & & & & & & \\
\hline 9 & Insinuación verbal & .088 & .034 & $.266^{\star *}$ & $.248^{* *}$ & $.296^{* \star}$ &.$-184^{*}$ & $.407^{* *}$ & $.324^{* *}$ & 1 & & & & & & & \\
\hline 10 & Avance verbal & .136 & .031 & .046 & .024 & .094 & $.318^{* *}$ & $.324^{* *}$ & $.184^{*}$ & .147 & 1 & & & & & & \\
\hline 11 & E. de presión & .110 & .129 & $.181^{*}$ & $.189^{*}$ & $.194^{*}$ & .023 & $.217^{\star *}$ & .136 & .015 & $.228^{* *}$ & 1 & & & & & \\
\hline 12 & E. de fuerza & -.010 & -.087 & $.173^{\star}$ & $.193^{*}$ & $.219^{\star *}$ & -.121 & -.110 & -.077 & -.011 & $.161^{*}$ & $.230^{* *}$ & 1 & & & & \\
\hline 13 & E. limitación directa & .150 & .084 & -.113 & -.141 & -.106 & .146 & .182 & $.205^{\star}$ & .087 & .098 & $.212^{* *}$ & .060 & 1 & & & \\
\hline 14 & E. limitac. indirecta & .132 & .064 & $.253^{\star *}$ & $.264^{\star *}$ & $.192^{*}$ & .103 & $.175^{*}$ & $.219^{\star *}$ & .151 & $.182^{*}$ & $.420^{\star *}$ & .151 & $.466^{\star *}$ & 1 & & \\
\hline 15 & Uso preservativo & -.116 & $-.273^{*}$ & -.116 & -.009 & .051 & $-.280^{*}$ & -.182 & -.176 & .100 & -.087 & .107 & .097 & .145 & .157 & 1 & \\
\hline 16 & Consentimiento sexual & .128 & .066 & -.148 & .166 & .054 & -.032 & .164 & .070 & .046 & -.004 & .158 & .043 & -.163 & .013 & .047 & 1 \\
\hline
\end{tabular}




\subsubsection{Motivaciones sexuales y estrategias de avance y limitación sexual}

Estrategias de avance sexual en contexto de pareja (Tablas 42 y 43)

La motivación de placer, correlaciona positivamente y en ambos sexos, con las estrategias de carácter físico: el avance físico y los gestos de seducción. Aunque en ambos sexos la motivación de placer también correlaciona con el avance verbal directo y las estrategias de presión, solo en los chicos lo hace con un nivel de significación substancial $(\mathrm{p}<.01)$. Así, concluimos que los adolescentes con una motivación de placer más importante inician actividad sexual con su pareja, a través de estrategias de contacto físico en mayor medida que aquellos con una motivación de placer menos importante. Los adolescentes varones que dan más importancia a la motivación de placer también utilizan más frecuentemente estrategias verbales directas y la presión para mantener actividad sexual, que aquellos que otorgan menos importancia a esta motivación.

La motivación de intimidad solo ha mostrado relación en la muestra de chicos con las estrategias directas, tanto el avance físico como el avance verbal y con la insinuación verbal indirecta. En la muestra de chicas no correlacionaba con ningún tipo de estrategia sexual. Concluimos por lo tanto, que los adolescentes varones para los que más importancia ha tenido la motivación de intimidad en su actividad sexual, han utilizado con mayor frecuencia las estrategias directas y verbales para iniciar encuentros sexuales con su pareja.

La motivación de autorregulación emocional se relaciona de manera positiva con el uso de estrategias de presión en pareja, en ambos sexos. Sólo en el caso de las chicas, esta motivación se relacionaba también con las estrategias de fuerza. Los adolescentes para los que más importancia ha tenido la autorregulación emocional como motivación sexual, tienen más probabilidad de utilizar estrategias de avance sexual basadas en la presión, que aquellos para los que esta motivación es menos importante. Las chicas que dan mucha importancia a la autorregulación emocional también tienen más probabilidad de utilizar estrategias de fuerza que aquellas con menor motivación de autorregulación. 
La motivación para evitar el rechazo de la pareja se relaciona de forma positiva con las estrategias de presión en ambos sexos y sólo en las chicas mantiene una relación inversa con las estrategias de avance directas, sobre todo con el avance verbal. Los adolescentes para los que más importancia tiene evitar el castigo por parte de la pareja, tienden a utilizar más las estrategias de presión que aquellos para los que esta motivación tiene menos importancia. Además las chicas que dan más importancia a este motivo a la hora de tener actividad sexual utilizan menos las estrategias directas, sobre todo, utilizan menos el avance verbal directo, que aquellas para las que evitar el castigo de la pareja tiene menos importancia.

Por último, la motivación para evitar el rechazo de los amigos ha mostrado también una asociación directa con las estrategias de presión en ambos sexos. Concluimos que aquellos adolescentes para los que más importancia tiene el evitar el rechazo de los pares utilizan más estrategias de presión para iniciar actividad sexual que aquellos que dan menos importancia a este motivo.

Resumiendo, en las relaciones de pareja, hemos visto que la motivación de placer tiende a relacionarse positivamente con casi todas las estrategias, incluidas las estrategias de presión. En chicos las asociaciones son más intensas que en las chicas, sobretodo con las estrategias directas, mientras que en las chicas sólo las estrategias de contacto físico muestran un incremento substancial en relación con la motivación de placer. La motivación de intimidad se asocia con las estrategias de carácter verbal y directo, aunque solo en la muestra de chicos. Las motivaciones negativas o de evitación llevan a un mayor uso de estrategias coercitivas de presión, y a un menor uso de estrategias directas también en ellas, en concreto para la motivación de búsqueda de aprobación de la pareja.

Estrategias de avance sexual en contexto de relaciones esporádicas (Tablas 44 y 45)

La motivación de placer tiene una relación significativa positiva con las estrategias físicas en ambos sexos: avance físico y gestos de seducción. En el caso de los chicos también correlaciona de manera alta con el avance verbal directo, además de con la insinuación verbal y las estrategias de presión, aunque en estos dos últimos casos la correlación es significativa a un nivel más bajo $(\mathrm{p}<.05)$. Aquellos adolescentes para los que más importancia ha tenido la motivación de placer, utilizan más estrategias de iniciación sexual de tipo físico en sus 
relaciones esporádicas, que aquellos para los que esta motivación ha tenido menos importancia. Los adolescentes varones con alta motivación de placer además tienen más probabilidades de utilizar también más estrategias verbales y de presión que aquellos con baja motivación de placer.

La motivación de intimidad solo parece relacionarse con el uso de estrategias sexuales en la muestra masculina nuevamente. Así, la motivación de intimidad en los chicos se asocia positivamente con todas las estrategias de avance sexual (excepto las de fuerza) y de manera muy significativa con las estrategias físicas: avance físico y gestos de seducción. Luego cuando la motivación de intimidad es importante en la vida sexual de los adolescentes varones, estos tienden a utilizar más a menudo todas las estrategias de avance, sobretodo las de contacto físico, en sus relaciones esporádicas, que aquellos para los que esta motivación no es tan importante.

La motivación de autorregulación emocional ha mostrado una asociación alta y directa con el uso de la insinuación verbal indirecta y un poco más leve con las estrategias de presión en ambos sexos. Además en el caso de los chicos se asocia también a los gestos de seducción y en el caso de las chicas se asocia también a las estrategias de fuerza aunque de una manera más leve. Así, concluimos que, aquellos varones para los que la autorregulación emocional es importante como motivo sexual utilizan más frecuentemente las estrategias de iniciación indirectas y las de presión, que aquellos para los que este motivo no es tan importante. Por otra parte aquellas adolescentes cuyas motivaciones de autorregulación son importantes en sus encuentros sexuales, tienden a emplear más la insinuación verbal y las estrategias coercitivas (aunque estas últimas con una intensidad de asociación más leve) que aquellas adolescentes para las que la autorregulación emocional no es importante como motivación sexual.

La motivación para evitar el rechazo de la pareja se relaciona con las estrategias sexuales de manera muy parecida a la motivación de autorregulación emocional. En ambos sexos se relaciona positiva y con alta significación, con la insinuación verbal en las relaciones esporádicas. En ambos sexos también se relaciona leve aunque significativamente con las estrategias de presión. En los chicos se asocia además levemente con los gestos de seducción y en las chicas con las estrategias de fuerza. Así los adolescentes chicos altamente motivados a evitar el castigo de la pareja, usarán más frecuentemente estrategias indirectas y de presión que los que no están motivados por esta razón. Las adolescentes chicas muy motivadas a evitar el castigo de la pareja, usarán en mayor medida la insinuación verbal y la coerción en sus encuentros esporádicos, que aquellas para las que esta motivación no es muy importante. 
La motivación sexual para evitar el rechazo de los amigos ha mostrado igualmente una asociación positiva con las estrategias coercitivas en ambos sexos, aunque solo la asociación con las estrategias de fuerza en las chicas es altamente significativa. También se asocia solo en la muestra femenina con la insinuación verbal de manera intensa y positiva. Nuevamente los adolescentes motivados por la reacción de sus iguales para iniciar encuentros sexuales esporádicos, tienden a utilizar en mayor medida las estrategias coercitivas e indirectas, que aquellos adolescentes que dan menos importancia a este motivo.

Resumiendo, en las relaciones esporádicas, hemos visto que las motivaciones sexuales positivas, como el placer y la intimidad, llevan a un mayor uso de estrategias sexuales de casi todo tipo en los varones, sobre todo físicas y directas. La motivación de placer en las chicas lleva a una mayor utilización de las estrategias físicas, como sucedía en las relaciones de pareja. Las motivaciones negativas o de evitación, parece que llevan a ambos sexos a emplear con más frecuencia estrategias de iniciación indirectas, sobretodo de insinuación verbal, y estrategias coercitivas de presión, aunque con menor significación.

La asociación entre las motivaciones sexuales y las estrategias de iniciación sexual es similar en los dos contextos relacionales. Sin embargo hay algunas diferencias: en las chicas, la motivación de placer influye más en el uso de estrategias sexuales en contextos de pareja que en contextos esporádicos. La influencia de las motivaciones sexuales en general, es más alta a la hora de utilizar estrategias de avance verbal directo o estrategias de presión en relaciones de pareja que en relaciones esporádicas. Por el contrario, las motivaciones sexuales se han visto más determinantes del uso de estrategias indirectas en relaciones ocasionales frente a las relaciones de pareja.

En cuanto a las diferencias por sexos, la más importante es que la motivación de intimidad sólo se ha visto asociada al uso de estrategias sexuales en la muestra masculina, mientras que parecía no jugar ningún papel el la iniciación sexual de las chicas. 


\section{Estrategias de limitación sexual}

Para comprobar si existía alguna relación entre las motivaciones sexuales y el uso de estrategias de limitación sexual, es decir, si los motivos por los que los adolescentes mantienen relaciones sexuales se relacionan de forma significativa con la manera de limitar la actividad sexual cuando no se desea, hicimos análisis de correlación con cada sexo por separado y de manera conjunta, entre las motivaciones sexuales y el uso de estrategias de limitación sexual en los dos contextos relacionales. En la Tabla 42 y 43 se pueden ver los resultados sobre estrategias de limitación en relaciones de pareja y en las Tablas 44 y 45, las correlaciones con las estrategias de limitación en relaciones esporádicas.

En el análisis de correlación, pudimos comprobar que en el caso de los chicos, las motivaciones sexuales negativas sólo tenían relación significativa y positiva con las estrategias indirectas usadas en relaciones de pareja, mientras que en las chicas estas motivaciones se relacionaban con el uso de estrategias indirectas en relaciones esporádicas únicamente.

Así que resumiendo, los adolescentes varones para quienes son importantes las motivaciones sexuales de evitación, como la autorregulación emocional o el evitar castigos sociales, tienden a utilizar más frecuentemente estrategias de limitación indirectas en las relaciones de pareja, que aquellos para los que estas motivaciones son menos importantes. En el caso de las chicas, aquellas más motivadas por la evitación de estados negativos o castigos sociales a la hora de tener actividad sexual serán las que más estrategias indirectas utilicen para limitar la actividad sexual en relaciones esporádicas. 


\section{PRÁCTICAS DE NEGOCIACIÓN SEXUAL RELACIONADAS CON EL RIESGO, Y SU RELACIÓN CON ESTRATEGIAS Y MOTIVACIONES SEXUALES.}

Dentro de estas conductas relacionadas con el riesgo, nos interesa fundamentalmente explorar el uso de la coerción sexual tanto en contextos de pareja como en contextos esporádicos, el uso del preservativo y el consentimiento que dan los adolescentes ante actividad sexual cuando no lo desean.

En primer lugar, analizaremos estas conductas desde un punto de vista descriptivo, atendiendo a la frecuencia con que se dan en cada contexto y a si existen diferencias en función del sexo o la edad. En segundo lugar se analizarán qué relaciones existen entre estas variables sexuales y el uso de estrategias sexuales, tanto de avance como de limitación sexual. En tercer lugar exploraremos las relaciones entre estas prácticas asociadas al riesgo, y las motivaciones y experiencia sexual. Los análisis se llevarán a cabo por separado para chicos y chicas y para cada contexto relacional.

\subsection{Uso de la coerción sexual}

Uso de la coerción sexual en relaciones de pareja

En primer lugar expondremos la prevalencia de la coerción sexual a través del porcentaje de adolescentes que alguna vez han utilizado alguna táctica de coerción sexual en sus relaciones de pareja, ya sea de presión o de fuerza. El porcentaje de adolescentes varones que al menos una vez ha utilizado alguna táctica de presión sexual con sus parejas es de 67,3\% frente a un 36,4\%, casi la mitad, en la muestra femenina. La puntuación media de utilización de las estrategias de presión es de 1,50 y la desviación típica es 0,58, lo que quiere decir que los adolescentes varones han utilizado la presión sexual una media de algo menos de una vez para iniciar encuentros sexuales, mientras que las chicas han empleado la presión sexual una media de 1,17 con 0,32 de desviación típica, lo que sitúa la frecuencia media de utilización de la presión sexual ligeramente por encima del "nunca" a la hora de iniciar actividad sexual. En cuanto a estrategias de avance basadas en la fuerza, contamos con un $3 \%$ y un $3,9 \%$ de chicos y chicas 
respectivamente que han utilizado alguna vez este tipo de tácticas con sus parejas. Vemos que el porcentaje de adolescentes que emplea las estrategias sexuales de fuerza es marginal, por lo que no evaluaremos su relación con las demás variables, ya que no se podrían considerar resultados representativos.

Las tácticas de presión más utilizadas en pareja por los chicos son "Intentar convencer con argumentos o negociar para tener actividad sexual" e "Invitar o hacer un regalo o favor para tener actividad sexual". Las tácticas de presión sexual más utilizadas por las chicas en pareja son "Intentar convencer con argumentos o negociar para tener actividad sexual" y "Presionar a tu pareja para tener actividad sexual (insistir mucho, deuda, chantaje)”.

En cuanto a la relación de la presión sexual con el uso de otro tipo de estrategias de avance sexual, vemos en la Tabla de correlaciones 42 en la muestra masculina, que se relaciona positivamente con el uso de todos los tipos de estrategias, sobre todo con el uso de estrategias indirectas en relaciones de pareja, aunque también con las estrategias de fuerza y el avance verbal directo. Con el uso del avance físico directo la correlación es de significación moderada. En la Tabla 43, vemos que en la muestra femenina, el uso de la presión en pareja sólo se asocia levemente al uso de gestos de seducción. Así, concluimos que los adolescentes varones que más utilizan la presión para iniciar encuentros sexuales con sus parejas utilizan también más el resto de estrategias de avance sexual, sobre todo estrategias indirectas.

Las estrategias de limitación sexual indirectas se asociaban positivamente al uso de la presión sexual en las chicas, aunque no existen relaciones significativas en varones.

Con relación a las motivaciones sexuales, en ambos sexos el uso de la presión en pareja se asocia positivamente con la importancia que para los adolescentes tienen las motivaciones sexuales de evitación y la motivación de placer, aunque la asociación con esta última motivación en las chicas es moderada. Concluimos que el empleo de la presión sexual se asocia positivamente a todas las motivaciones sexuales, exceptuando la intimidad, mientras que no tiene relación alguna con la experiencia sexual de los adolescentes. No hay en cambio correlación entre el nivel de experiencia sexual y el empleo de estrategias de presión sexual (véase Tabla 42 y 43 ). 
Uso de la coerción sexual en relaciones esporádicas

El porcentaje de adolescentes varones que alguna vez ha utilizado alguna táctica de presión sexual en sus relaciones esporádicas es de $61,3 \%$ frente a un $32,7 \%$, de nuevo la mitad, en la muestra femenina. La puntuación media de utilización masculina de las estrategias de presión en relaciones esporádicas es de 1,48 y la desviación típica es 0,70 y las chicas han empleado la presión sexual una media de 1,18 con 0,36 de desviación típica, una frecuencia media prácticamente igual a la de las relaciones de pareja. Vemos que tal y como apuntaban los resultados del punto 2.1., no hay apenas diferencias en el uso de estrategias de presión en función del contexto relacional, aunque sí en función del sexo. La edad no se ha asociado de manera significativa al uso de la presión sexual en ningún contexto relacional. En cuanto a estrategias de avance basadas en la fuerza, contamos con un 5,3\% y un 4,4\% de chicos y chicas respectivamente, que han utilizado alguna vez este tipo de tácticas en sus relaciones esporádicas, porcentajes nuevamente marginales de la muestra.

Las tácticas de presión más utilizadas en relaciones esporádicas por los varones son, al igual que en relaciones de pareja, "Intentar convencer con argumentos o negociar para tener actividad sexual" e "Invitar o hacer un regalo o favor para tener actividad sexual". Las tácticas de presión sexual más utilizadas por las chicas son "Emborrachar o aprovecharse de la borrachera de la otra persona para tener actividad sexual" e "Intentar convencer con argumentos o negociar para tener actividad sexual".

El uso de estrategias de presión sexual en varones en relaciones esporádicas correlaciona positivamente con el resto de estrategias de avance, como vemos en la Tabla 44, especialmente con estrategias de fuerza y con el avance verbal directo. En la muestra femenina vemos en la Tabla 45, que el uso de la presión se asocia positivamente a estrategias directas y al uso de la fuerza física. Concluimos que los adolescentes que mayor uso hacen de estrategias de presión en relaciones esporádicas son los que más utilizan también estrategias de fuerza y directas sobre todo, aunque en los varones se asocia con todo tipo de estrategias de avance sexual.

En ambos sexos, la presión sexual se ha visto asociada al empleo de la limitación sexual en relaciones esporádicas, más significativamente a la limitación de tipo indirecto. Así los adolescentes que más usan la presión como iniciación sexual, limitan también más 
frecuentemente los avances sexuales de otros sobre todo a través de estrategias de limitación indirectas.

En cuanto a las motivaciones sexuales, en la muestra masculina el uso de presión se asocia moderadamente a todas las motivaciones sexuales y en la femenina sólo a motivaciones de evitación y también moderadamente. El uso de la presión en relaciones casuales se asocia positivamente a la experiencia sexual unicamente en varones.

Resumiendo, en cualquiera de los dos contextos relacionales estudiados aquí, tenemos a dos tercios de chicos y a un tercio de chicas que alguna vez ha utilizado la presión para conseguir relaciones sexuales. En ambos contextos relacionales se ve asociado el uso de la presión sexual por parte de los varones con el uso de los demás tipos de estrategias de avance, aunque en el contexto de pareja más intensamente. En las chicas hay alguna diferencia entre contextos, puesto que en relaciones de pareja se ve asociado levemente a gestos de seducción, mientras que en relaciones esporádicas, las que utilizan la presión utilizan más también estrategias directas y de fuerza. Los adolescentes que más utilizan la presión en relaciones esporádicas utilizan también más estrategias de limitación sexual, pero esto no ocurre en relaciones de pareja. Por último, casi todas las motivaciones sexuales se asocian al uso de la presión por parte de los varones en ambos contextos, y en las chicas son sobre todo motivaciones sexuales de evitación.

\subsection{Uso del Preservativo}

Uso del preservativo en relaciones de pareja

En primer lugar expondremos la frecuencia en porcentaje de utilización del preservativo para las relaciones coitales en contextos de pareja por parte de los adolescentes. El porcentaje de jóvenes que utilizan el preservativo siempre es de $71 \%$, un porcentaje bastante alto. Aún así, hay un $12 \%$ de adolescentes que utilizó el preservativo en la mitad o menos de la mitad de las veces (véase Tabla 46). La media de utilización del preservativo se sitúa en 4,49 y la desviación típica es 0,96 . Es decir en general, los adolescentes utilizan el preservativo en la casi totalidad de sus relaciones sexuales en pareja. 
Tabla 46. Porcentajes de frecuencia de uso del preservativo en relaciones de pareja

\begin{tabular}{lccc}
\hline Frecuencia uso preservativo pareja & $\mathrm{N}$ & Porcentaje & Porcentaje acumulado \\
\hline Nunca & 4 & 2.2 & 2.2 \\
La minoría de las veces & 10 & 5.5 & 7.7 \\
La mitad de las veces & 8 & 4.4 & 12.0 \\
La mayoría de las veces & 31 & 16.9 & 29.0 \\
Siempre & 130 & 71.0 & 100.0 \\
\hline
\end{tabular}

En segundo lugar llevamos a cabo análisis correlacionales con el propósito de saber si el uso del preservativo se relacionaba de alguna manera con la frecuencia de utilización y el tipo de estrategias sexuales y si se relacionaba de manera diferente para chicos y chicas (véase Tablas 42 y 43). Vimos que en la muestra de chicos, había una relación significativa e inversa con las estrategias de presión y con las estrategias de avance físicas: avance físico y gestos de seducción en las relaciones de pareja. En la muestra de chicas no había relación con las estrategias de avance. Concluimos, que los adolescentes varones que inician actividad con sus parejas a través de estrategias de presión y de contacto físico con más frecuencia, utilizan en menor medida el preservativo, que aquellos que utilizan menos este tipo de avance sexual en sus relaciones de pareja.

Las estrategias de limitación sexual no se relacionaban significativamente con el uso del preservativo en pareja.

La utilización del preservativo, si estaba en cambio relacionada significativamente y también de manera inversa con la experiencia sexual en chicos y chicas, así como con otras medidas de experiencia relacional, ya que en las chicas el uso del preservativo se asociaba negativamente con la duración de la relación de pareja. Así, aquellos adolescentes con mayor experiencia sexual (y relacional en el caso de las chicas) usarán menos el preservativo en sus relaciones de pareja que aquellos con menos experiencia.

Por último, las correlaciones entre el uso del preservativo en pareja y las motivaciones sexuales para chicos y chicas por separado no llegan a ser significativas. Concluimos entonces que las motivaciones sexuales de los adolescentes no parecen determinar el uso del preservativo en relaciones de pareja. 


\section{Uso del preservativo en relaciones esporádicas}

Igual que en las relaciones de pareja, se ofrece una relación de los porcentajes de utilización del preservativo en relaciones esporádicas. Vemos que las cifras son muy similares al otro contexto. El 78\% de los adolescentes utiliza en preservativo en todas sus relaciones sexuales, y el $11 \%$ lo utiliza en la mitad o menos de la mitad de las veces que tienen relaciones sexuales (véase Tabla 47). En este caso el número de adolescentes que ha decidido contestar a esta pregunta es de 173 adolescentes de los 328 que manifiestan haber tenido relaciones esporádicas. Es posible que muchos de ellos no llegasen a tener relaciones coitales, y que por tanto no contestasen a esta pregunta. La media de utilización del preservativo se sitúa en 4,56 y la desviación típica es 1,00. Es decir en general, los adolescentes utilizan el preservativo en la casi totalidad de sus relaciones sexuales en contextos esporádicos.

Tabla 47. Porcentajes de frecuencia de uso del preservativo en relaciones esporádicas.

\begin{tabular}{lccc}
\hline Frecuencia uso preservativo casual & $\mathrm{N}$ & Porcentaje & Porcentaje acumulado \\
\hline Nunca & 8 & 4.6 & 4.6 \\
La minoría de las veces & 3 & 1.7 & 6.4 \\
La mitad de las veces & 8 & 4.6 & 11.0 \\
La mayoría de las veces & 19 & 11.0 & 22.0 \\
Siempre & 135 & 78.0 & 100.0 \\
\hline
\end{tabular}

Para conocer si el uso del preservativo en relaciones esporádicas se relacionaba en alguna manera con la forma de iniciar actividad sexual de los adolescentes, llevamos a cabo un análisis correlacional para cada sexo por separado (véase Tablas 44 y 45). El resultado es que en ninguno de los dos sexos existían relaciones significativas entre el uso del preservativo y el uso de estrategias de avance sexual en relaciones esporádicas. Las estrategias de limitación sexual tampoco se relacionaban significativamente con el uso del preservativo en relaciones ocasionales.

La relación del uso del preservativo en relaciones esporádicas con la experiencia sexual resulto significativa tanto para chicos como para chicas. Sin embargo, mientras que la relación se mostraba directa para los varones, era inversa para las mujeres. Parece que a diferencia de lo que ocurre en las relaciones de pareja y en las chicas, los chicos que utilizan el preservativo en sus relaciones casuales tienen más experiencia sexual que los que utilizan menos el 
preservativo. Es el único resultado en el que aparece una relación positiva entre la experiencia de los adolescentes y el uso del preservativo.

Por último en un análisis de correlación entre motivaciones sexuales y uso del preservativo vemos que existe una relación inversa entre éste y la motivación de intimidad, aunque solo para la muestra femenina. Así, las chicas adolescentes para las que más importancia tiene la intimidad en la actividad sexual, son las que menos utilizarán el preservativo en las relaciones casuales.

Diferencias en uso del preservativo en función del contexto relacional y el sexo

Finalmente para examinar si existían diferencias significativas en el uso del preservativo en función del contexto relacional y en función del género, llevamos a cabo un análisis de medidas repetidas con 116 adolescentes que habían contestado en ambas versiones del cuestionario. El contexto se introdujo como factor intra-sujetos e incluimos el sexo como factor inter-sujetos. El efecto del contexto relacional no resultó significativo $[\mathrm{F}(1,114)=2,346, \mathrm{p}=.128]$, el efecto del género tampoco $[\mathrm{F}(1,114)=0,106, \mathrm{p}=.745]$ y su interacción tampoco $[\mathrm{F}(1,114)=3,579$, $\mathrm{p}=.061]$. Así, no existen diferencias en el uso que hacen los adolescentes del preservativo en relaciones de pareja y en relaciones esporádicas, ni en el uso que hacen del mismo, chicos y chicas.

\subsection{Consentimiento de actividad sexual no deseada.}

\section{Consentimiento sexual en relaciones de pareja}

Otra práctica que se ha visto relacionada con conductas de riesgo en otros estudios es el consentir en mantener una relación sexual cuando en realidad no se desea. En nuestro estudio hemos evaluado la frecuencia con que se da esta conducta en la vida sexual de los adolescentes y hemos expuesto los resultados en porcentajes. Vemos que en las relaciones de pareja, el $33,8 \%$ de los adolescentes no ha consentido sexualmente en ninguna ocasión cuando no lo 
deseaba, mientras que un porcentaje similar, el 34,8\% consienten en tener actividad sexual sin desearla en la mitad, o más de la mitad de las ocasiones. El otro tercio lo componen aquellos que consienten sexualmente en la minoría de las ocasiones que no lo desean (véase Tabla 48).

Tabla 48. Porcentajes de frecuencia de consentimiento de actividad sexual no deseada en relaciones de pareja

\begin{tabular}{llcc}
\hline Frecuencia consentimiento pareja & $\mathrm{N}$ & Porcentaje & Porcentaje acumulado \\
\hline Nunca & 69 & 33.8 & 33.8 \\
La minoría de las veces & 64 & 31.4 & 65.2 \\
La mitad de las veces & 31 & 15.2 & 80.4 \\
La mayoría de las veces & 30 & 14.7 & 95.1 \\
Siempre & 10 & 4.9 & 100.0 \\
\hline
\end{tabular}

La frecuencia media con la que los adolescentes consienten sexualmente en sus relaciones de pareja es 2,25 con una desviación típica de 1,20. Es decir, que la media de ocasiones en las que los adolescentes consienten en tener actividad sexual sin desearla está entre la minoría y la mitad de las veces que no lo desean. La muestra que contestó a esta pregunta estaba formada por 204 adolescentes. La edad no correlacionaba con esta variable.

Para conocer si la medida en que los adolescentes dan su consentimiento sexual cuando no lo desean se relaciona de alguna manera con la medida en que ponen en marcha estrategias de iniciación o de rechazo sexual, llevamos a cabo correlaciones para cada sexo por separado. En ambos sexos, el consentimiento sexual se relacionaba positivamente con el uso de estrategias de presión en relaciones de pareja, aunque la relación en las chicas era más robusta en términos de significación que en los chicos. Parece que los adolescentes que consienten actividad sexual no deseada en mayor medida, son los que más utilizan las estrategias de presión en sus relaciones de pareja a la hora de mantener relaciones sexuales deseadas (véase Tablas 42 y 43).

En cuanto a las estrategias de limitación vemos que sólo en la muestra femenina el consentimiento sexual tiene una relación positiva y significativa con el uso de estrategias de limitación indirectas en las relaciones de pareja. El consentimiento de actividad sexual no deseada parece relacionarse con la manera en la que las adolescentes limitan la actividad sexual, ya que se asocia positivamente al empleo de las estrategias indirectas.

La medida en que se consiente sexualmente en pareja no tiene relación alguna con la experiencia sexual o relacional. Los adolescentes consienten en tener actividad sexual con sus 
parejas de una manera independiente a su nivel de experiencia sexual. Sí existe sin embargo, relación positiva aunque leve para ambos sexos, con las motivaciones sexuales de evitación. Los adolescentes varones con mayor motivación de autorregulación emocional en su actividad sexual, consienten actividad sexual no deseada a su pareja en mayor medida que aquellos con menor motivación de autorregulación emocional. Las chicas para las que la motivación de evitar el rechazo de su pareja es más importante, consienten actividad sexual con mayor frecuencia que aquellas para las que esta motivación es menos importante. Esta última asociación, a pesar de no ser muy fuerte, es muy clara conceptualmente hablando (véase Tablas 42 y 43).

\section{Consentimiento sexual en relaciones esporádicas}

Comenzamos exponiendo las cifras de la frecuencia con que los adolescentes consienten en tener actividad sexual sin desearlo. Vemos que en las relaciones esporádicas, el 46,6\%, casi la mitad de los adolescentes no ha consentido actividad sexual en ninguna ocasión cuando no lo deseaba, un dato mayor que en las relaciones de pareja. Un 29,5\% dan su consentimiento sexual en la minoría de las ocasiones que no lo desean. Finalmente el 23,8\% consienten en tener actividad sexual sin desearla en la mitad o más de la mitad de las ocasiones (véase Tabla 49).

Tabla 49. Porcentajes de frecuencia de consentimiento de actividad sexual no deseada en relaciones casuales

\begin{tabular}{lccc}
\hline Frecuencia consentimiento casual & $\mathrm{N}$ & Porcentaje & Porcentaje acumulado \\
\hline Nunca & 131 & 46.6 & 46.6 \\
La minoría de las veces & 83 & 29.5 & 76.2 \\
La mitad de las veces & 29 & 10.3 & 86.5 \\
La mayoría de las veces & 23 & 8.2 & 94.7 \\
Siempre & 15 & 5.3 & 100.0 \\
\hline
\end{tabular}

La frecuencia media con la que los adolescentes consienten actividad sexual en sus relaciones de pareja es 1,96 con una desviación típica de 1,75. Es decir, que la media de ocasiones en las que los adolescentes consienten sexualmente se sitúa en la minoría de las veces que no lo desean. La muestra que contestó a esta pregunta estaba formada por 281 adolescentes. La edad no correlacionaba con esta variable. 
El consentimiento de actividad sexual no deseada en relaciones esporádicas correlaciona sólo en la muestra de chicos con el resto de variables (véase Tabla 44). Existe una relación positiva y significativa con el uso de estrategias de avance de carácter físico, con estrategias de presión, y una correlación más leve con insinuación verbal. Así, los adolescentes varones que más uso hacen de las estrategias de avance en relaciones esporádicas, sobre todo de las físicas y las coercitivas, consienten en tener actividad sexual no deseada, en mayor medida que los adolescentes que emplean menos estas estrategias sexuales.

En cuanto a las estrategias de limitación, hay una asociación negativa y leve con estrategias de limitación directa en relaciones esporádicas. Aquellos que utilizan más frecuentemente la limitación sexual directa, consienten sexualmente en menor medida, que aquellos que no utilizan estrategias de limitación directas. Esta última asociación, aunque leve, es también muy clara desde un punto de vista conceptual.

El consentimiento de actividad sexual no deseada en relaciones esporádicas tampoco tiene relación con la experiencia sexual o relacional. Los adolescentes consienten en tener actividad sexual no deseada en las relaciones casuales, de una manera independiente a su nivel de experiencia sexual. Sí existe sin embargo, relación positiva con la motivación de placer. Los adolescentes varones con mayor motivación de placer en su actividad sexual, consienten sexualmente en sus relaciones esporádicas en mayor medida que aquellos con menor motivación de placer.

Diferencias en consentimiento de actividad sexual no deseada en función del contexto relacional y el género.

Finalmente para examinar si hay diferencias en la frecuencia del consentimiento de actividad sexual no deseada en función del contexto relacional o del género, llevamos a cabo un análisis de medidas repetidas en el factor contexto relacional como factor intra y el sexo como factor inter-sujetos, con 154 adolescentes que manifestaban haber realizado esta conducta en ambos contextos relacionales. El efecto del contexto relacional resultó significativo $[\mathrm{F}(1,152)=$ $11,262, \mathrm{p}=.001, \eta 2=.7]$. Concluimos que el consentimiento de actividad sexual no deseada, es más frecuente en relaciones de pareja que en relaciones esporádicas (véase Tabla 50). 
Tabla 50. Estadísticos descriptivos en frecuencia de consentimiento de actividad sexual no deseada en ambos contextos.

\begin{tabular}{lccc}
\hline Contexto relacional & $\mathrm{N}$ & Media & Desviación Típica \\
\hline R. de pareja & 154 & 2.32 & 1.23 \\
R. esporádica & 154 & 2.02 & 1.25 \\
\hline
\end{tabular}

El efecto del género también resultó significativo $[\mathrm{F}(1,152)=49,741, \mathrm{p}=.000, \eta 2=.24]$. Los chicos consienten significativamente más actividad sexual no deseada que las chicas, un resultado bastante robusto, a juzgar por el tamaño del efecto (véase Tabla 51). La interacción entre ambos efectos no resultó significativa $[\mathrm{F}(1,152)=0,393, \mathrm{p}=.532]$.

Tabla 51. Estadísticos descriptivos en frecuencia de consentimiento de actividad sexual no deseada en varones y mujeres.

\begin{tabular}{lccc}
\hline Sexo & N & Media & Desviación Típica \\
\hline Chicos & 80 & 2.70 & 1.08 \\
Chicas & 74 & 1.60 & 1.12 \\
\hline
\end{tabular}





\section{CONCLUSIONES Y DISCUSIÓN}

En este apartado pretendemos destacar las principales conclusiones obtenidas en el estudio en función de los objetivos e hipótesis de las que partíamos, y ubicarlas en el panorama teórico y empírico de que disponemos. Esto lo haremos teniendo en cuenta la consistencia de nuestras conclusiones con resultados previos, así como sus implicaciones para investigaciones futuras.

\section{ESTRATEGIAS DE AVANCE Y LIMITACIÓN SEXUAL}

En nuestro estudio pretendíamos conocer cómo se agrupaban las tácticas de negociación sexual estudiadas en tipos de estrategias generales, y esperábamos obtener una categorización basada en estrategias directas e indirectas, y estrategias coercitivas y no coercitivas, en el caso del avance sexual. Esta hipótesis se ha visto confirmada, puesto que las tácticas se han agrupado según estas dos dimensiones. Sin embargo, una tercera dimensión resultó del análisis factorial: estrategias verbales y estrategias no verbales (o de contacto físico). Así, contábamos con dos 
tipos de estrategias directas: avance físico directo y avance verbal directo; dos tipos de estrategias indirectas: gestos de seducción e insinuación verbal; y dos tipos de estrategias coercitivas: estrategias de presión y de fuerza. Por otro lado también se podrían dividir en dos tipos de estrategias físicas: avance físico directo y gestos de seducción; dos tipos de estrategias verbales: insinuación verbal y avance verbal directo; y dos tipos de estrategias coercitivas: estrategias de presión y de fuerza.

A pesar de que la dimensión verbal-no verbal no formaba parte de la hipótesis, tal y cómo la habíamos formulado, resulta coherente con nuestros planteamientos básicos, ya que éstos implican una distinción en cuanto a la eficacia y claridad, en las estrategias de comunicación sexual. En este sentido, consideramos que las estrategias verbales en general, facilitan el éxito en la comunicación de deseos e intenciones sexuales en mayor medida que las estrategias no verbales. Esta consideración se ve avalada por el estudio de Byers y Heinlein (1989) quienes encontraron que el rechazo a un avance sexual era más satisfactoriamente resuelto cuando la iniciación se había producido a través de una estrategia verbal, sugiriendo que es más fácil decir y aceptar un "no" cuando la propuesta es verbal. Entendemos que el lenguaje ofrece una mayor versatilidad a la hora de expresar deseos personales que pueden no estar en sintonía con los de otra persona, y que dependen de un medio de comunicación capaz de transmitir matices, preferencias, reservas o condiciones.

La investigación que existe sobre tácticas de avance sexual y su agrupación en estrategias, coincide en señalar estas tres dimensiones de categorización: verbal-no verbal, directa-indirecta, y coercitiva-no coercitiva, sobre todo para las dos primeras dimensiones (McCormick, 1979; Byers y Heinlein, 1989; O’Sullivan y Byers, 1992; Grossman et al., 2002; Dybvig-Pawelko, 2007; Rosenthal y Peart, 1996). Esta clasificación es común a los criterios con los que se valora la comunicación general, en cualquier ámbito de la sociedad, no sólo en el terreno sexual. Todo acto de comunicación por una parte se vale de una vía o canal, que puede ser verbal o no verbal, y por otra parte muestra un grado determinado de transparencia o claridad, que se representa en lo directo o indirecto que sea tal acto de comunicación con respecto al receptor del mensaje.

Sin embargo, el grado de coerción que caracteriza un acto de comunicación o en su caso, un acto de influencia, es un criterio que se ha visto particularmente ligado la negociación en el ámbito específico de la sexualidad. En este sentido, varios estudios han observado que entre los tipos de estrategias de avance sexual, se clasifican las tácticas coercitivas como categoría, y que a veces se subdividen en estrategias de presión verbal, y de fuerza física (McCormick, 1979; Christopher y Frandsen, 1990; Schmitt y Buss, 1996; Dybvig-Pawelko, 2007; Eyre et al., 1997), 
otorgando validez al planteamiento de la coerción sexual como continuo (Dybvig-Pawelko, 2007), y a las categorías fruto del cruce entre las dimensiones expuestas. Así, en nuestro estudio podemos hablar de dos categorías de estrategias coercitivas: la presión sexual, en su mayoría compuesta por tácticas de presión verbal (interesantes excepciones son las tácticas no verbales de emborrachar o invitar a la víctima para tener actividad sexual) y la fuerza física, de carácter físico, aunque ésta última con una prevalencia marginal.

En cuanto a las estrategias de limitación sexual, obtuvimos una categorización basada unicamente en estrategias de limitación directas e indirectas, tal y como habíamos hipotetizado. Los pocos estudios que hay sobre empleo de estrategias de evitación de la actividad sexual también han clasificado las estrategias en directas e indirectas (Rosenthal y Peart, 1996; McCormick, 1979; LaPlante et al., 1980). Un estudio (Turchick et al., 2007) utilizó una escala que clasificaba la resistencia sexual femenina en función de si ésta era verbal o física, pero esto se evaluaba sólo como respuestas a situaciones de coerción sexual. Es posible que la dimensión verbal-no verbal no haya repercutido en las estrategias de comunicación sexual para la limitación de la actividad sexual, porque sean tácticas generadas de manera reactiva y dependiente del avance sexual correspondiente. Así, si el avance sexual se produjo de manera verbal o no verbal, probablemente condicionó la manera en que se produciría el rechazo sexual, y quizás por eso, esta decisión no se refleje en un patrón específico a la hora de puntuar el uso de las estrategias. Un modo directo o indirecto de limitar la actividad sexual en cambio, es probable que se vea más desligado de la forma en que se produjo el avance sexual, y se vincule más a otros factores como preferencias personales o situacionales, capaces de reflejarse en un patrón de respuesta.

Por otra parte, pretendíamos examinar qué estrategias sexuales eran las más utilizadas por los adolescentes. En este sentido, tanto en relaciones de pareja como en relaciones esporádicas, las estrategias de iniciación más empleadas fueron las tácticas de avance físico directo. Después del contacto físico directo, la manera más frecuente de iniciar actividadad sexual en la adolescencia es a través de estrategias de comunicación indirectas fundamentalmente, insinuación verbal y gestos de seducción. Los siguientes tipos de estrategias más utilizados son el avance verbal directo, estrategias de presión, y de fuerza física, estos dos últimos bastante más diferenciados en cuanto a su frecuencia de uso que los demás. El estudio de Dybvig-Pawelko (2007), a pesar de que estudiaba a población adulta, llegó a una conclusión relativamente parecida en cuanto al orden de uso de estrategias de iniciación sexual, puesto que era: $1^{\circ}$ actos físicos cubiertos, $2^{\circ}$ actos verbales indirectos, $3^{\circ}$ actos verbales directos, $4^{\circ}$ coerción verbal y $5^{\circ}$ coerción no verbal. 
Con relación a las estrategias de limitación sexual, las tácticas de limitación más utilizadas eran las directas, por encima de las indirectas.

De esta manera, podríamos describir los guiones de iniciación sexual adolescentes como caracterizados por actos de comunicación de carácter físico, indirecto y no coercitivo fundamentalmente, y los guiones de limitación sexual en la adolescencia se caracterizan, por estrategias de comunicación de carácter directo. Sin embargo, a pesar de que existe un guión de iniciación sexual predominante para los adolescentes, hay también variantes que representarían los guiones sexuales individuales. El resto de la investigación se ha ocupado de examinar qué circunstancias individuales e interpersonales influyen a los adolescentes para elegir un tipo $\mathrm{u}$ otro de estrategia, y las conclusiones a las que hemos llegado serán expuestas a continuación.

\subsection{Contexto relacional y género en el uso de estrategias sexuales}

Tal y como hemos expuesto en diversas ocasiones a lo largo de este trabajo y según la teoría de los guiones sexuales, las estrategias que un individuo pone en marcha para iniciar actividad sexual están determinadas además de por factores culturales, que no evaluamos en este trabajo, por factores interpersonales, como el tipo de relación que exista entre las dos personas, y por factores individuales como el género. Podemos decir en este sentido que el contexto relacional y el género son factores que influyen en cierta medida en el empleo de estrategias de negociación sexual en la adolescencia. El género y el contexto sin embargo, parecen influir de manera muy diferente según el tipo de estrategia en cuestión: mientras que algunas estrategias se ven afectadas por el tipo de relación otras no se ven afectadas en absoluto por esta variable. Lo mismo sucede con el género de los adolescentes: algunas estrategias son más susceptibles de ser más utilizadas por uno de los dos géneros, mientras que otras no.

La hipótesis que formulamos sobre la influencia del contexto en el uso de estrategias de iniciación sexual se ha visto confirmada. En concreto, esperábamos que los adolescentes utilizaran estrategias directas más frecuentemente en sus relaciones de pareja, que en las relaciones ocasionales, y lo contrario para el uso de estrategias indirectas. El contexto relacional se ha mostrado en alguna medida determinante en el uso de estrategias directas y verbales, puesto que los adolescentes en relaciones de pareja tienden a emplear más este tipo de tácticas de comunicación efectiva, que en relaciones esporádicas. 
Consideramos además, que este efecto, aunque pequeño, es un efecto atribuible al contexto relacional, es decir, a estar en un tipo u otro de relación (de pareja vs. ocasional), puesto que contamos con un análisis en el que se compara a los mismos participantes, en medidas repetidas, en cuanto a su vivencia en los dos contextos, y la diferencia obtenida es probablemente la consecuencia del cambio de contexto relacional, en ningún caso de características individuales de los participantes. Por otra parte, consideramos que el efecto obtenido responde a las diferencias subjetivas que supone estar en uno u otro contexto, puesto que se eliminó del análisis en lo posible, el efecto objetivo de las oportunidades en el tiempo, en meses de relación de pareja o en cantidad de relaciones casuales, para poner en marcha las estrategias sexuales. Además, el hecho de haber obtenido en nuestros dos análisis el mismo resultado, minimiza las probabilidades de que la diferencia entre contextos obtenida en el análisis de medidas repetidas, sea consecuencia de factores relacionados con la causalidad, como que una experiencia relacional previa puede condicionar las características de una experiencia relacional posterior.

La lectura complementaria de esta conclusión sería que hay ciertas tácticas, como son los gestos de seducción y las tácticas sexualmente coercitivas, que dependen en menor medida del contexto relacional en el que se encuentre el adolescente y que por tanto, pueden estar más vinculadas a factores individuales. Los primeros análisis correlacionales ya apuntaban en esta dirección, puesto que el uso de estas estrategias en diferentes contextos, era el que mostraba correlaciones más altas, sugiriendo que los adolescentes que empleaban este tipo de tácticas indirectas y coercitivas en un tipo de contexto, probablemente las emplearían en el otro contexto relacional.

La confirmación de la hipótesis es sin embargo parcial, puesto que aunque los adolescentes sí emplean más estrategias de avance sexual directas en sus relaciones de pareja que en las esporádicas, no se ha demostrado que en éstas relaciones ocasionales se empleen en mayor medida estrategias de tipo indirecto, que era la segunda parte de nuestra primera hipótesis. De hecho, la insinuación verbal, un tipo de estrategia considerada en este trabajo como indirecta, ha resultado ser más frecuente en relaciones de pareja que en relaciones ocasionales. Entendemos a raíz de este resultado, que algunas tácticas de insinuación se han podido considerar como actos que promueven la intimidad emocional, como sucede en algunas ocasiones con acciones como "hablar de sexo", "hablar de lo que sientes hacia la otra persona" y "decir cosas halagadoras", más que como meras insinuaciones sexuales. Además el componente verbal de este tipo de estrategia, la hace susceptible de formar parte del grupo de estrategias de comunicación claras y 
eficaces, ya que como hemos comentado previamente, el lenguaje ofrece una vía de comunicación más versátil, y posibilita una mejor transmisión de mensajes, aunque sea lenguaje indirecto, que la comunicación no verbal.

En cuanto a la otra estrategia indirecta, los gestos de seducción, encontramos dos posibles razones por las que su empleo no ha resultado más propio del contexto ocasional. En primer lugar, tal y como señalan algunas investigaciones (Renninger et al., 2004; O'Sullivan y Byers, 1992) puede que debido a la sutileza de algunas tácticas indirectas (gestos, posturas, miradas, etc.) que tienen lugar normalmente de manera previa a las estrategias directas, los adolescentes hayan sido menos hábiles a la hora de reconocerlas y percibirlas como tácticas de avance sexual, y por tanto también a la hora de puntuar su uso de manera precisa en las relaciones esporádicas. Esto podría haber dificultado que el índice de utilización de estrategias indirectas en relaciones esporádicas fuese adecuadamente valorado y superase al índice de empleo de estas estrategias, en relaciones de pareja. Otra explicación podría ser que, debido a la falta de experiencia de los adolescentes y a la corta duración de algunas relaciones de pareja (el límite mínimo fue establecido en 3 meses de duración), la distinción entre los dos contextos relacionales propuestos no haya resultado lo suficientemente grande, y en algunas relaciones de pareja se sigan utilizando tácticas indirectas propias de relaciones casuales. Esto implicaría que, en lo que a utilización de gestos de seducción se refiere, los adolescentes no hacen distinciones entre los tipos de relación interpersonal propuestos en este estudio, empleando estas formas de comunicación indirecta, de manera indistinta en uno y otro contexto.

Los estudios con los que contamos apoyan los resultados encontrados, en cuanto a la diferencia en la frecuencia total de iniciación sexual entre diferentes contextos relacionales, a favor de las relaciones de pareja estable (O`Sullivan y Byers, 1992). También en cuanto a que sitúan mayoritariamente el empleo de estrategias de comunicación directas y explícitas en relaciones románticas estables, monógamas, y caracterizadas por una importante afectividad (Mitchell y Wellings, 1998; Seal y Ehrhardt, 2003; Byers y Heinlein, 1998). En relación con la importancia que tiene la utilización de este tipo de estrategias de avance directas y explicitas en sexualidad, son múltiples los trabajos que han demostrado por una parte, que la comunicación sexual abierta y clara aumenta la satisfacción sexual y hace que la experiencia sea positiva y que haya menos probabilidades de sentir arrepentimiento, y por otra, que la comunicación ambigua o las estrategias sexualmente coercitivas conducen a experiencias emocionales negativas y consecuencias físicas y psicológicas no deseadas (Ingham et al., 1991; Byers y Heinlein, 1998; 
Mitchell y Wellings, 1998; Zweig et al., 1999; Livingstone et al., 2004; Meston y O’Sullivan, 2007; Donald et al., 1995; Crawford et al., 1994).

Después de contrastar la hipótesis y de exponer la consistencia de este resultado con otras investigaciones sobre el tema, nos gustaría indagar brevemente sobre las razones por las que en relaciones de pareja se da una comunicación sexual más directa y clara que en las relaciones de una noche u ocasionales. En primer lugar y desde un punto de vista focalizado en el momento, en los dos contextos relacionales se dan diferentes niveles de anticipación y previsión de la actividad sexual, y por lo tanto, diferentes niveles de preparación psicológica. Es más probable que en las relaciones de pareja ambos miembros sepan cuándo y como se producirá el encuentro sexual, y que llegado el momento puedan responder y comportarse con mayor naturalidad y transparencia. En cambio, en relaciones ocasionales, la anticipación del encuentro es más difícil porque muchas veces para los adolescentes sería inaceptable asumir que ocurrirá algo sexual en un principio, y por lo tanto son reacios a comportarse de manera que se puedan anticipar las intenciones sexuales.

Desde un punto de vista más general y profundo, consideramos que hay otras razones por las que en los dos contextos existe un diferente afrontamiento de la comunicación sexual. Evidentemente estas razones no pueden ser otras, que aquellas relacionadas con las características de las relaciones románticas, que a su vez dependen en gran medida de los objetivos y necesidades que el adolescente pretende cubrir con la experiencia de esas relaciones (Sanderson y Cantor, 1995).

Varios autores (Brown, 1999; Connolly y Goldberg, 1999) han propuesto diferentes modelos de relaciones románticas en la adolescencia, caracterizados por diferentes estadios de madurez y diferentes necesidades. Los adolescentes en relaciones de menor compromiso y duración, o en fases iniciales de una relación, buscan satisfacer necesidades relacionadas con el establecimiento de su identidad, como extender y precisar el propio autoconcepto, y ganar confianza en sus habilidades de relación con posibles parejas románticas. Sus preocupaciones de centran en torno a sí mismos, cómo se sienten, cómo actúan, que imagen dan a sus amigos, etc. y estas relaciones son vividas con altos niveles de estrés y bajos niveles de intimidad (Nieder y Seiffge-Krenke, citado en Shulman y Seiffge-Krenke, 2001).

Así, entendemos que la falta de confianza en las propias habilidades, combinada con el estrés y la preocupación por la propia imagen y estatus en el grupo, y los bajos niveles de intimidad, son los ingredientes que dificultan una comunicación sincera y abierta con otra persona, puesto que por una parte, estas relaciones pueden estar funcionando como meros ensayos, y por otra, la 
propia vulnerabilidad percibida por estos adolescentes les puede estar impidiendo "correr el riesgo" de exponer con claridad sus intenciones, deseos, y temores, en relación con la sexualidad.

Frente a este escenario, estarían las relaciones de pareja en la adolescencia, en las que existe un mayor énfasis tanto en la búsqueda de intimidad con la pareja, como en la búsqueda de actividad sexual, objetivos ambos centrados en la pareja, y no tanto en la definición de la propia identidad. El papel del grupo de amigos en estas relaciones suele ser menos importante, y la pareja funciona como una díada.

Taradash y Connolly (citado en Shulman y Seiffge-Krenke, 2001) encontraron en su estudio, que cuanto más tiempo pasaban los adolescentes con sus parejas, y fuera del grupo de amigos, más cómodos estaban expresando sus propias opiniones y más competentes eran socialmente. Al contrario, adolescentes que eran incapaces de mantener relaciones de pareja estables, tendían a involucrarse con más parejas sexuales, y se mostraban menos competentes socialmente. Nuestro trabajo ofrece apoyo a este resultado al haber hallado que el empleo de las estrategias de avance sexual de tipo directo, son las únicas que se ven positivamente asociadas la duración de la relación de pareja, confirmando así, que la duración de la relación aumenta las oportunidades del adolescente de poner en marcha formas de comunicación sexual directas.

Así, por una parte, los adolescentes en relaciones de pareja están más interesados en cubrir necesidades relacionadas con la intimidad emocional y sexual con la pareja, y por otra, las características de estas relaciones de pareja estables en la adolescencia, como son la afectividad, el compromiso y las conductas de cuidado, garantizan el desarrollo de habilidades sociales y emocionales. La combinación de los objetivos comunales del adolescente, con el aprendizaje y desarrollo de habilidades relacionales que se lleva a cabo en la propia relación de pareja, es lo que finalmente podría estar permitiendo una comunicación directa y explícita de los propios deseos e intenciones sexuales a la pareja.

En cuanto al papel que juega el género en la influencia que el contexto relacional tiene sobre el uso de estrategias sexuales, los resultados obtenidos por ambos análisis fueron también parecidos. Nuestra hipótesis ha resultado confirmada, puesto que esperábamos que el contexto relacional tuviera mayor influencia en la muestra femenina que en la masculina a la hora de iniciar encuentros sexuales. Las estrategias que mostraban interacción entre el contexto relacional y el género eran las estrategias directas, y esta interacción se producía en el sentido de que el contexto relacional afectaba de manera más intensa a las chicas que a los chicos. Es decir, 
estar en relaciones de pareja favorecía el uso de estrategias de avance sexual directas en mayor medida que estar en relaciones esporádicas, sobretodo para la muestra femenina. Desde el otro punto de vista los resultados muestran efectivamente que mientras que en relaciones de pareja no hay diferencias significativas en el empleo de estrategias de avance sexual, en el contexto ocasional los varones inician actividad sexual algo más frecuentemente que las chicas.

Parece que el guión sexual tradicional está más instaurado en las relaciones ocasionales en comparación con las relaciones de pareja, que muestran mayor mutualidad entre chicos y chicas a la hora de iniciar actividad sexual. Diversos estudios (O'Sullivan y Byers, 1992; Seal et al., 2007; Gebhardt et al., 2003) sugieren que a medida que una relación va avanzando en el tiempo, los miembros de la pareja tienden a flexibilizar los roles de género que adoptaron en los inicios de la misma. Parece que cuando las personas no tienen suficiente información sobre una situación, como ocurre en una primera cita o encuentro sexual, tienden a seguir con mayor fidelidad las reglas sociales de interacción de las que disponen, denominadas por Gagnon y Simon (1973) escenarios culturales. Si estas reglas marcan diferencias entre sexos a la hora de comportarse, así actuarán las personas en situaciones novedosas e inciertas. A medida que estos encuentros se repiten, surgen oportunidades para tantear y negociar cambios por parte de los miembros de la pareja, para ajustar lo máximo posible lo que ocurre entre ellos sexualmente (el guión sexual interpersonal), a lo que en realidad desean o disfrutan personalmente (el guión sexual intrapsíquico).

De esta forma, es comprensible que en relaciones ocasionales se den mayores diferencias entre chicos y chicas a la hora de iniciar actividad sexual, siendo el varón el que adopta el rol masculino de iniciar activamente esta actividad, y siendo la chica la que adopta el rol femenino de aceptar o rechazar esta iniciativa, que en relaciones de pareja. Por otra parte, el contexto relacional condiciona mayores diferencias en la conducta femenina que en la masculina, sobre el tipo de estrategias más explícitas, como son las estrategias directas y verbales, un resultado que confirma las múltiples evidencias que describen a la sexualidad femenina como más dependiente del contexto relacional que la masculina (Oliva et al., 1992; Navarro-Pertusa et al., 2006; Carroll et al., 1985; Ramos, Fuertes, Martínez y Hernández, 2003; Papadopoulos et al., 2000).

A pesar de que el género de los adolescentes ha resultado ser menos determinante que el contexto (sus niveles de significación y tamaños de efecto así lo sugieren), sí se han hallado 
diferencias entre chicos y chicas en la utilización de tipos de estrategia de avance sexual. Las hipótesis de partida se ven parcialmente confirmadas con estas conclusiones. Esperábamos por un lado, que los varones empleasen más tácticas coercitivas que las chicas, y por otro, que las chicas utilizasen más estrategias de iniciación sexual indirectas que los chicos. La primera parte de la hipótesis ha sido confirmada, mientras que no hemos hallado evidencia significativa para confirmar la segunda parte.

A pesar de que las diferencias encontradas en función del género no son muy grandes, podemos concluir que los varones, independientemente del contexto relacional en el que se encuentren emplean más estrategias de presión sexual para iniciar la actividad sexual, que las mujeres. Nuestras hipótesis en este sentido han sido confirmadas y están en sintonía con las conclusiones ofrecidas en la revisión de investigaciones previas (Fuertes et al., 2006; Ramos, Fuertes y De la Orden, 2006; Felson, 2002; Christopher y Frandsen, 1990; Greer y Buss, 1994; DybvigPawelko, 2007; Eyre et al., 1997; Christopher et al., 1998). Hemos optado por aplazar la discusión de este resultado para cuando expongamos las conclusiones del apartado sobre coerción sexual como práctica sexual asociada al riesgo en la adolescencia.

En cuanto a la segunda parte de la hipótesis, esperábamos que las chicas empleasen más estrategias indirectas para iniciar encuentros sexuales, puesto que algunos resultados de la revisión de la investigación previa así lo sugerían (Jesser, 1978; Moore, citado en Seal y Ehrhardt, 2003; Renninger, Wade y Grammer, 2004; Impett y Peplau, 2003; Eyre et al., 1997; Greer y Buss, 1994). Además tradicionalmente el guión de iniciación sexual, como ya hemos visto, sitúa a las mujeres en un papel pasivo y reactivo a las iniciativas masculinas, hasta el punto de que a veces salirse de este guión para tomar la iniciativa sexual, puede implicar el riesgo de arruinar una posible relación romántica (Seal y Ehrhardt, 2003). Es pues comprensible que las chicas prefieran emplear, a la hora de iniciar actividad sexual o comunicar interés sexual, formas encubiertas y sutiles de comunicación.

Esto no se ha mostrado así en nuestra investigación. Tres posibles razones se nos ocurren para explicar nuestro resultado. La primera, es que además de la evidencia que señala un mayor uso de las estrategias de avance sexual indirectas por parte de las mujeres que de los hombres, también existe evidencia en el sentido opuesto, tal y cómo expusimos en la revisión teórica (Byers y Heinlein, 1989; O’Sullivan y Byers, 1992; Rosenthal y Peart, 1996; Grossman et al, 2002; Dybvig-Pawelko, 2007), que bien no encuentra diferencias o que éstas van en el sentido opuesto. Esta evidencia estaría en la línea de lo que hemos hallado nosotros, y establecería que 
el uso de insinuaciones, gestos, miradas, y del flirteo en general, no es "cosa de chicas". Así se establecería que la forma de iniciar encuentros sexuales en la actualidad, en lo que a empleo de tácticas de iniciación sexual indirectas se refiere, no se ajusta al estereotipo tradicional, teniendo este una prevalencia similar en ambos sexos. Esto podría ser debido al desvanecimiento de las normas sexuales asociadas al género cada vez más creciente en nuestra sociedad actual.

La segunda explicación para nuestros resultados es que puede ser que la naturaleza sexualmente inexperimentada de la población adolescente implique que todos los adolescentes, chicos y chicas, necesiten recurrir a tácticas encubiertas y tanteos tímidos, a la hora de iniciar una actividad sexual que, en la mayoría de los casos, está lejos de ser una actividad cotidiana. Podría ser por tanto, que las diferencias en el empleo en estrategias de avance sexual indirectas, surgieran más adelante, cuando los varones hubieran podido asimilar, a través de su experiencia y de la exposición a las expectativas culturales de género, un papel más activo y directo en el ámbito de la sexualidad.

La tercera explicación iría en la misma línea que la que ofrecíamos para la falta de diferencias en empleo de este tipo de tácticas indirectas en función del contexto relacional. De nuevo, podría ser que algunos gestos dirigidos a captar la atención o seducir pueden estar pasando desapercibidos por las participantes de nuestra investigación, y al no ser conscientes de ellos, pueden no estar identificándolos como tácticas o estrategias (O’Sullivan y Byers, 1992). Consideramos que esta falta de reconocimiento en torno a los gestos sutiles, podría afectar en mayor medida a la muestra femenina que a la masculina, si se diera el caso de que éstas aprenden a hacer un uso más automático, cotidiano e integrado en su repertorio de conductas, que los varones.

Los varones también han mostrado emplear algo más que las chicas, el avance verbal directo para iniciar encuentros sexuales en relaciones ocasionales. A pesar de que no lo habíamos formulado en nuestras hipótesis, este resultado es consistente con nuestros planteamientos generales, ya que basándonos en la influencia que pueden tener los estereotipos de género y el guión sexual tradicional en la adolescencia, esperábamos un comportamiento sexual más asertivo en los varones, sobre todo en contextos no formales, como son las relaciones ocasionales. Así, es más probable que en una relación casual, los varones digan directamente que desean tener actividad sexual, a que lo hagan las chicas.

Esto coincide con lo encontrado en investigaciones previas (Muehlenhard et al., 1986; Clark, Shaver y Abrahams, 1999; Eyre et al., 1997) y con lo expuesto en la teoría de los guiones sexuales (Gagnon y Simon, 1973) que mantiene que la manera en la que se inician encuentros sexuales está en gran medida estructurado y esquematizado, de acuerdo a unas normas 
culturales que distinguen entre otras cosas, la conducta masculina de la conducta femenina y viceversa. Estas normas y expectativas culturales mantienen que el varón tiene un afrontamiento sexual activo, directo y asertivo, mientras que la mujer muestra una actitud pasiva y reactiva a las iniciativas de varón. Desafiar estas normas supone sufrir determinados castigos sociales como el ganarse una reputación, por lo que cuando las mujeres deciden tomar la iniciativa sexual, es menos probable que lo hagan de manera visible y directa. Este encorsetamiento del modo de proceder convencional es especialmente aplicado en contextos relacionales esporádicos, en los que los dos miembros no saben lo que esperar de la otra persona en el ámbito sexual y por no correr riesgos, se dejan guiar por las reglas del juego que todos conocen. Este podría ser el mecanismo de aprendizaje que ha influido para que los varones muestren un mayor uso del avance verbal directo en relaciones ocasionales que las chicas.

En relación con las pocas discrepancias encontradas entre los dos análisis realizados para evaluar el efecto del contexto relacional y del género, consideramos que la diferencia de género en la utilización de estrategias físicas hallada en el análisis con diferentes grupos de adolescentes, es muy poco substancial y podría ser fruto del azar, puesto que además, no se ha reproducido en el análisis de medidas repetidas.

Por otro lado el hecho de que en el análisis por grupos se obtenga que, en relaciones de pareja, las chicas superan significativamente a los chicos en el empleo del avance verbal directo (resultado que no tampoco se ha obtenido en el análisis de medidas repetidas) podría ser explicado si suponemos diferentes características de personalidad en el grupo de adolescentes que ha tenido sólo la experiencia de relación de pareja, frente al grupo con ambas experiencias relacionales, en medidas repetidas. Podría ser que los adolescentes varones cuya única experiencia es la de relaciones de pareja (experiencia más acorde al rol femenino en la sexualidad) encajen en menor medida en el rol tradicional masculino de tomar la iniciativa sexual de una manera directa y dominante, y por lo tanto empleen menos que los otros adolescentes, el avance verbal directo para iniciar actividad sexual. Un vistazo a las medias de utilización del avance verbal directo en adolescentes varones en relaciones de pareja, en uno y otro análisis, corroboran esta explicación, puesto que los adolescentes con ambas experiencias relacionales emplean el avance verbal directo en relaciones de pareja, con una frecuencia de 1,10 puntos por encima de la frecuencia de uso de esta estrategia en el grupo de adolescentes varones con experiencia sólo en relaciones de pareja. Esto explicaría que las adolescentes chicas en este grupo les hubieran superado significativamente en el empleo de esta estrategia sexual. Podríamos apuntar en este sentido, que los adolescentes varones que sólo han tenido la experiencia de relaciones de pareja podrían emplear un tipo de comunicación sexual diferente, 
no sólo de los adolescentes con experiencia sólo en relaciones esporádicas, sino también de aquellos que han tenido los dos tipos de experiencia relacional.

Otra explicación podría ser que el resultado hallado en el análisis por grupos se considere cuestionable, dado el pequeño tamaño de los grupos de chicos y chicas en comparación. El grupo de adolescentes que sólo había tenido relaciones de pareja estaba compuesto por un total de 52 participantes.

En cuanto al empleo de formas de limitación sexual en la adolescencia, el contexto relacional no ha resultado relevante en la utilización de la limitación sexual. El género en cambio se ha mostrado significativo, puesto que las adolescentes chicas utilizan la limitación sexual directa más frecuentemente que los varones en ambos contextos relacionales.

La parte relativa a la influencia del contexto relacional en el uso de la limitación sexual no ha confirmado nuestras hipótesis ya que esperábamos diferencias en el empleo de la limitación sexual en función del contexto, concretamente esperábamos mayor utilización de tácticas directas en relaciones de pareja y mayor utilización de tácticas indirectas en relaciones ocasionales. Los resultados en la investigación han demostrado en cambio, que los adolescentes limitan la actividad sexual de manera independiente al contexto relacional en el que se encuentran. Esto implica, además del hecho de que estrategias de limitación sexual y estrategias de avance sexual no se rigen por las mismas normas asociadas al contexto relacional, que otros factores de carácter individual o cultural, y no interpersonal, condicionan en mayor medida la manera en la que los adolescentes comunican su rechazo de la actividad sexual.

Hay varios motivos por los que el uso en adolescentes de las estrategias de avance y de limitación sexual puede responder a normas y reglas diferentes. En primer lugar, las estrategias de limitación sexual son tácticas que se ponen en marcha de manera reactiva (respondiendo a demandas sexuales formuladas) y no proactiva, como sería el caso de las estrategias de iniciación sexual. El hecho de ser una respuesta a un avance sexual producido por otra persona, le confiere un carácter más espontáneo y más desprovisto de preparación previa. Puede ser que los adolescentes que inician voluntariamente un avance sexual estén algo más preparados, que los que limitan un avance sexual propuesto por otra persona. La diferencia puede ser mínima, quizás unos minutos, pero en este tiempo, los adolescentes dispuestos a iniciar actividad sexual pueden decidir y ajustar el tipo de táctica a circunstancias como puede ser el contexto relacional, mientras que la respuesta inmediata a un avance, especialmente si es una respuesta de rechazo, tiene más probabilidades de producirse de manera improvisada y espontánea. 
En segundo lugar, iniciar actividad sexual y verse en la tesitura de rechazar la iniciativa de otra persona, no parecen tener la misma carga emocional, o las mismas repercusiones potenciales, especialmente en los adolescentes. En su estudio Rosenthal y Peart (1996) señalan que mientras que las normas en torno a la actividad de comunicar y promover el interés sexual en adolescentes están muy claramente establecidas, siendo la mayoría de estas tácticas aceptadas por los adolescentes, a la hora de disuadir la actividad sexual, no hay normas claras, y pocas tácticas resultan rotundamente aceptadas por el conjunto de adolescentes, posiblemente porque no resulta fácil rechazar a una pareja sexual, sin que esto conlleve un daño a la relación. Esta diferencia, en cuanto a la regulación social y cultural existente para llevar a cabo el avance y la limitación sexual, podría explicar porqué en la primera tarea hay diferencias entre contextos relacionales (posiblemente reguladas por estas normas y expectativas) y porqué la tarea de disuadir los encuentros sexuales se produce de manera libre del contexto en el que ésta tenga lugar. Desafortunadamente no conocemos investigaciones que puedan apoyar o contradecir nuestro resultado.

La segunda implicación del resultado consistía en que al parecer, la manera de limitar la actividad sexual en la adolescencia puede estar más condicionada por factores culturales e individuales, que interpersonales. Esta suposición se ha visto apoyada por el hecho de que hayamos hallado un efecto significativo del género sobre el uso de la limitación sexual. Las chicas emplean más estrategias de limitación sexual que los varones, y esto ocurre de manera significativa en el empleo de estrategias de tipo directo.

Las diferencias de género obtenidas en cuanto al uso general de estrategias de limitación sexual han confirmado la hipótesis formulada en este sentido, y es consistente con el guión sexual tradicional y con algunos estudios previos (LaPlante et al., 1980) que indican un mayor uso de la limitación sexual por parte de las chicas que de los chicos.

Como expusimos en la revisión teórica, niños y niñas crecen otorgando diferentes significados a la sexualidad, por sus diferencias anatómicas y funcionales (genitales, concepción) y por los sutiles mensajes que reciben, ellos de independencia y exploración, y ellas de dependencia y precaución. Así, el significado de la sexualidad termina estando asociado para las chicas a relaciones amorosas por una parte, y a peligros potenciales para el cuerpo y la reputación por otra, mientras que en los chicos la sexualidad se asocia al placer fundamentalmente. Esta diferencia de significados entre ambos sexos podría facilitar el que las chicas en algún momento, experimentaran una posición de vulnerabilidad y desencuentro ante el 
comportamiento y los significados masculinos, y esto les llevara a dar credibilidad e interiorizar el papel otorgado por otros, de restrictoras de la actividad sexual.

Esta explicación parece coincidir plenamente con nuestro resultado de que las chicas limitan la actividad sexual en mayor medida que los chicos, sin embargo hay otras investigaciones que contradicen este resultado (McCormick, 1979; Byers y Heinlein, 1989; O'Sullivan y Byers, 1992; Rosenthal y Peart, 1996) y que indican un uso similar entre géneros de la limitación sexual. Esto nos hace plantearnos que es posible, que tal y como exponían en su trabajo Byers y Heinlein (1989), la diferencia encontrada pueda en parte ser consecuencia de las mayores oportunidades que tienen las chicas de estar en posición de rechazar un avance sexual. Es decir, si los varones inician más actividad sexual, es lógico, que las chicas necesiten emplear la limitación sexual en mayor medida que éstos, por pura probabilidad.

La diferencia de género encontrada está matizada además, por el hecho de que solo ha resultado significativa para el uso de tácticas directas, ya que chicos y chicas no difieren en su uso de tácticas indirectas para evitar encuentros sexuales. En su investigación con adolescentes, Rosenthal y Peart (1996) hallaron que las estrategias directas de limitación sexual no sólo eran más utilizadas por chicas que por chicos, sino que también eran consideradas como más aceptables por parte de ellas que de ellos. Estos resultados, reflejan que las chicas se sienten más cómodas que los chicos en la posición y ante la tarea de rechazar actividad sexual, y como consecuencia, lo hacen a través de una comunicación más franca y directa que los chicos. Estos en cambio, puede que se sientan inadecuados en la posición de rechazar actividad sexual, puesto que se enfrentan a determinadas expectativas y mitos en torno a la sexualidad masculina, como que un hombre está permanentemente disponible y preparado para la actividad sexual. Podría ser que el intento de no defraudar estas expectativas sea lo que lleve a los adolescentes varones del estudio, a emplear en menor medida que las chicas tácticas de limitación sexual directas.

Las estrategias directas aún así, muestran un uso superior a de las estrategias indirectas en ambos sexos. Así, parece haber normas claras en cuanto al tipo limitación que se utiliza, en cualquier contexto relacional. Este resultado está en consonancia con los obtenidos por otros estudios (McCormick, 1979; Byers y Heinlein, 1989; Christopher y Frandsen, 1990) que encontraron que el medio principal por el que se limitaba o evitaba la actividad sexual era un medio directo. Sin embargo estas investigaciones muestran diferencias metodológicas importantes como son el empleo de situaciones hipotéticas y no reales, una muestra de parejas adultas y cohabitantes, y la falta de estrategias de tipo indirecto con las que comparar a las 
directas (respectivamente). Además en el estudio de Rosenthal y Peart (1996), más cercano a nuestro trabajo, obtuvo el resultado opuesto: los adolescentes empleaban tácticas de limitación indirectas con mayor frecuencia que las directas. Esto podría introducir alguna duda en torno al establecimiento de esta conclusión.

\section{$\underline{\text { Resumen del apartado }}$}

Uno de los propósitos de este trabajo era caracterizar la comunicación sexual que se pone en marcha en la actualidad entre adolescentes para iniciar actividad sexual, puesto que la comprensión de los guiones de iniciación sexual que utilizan los adolescentes no sólo ayuda a entender los encuentros sexuales individuales, sino también las normas sociales y culturales que rodean tales encuentros sexuales. En este sentido, sabemos que en general, los adolescentes emplean estrategias de acercamiento físico, combinadas con tácticas indirectas, como la insinuación de interés, y la seducción y el flirteo. En menor medida declaran verbal y explícitamente su interés sexual y en menos casos todavía, se emplean estrategias sexualmente coercitivas. De hecho, el empleo de las estrategias de fuerza física es tan marginal, como vimos en el apartado de los resultados, que no ofreceremos ninguna conclusión sobre el uso de este tipo de estrategia sexual o sus correlatos, más allá de los resultados meramente descriptivos.

En segundo lugar consideramos en función de los resultado expuestos, que la manera en la que se inicia un encuentro sexual, depende en alguna medida del tipo de relación interpersonal que exista entre dos personas, siendo una forma de comunicación más directa y explícita cuanta mayor estabilidad emocional tenga esa relación. Por otra parte, el tipo de relación interpersonal parece tener mayor repercusión en las chicas que en los chicos, a la hora de poner en marcha estrategias de avance sexual, puesto que éstas toman en menor medida la iniciativa sexual en relaciones casuales, que en relaciones de pareja.

Además, la manera en la que se inicia un encuentro sexual podría depender en alguna medida del género del adolescente, puesto los varones emplean algo más frecuentemente estrategias de presión sexual en cualquier contexto que las chicas, y en relaciones esporádicas también emplean algo más que éstas el avance verbal directo para iniciar encuentros sexuales, lo cual es consistente con el papel tradicional masculino en sexualidad, caracterizado por una mayor asertividad y agresividad en las iniciativas sexuales. 
Por otra parte, la manera en la que los adolescentes limitan la actividad sexual parece ser independiente del tipo de relación en el que se encuentren. Los roles de género en cambio, sí podrían estar explicando el hecho de que se de un mayor uso de la limitación sexual directa y explícita por parte de las chicas que de los chicos, ya que las investigaciones revisadas sugieren que las mujeres suelen sentirse más cómodas limitando la actividad sexual que los hombres.

\section{EXPERIENCIA Y MOTIVACIONES SEXUALES}

\subsection{Experiencia sexual en la adolescencia}

Otros factores de interés en la sexualidad adolescente, que además esperábamos tuvieran relevancia en el tipo de comunicación y negociación sexual que ponen en marcha los adolescentes, son el nivel de experiencia sexual y la motivación sexual. En este trabajo pretendíamos por una parte explorar la experiencia sexual de los adolescentes, así como las motivaciones que impulsan tal desarrollo sexual, y por otra parte averiguar qué influencia tienen estos dos factores en el empleo de estrategias de avance y limitación sexual.

En el análisis que hicimos de la experiencia sexual llegamos a las siguientes conclusiones. Existe una secuencia normativa de conductas heterosexuales a través de las que los adolescentes van incrementando su experiencia sexual. Estas conductas se agrupan en nuestra muestra en función de la frecuencia con la que son practicadas y de la intimidad que suponen para los adolescentes. Así el paso de un grupo de conductas sexuales a otro grupo de conductas sexuales de mayor intimidad puede suponer un cambio cualitativo en la vivencia de los adolescentes. El primer paso de los adolescentes parece ser el beso íntimo, que da lugar a caricias por encima de la ropa, y posteriormente se inician caricias por debajo de la ropa. Otro paso sería el inicio de caricias y actividades dirigidas a la consecución del orgasmo, como la masturbación y el coito, y finalmente, se darían las conductas de sexo oral, como el último escalón en cuanto a experiencia e intimidad sexual en los adolescentes. La mayoría de los adolescentes de nuestra muestra han practicado las primeras conductas de besos y caricias (95-72\%), dos tercios han practicado alguna vez caricias dirigidas a la consecución del orgasmo, y el 56,5\% han practicado el coito. El sexo oral fue experimentado por un tercio de los adolescentes. No había diferencias entre chicos y chicas en el nivel de experiencia sexual. 
Cuando comparamos nuestros resultados con algunos resultados de estudios previos sobre sexualidad adolescente, vemos que la frecuencia de las conductas del principio de la secuencia, caricias y besos, son muy similares, aunque la frecuencia de la conducta coital se muestra algo más variable dependiendo fundamentalmente del rango de edad con el que trabajara cada estudio (en el nuestro la media de edad era 16,74 años). Así la frecuencia coital se muestra más baja en estudios españoles o en estudios que incluyen a adolescentes tempranos (Ramos et al., 2006; INJUVE, 2000; Palenzuela, 2006; Diz, Sueiro, Chas y Diéguez, 2003; Gómez-Zapiaín, 2005; Eggermont, 2006). Y otros estudios con una muestra de adolescentes tardíos y jóvenes adultos, muestran una tasa de practica coital superior (Gebhardt et al., 2003; Impett y Tolman, 2006). Tal y como comentábamos en la revisión teórica, no en todos los estudios aparece el sexo oral como la última conducta en la secuencia normativa de adquisición de experiencia sexual, a veces aparece antes que el coito (Impett y Tolman, 2006). A pesar de las diferencias de género halladas en otros aspectos de la sexualidad adolescente, pocas o ninguna diferencia se ha encontrado en la frecuencia de actividad sexual en algunos estudios, coincidiendo con el resultado hallado en nuestra investigación (Ramos, Fuertes, Martínez y Hernández, 2003; Navarro-Pertusa et al., 2006; Larsson y Svedin, 2002; Schwartz, citado en Savin-Williams y Diamond, 2004).

Esperábamos en nuestra hipótesis sobre experiencia sexual que aquellos adolescentes que habían experimentado relaciones de pareja tuvieran mayor experiencia sexual que aquellos que sólo habían tenido relaciones esporádicas. Nuestros resultados han confirmado las hipótesis. Aunque hemos visto que el $56 \%$ de la muestra tiene experiencia coital, en el grupo de adolescentes que sólo ha tenido relaciones de pareja, el 75\% tiene experiencia coital, mientras que en el grupo que tuvo sólo relaciones esporádicas, un 30,5\% llegó a tener experiencia coital. Estos porcentajes son coherentes con los resultados en otros estudios sobre adolescentes, como el estudio de Gebhardt (2003) en el que el 93\% de los adolescentes en pareja tienen relaciones sexuales, y el $46 \%$ de los adolescentes en relaciones casuales tiene experiencia coital. En el trabajo de Manning et al. (2000), el 23\% de los adolescentes dicen haber tenido su primera experiencia sexual coital con un amigo, conocido o desconocido, fuera de una relación de pareja, y en el estudio de Eyre et al. (1997) alrededor de un 75\% de los adolescentes en pareja, mantenían relaciones sexuales. Una conclusión muy documentada es que las relaciones de pareja son un contexto especialmente oportuno para el desarrollo sexual de los adolescentes. Así, es mucho más probable que los adolescentes logren una progresión adecuada en la 
secuencia de conductas sexuales durante una relación de pareja, que a través de una serie de relaciones casuales.

Sin embargo, hemos observado una diferencia leve entre los sexos a este respecto, de manera que la experiencia relacional tenía diferentes efectos sobre la experiencia sexual en cada sexo. Nuestra conclusión es que a pesar de que chicos y chicas no difieren en su nivel de experiencia sexual final, existe alguna diferencia en torno al papel que tienen las relaciones románticas en la adquisición de esta experiencia sexual. Los chicos la adquieren de manera acumulativa a través de los dos tipos de relaciones aquí estudiadas, mientras que las chicas lo hacen a través, fundamentalmente, de sus relaciones de pareja. Esta conclusión se podría unir por su coherencia, con otras conclusiones halladas en esta investigación, como es la conclusión de que las chicas reducen la frecuencia de la iniciación sexual en relaciones ocasionales, mientras que los varones mantienen la misma frecuencia de avance sexual en los dos contextos relacionales, o que los varones tienen más parejas sexuales que las chicas. Estas conclusiones vienen a apoyar otros resultados previos que nos han mostrado cómo la adquisición de experiencia sexual está más ligada a las relaciones de pareja estables, en chicas que en chicos, o visto de otra manera, que las normas sexuales culturales permiten a los varones un desarrollo sexual más independiente de las relaciones y más centrado en sí mismos, que a las mujeres (Taris y Semin, 1997; Reiss, 1960; Hynie et al., 1998; Regan, 1997; Mathes et al., 2002; Peplau, 2003; NavarroPertusa, 2006).

\subsubsection{Experiencia sexual y estrategias de negociación sexual}

Según los resultados, la experiencia sexual parece jugar un papel diferente en la frecuencia de uso de estrategias de iniciación sexual, según el sexo y el contexto relacional. En las chicas, la experiencia sexual potencia sobretodo la comunicación sexual directa en ambos contextos, aunque de manera más intensa en las relaciones de pareja, puesto que la asociación tiene mayor intensidad, y además aparece con los gestos de seducción también.

$\mathrm{Al}$ contrario, en adolescentes varones, la experiencia sexual tiene una clara mayor influencia en el contexto de relaciones casuales que en las relaciones de pareja. Mientras que en relaciones de pareja la experiencia sexual sólo incrementa el empleo de estrategias de iniciación directas, en relaciones esporádicas, los adolescentes más experimentados sexualmente utilizan más las 
estrategias de contacto físico, la presión sexual y el avance verbal directo, que los menos experimentados. Además, las asociaciones se muestran más intensas en el contexto esporádico que en el contexto de pareja.

De estos resultados podemos extraer varias conclusiones. Nuestra primera conclusión es que la experiencia sexual incrementa la utilización de estrategias de iniciación sexual. Estos resultados apoyan los obtenidos en otros estudios (Auslander et al., 2007; Christopher y Frandsen, 1990) que vinculan la mayor experiencia sexual con la mayor frencuencia de iniciación sexual, aunque también hay otros que no encontraron asociaciones significativas entre estas dos variables (Eyre et al., 1997; O’Sullivan y Byers, 1992).

En segundo lugar, las estrategias de tipo directo han sido las más afectadas por el nivel de experiencia sexual. Aunque no habíamos hipotetizado sobre tipos de estrategias concretas, este resultado encaja en nuestro planteamiento general. Los adolescentes con mayor experiencia sexual, es más probable que tengan también mayor experiencia vital general, incluyendo aquí, las experiencias en relaciones interpersonales. La mayor experiencia en todos estos ámbitos tiene la consecuencia de dejar una huella cognitiva y emocional, que se traduce normalmente, y entre otros, en un mayor desarrollo de habilidades sociales en general, y de comunicación sexual en particular, siendo la iniciación directa un buen ejemplo de esta comunicación. La relación podría ser la inversa, y ser el mayor uso de estrategias de iniciación directas las que estuviesen facilitando una mayor adquisición de experiencia sexual, aunque lo más probable es que sea una influencia bidireccional.

Una excepción a esta conclusión es que en los varones que se encuentran en relaciones ocasionales, las estrategias que más se asocian a la experiencia sexual no son tanto las directas sino más las de contacto físico. Además la experiencia sexual también favorece el empleo de la presión sexual en relaciones casuales. Esto podría significar que en relaciones ocasionales, las estrategias que comunican las intenciones sexuales de manera directa no resultan tan efectivas a los varones, como pueden resultar las estrategias de contacto físico y la seducción, o las estrategias de presión sexual, ya que los adolescentes que más las utilizan en relaciones ocasionales para tener actividad sexual, tienen más experiencia sexual, que aquellos que las emplean en menor medida. El estudio de Rosenthal y Peart (1996) presta apoyo a esta conclusión puesto que observaron que las chicas puntuaron las estrategias de avance directas como más eficaces de lo que puntuaron los chicos, y explicaron que esto podría suceder porque las chicas consiguen con estas estrategias directas comunicar mejor sus necesidades e 
intenciones, mientras que los chicos pueden haber comprobado que estas estrategias directas no les funcionan, precisamente porque comunican mejor sus intenciones. Esto cobra todavía mayor sentido en un contexto de relaciones casuales.

Una última conclusión es que en los chicos, la experiencia sexual incrementa más el uso de estrategias de iniciación en el contexto esporádico, mientras que en las chicas, la experiencia sexual potencia más a la iniciación sexual en relaciones de pareja. De nuevo vemos la influencia que tienen las normas y expectativas culturales de género en torno al comportamiento sexual adolescente.

La experiencia sexual favorece la iniciativa sexual en general, pero sobre todo en el contexto en el que las chicas más se permiten tomar esta iniciativa, que es en relaciones de pareja, en las que posiblemente ha habido oportunidad de negociar y flexibilizar los roles de género. En relaciones esporádicas en cambio, no suelen darse oportunidades para tantear y negociar la iniciación sexual, por lo que según numerosos estudios, se emplean en mayor medida fórmulas tradicionales de iniciación sexual basadas en los roles de género (O’Sullivan y Byers, 1992; Seal et al., 2007; Gebhardt et al., 2003). Estas fórmulas o guiones de iniciación sexual tradicional establecen que el hombre es la parte activa, que toma decisiones y dirige la acción, y la mujer tiene un papel más reactivo a las iniciativas sexuales masculinas (Muehlenhard et al., 1986; Clark, Shaver y Abrahams, 1999; Eyre et al., 1997 La Plante et al., 1980; Seal y Ehrhardt, 2003). Así, es comprensible que una mayor experiencia sexual en los varones facilite en mayor medida la iniciación sexual en el contexto en el que tienen una mayor responsabilidad, como es el contexto casual, ya que en pareja pueden compartir, y de hecho comparten, la tarea de iniciar relaciones sexuales.

Por otra parte, también podría ser, de manera complementaria, que las chicas con más experiencia sexual se hubieran dado cuenta en mayor medida de las reticencias sociales que conlleva la iniciación sexual femenina en relaciones casuales (precisamente por tener más experiencia sexual), y estuviesen inhibiendo en alguna medida, la decisión y la iniciativa natural asociada a esa mayor experiencia sexual, en contextos esporádicos. Esto sería el efecto complementario a la explicación anterior, de que las chicas se permiten expresar su mayor experiencia sexual a través de una toma de iniciativas sexuales más frecuente, sobre todo en relaciones de pareja.

En cuanto a la influencia de la experiencia sexual sobre el uso de estrategias de limitación sexual, sólo en los varones encontramos una relación significativa. Los adolescentes chicos, con más experiencia sexual emplearán estrategias de limitación directa en sus relaciones casuales 
con mayor frecuencia que aquellos con menos experiencia sexual. La experiencia sexual sin embargo, no parece influir en la medida en que las chicas limitan la actividad sexual en sus relaciones. Esto podría deberse a que las chicas han interiorizado y han adoptado tradicionalmente el papel de responsables, vigilantes, y restrictoras de la actividad sexual, y el tener mayor experiencia sexual ni favorece ni dificulta esta tarea. En cambio, los chicos pueden sentirse menos cómodos en este papel como ya hemos visto, por lo que la mayor perspectiva que ofrece la experiencia sexual, podría disminuir la influencia que las expectativas de género ejercen sobre ellos.

Estos resultados son en cierto modo inconsistentes con otros resultados previos que muestran que la experiencia sexual está negativamente relacionada con estrategias de limitación (Auslander et al., 2007). En el trabajo de Christopher y Frandsen (1990) concluían que el uso de la lógica y la razón, utilizada para limitar la actividad sexual, se asociaba a una menor experiencia sexual. Sin embargo, el primer estudio se llevó a cabo sólo con una muestra de chicas adolescentes, y en el segundo el uso de la lógica y la razón, había sido considerado en realidad una estrategia de avance sexual y no de limitación sexual, con lo que la generalizabilidad de este resultado es dudosa.

\section{$\underline{\text { Resumen del apartado }}$}

Aunque no hay diferencias significativas entre chicas y chicos en el nivel de experiencia sexual y para ambos las relaciones de pareja son el contexto que más facilita la adquisición de experiencia sexual, parece que en alguna medida los diferentes contextos relacionales estudiados en esta investigación tienen diferente peso en la adquisición de experiencia sexual de chicas y chicos. Parece que los varones adquieren su experiencia sexual a través de tanto las relaciones de pareja como las relaciones esporádicas, y las chicas en cambio, adquieren su experiencia sexual a través fundamentalmente de sus relaciones de pareja.

Los adolescentes con más experiencia sexual tienden a utilizar sobre todo estrategias directas, tanto de avance como de limitación sexual, en mayor medida que aquellos con menor experiencia sexual. Esto se podría deber al incremento en el desarrollo de habilidades de interacción y comunicación que conlleva la mayor experiencia en relaciones interpersonales, que suele ir asociada a la mayor experiencia sexual. 
Sin embargo existen algunas excepciones, ya que la mayor experiencia sexual en varones parece incrementar también el empleo de estrategias indirectas y coercitivas en relaciones casuales. Podría ser que este tipo de estrategias sean percibidas por los varones como más eficaces que las estrategias directas en contextos casuales y por eso, los adolescentes varones más experimentados las utilicen para iniciar relaciones sexuales casuales más frecuentemente, que los menos experimentados.

Además la experiencia sexual muestra una influencia más intensa en el uso de estrategias sexuales en relaciones de pareja para las chicas, y en cambio para los varones, muestra una mayor influencia en el empleo de estrategias en relaciones casuales. Estas concluisiones sugieren que la adquisición de experiencia sexual está más ligada a las relaciones de pareja estables, en chicas que en chicos, una conclusión que cuenta con el apoyo de numerosas investigaciones que proponen que las normas sexuales culturales permiten a los varones un desarrollo sexual más independiente de las relaciones y más centrado en sí mismos, que a las mujeres.

Vemos pues que en la adolescencia se aprecia en alguna medida que cada sexo podría seguir un guión sexual interpersonal correspondiente y adecuado a lo que tradicionalmente se espera de su género, al menos en términos de conductas. A continuación discutiremos como no es así en términos de vivencias interiores, o guiones intrapsíquicos, como ocurre en el caso de las motivaciones sexuales.

\subsection{Motivaciones sexuales en la adolescencia}

En nuestra investigación la motivación sexual más importante para los adolescentes ha sido la motivación de intimidad, en segundo lugar se situaba la motivación de placer, seguida de la motivación de autorregulación emocional, y finalmente, cercanas la una a la otra, las motivaciones de evitación de rechazo de la pareja y de los amigos, en ese orden. La mayoría de las investigaciones que han tratado el tema de las motivaciones sexuales coinciden en señalar estas motivaciones positivas o de aproximación, como las más frecuentes a la hora de tener relaciones sexuales (Leigh, 1989; Spague y Quadagno, 1989; Brigman y Knox, 1992; Cooper et al., 1998; O'Sullivan y Gaines, 1998; Smiler, 2007). Sin embargo se han documentado también otro tipo de motivaciones relacionadas con la evitación de consecuencias o estados emocionales negativos, a las que se ha denominado como motivaciones aversivas o negativas (Cooper et al., 
1998; Christopher y Cate, 1984; Brigman y Knox, 1992; Caffray y Schneider, 2000). Estas se agruparon en el estudio de Cooper et al. (1998) en motivaciones de afrontamiento y autoafirmación, cuando se trata de evitar estados de ánimo personales, y en motivaciones de aprobación de la pareja o de los amigos, cuando se trata de evitar castigos o rechazos sociales.

En primer lugar, esperábamos que la motivación de intimidad fuese superior en la muestra de chicas que en la de chicos, y que ocurriese lo contrario para la motivación de placer. Esta hipótesis no se ha visto confirmada puesto que los adolescentes no difieren significativamente en motivación sexual en función del sexo. Este es un resultado muy interesante, ya que en primer lugar la motivación de intimidad también es la más importante para los chicos, por encima de la motivación de placer, y en segundo lugar, no existen diferencias entre chicos y chicas en los motivos por los que deciden tener actividad sexual.

Es interesante por un lado porque existe cierta controversia en cuanto a diferencias de género en motivación sexual. Múltiples investigaciones, en las que nos basamos para formular las hipótesis, señalan que los varones tienen mayores índices en todas las motivaciones, excepto en la motivación de intimidad (Clark et al., 1999; Cooper et al., 1998; Meston y Buss, 2007) o bien que los varones aducen más motivaciones relacionadas con la gratificación física y el placer a la hora de tener relaciones sexuales, mientras que las mujeres tienden a estar más motivadas por la necesidad de experimentar intimidad emocional que ellos (Carroll, Volke y Hyde, 1985; Leigh, 1989; Nelson, 1978; Browning, Hatfield, Kessler y Levine, 2000; Murstein y Tuerkheimer, 1998; Sprague y Quadragno, 1989; Seal y Ehrhardt, 2003; Patrick et al., 2007). Esto no ha sido así en nuestra investigación.

Sin embargo también contamos con una serie de investigaciones que, o no han encontrado diferencias entre hombres y mujeres en motivaciones sexuales, al igual que nuestro estudio (O'Sullivan y Gaines, 1998; Impett et al., 2005; Gebhardt et al., 2003) o introducen matices que apuntan en la dirección de nuestros resultados. Por ejemplo, Navarro-Pertusa et al. (2003) sugieren que las atribuciones que hicieron los adolescentes sobre motivaciones sexuales podrían reflejar estereotipos de género y no motivaciones personales. Horowitz (2000) descubrió que factores como el conformismo y la auto-acepetación mediaban los resultados situándose así como predictores de la motivación sexual por encima del género. Ott el al. (2006) señalan que en términos generales los adolescentes varones valoraban la intimidad por encima del placer, con lo que concluían la necesidad de revisar las asunciones tradicionales sobre la sexualidad masculina. Igualmente en el estudio de Smiler (2007) señalaban que las motivaciones sexuales 
más frecuentes de chicos adolescentes eran las relacionadas con la pareja y la relación, y que éstas se mostraban consistentes entre diferentes conductas sexuales y relaciones. En el estudio de Sprague y Quadragno (1989) encontraron interacciones entre el género y la edad, en el sentido de que a medida que los participantes avanzaban en edad, los dos sexos se aproximaban a las motivaciones sexuales propias del sexo opuesto. Además contamos con evidencia, que sugiere que las motivaciones sexuales de intimidad y de placer se entrelazan y en muchas ocasiones concurren (Seal et al., 2008).

Estos estudios, introducen variables que cuestionan y matizan unas asunciones tremendamente extendidas sobre las diferencias de género en motivación sexual, otorgando al tema una mayor complejidad e interés. Es posible que los estudios más recientes estén evaluando las motivaciones sexuales con una metodología que ha permitido reflejar el desleimiento de las diferencias de género en materia de motivación sexual, y la confluencia creciente de varones y mujeres hacia una motivación más basada en la intimidad emocional, integrada con la búsqueda del placer físico principalmente.

La otra conclusión interesante es que, tal y como señalan varios estudios (Seal et al., 2008; Ott et al., 2006; Smiler, 2007), incluido el nuestro, la necesidad y búsqueda de intimidad emocional parece ser el principal motor a la hora de mantener relaciones sexuales, tanto en chicas como en chicos adolescentes. Según algunos autores (Sanderson y Cantor, 1995; Cooper et al., 1998), las motivaciones sexuales nacen en función de las necesidades y el desarrollo evolutivo, ya que encontraron que la edad se asociaba positivamente a las motivaciones aproximativas, y negativamente a las aversivas. Así, es posible que en adolescentes más jóvenes se hubieran reflejado en mayor medida las necesidades relacionadas con la conformación de la identidad, a través de un mayor peso de las motivaciones centradas en uno mismo, como el placer y la autorregulación emocional, y de las motivaciones de aprobación social.

En nuestro estudio no se dieron asociaciones significativas entre las motivaciones sexuales y la edad de los participantes, puede que porque no incluíamos la adolescencia temprana, y no disponíamos de suficiente amplitud en rango de edad. Sin embargo, suponemos que en nuestra muestra de adolescentes medios y tardíos, estas necesidades de identidad están algo más cubiertas, lo que permite cambiar el foco de interés y curiosidad de los adolescentes, hacia el mundo de posibilidades que se abre ante ellos con el inicio de las relaciones de intimidad con parejas románticas. La novedad podría ser que los adolescentes varones están empezando a reconocer estas necesidades de intimidad y de expresión de sentimientos de una manera más abierta, y más paralela a las necesidades de las chicas adolescentes. 
Otra hipótesis que habíamos formulado mantenía que las motivaciones positivas de intimidad y placer se asociarían a un mayor nivel de experiencia sexual y que las motivaciones aversivas de autorregulación y evitación del rechazo social (parejas y amigos), se asociarían negativamente al nivel de experiencia sexual en adolescentes. Los resultados obtenidos han confirmado en alguna medida esta hipótesis, puesto que los adolescentes con mayores índices de motivaciones aproximativas, de placer y de intimidad tenían algo más experiencia sexual que los adolescentes con menores índices de estas motivaciones, mientras que los adolescentes con mayores índices de motivación de evitación del rechazo social, eran algo menos experimentados sexualmente que aquellos menos motivados por la aprobación social. La mayor parte de los estudios coinciden con estos resultados, ya que las motivaciones que han mostrado incrementar la frecuencia sexual son las motivaciones de placer o intimidad emocional o expresión de amor (Leigh, 1989; Browning et al., 2000; Cooper, Powers y Shapiro, 1998; Impett et al., 2005, 2006; Ott et al., 2006; Patrick, Maggs y Abar, 2007) así como que generalmente las motivaciones negativas se han relacionado con menor frecuencia de actividad sexual (Cooper et al., 1998; Impett, Peplau y Gable, 2005).

Esto es coherente con la perspectiva funcionalista de la motivación sexual, que sostiene que tener diferentes motivaciones sexuales estará asociado con diferentes patrones de conducta sexual, ya que las personas pueden utilizar, y utilizan, la actividad sexual para cubrir difeentes necesidades psicológicas. Según los análisis que llevaron a cabo Cooper et al. (1998) el patrón de relaciones entre las motivaciones positivas de intimidad y placer, y otras variables como la necesidad de sexo, la necesidad de intimidad, la búsqueda de sensaciones, erotofilia etc., sugería que estas motivaciones mantenían una orientación positiva y hedonista hacia la sexualidad y el sexo. Sin embargo, el patrón de relaciones de las motivaciones aversivas personales con otras variables sexuales, indicaba que este tipo de motivación sexual tenía una orientación ambivalente hacia el sexo, ya que incluía relaciones positivas con el neuroticismo, y con la necesidad general de aprobación social. Por otra parte las motivaciones aversivas sociales se caracterizaban por una ausencia de incentivos positivos para el sexo, mostrando relaciones casi insignificantes con la necesidad de sexo, de intimidad, búsqueda de sensaciones y erotofilia. Las relaciones más significativas las mostraban con erotofobia, neuroticismo y necesidad general de aprobación social. Según los autores, el miedo al rechazo parece ser lo único que motivaría hacia el sexo a los individuos que muestran este tipo de necesidades. 
Cooper et al., (1998) proponen que tener diferentes motivaciones sexuales estará asociado con diferentes patrones de conducta sexual, pero no sólo porque diferentes conductas satisfacen a personas motivadas por diferentes objetivos, sino porque personas con unos motivos dados, buscan y eligen circunstancias interpersonales concretas que facilitan la consecución de estas metas, y son estas circunstancias las que en última instancia, determinan la conducta sexual. En este sentido, nosotros habíamos formulado una hipótesis sobre motivaciones sexuales y contextos relacionales. Concretamente habíamos hipotetizado que los adolescentes que habían tenido ambas experiencias relacionales o bien sólo relaciones de pareja, mostrarían mayores índices de motivaciones sexuales positivas, que los adolescentes que sólo habían experimentado relaciones casuales, y que éstos en cambio, tendrían mayores índices de motivación sexual aversiva que aquellos.

Nuestros resultados han confirmado en alguna medida esta hipótesis, apoyando las propuestas de otros autores (Sanderson y Cantor, 1995; Cooper et al., 1998), puesto que los adolescentes que habían tenido los dos tipos de relaciones o sólo relaciones de pareja, mostraban niveles levemente mayores de motivación de intimidad que los adolescentes que sólo habían experimentado relaciones casuales. Por el contrario, estos adolescentes mostraban niveles ligeramente superiores de motivación para evitar el rechazo de los amigos, que los adolescentes que tenían experiencia en relaciones de pareja.

Según Cooper et al., 1998, las motivaciones sexuales que tienen las personas son una manifestación de su estilo de apego, siendo las motivaciones aproximativas más propias de personas con estilos de apego seguro y las motivaciones de evitación de consecuencias negativas, más propias en personas con estilo de apego inseguro. Así, nuestros resultados podrían estar apoyados en alguna medida por algunos estudios que relacionan el apego seguro con una tendencia a establecer relaciones de pareja estables y el apego inseguro con una tendencia a mantener relaciones a corto plazo (Schachner y Shaver, 2004; Paul, MacManus y Hayes, 2000; Cooper, Shaver y Collins, 1998).

Concluimos por tanto que las necesidades de intimidad emocional llevan en cierta medida a los adolescentes, a buscar contextos y circunstancias interpersonales, como son las relaciones de pareja, que faciliten la consecución o puesta en marcha de actividades sexuales o no sexuales, que puedan cubrir esas necesidades de expresión emocional. Y que la necesidad de aprobación de los pares, parece dificultar en alguna medida el establecimiento de relaciones de pareja estables, ya que, tal y como expusieron Cooper et al., (1998), el miedo al rechazo parece ser lo único que motivaría hacia el sexo, a los individuos que muestran este tipo de necesidades. Esto 
dejaría las relaciones esporádicas como único contexto probable para la puesta en marcha de actividades dirigidas a cubrir la necesidad de aprobación social en adolescentes.

Estos autores llegaron a la conclusión de que las motivaciones de autorregulación emocional y aprobación social, nacen principalmente de procesos de motivación aversiva, y que la clave distintiva entre tipos de motivaciones tiene más que ver con la valencia positiva o negativa de los incentivos que las caracterizan, que con el grado en el que están centrados en uno mismo o en los demás. En nuestros resultados hemos podido comprobar que efectivamente es la dimensión búqueda vs. evitación la que principalmente distingue a los adolescentes con unas u otras motivaciones. Sin embargo, con éste último resultado se ha puesto de manifiesto cierta repercusión de la dimensión objetivo individual vs. objetivo social, al ser la motivación sexual de intimidad (objetivo social) la única que parece promover y facilitar el establecimiento de relaciones de pareja, a diferencia de la motivación sexual de placer (objetivo individual).

2.2.1. Motivaciones sexuales y estrategias de negociación sexual

Por otra parte el estudio pretendía examinar qué influencia tenían las diferentes motivaciones sexuales sobre el empleo de estrategias de negociación sexual. Según la teoría de Gagnon y Simon (1973), el nivel intrapsíquico de los guiones sexuales son los elementos motivacionales que dan significado a las conductas sexuales y el nivel interpersonal, es la plasmación del guión intrapsíquico en secuencias de conducta compartidas socialmente. De esta manera esperábamos que, entre las motivaciones que impulsan y dan significado a las conductas sexuales, y las propias conductas o estrategias sexuales implusadas, existieran asociaciones significativas.

Además de la teoría de los guiones sexuales, hay otras teorías que respaldan esta propuesta, como la teoría de los estilos de apego adulto (Hazan y Shaver, 1994; Bartholomew y Horowitz, 1991), que señala que las necesidades en términos de apego guían las conductas destinadas a favorecer o dificultar el establecimiento de relaciones románticas; las teorías evolucionistas (Buss y Schmitt, 1993; Gangestad y Simpson, 1990) que argumentan que hombres y mujeres se enfrentan a necesidades evolutivas diferentes, por lo que las estrategias sexuales para cubrirlas son también diferentes; o el modelo de intimidad interpersonal (Reis y Shaver, 1988) que propone que las estrategias utilizadas en la búsqueda de la intimidad emocional pueden ser diferentes de aquellas utilizadas al servicio de la intimidad sexual. 
En nuestro estudio, concretamente esperábamos que las motivaciones sexuales aproximativas, las motivaciones de placer e intimidad, promoviesen un mayor uso de estrategias de negociación sexual de tipo no coercitivo y directo. Por el contrario, esperábamos que las motivaciones sexuales de evitación de consecuencias negativas impulsasen en mayor medida el empleo de estrategias indirectas y coercitivas.

Nuestras hipótesis en este sentido, han sido parcialmente confirmadas. La primera parte de la hipótesis es la más controvertida, puesto que a pesar de que las motivaciones de carácter aproximativo impulsan sobre todo el empleo de estrategias de avance sexual de tipo no coercitivo y directo, la motivación de placer se asocia además a otros tipos de estrategias, como la presión sexual, y la motivación de intimidad sólo tiene impacto en el empleo de comunicación directa en la muestra masculina.

La segunda parte de la hipótesis obtiene una confirmación más integral, puesto que en los dos contextos relacionales y para los dos sexos, las motivaciones negativas o de evitación de consecuencias negativas llevan a un mayor uso de estrategias de avance sexual de tipo indirecto y coercitivo.

Una conclusión que parece clara, es que las motivaciones que buscan conseguir un objetivo y las motivaciones que intentan evitar una consecuencia negativa, tienen diferentes repercusiones sobre la iniciación sexual. La distinción entre motivaciones positivas y negativas (de aproximación y de evitación de consecuencias negativas) ha demostrado tener implicaciones en el bienestar personal e interpersonal de las personas, en términos de emociones y satisfacción interpersonal (Impett; Downey et al., citado en Impett, Peplau y Gable, 2005). En trabajos posteriores estos autores (Impett et al., 2005) sugerían que el mecanismo mediador podría consistir en que cuando un individuo se involucra en actividad sexual por motivos de aproximación, como el placer o la intimidad, puede expresar de una manera más clara y explícita, verbal o fisicamente, su deseo y su placer, lo que tendría un efecto directo sobre la percepción de la pareja y la satisfacción general de ambos miembros. En cambio, la conducta sexual motivada por la evitación de consecuencias negativas, puede ser manifestada con mayor reticencia y ambigüedad, y menor entusiasmo, lo que puede ser percibido por la pareja y afectar negativamente a la satisfacción de ambos miembros.

Así, las motivaciones positivas parecen determinar una expresión más clara e inequívoca del interés sexual, a través del uso de estrategias sexuales más directas y explicitas, mientras que las 
motivaciones negativas determinan una forma de comunicación más ambigua y confusa con el empleo de estrategias indirectas, implícitas, o incluso coercitivas.

Hemos considerado más apropiado discutir las conclusiones relativas a las motivaciones aproximativas por separado, la motivación de placer por una parte, y la motivación de intimidad por otra, debido a las diferencias que han mostrado a la hora de asociarse al uso de estrategias sexuales. La motivación de placer se ha asociado en ambos contextos de manera muy similar: los chicos con mayor motivación de placer empleaban en mayor medida casi todas las estrategias de avance sexual, que aquellos con menor motivación de placer, y las chicas para las que la motivación de placer era más importante a la hora de tener actividad sexual utilizaban en mayor medida estrategias de contacto físico, que aquellas para las que esta motivación era menos importante. Así, la motivación de obtener gratificación física, al ser una motivación acorde al rol masculino y casi normativa en los varones, impulsa el empleo de una amplia variedad de estilos de avance sexual en los varones, y en las chicas, al ser una motivación sexual algo menos acorde al rol femenino, impulsa sólo tácticas de contacto físico.

A pesar de que habíamos hipotetizado una relación positiva con las estrategias directas específicamente, encontramos apoyo para nuestros resultados en algunos estudios que relacionan las motivaciones con la iniciación romántica y sexual, y que señalan que el placer sexual se busca a través del contacto físico, estrategias indirectas, flirteo y también manipulación, mientras que la motivación de amor o intimidad se persigue sobre todo a través de estrategias directas, verbales, y activas (Clark et al., 1999; Seal y Ehrhardt, 2003).

En el caso de la motivación de intimidad, los estudios expuestos sólo apoyarían a los resultados obtenidos en la muestra de varones, ya que sólo en ellos, la motivación de intimidad demostró impulsar la utilización de estrategias sexuales directas y verbales para iniciar encuentros sexuales. Además esta asociación sólo se dio así para el contexto de pareja, ya que en las relaciones esporádicas la motivación de intimidad favorecía el empleo de estrategias de avance de todo tipo, aunque sobre todo de contacto físico.

No tenemos una explicación muy segura de por qué la motivación de intimidad no se asociaba al uso de estrategias en la muestra femenina. Es posible que la motivación de incrementar la intimidad emocional, sea una motivación normativa y general en las adolescentes, es decir, no esté tan sólo asociada a la sexualidad sino que se encuentre detrás de muchas otras decisiones y conductas, y tenga un impacto mayor en otro tipo de comportamientos no sexuales. En línea con 
este razonamiento, están las conclusiones obtenidas en el estudio de Ott et al. (2006), que señalan que las chicas adolescentes tienen menores expectativas de que el sexo les conduzca a los objetivos buscados (en este estudio eran la intimidad, el estatus, y el placer, en este orden) que los varones adolescentes. De esta manera, puede ser que ante la menor expectativa de conseguir intimidad emocional a través del sexo, las chicas opten por buscar intimidad a través de otros medios, y por lo tanto, la frecuencia de iniciación sexual no se vea afectada por la motivación de intimidad. Así, las chicas más motivadas por la búsqueda de intimidad, pueden tener relaciones sexuales con este objetivo principalmente, pero pueden no estar motivadas para iniciar ellas la actividad sexual.

En cuanto a la diferente influencia de la motivación de intimidad en la iniciación sexual en ambos contextos para varones, diremos que nuestras expectativas sólo se vieron confirmadas para las relaciones de pareja, puesto que los varones con alta motivación de intimidad empleaban más estrategias de avance directas y verbales sólo en pareja, en relaciones esporádicas empleaban más las estrategias de carácter físico. Así, parece que las motivaciones sexuales se manifiestan o expresan de diferentes maneras en diferentes contextos relacionales tal y como sugerían Cooper et al. (1998). La misma motivación sexual, en este caso de búsqueda de intimidad emocional, parece suscitar diferentes estilos de negociación sexual a la hora de iniciar encuentros sexuales, en diferentes contextos relacionales en los varones. Los adolescentes chicos motivados por la búsqueda de intimidad, pueden evaluar las características de la relación en la que se encuentran y entonces ajustar o amoldar su guión intrapsíquico al guión interpersonal predominante, y así emplear unas u otras formas de comunicación sexual: en una relación de pareja se permiten emplear en mayor medida estrategias de avance directas y explícitas, mientras que en relaciones casuales prefieren emplear estrategias físicas, tanto directas como indirectas.

Cooper et al. (1998) en su trabajo sobre motivaciones sexuales en la adolescencia también demostraron que el estatus relacional jugaba un papel importante en la relación entre motivaciones y conductas sexuales. En concreto, proponían que el efecto de las motivaciones sexuales se ve moderado por otros factores, como el contexto relacional. Así, la influencia de las motivaciones de placer, intimidad y búsqueda de aprobación sobre el uso del condón difería tanto en magnitud como en dirección, entre individuos que estaban en relaciones de pareja estables, comparados con aquellos que no lo estaban. En un ámbito diferente, relacionado con el estudio de estrategias de resolución de conflictos relacionales, Sanderson y Karetsky (2002) descubrieron por una parte que los estudiantes universitarios más centrados en la intimidad 
empleaban más estrategias de comunicación abierta para manejar el conflicto, que aquellos menos centrados en la consecución de intimidad, pero por otro lado, vieron que el estatus relacional interaccionaba significativamente, siendo aquellos que estaban en una relación de pareja, los que más probablemente utilizarían estas estrategias, frente a los que no tenían una relación de pareja en ese momento.

En cuanto a las conclusiones relativas a las motivaciones negativas, el hecho de que los adolescentes más motivados por el deseo de evitar consecuencias negativas sean los que más frecuentemente emplean formas de negociación sexual indirectas y coercitivas puede explicarse con algunos estudios previos que ofrecen resultados que podrían apuntar en esta dirección. Como ya hemos comentado, algunos estudios han examinado la relación entre motivaciones aproximativas y aversivas, y determinadas consecuencias para el bienestar de las personas. Gable, Reiss y Elliot (2000) encontraron que participantes con una alta sensibilidad al sistema de inhibición, es decir aquellos individuos más probablemente motivados hacia la evitación de eventos y consecuencias, indicaban mayores índices de emociones negativas diarias, aunque no menor índice de emociones positivas, que aquellos con baja sensibilidad al sistema de inhibición. Además en términos de salud, la motivación de evitación se asocia con más muestras de síntomas físicos, mayor depresión y menores niveles de optimismo vital (Elliot y Sheldon, 1997). También hemos visto, que en el nivel interpersonal, las motivaciones de tipo aversivo se vinculaban con menores índices de satisfacción relacional.

Así, iniciar o acceder a tener relaciones sexuales por evitar un conflicto, una decepción o un malestar emocional, puede en el mejor de los casos conducir al alivio, y en el peor producir las emociones negativas y la tensión que se estaba intentando evitar (Purdie y Downey, 2000; Downey et al., citado en Impett, Peplau y Gable, 2005). Es posible que sea, a través de este circuito de motivación aversiva y emoción negativa, que los adolescentes tienden a emplear formas de negociación sexual menos claras o menos constructivas con otra persona. La inseguridad emocional y los temores dificultan la confianza en uno mismo y en los demás, e incrementan la vulnerabilidad y la sensibilidad al rechazo, por lo que pueden conducir a la utilización de estrategias sexuales más encubiertas por una parte para reducir lo máximo la propia exposición, y coercitivas por otra parte, para reducir lo máximo las posibilidades del rechazo.

Si acudimos al estilo de apego como fuente de diferencias en motivaciones sexuales, vemos que contamos con estudios que asocian el apego inseguro ansioso (relacionado con motivaciones 
sexuales negativas) con la inefectividad en negociaciones sexuales (Feeney, Peterson, Gallois y Terri, 2000). Igualmente, nuestros resultados son consistentes con los resultados del estudio sobre apego y presión sexual de Brassard et al. (2007) en el que han vinculado el apego inseguro ansioso con la mayor utilización de la presión sexual, frente al apego seguro, aunque sólo obtuvieron este resultado en la muestra masculina.

Hemos observado que la vinculación entre motivaciones sexuales de evitación de consecuencias negativas y uso de estrategias de presión en relaciones de pareja es de significación alta y en relaciones casuales, es moderada. Además, ocurre lo contario para la asociación de estas motivaciones negativas con el uso de estrategias indirectas, que se muestra algo más intensa para las relaciones ocasionales que para las relaciones de pareja. Esto ocurre tanto en chicas, como en chicos. De nuevo, observamos cómo las motivaciónes sexuales se podrían estar manifiestando o expresando de manera diferente en la conducta de iniciación sexual, en función del tipo de relación en la que se encuentre el adolescente. Los adolescentes con motivaciones sexuales negativas intensas podrían estar eligiendo su forma de negociación sexual en función por un lado, de su guión motivaciónal intrapsíquico basado en el deseo de evitar consecuencias negativas, y por otro, del guión interpersonal predominante, basado en "lo que se hace" según el tipo de relación que mantiene con la otra persona.

Los adolescentes con motivaciones sexuales basadas en la inseguridad emocional podrían sentirse más inclinados a emplear formas de presión más que estrategias indirectas para iniciar encuentros sexuales con sus parejas, ya que podría predominar el objetivo de minimizar las posibilidades de rechazo, sobre objetivos tales como minimizar la propia exposición. En relaciones de pareja, en donde existe mayor posibilidad de compartir sentimientos, actividades y tiempo, surgen más oportunidades para que la inseguridad emocional, ya sea en la forma general de apego inseguro o en la forma más específica de motivaciones sexuales negativas, se exprese a través de conductas menos constructivas y desadaptativas, como es la presión sexual. En este sentido contamos con estudios que han asociado el apego inseguro ansioso, con el empleo de formas de presión e insistencia sexual principalmente en relaciones de pareja (Davis, 2006; Brassard, Shaver y Lussier, 2007), ya que se utiliza la presión sexual cuando sienten que la relación o la intimidad están amenazadas. La falta de familiaridad y la menor involucración emocional que se da en las relaciones casuales podría en cambio determinar las formas de iniciación sexual hacia otras direcciones: los adolescentes motivados sexualmente por temores e inseguridades podrían en este contexto tender en mayor medida al empleo de estrategias de avance sexual indirectas, con el objetivo de minimizar la propia exposición, que es lo que más podría interesar en este contexto menos familiar. 
Con relación a la influencia que tienen las motivaciones sexuales sobre el uso de la limitación sexual, hallamos que las motivaciones aversivas se asociaban positivamente al empleo de estrategias indirectas de limitación sexual en ambos sexos, aunque en los chicos en el contexto de pareja y en las chicas en el contexto de relaciones esporádicas. Consideramos este un resultado más, que confirma nuestra hipótesis de que las motivaciones sexuales aversivas incrementan la probabilidad de emplear tácticas indirectas y coercitivas en la negociación sexual entre adolescentes.

Concluimos que los adolescentes impulsados sexualmente por el deseo de evitar conflictos y por el temor de ser rechazados, tienden a utilizar una comunicación sexual encubierta y coercitiva para iniciar encuentros sexuales, y una forma de limitación sexual basada en excusas, rodeos y distracciones, en mayor medida que aquellos que no lo están. Como ya vimos en la revisión teórica, el empleo de excusas y formas indirectas para limitar la actividad sexual tiene muy poca eficacia puesto que estos impedimentos improvisados son facilmente desmontables, y dejan a la persona indefensa, una vez que son superados (Crawford et al., 1994). Esto aumenta la probabilidad de tener experiencias sexuales no deseadas, y sentimientos de verguenza y de culpa tras el encuentro sexual, lo que a su vez puede inducir a una inseguridad y vulnerabilidad emocional general, que fomenta el desarrollo de motivaciones sexuales basadas en los temores al rechazo, y la evitación de estados emocionales negativos. Y de nuevo, las personas motivadas por temores y por el malestar emocional, comprensiblemente se sienten menos capaces de expresar de una manera asertiva y directa sus deseos e intenciones sexuales, por lo que recurren a formas de comunicación encubiertas. De esta forma consideramos que se mantiene el mecanismo que explica la asociación entre motivaciones sexuales de evitación de consecuencias negativas y formas de comunicación sexual. En el proximo apartado discutiremos, más concretamente y entre otras cosas, la relación entre motivaciones sexuales y formas coercitivas de iniciación sexual.

\section{$\underline{\text { Resumen del apartado }}$}

El principal motor que impulsa la actividad sexual en la adolescencia es la motivación sexual de intimidad emocional, seguida de la motivación sexual de placer. Esto es así para ambos sexos, lo cual sugiere cierta confluencia entre los género en términos de guiones intrapersonales, puede que debido a que los adolescentes varones están empezando a percibir y reconocer estas 
necesidades de intimidad y de expresión de sentimientos de una manera más abierta, y más paralela a las necesidades de las chicas adolescentes. La tercera motivación sexual más frecuente es la motivación de autorregulación emocional, seguida de las motivaciones que evitan el rechazo, en forma de búsqueda de aprobación de la pareja y del grupo de amigos, bastante menos frecuentes.

Por otra parte, las diferentes motivaciones sexuales se han asociado a diferentes patrones de conducta sexual y romántica. Las motivaciones sexuales aproximativas han mostrado tener una orientación positiva hacia el sexo, contribuyendo en cierta medida a incrementar la experiencia sexual de los adolescentes. Por el contrario, las motivaciones sexuales de evitación de consecuencias negativas, que se caracterizan por una ausencia de incentivos positivos para el sexo, parecen dificultar la frecuencia de la actividad sexual, y con ella la adquisición de experiencia sexual en adolescentes. Las motivaciones sexuales además, parecen contribuir en alguna medida a que los adolescentes busquen circunstancias interpersonales concretas que faciliten la consecución de sus metas. En este sentido la motivación sexual de intimidad parece facilitar en los adolescentes el establecimiento de relaciones de pareja como contexto que mejor posibilita cubrir estas necesidades de expresión emocional. Por otra parte, la motivación sexual de evitación del rechazo del grupo de iguales podría dificultar en alguna medida el establecimiento de relaciones de pareja, lo que dejaría las relaciones casuales como único contexto probable para la puesta en marcha de actividades dirigidas a cubrir la necesidad de aprobación social en adolescentes.

Las diferentes motivaciones se han asociado además a diferentes estilos de comunicación y negociación sexual, en la iniciación y limitación de actividad sexual. El placer sexual parece suscitar el empleo de casi todas las estrategias de avance sexual, incluyendo las estrategias de presión sexual. La motivación sexual de intimidad emocional sólo se ha reflejado en la iniciación sexual de los chicos, concretamente incrementa el uso de comunicación sexual directa y verbal en relaciones de pareja, y el uso de estrategias físicas en relaciones casuales. Atribuimos la falta de reflejo de esta motivación en la iniciación sexual femenina, a que quizás las chicas tengan una menor expectativa de lograr una mayor intimidad emocional a través del sexo y opten por buscar intimidad a través de otros medios.

Los adolescentes impulsados sexualmente por el deseo de evitar conflictos y por el temor de ser rechazados, tienden a utilizar una comunicación sexual encubierta y coercitiva para iniciar encuentros sexuales, entendemos que para reducir lo máximo la propia exposición, asi como las posibilidades de rechazo. También emplean una forma de limitación sexual basada en excusas, rodeos y distracciones, en mayor medida que aquellos que no están impulsados por estas 
motivaciones, posiblemente porque su inseguridad emocional dificulta el que puedan expresar de una manera asertiva y directa sus deseos sexuales.

Finalmente parece que el contexto relacional podría jugar cierto papel en la manera en la que las motivaciones sexuales se manifiestan en la comunicación sexual: la motivación sexual de intimidad podría favorecer en los varones una comunicación sexual directa y verbal, sobre todo en relaciones de pareja; las motivaciones sexuales de evitación de consecuencias negativas impulsarían formas de comunicación sexual indirectas sobre todo en relaciones casuales, y formas de comunicación sexual coercitivas especialmente en relaciones de pareja. Quizás futuros estudios puedan examinar con mayor profundidad la relación entre motivaciones sexuales, contexto relacional y comunicación sexual.

\section{PRACTICAS SEXUALES ASOCIADAS AL RIESGO}

\subsection{Coerción sexual en la adolescencia}

Las principales conclusiones que proponemos sobre el empleo de la coerción sexual en adolescentes a nivel descriptivo son las siguientes. En primer lugar la prevalencia de las tácticas de presión sexual y de fuerza física son muy diferentes. Mientras que contamos con dos tercios de chicos y un tercio de chicas que alguna vez han utilizado alguna táctica de presión sexual en ambos contextos relacionales, sólo entre un 3\% y un 5\% de los adolescentes de esta muestra han utilizado alguna táctica de fuerza física para tener actividad sexual, también en ambos contextos relacionales.

Afortunadamente, los índices de empleo de estrategias de forzamiento físico sexual son marginales, sin embargo, un porcentaje muy destacable de adolescentes ha empleado alguna vez la presión sexual. Los porcentajes de empleo de la presión sexual son algo superiores a los encontrados en otros estudios sobre coerción (Sipsma et al., 2000; Fuertes et al., 2005; Ramos y Fuertes, 20005; Ramos et al., 2006; Fuertes et al., 2006; Anderson y Newton, 2004; Russell y Oswald, 2001), quizas porque nuestro porcentaje se deriva del mínimo uso de alguna estrategia de presión sexual, entre las que además se encuentra alguna forma de argumentación e insistencia verbal, agrupada en nuestro estudio entre otras tácticas de presión y manipulación más claramente coercitivas. Sin embargo, son datos que requieren una atención particular, 
puesto que es en la adolescencia cuando se establecen los hábitos y normas de interacción sexual, que muy probablemente se arraiguen en la adultez, y lo que comienza siendo un mero intento de convencimiento puede evolucionar a otras formas de insistencia persistente y manipulación. Por otra parte, la intensa asociación entre el uso de la presión sexual y la fuerza física nos lleva a pensar que los pocos adolescentes que emplean la fuerza física, han podido utilizar previamente la presión sexual para conseguir tener relaciones sexuales, lo que justifica cierta inquietud frente a formas incipientes de insistencia sexual.

La segunda conclusión, es que no hay diferencias en función del contexto relacional en el uso de estrategias de coerción, por lo que entendemos que son más probablemente variables de personalidad las que condicionan principalmente el uso de estrategias coercitivas. Esta conclusión ha sido obtenida a través diversos análisis a lo largo de la investigación, tanto en la comparación realizada con los mismos participantes y variando el contexto relacional, como con diferentes sujetos con diferentes experiencias relacionales. Algunos estudios (Christopher y Frandsen, 1990) sugieren que las tácticas de influencia coercitiva se explican más a través de variables de personalidad, mientras que el uso de tácticas de influencia positiva se explica en mayor medida por dinámicas de relación.

Por otros estudios conocemos que hay determinadas variables de personalidad directamente implicadas en la puesta en marcha de formas de coerción sexual, mientras que lo que sabemos sobre los factores relacionales, tiene que ver con aspectos circunstanciales: cómo afectan al tipo de táctica coercitiva empleada, a la vivencia de la víctima, o a la evaluación que se hace del suceso, pero no con que determinen la puesta en marcha de actos sexualmente coercitivos (Livigstone et al., 2004; Cleveland et al., 1999; Malamuth et al., 1991; Fuertes et al., 2005; Dybvig-Pawelko, 2007; Davis, 2006; Littleton y Axsom, 2003). A este respecto, también hemos hallado en nuestro estudio una diferencia interesante, y es que la táctica de presión de "emborrachar o aprovecharse de la borrachera de la otra persona para tener actividad sexual", era significativamente más frecuentemente empleada en el contexto casual, que en el de pareja, lo que coincidía con el estudio de Cleveland et al. (1999) en el que encontraron que el uso de la fuerza y la intoxicación decrecían en relaciones de mayor intimidad, en las que hay un acceso más fácil a la víctima. En este sentido consideramos que es de notable importancia continuar investigando para clarificar el papel que el tipo de relación puede tener o no tener, en la puesta en marcha de estrategias sexualmente coercitivas. 
En tercer lugar, los adolescentes varones, como ya hemos visto antes, emplean en mayor medida estrategias de presión sexual para iniciar actividad sexual, que las chicas. Nuestros resultados están en sintonía con las conclusiones ofrecidas en la revisión de investigaciones previas (Fuertes et al., 2006; Ramos, Fuertes y De la Orden, 2006; Felson, 2002; Christopher y Frandsen, 1990; Greer y Buss, 1994; Dybvig-Pawelko, 2007; Brassard el al., 2007; Eyre et al., 1997; Christopher et al., 1998).

Hay múltiples factores que explican el mayor empleo de la presión sexual por parte de los varones, aunque el telón de fondo es siempre la desigualdad entre géneros. En primer lugar, los estereotipos sociales en torno a lo que implica la masculinidad, en términos de fortaleza, independencia y poder, frente a la feminidad, impregnan los procesos de construcción de identidad en la adolescencia. Estas mismas concepciones y expectativas sociales, dan forma a los guiones conductuales que se toman como referencia para la interacción social, es decir, son el contenido del guión sexual predominante, en el que el varón toma la iniciativa y la dirección del encuentro sexual, mientras la mujer adopta un papel acorde a su cualidad femenina, dependiente, reactiva, etc. (LaPlante et al., 1980; Metz y Spitzberg, 1996; Byers, 1996). Este esquema implica que el hombre además de iniciar, tendrá muchas veces que esforzarse, cruzando aveces la fina línea de la legitimidad, por superar las resistencias de la mujer, ya que el papel otorgado a la mujer como responsable limitadora de la actividad sexual, y la devaluación que supone para una mujer tener múltiples parejas sexuales, puede llevar al hombre a pensar que su resistencia no es genuina (García, 1998; Muelenhard et al., 1996).

Además hay determinados mitos sobre las agresiones sexuales, que justifican la agresión sexual fomentando las creencias de que "la mujer es la que provoca", o que "en el fondo le gusta" (Kowalski, 1992; Muelenhard, 1988). Estas creencias son reforzadas por el hecho de que los varones suelen percibir mayor interés sexual por parte de los demás, especialmente por parte de las mujeres, que las mujeres (Abbey, citado en Littleton y Axsom, 2003; Shotland y Craig, 1988).

Por otra parte, los rasgos de personalidad que se han visto asociados al empleo de la coerción sexual, tienen todos algo en común, y es que en general son rasgos que suelen ser más propios de los varones, como la masculinidad hostil, la predisposición al sexo casual, la menor capacidad empática, la agresividad, etc. Todos estos elementos explican que la coerción sexual, en nuestro caso, la presión sexual, sea más empleada por varones que por mujeres, tal y como exponen en general múltiples investigaciones (Malamuth et al., 1991; Bourg, 2001). Esto no implica sin embargo, que no haya que inquietarse por el uso que de la coerción sexual hacen las 
mujeres hacia los hombres. En nuestra investigación alrededor de un 30\% de las adolescentes ha empleado alguna vez alguna táctica de presión y manipulación sexual, un hecho sobre el que es imprescindible reflexionar e investigar en profundidad.

En cuanto a la asociación entre uso de estrategias de presión y uso de otro tipo de estrategias de iniciación sexual, hemos visto que en los varones se asocia positivamente al uso de todo tipo de estrategias de avance sexual en ambos contextos relacionales. Las chicas que utilizan la presión sexual en relaciones de pareja utilizan levemente más los gestos de seducción, y en relaciones casuales utilizan en mayor medida estrategias de iniciación sexual directa. Sólo en las chicas se asocia el uso de la presión sexual en pareja con la limitación indirecta. En relaciones casuales, los adolescentes que utilizan más la presión son los que más usan la limitación sexual en general.

Así, el empleo de la presión sexual en los varones en ambos contextos relacionales, además de ser más frecuente que el de las chicas, está integrado en un repertorio más amplio de conductas de iniciación. Los adolescentes varones que emplean estrategias coercitivas de presión, probablemente utilicen además todo tipo de estrategias diferentes para lograr su objetivo. Encontramos apoyo para este resultado en el estudio de Dybvig-Pawelko (2007), ya que introdujeron una medida de agresividad sexual que correlacionaba positivamente con casi todos los tipos de estrategias de avance sexual, coercitivas y no coercitivas. Las chicas que utilizan estrategias de presión sexual en cambio, apenas emplearan en mayor medida otros tipos de estrategía de avance sexual, sólo gestos de seducción en pareja, y estrategias directas y de fuerza en relaciones casuales. Así, puede que la existencia de una agresividad sexual más normativa en los varones, se manifieste a través del empleo de todo tipo de estrategias para iniciar encuentros sexuales, mientras que una agresividad sexual menos normalizada en chicas, afecte de manera más selectiva sobre la utilización de estrategias de avance más específicas.

En relación con la asociación entre motivaciones sexuales y uso de la presión sexual, como ya vimos en el apartado anterior en la muestra de varones todas las motivaciones sexuales, menos la de intimidad, muestran una correlación positiva con el empleo de la presión sexual. En las chicas, sólo las motivaciones negativas incrementan el uso de la presión para iniciar actividad sexual. La relación encontrada entre las motivaciones negativas y el uso de la presión sexual la discutimos en el apartado anterior, en el que exponíamos que los adolescentes cuyas motivaciones se basan en los temores y el deseo de evitar el rechazo, se pueden sentir más vulnerables emocionalmente, y puede que esto favorezca que tiendan a emplear formas insistentes de presión sexual, para reducir las posibilidades de ser rechazados. En esta línea, el 
estudio de Bourg (2001) destacaba que la aceptación social se constituía como una de las principales motivaciones sexuales vinculadas al uso de la coerción y agresión sexual.

Como también vimos, la asociación entre motivaciones sexuales negativas y el uso de la presión sexual era más significativa en las relaciones de pareja $(\mathrm{p}<.01)$ que en las relaciones esporádicas $(\mathrm{p}<.05)$ para ambos sexos, luego los adolescentes con motivaciones sexuales de evitación de consecuencias negativas, tendrían mayor probabilidad de emplear formas de presión sexual en relaciones de pareja, que en relaciones casuales. Esto deja abierta la cuestión de que si ninguna de las motivaciones sexuales estudiadas se asocia poderosamente al uso de la presión sexual en relaciones casuales, es posible que haya otro tipo de motivaciones sexuales no contempladas en este trabajo, como podría ser la motivación de poder o de control, que se vinculen más intensamente al empleo de la presión sexual en contextos esporádicos. A este respecto, sería interesante la inclusión de otro tipo de motivaciones sexuales en el estudio de la coerción sexual en relaciones casuales.

La motivación sexual de intimidad es la única que no impulsa la puesta en marcha de estrategias de presión sexual (apenas levemente en varones en relaciones casuales). Esta es quizás la motivación sexual más prosocial, puesto que ademas de ser positiva, está orientada a los demás. Sabemos que los adolescentes que desean conseguir un acercamiento emocional a sus parejas, tienen más probabilidades de expresar sus deseos de manera abierta y constructiva (Sanderson y Karetsky, 2002). Además en el estudio de Tschann et al. (2002) se concluyó que los adolescentes con mayor deseo de intimidad emocional, eran considerados como el miembro con menos poder relacional en la pareja, lo que puede contribuir a que sea menos probable que éste miembro de la pareja, consiga ejercer presión sobre el otro miembro (con mayor poder relacional) para conseguir tener relaciones sexuales.

En resumen, el género ha resultado ser un factor determinate en el empleo de la presión sexual, ya que los chicos hacen un mayor uso de la presión que las chicas y que éste uso, se ve además integrado dentro de un repertorio más variado de estrategias y suscitado también por más variedad de motivaciones sexuales, incluidas motivaciones aproximativas, mientras que sólo las motivaciones sexuales negativas impulsarían la presión sexual en las chicas. Luego cabe pensar, que la presión como estrategia sexual, no sólo es más frecuente, sino que está más normalizada en la muestra masculina que en la femenina. Esto no significa sin embargo, que haya que despreocuparse del uso que de la presión sexual hacen las chicas hacia los chicos.

Aunque el contexto relacional no parece afectar directamente a la frecuencia de uso de la presión sexual, sí podría ser un factor discriminante en cuanto a algunos correlatos en el uso de 
la presión sexual, como son las motivaciones sexuales de evitación de consecuencias negativas. Así, los adolescentes con motivaciones sexuales de evitación de consecuencias negativas, tendrían mayor probabilidad de emplear formas de presión sexual en relaciones de pareja, que en relaciones casuales.

Por último, el uso de la fuerza en ambos contextos se puede considerar marginal. La fuerza como estrategia sexual está mucho menos normalizada en la muestra de varones que el uso de la presión. Sin embargo, su alta correlación mutua, sobre todo en relaciones esporádicas, hace pensar que de los pocos adolescentes varones que utilizan la fuerza para obtener relaciones sexuales, la mayoría han utilizado también la presión sexual.

\subsection{Uso del preservativo en la adolescencia}

Las principales conclusiones obtenidas sobre la utilización del preservativo en adolescentes son en algunos aspectos alentadoras. Los adolescentes utilizan el preservativo en casi la totalidad de las relaciones coitales, tanto en pareja como en relaciones esporádicas. Sin embargo, hay alrededor de un $12 \%$ de adolescentes que utilizó el preservativo sólo en la mitad o menos de la mitad de las veces que tuvo relaciones coitales. Diversos estudios realizados en España con adolescentes coinciden con nuestros resultados ya que el porcentaje de utilización del preservativo se sitúa entre el 75 y el $85 \%$ en la primera o en la última relación sexual (Ramos, Fuertes, Martínez y Hernández, 2003; Diz et al., 2003; Planes et al., 2004; Espadalé, Planes y Gras et al., 2005; Cerqueira-Santos et al., 2008; INJUVE, 2000).

Nuestra hipótesis de que la utilización del preservativo sería más frecuente en relaciones esporádicas sobre las relaciones de pareja no ha sido confirmada, puesto que no hemos hallado diferencias en función del contexto relacional en el uso del condón. Habíamos esperado esa diferencia puesto que la mayoría de los estudios que examinan el uso del condón en diferentes contextos relacionales, observan que a medida que pasa el tiempo en una relación de pareja el empleo del preservativo va reduciendose paulatinamente a favor de otros métodos como la píldora anticonceptiva (Bauman y Berman, 2005; Rosenthal et al., 1998; Hynie et al., 1998; Friedman et al., 2001; Gebhardt et al., 2003).

Es posible que no hayamos obtenido tal diferencia porque las relaciones de pareja en este estudio no tengan una duración lo suficientemente larga como para sustituir el preservativo por la píldora, ya que la mínima duración requerida era de 3 meses. De hecho, la duración de la 
relación de pareja sí ha mostrado una relación inversa con el uso del preservativo, aunque sólo en las chicas. Así, el hecho de que a medida que las chicas lleven más tiempo en una relación de pareja, utilicen cada vez menos el preservativo podría verse como un indicio de apoyo para nuestra hipótesis, ya que en relaciones de pareja las chicas utilizarían menos el preservativo que en relaciones esporádicas, siempre y cuando las relaciones de pareja sean estables y duraderas.

Puesto que no hemos observado diferencias entre contextos, entendemos que este $12 \%$ de adolescentes que emplean el preservativo en la mitad o menos de las ocasiones, podrían diferir de los que utilizan el condón siempre o casi siempre, en variables más relacionadas con la personalidad. Sin embargo, el género no sería una de estas variables, ya que no hemos encontrado diferencias entre chicos y chicas en la utilización del preservativo.

La variable experiencia sexual sí ha resultado determinante para la utilización del preservativo, puesto que en general, cuanta más experiencia sexual tienen los adolescentes, menos probable es que utilicen el preservativo. Esto es sin embargo al revés para el caso de los varones que se encuentran en relaciones casuales, quienes utilizan más el condón en la medida en la que tienen mayor experiencia sexual. Nuevamente el contexto relacional en que se encuentran los adolescentes, modera de alguna manera la influencia que tiene la experiencia sexual en la puesta en marcha de conductas como la utilización del preservativo. Parece que la experiencia sexual incrementa la utilización del preservativo en relaciones casuales y lo disminuye en relaciones de pareja en los chicos. La experiencia sexual en adolescentes, se ha visto asociada negativamente al uso del preservativo en algunos estudios (Auslander, Perfect, Succop y Rosenthal, 2007; Kvalem y Traeen, 2000), pero desafortunadamente no contamos con datos sobre utilización del preservativo y la experiencia sexual, en función del contexto relacional. Sin embargo, el hecho de que la experiencia sexual juegue a favor del preservativo en relaciones casuales y en contra en relaciones de pareja, es consistente con la idea de que el sexo casual desprotegido es más arriesgado que el sexo desprotegido en pareja, idea que puede desarrollarse a medida que se va teniendo más experiencia y conocimientos. Tal y como escribieron Cooper et al. (1998) influencias que son perjudiciales en determinados entornos, pueden resultar benignas en otros.

Las motivaciones sexuales son otro factor a tener en cuenta en la utilización del preservativo, aunque sólo para las chicas en relaciones esporádicas. La utilización del preservativo en relaciones de pareja no ha mostrado ninguna vinculación a las motivaciones sexuales para ningún sexo, luego concluimos que el uso del preservativo en pareja es independiente a las motivaciones sexuales de los adolescentes. La utilización del preservativo en relaciones 
esporádicas en cambio se ve disminuida por la presencia de una alta motivación sexual de intimidad en las chicas. Nuestra hipótesis ha sido pues parcialmente confirmada.

El hecho de que no se haya encontrado una relación inversa con la motivación de placer, como experábamos, es inconsistente con algunos resultados obtenidos en investigaciones previas. Varios estudios por ejemplo han relacionado negativamente la motivación de placer y el uso del preservativo (Cooper et al., 1998; Browning, Hatfield, Kessler y Levine, 2000) en ambos sexos, sugiriendo así que la motivación de experimentar el placer durante un encuentro sexual puede dificultar el hecho de interrumpir el momento para tomar medidas preventivas. Esto se ha encontrado sobre todo en contextos de pareja (Cooper et al., 1998), aunque no se ha reflejado así en nuestra investigación para ninguno de los dos sexos.

En cuanto a la motivación de intimidad, nuestro resultado sí es consistente con investigaciones previas puesto que se ha observado una relación negativa entre esta motivación en las relaciones sexuales, y la utilización del preservativo (Cooper et al., 1998; Gebhardt et al., 2003) y este resultado se ha apreciado especialmente en chicas (Gebhardt et al., 2006), al igual que en nuestro estudio. En el caso de los chicos, hay resultados que muestran que las motivaciones sexuales relacionadas con el amor aumentan el uso del preservativo (Kvalem y Traeen, 2000).

La explicación para este resultado la ofrecen en su trabajo sobre el poder relativo Tschann et al. (2002), quienes señalan que el miembro de la pareja que tiene menor deseo de intimidad emocional es el que tiene mayor poder en esa relación y que aquellos adolescentes que tienen mayor poder que sus parejas en el ámbito de la intimidad emocional, tienen mayores probabilidades de salirse con la suya en términos de uso del preservativo. Además se observó que los chicos solían tener mayor poder relativo en el ámbito de la intimidad emocional que las chicas. Así parece probable que las chicas que desean mayor nivel de intimidad no se atrevan a insistir en llevar a cabo sus deseos sexuales (como el uso del condón) y prefieran no emprender ninguna acción que ponga en peligro la relación en la que desean invertir emocionalmente. Esto coincide con las conclusiones obtenidas por otros autores, que exponen que las mujeres que valoran altamente los aspectos íntimos de su relación, tienen mayor probabilidad de amoldarse a los deseos de su pareja en cuestión de métodos anticonceptivos, como consecuencia de su deseo de mantener la relación (Amaro, 1995; Hynie et al., 1998).

El hecho de que esta relación inversa sólo se haya obtenido en relaciones esporádicas puede ser explicado por las conclusiones obtenidas en el estudio de Sanderson y Cantor (1995). Estos 
autores expusieron que cuando los adolescente están en un contexto relacional coherente con sus necesidades y objetivos, es decir, cuando están por ejemplo en relaciones de pareja en las que pueden satisfacer sus necesidades de intimidad, es más probable que lleven a cabo prácticas sexuales seguras, mientras que estar en un contexto casual, con objetivos sociales basados en la búsqueda de intimidad es más probable que conlleve cierta tensión y frustración. Esta frustración puede dificultar que se den las condiciones apropiadas para asegurar las conductas preventivas, a través por ejemplo de un mayor consumo de alcohol, o cediendo el control de la situación a la pareja. Igualmente Cooper et al. (1998) encontraron que mientras que la motivación de intimidad favorecía el uso del condón en relaciones de pareja, lo dificultaba en relaciones casuales. Podemos decir, al igual que estos autores, que la influencia de las motivaciones sexuales se ve afectada por el contexto relacional, ya que sólo en el contexto esporádico ha resultado ser desventajosa la motivación de intimidad en las chicas, con relación al uso del preservativo.

En cuanto a cómo se integra el uso del preservativo en la puesta en marcha de los guiones de iniciación sexual, parece que sólo se ha asociado negativamente en la muestra masculina a algunos tipos de estrategia de avance sexual en relaciones de pareja. Nuestra conclusión es por lo tanto que los adolescentes varones que inician la actividad sexual en pareja, a través de estrategias de presión y de estrategias de contacto físico, utilizan en menor medida el preservativo que aquellos que utilizan menos estas formas físicas y coercitivas de iniciación sexual.

A pesar de no haber encontrado estudios que relacionasen el uso del preservativo con el empleo de determinadas estrategias de iniciación o limitación sexual, hay alguna evidencia que sugiere cierta relación positiva entre la coerción sexual y mayor riesgo de contraer enfermedades de transmisión sexual. Esta relación se ha hallado más para víctimas de coerción, que para perpetradores (Choi et al., 1998). Parece probable que la violencia ejercida principalmente por el hombre juegue un papel importante a la hora de disuadir a la mujer para que intente negociar el uso del preservativo (Doll y Carballo-Diéguez, 1998). La asociación obtenida entre uso de la presión sexual en pareja por parte de los varones, y menor uso del preservativo, puede reflejar una desequilibrio de poder entre los miembros de la relación de pareja. Es probable que el miembro en posición de exigir y presionar para conseguir la actividad sexual deseada, sea también el que se salga con la suya en cuanto a la utilización de métodos anticonceptivos. Normalmente suele ser el varón el que prefiere la interrupción del uso del preservativo a favor de la píldora anticonceptiva, o a favor de otros métodos más cuestionables, ya que de nuevo, el 
papel responsable, y de limitación de la actividad sexual, pertenece tradicionalmente a las chicas.

El hecho de no haber hallado eviencia de relación entre formas activas de iniciación sexual, y uso del preservativo en la muestra femenina es consistente con las conclusiones obtenidas en el estudio sobre asertividad sexual en chicas adolescentes de Auslander et al. (2007). En el estudio se observó que la asertividad percibida a la hora de iniciar encuentros sexuales, no correlacionaba con la asertividad en el uso de anticonceptivos o en el rechazo de actividad sexual. Esto parece apuntar a que la asertividad sexual puede no aplicarse por igual a diferentes ámbitos de la conducta sexual femenina. También existe un salto entre autoeficacia en el uso de anticonceptivos, que suele ser mayor en chicas que en chicos, y uso real del condón, que suele ser menor en chicas que en chicos (Kvalem y Traeen, 2000; Robinson et al., 2007; Vogels et al., citado en Gebhardt et al., 2003; Bauman y Berman, 2005).

Este salto entre asertividad en la iniciación sexual, autoeficacia, y uso real del preservativo en chicas adolescentes, podría tener su explicación en el hecho de que la utilización del preservativo está finalmente bajo el control físico del varón, explicación que se ve confirmada por el hecho de que la autoeficacia en contracepción femenina se asocia más coherentemente con el uso adecuado de la píldora anticonceptiva, método controlado por la mujer (Tschann et al., 2002; Kvalem y Traeen, 2000).

En resumen, el uso del preservativo en relaciones sexuales es sistemático en un importante porcentaje de los adolescentes, pero que aún asi, existe un porcentaje del $12 \%$ de los adolescentes que no utiliza el preservativo consistentemente. A pesar de no haber hallado diferencias entre sexos, ni entre contextos relacionales en el uso del preservativo, sabemos que a mayor duración en una relación de pareja y a mayor experiencia sexual, menor es el uso del preservativo. En varones sin embargo, la experiencia sexual parece jugar a favor cuando se trata de usar el preservativo en relaciones sexuales casuales.

La motivación sexual de intimidad influye negativamente en el uso del preservativo que hacen las chicas en relaciones casuales. La necesidad de intimidad emocional, y la pérdida de poder relacional asociada a esta necesidad en las chicas, podría dificultar el que se atrevan a insistir en la toma de precauciones durante una relación sexual esporádica.

Finalmente, el uso del preservativo se ha asociado negativamente al empleo de estrategias de iniciación físicas y coercitivas en pareja, y sólo en varones, sugiriendo que el miembro de la pareja que está en posición de poder para presionar sexualmente, será también el que se salga con la suya en cuanto a la utilización de métodos anticonceptivos; en nuestro estudio seria el 
varón. La falta de asociación en la muestra femenina, podría indicar que la asertividad a la hora de iniciar actividad sexual es una faceta independiente de la asertividad necesaria para utilizar un condón, algo que por otro lado, está bajo en control físico del varón.

\subsection{Consentimiento de actividad sexual no deseada en la adolescencia}

Más de un tercio de los adolescentes consienten en tener actividad sexual en sus relaciones de pareja, en la mitad o más de la mitad de las veces que no lo desean. La media de frecuencia en consentimiento sexual en pareja se sitúa entre la mitad y la minoría de las veces que no se desea. En relaciones casuales, el porcentaje de adolescentes que consienten sexualmente en la mitad o más de la mitad de las veces que no se desea, es de 23,8\% de los adolescentes. Estos son porcentajes muy notables, e indican, como ya vimos en la revisión de la investigación, que el consentimiento de actividad sexual no deseada es un fenómeno muy frecuente, ya desde los inicios de la vida sexual en los adolescentes.

Aunque no están en nuestro conocimiento datos sobre prevalencia del consentimiento de actividad sexual no deseada en poblaciones adolescentes, los datos que conocemos en otras poblaciones adultas, reflejan la existencia de una gran variabilidad de estudio a estudio, debido principalmente a diferencias en las técnicas de metodología y en las definiciones conceptuales. En estudios con definiciones más exclusivas (Sprecher et al., 1994; O’Sullivan y Allgeier, 1998; Impett y Peplau, 2003) coincidían en una prevalencia de entre 38 y 50\% de participantes, que habían consentido alguna vez sexualmente, mientras que con definiciones más inclusivas (Reneau, 2004) la prevalencia se incrementaba hasta el punto de que casi todos los participantes habían consentido alguna vez en tener actividad sexual no deseada (83\%).

Esperábamos en nuestra primera hipótesis que la prevalencia del consentimiento sexual fuese mayor en relaciones de pareja que en relaciones esporádicas. Esta hipótesis ha sido confirmada, puesto que los adolescentes consentían en tener actividad sexual no deseada con mayor frecuencia en sus relaciones de pareja que en sus relaciones casuales. Hemos de recordar que esta comparación se llevó a cabo con los mismos adolescentes en diferentes contextos relacionales, y que la medida de frecuencia del consentimiento sexual era una medida de tipo porcentual, con respecto a las oportunidades objetivas, por lo que podemos concluir que la diferencia psicológica que supone estar en una relación de pareja frente a una relación casual, favorece modestamente una mayor incidencia del consentimiento sexual. Las pocas y recientes 
investigaciones que hay sobre el tema apoyan estos resultados a pesar de que no examinan específicamente el papel del contexto, ya que reflejan que la mayoría de hombres y mujeres que han consentido alguna vez en tener actividad sexual lo hacen en relaciones de pareja estables (Impett y Peplau, 2002; O’Sullivan y Allegeir, 1998; Reneau, 2004; Shotland y Hunter, 1995). Puesto que el tener actividad sexual no deseada voluntariamente es un fenómeno un tanto incoherente desde un punto de vista individual o centrado en uno mismo, es lógico que el consentimiento sexual sea más frecuente en un contexto de pareja, ya que en este contexto existen dinámicas de mutualidad e intereses centrados en la relación, que a veces se colocan por encima de los deseos personales.

Además, como veíamos en la revisión teórica, los motivos que llevan al consentimiento sexual en relaciones de pareja, probablemente contribuyen a que el consentimiento tenga consecuencias más beneficiosas que los motivos para el consentimiento sexual en relaciones casuales, por lo que es comprensible que sea más frecuente en este contexto relacional (O'Sullivan y Gaines, 1998; Livingstone et al., 2004).

Esperábamos que los chicos consintieran actividad sexual más frecuentemente que las chicas en relaciones esporádicas, mientras que en relaciones de pareja esperábamos que las chicas consintieran sexualmente más que los chicos. Habíamos hipotetizado esa interacción, puesto que en general, la prevalencia del consentimiento sexual en los estudios realizados es mayor en las chicas que en los chicos, pero esto sucede principalmente en relaciones de pareja. Además resultados en otras investigaciones apuntaban hacia el hecho de que consentir actividad sexual no deseada, podría ser un fenómeno más frecuente y propio de los varones que de las chicas. Sería un fenómeno más propio de los varones teniendo en cuenta el guión sexual tradicional, en el que se espera que el hombre esté siempre disponible y activo para las relaciones sexuales, mientras que las respuestas esperables en la mujer son aceptar o rechazar el encuentro. Según este esquema cultural y según algunas investigaciones (Grauerholz y Serpe, 1985), las mujeres se sienten más cómodas que los hombres rechazando actividad sexual. Como la adherencia a roles de género tradicionales es mayor en relaciones ocasionales que en relaciones estables (O’Sullivan y Byers, 1992; Seal et al., 2007; Gebhardt et al., 2003), esperábamos que fuesen los adolescentes chicos los que consintieran en tener actividad sexual no deseada en mayor medida que las chicas, en relaciones esporádicas.

Esta explicación se ha visto reforzada por nuestros resultados, ya que la prevalencia del consentimiento sexual fue mayor en chicos que en chicas en relaciones casuales. Sin embargo, la hipótesis ha sido parcialmente rechazada, ya que también en relaciones de pareja, los chicos 
consentían en tener actividad sexual no deseada en mayor medida que las chicas. Este resultado se contrapone a lo hallado por otras investigaciones sobre consentimiento de actividad sexual no deseada, en las que las mujeres muestran mayor consentimiento sexual que los hombres (Impett y Peplau, 2002; O'Sullivan y Allegeir, 1998; Reneau, 2004; Shotland y Hunter, 1995). Una de las explicaciones que encontramos para esta discrepancia, es la diferencia de edad de la población examinada. En nuestro estudio evaluamos a adolescentes en relaciones de pareja, que pueden no superar por mucho los tres meses de duración, mientras que en los anteriores trabajos, examinan el comportamiento de adultos en relaciones de pareja más duraderas. Podría ser que la menor madurez y experiencia relacional de nuestros participantes contribuya a que se de una mayor adherencia a roles de género tradicionales en la toma de decisiones sexuales, que facilite que las chicas limiten la actividad sexual no deseada en mayor medida que los chicos.

Por otro lado contamos con resultados en otros estudios que apuntan en la misma dirección que nuestros resultados. Por ejemplo en el estudio de O'Sullivan y Gaines (1998) sobre ambivalencia sexual señalaban que ante la ambivalencia, los hombres tenían mayor probabilidad de fingir interés sexual y participar en el encuentro sexual, que las mujeres. Además era menos probable que los hombres comunicasen sus sentimientos de ambivalencia a la pareja, que las mujeres, lo que podría estar indicando cierta resistencia en algunos hombres a aparecer como alejados del ideal masculinos de "siempre a punto" para un encuentro sexual. En otro estudio con adolescentes (Kvalem y Traeen, 2000), encontraron que las chicas de su estudio mostraban mayor autoeficacia a la hora de prevenir relaciones sexuales no deseadas, que los adolescentes chicos, lo que se puede interpretar como un apoyo a la explicación basada en las expectativas y roles de género en la interacción sexual.

También podemos entenderlo desde el punto de vista del mayor interés sexual documentado en varones que en mujeres (Baumeister, 2000), lo que apuntaría a que no dejar pasar una oportunidad sexual puede actuar como otro elemento importante de motivación sexual masculina (Eyre y Millstein, 1999), en situaciones de ambivalencia o falta de deseo sexual. Esto podría ser especialmente aplicable a la población de varones adolescentes, quienes por su menor experiencia sexual, podrían estar más dispuestos a aprovechar cualquier oportunidad sexual, independientemente de su deseo sexual inicial.

En cualquier caso, la robusta diferencia de género encontrada en nuestro estudio en la frecuencia de consentimiento de actividad sexual no deseada, es congruente con la diferencia de género encontrada en frecuencia de limitación sexual. En nuestro estudio, las chicas limitan la 
actividad sexual no deseada en mayor medida que los chicos, y estos consienten actividad sexual no deseada en mayor medida que las chicas.

Otro de nuestros objetivos era examinar cómo se asociaba las motivaciones sexuales con el consentimiento de actividad sexual no deseada. Es necesario puntualizar, que estas motivaciones se refieren a las razones que tienen los adolescentes para mantener actividad sexual en general, y no se pueden confundir con las razones para consentir actividad sexual no deseada, que son motivaciones más específicas. Aún así, considerábamos que podían existir conexiones significativas entre las motivaciones sexuales generales, y la decisión voluntaria de mantener actividad sexual no deseada.

Efectivamente diferentes motivaciones sexuales se asociaban al consentimiento sexual en relaciones de pareja y en relaciones esporádicas, y en chicos y chicas. En relaciones de pareja, la motivación sexual de autorregulación emocional se asociaba significativamente al consentimiento en varones, y en chicas era la motivación de evitar el castigo de la pareja la que se asociaba al consentimiento sexual. Parece que los adolescentes que consienten actividad sexual no deseada en pareja, manifiestan tener en mayor medida motivaciones sexuales de evitación de consecuencias negativas a la hora de mantener relaciones sexuales, que los que consienten sexualmente en menor medida. Tal y como exponen Feeney, Peterson, Gallois y Terri (2000) la intensa necesidad de aprobación y de seguridad emocional puede conllevar una mayor ineficacia en las negociaciones sexuales, a la hora de involucrarse en actividad sexual no deseada. La diferencia entre chicas y chicos en cuanto al tipo de motivación concreta, es consistente con investigaciones previas que han hallado que es más probable que las mujeres se involucren en relaciones sexuales no deseadas por motivos relacionales, que los hombres, especialmente cuando estos motivos se derivan de sentimientos de obligación relacional (Impett y Peplau, 2003). Shotland y Goodstein (1992) sugirieron que una vez que se ha experimentado el sexo en una relación, la mujer tiende a sentirse obligada a continuar proporcionando relaciones sexuales, y el hombre tiende a sentirse en derecho de continuar recibiendo sexo. Por otra parte, tanto en el estudio de O'Sullivan y Allgeier (1998), como en el de Bartels (2007) observaron que los hombres exponían la motivación de evitar tensión con mayor frecuencia que las mujeres. Así, los chicos y chicas que mayor indice de motivaciónes sexuales evitativas tienen, son los que más frecuentemente consienten actividad sexual no deseada en pareja, sólo que ellos tratan concretamente de evitar estados emocionales negativos propios, y ellas tratan de evitar consecuencias negativas en la relación de pareja. 
En las relaciones casuales sin embargo, el consentimiento sexual sólo se vinculó positivamente a la motivación de placer en chicos. Los adolescentes varones para los que es más importante la motivación de placer a la hora de tener actividad sexual, son los que más frecuentemente consienten actividad sexual no deseada en relaciones casuales. Esta vinculación nos sugiere que, puesto que el placer es la principal motivación de estos adolescentes, puede que ante una oportunidad sexual fortuita sean capaces de anticipar en mayor medida este placer, a pesar de no sentir deseo sexual previo. Esta anticipación podría hacerles valorar y no dejar pasar las oportunidades sexuales ocasionales.

Este resultado apoya en alguna medida la explicación basada en el interés sexual, que proponíamos anteriormente para justificar el mayor consentimiento sexual encontrado en chicos que en chicas. Esta explicación sostiene que el mayor interés sexual, que no mayor motivación de placer, documentado en los varones (Baumeister, 2000) podría influir de manera que no dejar pasar una oportunidad sexual, actuaría como un elemento importante de motivación sexual masculina, en situaciones de ambivalencia o falta de deseo sexual. En nuestro estudio no hemos incluido la motivación de oportunidad sexual, pero podría ser que la motivación que más se aproxime a ésta, fuese la motivación de placer. Así, el mayor interés sexual de los varones, en combinación con una importante motivación de placer, podría incrementar en mayor medida la tasa de consentimiento sexual en los adolescentes chicos, que en las chicas.

En cuanto a la relación del consentimiento sexual con las formas de negociación sexual, en relaciones de pareja, el consentimiento sexual se ha asociado positivamente a las estrategias de presión sexual y a las estrategias de limitación sexual indirectas, y en las relaciones casuales se ha asociado sólo en la muestra masculina a estrategias físicas y coercitivas, y negativamente a la limitación directa.

El hecho de que los adolescentes más ambiguos a la hora de iniciar y sobre todo de limitar la actividad sexual, sean los que más consienten sexualmente podría tener como telón de fondo cierta carencia de asertividad sexual y de habilidades de comunicación, que dificultaría una comunicación correcta y consistente de deseos, e intenciones sexuales. En este sentido, Bartels (2007) puso de manifiesto que la habilidad para comunicar las propias preferencias sexuales contribuía a reducir el índice de consentimiento sexual, a través del debilitamiento de la influencia de los roles de género en sexualidad. Así, las habilidades comunicativas podrían ayudar a los adolescentes a encauzar su comportamiento sexual en una via acorde a sus propios deseos sexuales. En este sentido varios estudios han hallado asociaciones entre baja asertividad 
sexual y experiencias de victimización sexual (Livingstone, Testa y Van Zile-Tamsen, 2007; Rickert, Neal, Wiemann y Berenson, 2000).

Consideramos especialmente interesante el hecho de que los adolescentes que más estrategias de presión utilizan en nuestro estudio, sean los que más consienten sexualmente, ambos sexos en relaciones de pareja, y sólo los chicos en contextos casuales. Es posible que una concepción o actitud permisiva ante la sexualidad no consensuada en los adolescentes, esté propiciando una toma de decisiones sexuales desprovista del respeto necesario hacia los deseos sexuales propios y ajenos, y esto incremente tanto el consentir como el presionar.

Sabemos por una parte, que el consentimiento sexual aumenta el riesgo de victimización sexual (Krahe et al., 2000; Impett y Peplau, 2003) y por otra parte, que algunos estudios han visto conexiones entre sufrir la presión sexual en pareja y el empleo de presión sexual por parte de la misma persona que la sufre en otras ocasiones (Brassard, Shaver y Lussier, 2007). En este sentido y en línea con lo que veíamos sobre el papel de las habilidades de comunicación sexual como protección, parece que la comunicación sexual inconsistente, como es el consentimiento sexual, puede llevar a actitudes más permisivas ante el uso de la fuerza o la coerción con fines sexuales. Esto ocurriría no sólo a través de un mayor índice de victimización y tolerancia de los que consienten, sino también a través de un posible moldeamiento en las propias tácticas de avance sexual de las personas que dan el consentimiento, hacia estilos más coercitivos. Según Krahe et al. (2006) la manera en la que los adolescentes conceptualizan las interacciones sexuales consensuadas, juega un papel importante en su disposición y tendencia a utilizar la agresión sexual.

De esta manera, el consentimiento sexual, y la aceptación y normalización de la coerción en las relaciones, pueden ser vistos como elementos conectados, de una representación de la sexualidad más amplia. Desde la óptica de nuestro trabajo, la representación de esta sexualidad, formaría parte del guión intrapsíquico de algunos adolescentes, que se reflejaría en la puesta en marcha de un guión interpersonal específico, en el que conductas como el consentimiento y la presión sexual serían elementos legítimos y regulares.

Resumiendo, el consentimiento de actividad sexual no deseada es un fenómeno muy frecuente, ya desde los inicios de la vida sexual en los adolescentes, y se dá algo más en relaciones de pareja que en relaciones esporádicas. Los chicos adolescentes por otro lado consienten sexualmente en mayor medida que las chicas, lo que podría explicarse bien por que las chicas se sienten más cómodas rechazando actividad sexual no deseada, que los chicos (lo hacen más 
frecuentemente) o bien porque los varones muestran un mayor interés sexual que puede influir de manera que no dejar pasar una oportunidad sexual puede actuar como otro elemento importante de motivación sexual masculina en situaciones de falta de deseo sexual previo.

La asociación entre motivación de placer y consentimiento sexual en relaciones casuales en varones apoyaría esta explicación. En cuanto a las relaciones de pareja, el consentimiento sexual se asocío con motivaciones sexuales negativas: los chicos que más consienten tratan concretamente de evitar estados emocionales negativos propios con el sexo, y las chicas tratan de evitar consecuencias negativas en la relación de pareja. Finalmente, los adolescentes que emplean formas de negociación indirectas y coercitivas son los que más consienten sexualmente. Esto sugiere que la falta de habilidades comunicativas y asertivas, y una concepción permisiva de la sexualidad no consensuada, podrían estar detrás de estas prácticas sexuales asociadas al riesgo. 


\section{COMENTARIOS FINALES}

\section{RESUMEN FINAL}

El primer obejtivo del estudio era conocer qué formas de negociación sexual, concretamente qué estrategias sexuales de avance y limitación sexual, ponen en marcha los adolescentes. En este sentido sabemos que en general, los adolescentes emplean estrategias de acercamiento y contacto físico, combinadas con tácticas indirectas, como la insinuación de interés, y la seducción y el flirteo. En menor medida declaran verbal y explícitamente su interés sexual y en menos casos todavía, se emplean estrategias sexualmente coercitivas. A la hora de limitar la actividad sexual, emplean en mayor medida estrategias directas que indirectas.

Los tipos de estrategias representan componentes de los guiones sexuales, y los individuos deciden si utilizan una o más estrategias y cuáles, a la hora de poner en marcha su propia forma de comunicación sexual. Así, a pesar de que existe un guión de iniciación sexual predominante para los adolescentes, hay también variantes que representarían los guiones sexuales individuales. En esta investigación hemos intentado examinar algunas circunstancias 
individuales e interpersonales, que podrían influir a los adolescentes para elegir un tipo u otro de estrategia, llegando a las siguientes conclusiones.

El contexto relacional y el género parecen ser circunstancias en cierta medida relevantes en el empleo de determinadas estrategias de avance sexual. Ambos sexos emplean estrategias sexuales de tipo directo y verbal con mayor frecuencia en relaciones de pareja que en relaciones esporádicas, aunque esta diferencia es más acusada en la muestra femenina que en la masculina. Entendemos que el guión sexual tradicional, en el que el varón tiene la responsabilidad de tomar la iniciativa, está algo más instaurado en las relaciones ocasionales en comparación con las relaciones de pareja, que muestran mayor mutualidad entre los sexos a la hora de iniciar actividad sexual. Por otro lado los adolescentes varones emplean algo más estrategias de presión sexual que las chicas, y éstas emplean en mayor medida estrategias para limitar la actividad sexual.

El nivel de experiencia sexual ha resultado ser un factor, que influye más decisivamente en la elección de determinadas estrategias de negociación sexual. Los adolescentes con mayor experiencia sexual, que además son los que más experiencia relacional tienen, utilizan en mayor medida estrategias sexuales directas sobre todo, tanto para iniciar como para limitar la actividad sexual. La mayor experiencia sexual y relacional, entendemos que se traduce normalmente, y entre otros, en un mayor desarrollo de habilidades sociales en general, y de comunicación sexual en particular, siendo la iniciación directa un buen ejemplo de esta comunicación. Una excepción sería el hecho de que la experiencia sexual en varones parece incrementar también el empleo de estrategias indirectas y coercitivas en relaciones casuales, quizás porque en este contexto, los varones perciben estas estrategias como más eficaces que las estrategias directas.

Algo más de la mitad de nuestros adolescentes ha tenido alguna experiencia sexual coital. A pesar de que chicos y chicas no difieren en su nivel de experiencia sexual final, existe alguna diferencia en torno al papel que tienen las relaciones románticas en la adquisición de esta experiencia sexual. Los chicos adquieren la experiencia sexual a través de los dos tipos de relaciones estudiadas y ambas contribuyen por igual, mientras que las chicas lo hacen a través sobre todo, de sus relaciones de pareja. Estas conclusiónes son consistentes con otros resultados hallados en esta misma investigación, como es que las chicas reducen en alguna medida la frecuencia de la iniciación sexual en relaciones ocasionales, mientras que los varones mantienen la misma frecuencia de avance sexual en los dos contextos relacionales, o que los varones tienen más parejas sexuales que las chicas. Estas conclusiones además apoyan estudios previos que nos 
han mostrado cómo la adquisición de experiencia sexual está más ligada a las relaciones de pareja estables, en chicas que en chicos, quizá porque las normas sexuales culturales permiten en los varones un desarrollo sexual más independiente de las relaciones y más centrado en sí mismos, que en las chicas.

Bien sea por normas aprendidas o por una disposición natural diferente en cada sexo, o por ambas, lo cierto es que en la adolescencia se aprecia en alguna medida, cómo cada sexo podría estar siguiendo un guión sexual interpersonal adecuado a lo que tradicionalmente se espera de su género, al menos en términos estrictamente conductuales. Sin embargo, también podemos situar el punto de mira en los indicios que pueden estar mostrando una confluencia entre géneros, como son el hecho de que los tamaños de efecto en las diferencias de género eran los más pequeños, que hay ámbitos que están prácticamente libres de diferencias de género como el comportamiento en relaciones de pareja y el nivel de experiencia sexual, y sobre todo, que en términos de vivencias interiores o guiones intrapsíquicos, como ocurre en el caso de las motivaciones sexuales, no hemos hallado diferencias entre chicos y chicas.

La necesidad y búsqueda de intimidad emocional parece ser el principal motor para la puesta en marcha de actividad sexual, tanto en chicas como en chicos adolescentes. Podría ser que los chicos adolescentes medios y tardíos estén empezando a reconocer estas necesidades de intimidad y de expresión de sentimientos de una manera más abierta, y más paralela a las necesidades de las chicas adolescentes. Además, no existen diferencias entre chicos y chicas en el resto de motivos por los que deciden tener actividad sexual, lo que cuestiona unas asunciones tremendamente extendidas sobre las diferencias de género en motivación sexual.

Hemos visto que las necesidades de intimidad emocional podrían llevar en alguna medida a los adolescentes a buscar contextos y circunstancias interpersonales, como son las relaciones de pareja, que puedan cubrir esas necesidades de expresión emocional, y que además facilitan la adquisición de experiencia sexual. La necesidad de aprobación como motor de la actividad sexual en cambio, parece dificultar el establecimiento de relaciones de pareja estables, y con ello, la adqusición de experiencia sexual. Además de condicionar la búsqueda de contextos relacionales, los motivos por los que los adolescentes tienen actividad sexual influyen en la propia conducta sexual estudiada en esta investigación: en la frecuencia del sexo casual, en la utilización del preservativo, en el consentimiento de actividad sexual no deseada, y por supuesto, en las estrategias de iniciación sexual. Hemos visto que las motivaciones sexuales aproximativas, sobre todo la motivación de intimidad en la muestra masculina, facilitaban 
conductas más saludables y constructivas, mientras que las motivaciónes sexuales de evitación de consecuencias negativas han promovido conductas más cuestionables como el uso de estrategias indirectas, la coerción y el consentimiento de actividad sexual no deseada.

De esta manera, los adolescentes impulsados sexualmente por el deseo de evitar conflictos y por el temor de ser rechazados, tienden a utilizar una comunicación sexual encubierta y coercitiva para iniciar encuentros sexuales, y una forma de limitación sexual basada en excusas, rodeos y distracciones, en mayor medida que aquellos que no lo están. Entendemos que la inseguridad emocional y los temores dificultan la confianza en uno mismo y en los demás, e incrementan la vulnerabilidad y la sensibilidad al rechazo, por lo que pueden conducir a la utilización de estrategias sexuales más encubiertas por una parte, para reducir lo máximo la propia exposición en relaciones ocasionales, y coercitivas por otra parte, para reducir lo máximo las posibilidades del rechazo, sobre todo en relaciones de pareja. El hecho de que este tipo de motivaciones dificulten las relaciones de pareja y promuevan una serie de relaciones breves y casuales, podría contribuir a este circuito de motivación negativa, vulnerabilidad e inseguridad, y conducta sexual poco constructiva.

Otro de nuestros objetivos era examinar en detalle algunas prácticas sexuales asociadas al riesgo en la adolescencia como la coerción sexual, el uso del preservativo, o el consentimiento de actividad sexual no deseada. Como ya hemos visto, el género ha resultado determinante en el uso de presión sexual, puesto que la presión como estrategia sexual no sólo es más frecuente sino que está más normalizada en la muestra masculina, que en la femenina. El contexto relacional no influyó directamente en la frecuencia de este tipo de estrategia, pero podría ser un factor discriminante en cuanto a algunos correlatos en el uso de la presión sexual, como podrían ser las motivaciones sexuales que lo subyacen.

El uso del preservativo en relaciones sexuales es sistemático en un importante porcentaje de los adolescentes, pero aún asi, existe un porcentaje del $12 \%$ de los adolescentes que no utiliza el preservativo consistentemente. A pesar de no haber hallado diferencias entre chicos y chicas, ni entre contextos relacionales en el uso del preservativo, sabemos que a mayor duración en una relación de pareja y a mayor experiencia sexual, menor es el uso del preservativo, sobre todo en las chicas. También en las chicas, la motivación de intimidad emocional y la pérdida de poder relacional asociada a esta necesidad, parece dificultar el que se atrevan a insistir en la toma de precauciones en sus relaciones sexuales esporádicas. 
El consentimiento de actividad sexual no deseada es un fenómeno bastante frecuente, ya desde los inicios de la vida sexual en los adolescentes, y se dá algo más en relaciones de pareja, que en relaciones esporádicas. Los chicos adolescentes por otro lado, consienten sexualmente en mayor medida que las chicas, lo que podría explicarse bien porque por roles de género las chicas se sienten más cómodas rechazando actividad sexual no deseada que los chicos (lo hacen más frecuentemente), o bien porque los varones muestran un mayor interés sexual, de manera que no dejar pasar una oportunidad sexual puede actuar como otra motivación sexual masculina, en situaciones de falta de deseo sexual previo. La asociación entre motivación de placer y consentimiento sexual en relaciones casuales en varones apoyaría esta explicación. El consentimiento sexual en pareja en cambio, se asoció con motivaciones sexuales de evitación de consecuencias negativas. Finalmente, los adolescentes que emplean formas de negociación indirectas y coercitivas son los que más consienten sexualmente. Esto sugiere que la falta de asertividad y habilidades comunicativas, y una concepción permisiva de la sexualidad no consensuada, hacia uno mismo y hacia los demás, podrían estar detrás de estas prácticas sexuales asociadas al riesgo.

Según la teoría de los guiones sexuales (Gagnon y Simon, 1973), los individuos que siguen los guiones sexuales, tratan de adaptarse a los roles socialmente construidos de que disponen. Consideramos que nuestro estudio ha contribuido a una mayor comprensión de los roles de que disponen los adolescentes para negociar la actividad sexual. Por una parte, los adolescentes siguen en alguna medida el rol de género que tienen disponible, y por otra parte, hemos visto que los adolescentes siguen en alguna medida el rol de "pareja estable" para iniciar actividad sexual de manera directa y explícita en algunos momentos, mientras que siguen el rol de "amigo-rollo" para iniciar actividad sexual en otros momentos, distinción que intensifican sobre todo las chicas, y que no se produce de cara a la limitación de la actividad sexual.

Además de adaptar su estilo de negociación sexual a los roles de que disponen en función de si son chicos o chicas y en función del contexto relacional, los adolescentes desarrollan diferentes necesidades y motivaciones sexuales que se plasman o expresan en diferentes estilos de negociación sexual, siendo la comunicación sexual ambigua o coercitiva un posible resultado de motivaciones sexuales basadas en la inseguridad emocional. La experiencia sexual por su parte, parece favorecer el empleo de formas de negociación directas, de acuerdo a un desarrollo maduracional mayor.

Tanto la experiencia sexual como las motivaciones sexuales se vinculan en alguna medida al contexto relacional en el que se encuentre el adolescente, puesto que en relaciones de pareja es 
más probable que el adolescente adquiera mayor experiencia sexual, y es menos probable que muestre motivaciones sexuales de aprobación social, que en relaciones esporádicas.

Aunque consideramos que tanto las experiencias de pareja, como las experiencias relacionales esporádicas son positivas, puesto que las dos cubren diferentes necesidades del adolescente, y las dos proporcionan un contexto en el que llevar a cabo tareas muy valiosas para su desarrollo psicosocial en el camino hacia la adultez, entendemos que la experiencia en relaciones de pareja ofrece ciertas posibilidades a los adolescentes, en términos de establecimiento de hábitos de comunicación, de las que convendría no prescindir.

En cuanto a lo que los profesionales podemos hacer en el ámbito de la investigación, consideramos que es importante conocer qué circunstancias influyen en la comunicación y negociación sexual que ponen en marcha los adolescentes, ya que parece que la comunicación sexual abierta y clara aumenta la satisfacción sexual, y hace que la experiencia sea positiva y que haya menos probabilidades de sentir arrepentimiento. Además, las formas de negociación sexual en la adolescencia pueden fácilmente arraigarse de cara a la adultez, e incluso extenderse a otros ámbitos no sexuales, y convertirse en hábitos de comunicación generales. De manera más general, consideramos de gran interés la inclusión de constructos relacionados con el significado que tiene el sexo para los adolescentes, así como el hecho de tener en cuenta el tipo de relación en el que se encuentran, puesto que estos factores pueden incrementar notablemente nuestra comprensión del afrontamiento de la comunicación sexual, y de la conducta sexual adolescente en general.

En el ámbito educativo y social, proponemos que el contenido sobre el que se centren las intervenciones y mensajes educativos dirigidos a la población adolescente, incluya la transmisión de sentimientos de valía personal y respeto propio en la sexualidad, el desafío de normas culturales en torno a la aceptación de la coerción o el consentimiento sexual, y el entrenamiento en habilidades de comunicación y negociación sexual. El foco de atención en estas tres áreas cubriría tres aspectos de la sexualidad adolescente actual que, desde los niveles individual, cultural e interpersonal respectivamente, podrían estar dificultando a nuestro entender, una vivencia segura y positiva de la sexualidad. 


\section{LIMITACIONES DEL ESTUDIO}

Las formas de mejorar este trabajo son múltiples y variadas, sin embargo expondremos algunas limitaciones concretas, que pueden ser de utilidad en investigaciones posteriores. En primer lugar, existe cierto riesgo de que nuestros datos estén sesgados por falta de fiabilidad en los recuerdos o por deseabilidad social, ya que estos son riesgos muy habituales en estudios que emplean medidas de autoinforme. Esto podría ser especialmente así en nuestro caso, ya que las preguntas formuladas a los adolescentes tratan sobre algunos aspectos de su sexualidad, y en concreto se evalúan algunos aspectos controvertidos socialmente como son el empleo de coerción sexual o el uso del preservativo. En este sentido nos hemos esforzado por minimizar estos riesgos, asegurando a los adolescentes la confidencialidad y el anónimato de sus respuestas, así como la privacidad a la hora de completar los cuestionarios en las aulas.

Otra posible dificultad, también derivado de la metodología de autoinforme, es que en el cuestionario que evalúaba la frecuencia de uso de estrategias de avance y de limitación sexual, algunas de las tácticas de la categoría "avance físico directo" (ej: besar, empezar a acariciar por debajo de la ropa) podrían heberse confundido con la propia actividad sexual perseguida, puesto que además de ser tácticas, son también actividad sexual en sí mismas. Así, los adolescentes menos experimentados, en vez de estar puntuando el uso de estas estrategias para un fín, que podría ser tener relaciones coitales, podrían estar evaluando la frecuencia con la que han practicado estas conductas (besar, acariciar por debajo de la ropa), pasando por alto otras tácticas previas más sutiles, como las tácticas indirectas. Por su parte, es posible que con los gestos de seducción, haya sucedido lo contrario, ya que al ser tácticas relativamente inconscientes y espontáneas, su uso se ha podido ver infravalorado. Esto podría explicar que el uso de estrategias indirectas, como el flirteo o hacerse notar, haya sido inferior al avance físico directo en el contexto esporádico, algo que no habíamos hipotetizado. Lógicamente, no podemos saber con certeza cómo respondían exactamente los adolescentes, y por otra parte, las instrucciones precisaban a este respecto, que no contaban las veces que habían realizado estas conductas sin la pretensión de tener actividad sexual por lo que, aunque animamos a futuros estudios a tener en cuenta estas posibles dificultades, debemos dar por buenos nuestros resultados.

Por otra parte, hemos evaluado algunas conductas sexuales, que formaban parte de un cuestionario bastante largo, a través de un único ítem, como es el caso de la frecuencia de uso 
del preservativo o la frecuencia del consentimiento de actividad sexual no deseada. Estas variables podrían ser evaluadas con mayor detenimiento, a través de escalas de múltiples ítems en futuras investigaciones.

El diseño elegido en nuestro estudio y la manera en la que hemos analizado los datos tiene ventajas y desventajas. En vez de obtener una medida única de uso de estrategias sexuales, y después evaluar la situación o experiencia relacional del adolescente, decidimos plantear dos medidas de empleo de estrategias, cada una de ellas asociada a un contexto relacional. Las ventajas de este diseño, eran en primer lugar, que no perdíamos información de aquellos adolescentes que tenían ambas experiencias relacionales (y que resultaron ser la mayoría), y con ello, evitábamos el sesgo de autoselección que se hubiese podido producir de haber dividido a la muestra según su experiencia relacional. En segundo lugar, los adolescentes con ambas experiencias podían situarse contextualmente al la hora de responder al cuestionario, pudiéndolo hacer de manera más precisa, y en tercer lugar, podíamos establecer una comparación con un análisis de medidas repetidas que nos permitiera obtener un efecto únicamente atribuible al efecto subjetivo de estar en uno u otro contexto relacional. Este diseño, tenía el inconveniente de que, al no contar con una medida de uso de estrategias desvinculada del contexto relacional, no podíamos utilizar el contexto relacional como variable predictora relacional, y compararla con otras variables predictoras individuales, lo que quizas nos hubiese podido permitir averiguar qué variables explican en mayor medida el uso de estrategias de negociación sexual en análisis de regresión múltiple.

Los criterios para definir los contextos relacionales eran dos: un criterio de duración que establecía una duración mínima de 3 meses para las relaciones de pareja y el hecho de considerar subjetivamente "pareja" a la otra persona. Estos criterios han podido resultar inadecuados, en tanto a que han podido contradecirse en algún caso, o en tanto a que pueden no haber discriminado lo suficiente entre contextos, debido a la duración de pareja mínima establecida. Quizas, con una duración de pareja mínima más restrictiva, de por ejemplo 6 meses, se hubiesen obtenido resultados más consistentes en torno al papel del contexto relacional. Sin embargo, con este criterio la muestra de adolescentes con relaciones de pareja se hubiese reducido considerablemente, y la comparación entre grupos, hubiese sido imposible.

La naturaleza transversal y correlacional del estudio nos limita a la hora de extraer y establecer conclusiones de causalidad. Hemos concluido en algunas ocasiones que el nivel de experiencia sexual de los adolescentes podría estar condicionando la elección y puesta en marcha de 
determinadas estrategias sexuales, cuando también es posible que la puesta en marcha de determinadas estrategias facilite la adquisición de experiencia sexual en los adolescentes. También nos hemos inclinado a proponer que las motivaciones sexuales de los adolescentes condicionaban la elección de contextos relacionales, asi como que impulsaban el empleo de determinadas estrategias, pero podría ser que la experiencia sexual y relacional impacte en la motivación para tener actividad sexual, o bien que entre estas variables se produzca una influencia mutua y bidireccional, lo que nos parece más probable. De esta manera nos vemos incapacitados a la hora de precisar todo lo que nos gustaría en nuestras conclusiones.

Los tamaños de efecto correspondientes a algunas variables del estudio han resultado ser pequeños, lo que indica que es necesario desarrollar medidas más potentes por un lado, y considerar la inclusión de otros posibles factores por otro, en el estudio de las motivaciones y estrategias de negociación sexual en la adolescencia. En el caso de las estrategias de negociación sexual, las motivaciones y la experiencia sexual, han resultado relativamente predictivas, por lo que quizas, podrían introducirse variables relacionadas como erotofiliaerotofobia, deseo sexual, estilo de apego, asertividad sexual y habilidades sociales. La asociación entre coerción, consentimiento sexual, y limitación sexual indirecta también sugiere que sería interesante incluir variables relacionadas con las creencias sobre la sexualidad no deseada, ya que la manera en la que los adolescentes conceptualizan las interacciones sexuales consensuadas, y el respeto que tienen hacia sus propios deseos sexuales, condiciona sin duda el afrontamiento que tienen de la sexualidad compartida. En cuanto a las motivaciones sexuales, consideramos que futuros estudios podrían emplear instrumentos de medida qe diversifiquen algo más los tipos de motivación sexual, puesto que en algunas ocasiones, los tres tipos de motivaciones aversivas han funcionado de manera muy paralela (de acuerdo a su base aversiva común) y en otras ocasiones, hemos echado de menos la inclusión de otras motivaciones sexuales también características en la población adolescente, como la motivación de oportunidad sexual, la motivación de poder o control, la motivación de curiosidad, etc. Lo mismo podría hacerse respecto al contexto relacional, ya que posiblemente existen otros tipos de relación romántica, además de las contempladas en este trabajo, que podrían ofrecer una discriminación más precisa en cuanto a estilos de negociación sexual. De esta forma, además de ofrecer un panorama más completo de la negociación sexual adolescente, podríamos comprobar algunas de las interpretaciones propuestas en esta investigación. 


\section{REFERENCIAS BIBLIOGRÁFICAS}

Agocha, V.B. (2002). Safer-sex decision-making: A motivated cognition explanation of its underlying mechanism. Tesis doctoral en internet. University of Missouri, Columbia, 238 páginas; AAT 3036803 .http://proquest.umi.com.

Ajzen, I. (1985). From intentions to actions: A theory of planned behavior. En J. Kuhi \& J. Beckmann (Eds.), Action.control: From cognition to behavior (pp. 11.39). Heidelberg: Springer.

Ajzen, I. (1991). The theory of planned behavior. Organizational Behavior and Human Decision Processes, 50, 179-211.

Allen, J.S. y Bailey, K.G. (2007). Are Mating Strategies and Mating Tactics Independent Constructs?. Journal of Sex Research, 44(3), 225-232.

Amaro, H. (1995). Love, sex and power: Considering women's realities in HIV prevention. American Psychologist, 50, 437-447. 
Andersen BL, Cyranowski JC, Espindle D. (1999). Men's sexual self-schema. Journal of Personality and Social Psychology, 76, 645-661.

Anderson, P.B., \& Newton, M. (2004). Predicting the use of Sexual Initiation Tactics in a Sample of College Women. Electronic Journal of Human Sexuality, 7, [www document] URL http://www.ejhs.org/volume7/Anderson/text.html

Anderson , P.B., Kontos, A.P., Tanigoshi, H., \& Struckman-Johnson, C. (2005, November). An Examination of Sexual Strategies Used by Urban Southern and Rural Midwestern University Women. Journal of Sex Research, 42(4), 335-341.

Auslander B.A, Perfect M.M., Succop P.A., Rosenthal S.L. (2007). Perceptions of sexual assertiveness among adolescent girls: initiation, refusal, and use of protective behaviors. Journal of pediatric and adolescent gynecology, 20(3), 157-162.

Bakan, D. (1966). The duality of human existence. Chicago, IL: Rand McNally.

Bancroft, J. (1989). Human Sexuality and Its Problems, pp 282-298. Edinburgh: Churchill Livingstone.

Bancroft, J. (2000). En J. Bancroft (Ed). The Role of Theory in Sex Research. Vol. VI in The Kinsey Institute Series. Bloomington: Indiana University Press.

Bandura, A. (1977). Social Learning Theory. New York: General Learning Press.

Bandura, A. (1994). Social cognitive theory and exercise of control over HIV infection. En R. J. DiClemente \& J. L. Peterson (Eds.), Preventing AIDS: Theories and methods of behavioral interventions (pp. 25-59). New York: Plenum.

Baron, R. M., \& Kenny, D. A. (1986). The moderator-mediator variable distinction in social psychological research: Conceptual, strategic, and statistical considerations. Journal of Personality and Social Psychology, 51, 1173-1182. 
Bartels, B. (2007). Consenting to unwanted sexual activity in heterosexual relationships: A sociocultural examination. Tesis doctoral en internet. Marquette University. http://epublications.marquette.edu/dissertations/AAI3277086

Bartholomew, K. y Horowitz, L.M. (1991). Attachment styles among young adults: A test of a model. Journal of personality and social psychology, 61, 226-144.

Basson, R. (2000). The female sexual response: a different model. Journal of sex \& marital therapy, 26(1), 51-65.

Bauman, L.J. y Berman, R. (2005). Adolescent relationship and condom use: Trust, love and commitment. AIDS and Behavior, 9, 211-222.

Baumeister, R. F. \& Tice, D. M. (2001). The social dimension of sex. Boston: Allyn \& Bacon.

Baumeister, R. F. (2000). Gender differences in erotic plasticity: The female sex drive as socially flexible and responsive. Psychological Bulletin, 126, 247-374.

Baumeister, R.F., Catanese, K.R., \& Vohs, K.D. (2001). Is There a Gender Difference in Strength of Sex Drive? Theoretical Views, Conceptual Distinctions, and a Review of Relevant Evidence. Personality and Social Psychology Review, 5, 242-273.

Bentler PM. (1968). Heterosexual behavior assessment. I. Males. Behavior Research and Therapy , 6 (1), 21-25.

Bentler PM. (1968). Heterosexual behavior assessment. II. Females. Behavior Research and Therapy , $6(1), 27-30$.

Bianchi, SM, \& Casper, LM (2000). American families. Population Bulletin, 55(4) Washington, DC: Population Reference Bureau.

Bleske-Rechek, A. \& Buss, D.M. (2006). Sexual strategies pursued and mate attraction tactics deployed. Personality and Individual Differences, 40, 1299-1311.

Bogle, K. A. (2004). From dating to hooking up: The emergence of a new sexual script. Tesis doctoral en internet. University of Delaware. Unpublished 3112658. 
Boldero, J., Moore, S., \& Rosenthal, D. (1992). Intentions, context, and safe sex: Australian adolescents' responses to AIDS. Journal of Applied Social Psychology, 22, 13741396.

Bourg, S. (2001). Sexual and physical aggression within a dating/ acquaintance relationship: Testing models of perpetrator characteristics. Tesis doctoral en internet. Auburn University. 121 páginas, AAT 3002880.http://proquest.umi.com/pqdweb?did= $728459911 \&$ sid $=1 \&$ Fmt $=2 \&$ clientId $=40776 \&$ RQT $=309 \&$ VName $=P Q D$

Bowlby, J. (1970). Reasonable fear and natural fear. International Journal of Psychiatry, 9, 7988.

Brassard, A., Shaver, P., Lussier, Y. (2007), Attachment, sexual experience, and sexual pressure in romantic relationships: A dyadic approach. Personal Relationships, 14 475-493.

Breakwell, G.M. y Millward, L.J. (1997). Sexual self-concept and sexual risk-taking. Journal of Adolescence, 20, 29-41.

Brigman, B., and Knox, D. (1992). University students' motivation to have intercourse. College Student Journal, 26, 406-408.

Brown, B. B. (1999). "You're going with who?!": Peer group influences on adolescent romantic relationships. En: W. Furman, B. B. Brown, \& C. Feiring (Eds.), The Development of Romantic Relationships in Adolescence. (pp. 291-329) London: Cambridge University Press.

Brown, B. B., Feiring, C., \& Furman, W. (1999). Missing the Love Boat: Why researchers have shied away from adolescent romance. En: W. Furman, B. B. Brown, \& C. Feiring (Eds.), The Development of Romantic Relationships in Adolescence (pp. 1-16) London: Cambridge University Press.

Browning, J. R., Hatfield, E., Kessler, D., and Levine, T. (2000). Sexual motives, gender, and sexual behavior. Archives of Sexual Behavior, 29, 135-153. 
Buist, K., Dekovic, M., Meeus, W., \& van Aken, M.A.G. (2004). The reciprocal relationship between adolescent attachment and psychosocial adjustment. Journal of Adolescence, $27,251-266$.

Buss, D. M., \& Schmitt, D. P. (1993). Sexual strategies theory: An evolutionary perspective on human mating. Psychological Review, 100, 204-232.

Buss, D. M. (1989). Sex differences in human mate preferences: Evolutionary hypotheses tested in 37 cultures. Behavioral and Brain Sciences, 12, 1-49.

Buss, D. M. (1995). Evolutionary psychology: A new paradigm for psychological science. Psychological Inquiry, 6, 1-49.

Buss, D. M. (1999). Evolutionary psychology. The new science of the mind. Boston: Allyn and Bacon.

Buss, D. M. (2003). The evolution of desire: Strategies of human mating (Rev. ed.). New York: Free Press.

Byers, E. S. \& Demmons, S. (1999). Sexual satisfaction and sexual self-disclosure within dating relationships. The Journal of Sex Research, 36, 180-189.

Byers, E. S. \& Heinlein, L. (1989). Predicting initiations and refusals of sexual activities in marriedand cohabiting couples. The Journal of Sex Research, 26, 210-231.

Byers, E. S. (1995). Sexology in Canada. (1995). Canadian Journal of Human Sexuality, 4, 7983.

Byers, E. S. (1996). How well does the traditional sexual script explain sexual coercion?: Review of a program of research. Journal of Psychology and Human Sexuality, 8, 7-25.

Caffray, C. M., \& Schneider, S. L. (2000). Why do they do it?: Affective motivators in adolescents' decisions to participate in risky behaviors. Cognition and Emotion, 14, (Special issue on Emotion, Cognition, and Decision Making), 543-576. 
Carrol, J.L., Volk, K.D. \& Hyde, J.S. (1985). Differences between males and females in motives for engaging in sexual intercourse. Archives of Sexual Behavior, 14, 131-139.

Carver, C. S., \& Scheier, M. F. (1998). On the self-regulation of behavior. New York: Cambridge University Press.

Carver, C. S., Sutton, S. K., \& Scheier, M. F. (2000). Action, emotion, and personality: Emerging conceptual integration. Personality and Social Psychology Bulletin, 26, 741751.

Centers for Disease Control and Prevention. (2004). Sexually transmitted diseade surveillance, 2003. Atlanta, GA: U.S. Department of Health and Human Services.

Centers for Disease Control and Prevention. (2002). Tracking the Hidden Epidemics: Trends in STDs in the United States. Atlanta, GA: Centers for Disease Control and Prevention, 2000.

Cerqueira-Santos E, Koller S, Wilcox B. (2008). Condom use, contraceptive methods, and religiosity among youths of low socioeconomic level. Spanish Journal of Psychology, 11(1), 94-102.

Clark, C.L., Shaver, P.R., \& Abrahams, M.F. (1999). Strategic behaviours in romantic relationship initiation. Personality and Social Psychology Bulletin, 25 (6), 707-720.

Clawson, C.L. \& Reese-Weber, M. (2003). The amount and timing of parent-adolescent sexual communication as predictors of late adolescent sexual risk taking behaviors. The Journal of Sex Research, 40, 256-265.

Cleveland, H.H., Koss, M.P., \& Lyons, J. (1999) Rape tactics from the survivor's perspective: Contextual dependence and within-event independence. Journal of Interpersonal Violence, 14, 532-547.

Cody, M.J., Mclaughlin, M. L., \& Jordan, W.J. (1980). A multidimensional scaling of three sets of compliance-gaining strategies. Communication Quarterly, 28(3), 34-46. 
Cohen M. (1995). Adolesceent sexual activity as all expression of nonsexual needs. Pediatric Annals, 24, 324-329.

Coleman, L.M. \& Ingham, R. (1999). Exploring young people's difficulties in talking about contraceptives: How can we encourage more discussion between partners? Health Education Research, 14, 741-750.

Connolly, J. A., \& Goldberg, A. (1999). Romantic relationships in adolescence: The role of friends and peers in their emergence and development. En W. Furman, B. B. Brown, \& C. Feiring (Eds.), The development of romantic relationships in adolescence (pp. 266-390). New York: Cambridge University Press.

Cooksey, E. C., Mott, F. L., and Neubauer, S. A. (2002). Friendships and Early Relationships: Links to Sexual Initiation Among American Adolescents Born to Young Mothers. Perspectives on Sexual and Reproductive Health, 34(3),118-126.

Cooper, M.L., Shapiro, C.M., \& Powers, A.M. (1998). Motivations for sex and risky sexual behavior among adolescents and young adults: A functional perspective. Journal of Personality and Social Psychology, 75, 1528-1558.

Cooper, M.L., Shaver, P.R., \& Collins, N.L. (1998). Attachment styles, emotion regulation, and adjustment in adolescence. Journal of Personality and Social Psychology, 74, 1380-1397.

Crawford, J., Kippax, S. \& Waldby, C. (1994). Women's sex talk and men's sex talk: Different worlds. Feminism and Psychology, 4, 571-587

Curran, J.P. (1975). Social skills training and systematic desensitization in reducing dating anxiety. Behavior Research and Therapy, 13, 65-68.

Choi, K. H., Binson, D., Adelson, M., \& Catania, J. (1998). Sexual harassment, sexual coercion and HIV risk among US adults 18-49 years. AIDS and Behavior, 2, 33-40. 
Christopher, F.S. \& Cate, R.M. (1984). Influences of sexual decision making. Journal of Sex Research, 20, 363-376.

Christopher, F. S., \& Frandsen, M. M. (1990). Strategies of influence in sex and dating. Journal of Social and Personal Relationships, 7, 89-107.

Christopher, F. S., Madura, M. \& Weaver, L. (1998). Premarital sexual aggressors: A multivariate analysis of social, relational, and individual correlates. Journal of Marriage and the Family, 60, 56-69.

Christopher, F. S. (2001). To dance the dance: A symbolic interactional exploration of premarital sexuality. Mahwah, NJ: Lawrence Erlbaum.

Davis, P. \& Lay-Yee, R. (1999). Early sex and its behavioral consequences in New Zealand. The Journal of Sex Research, 36(2), 135-144.

Davis, D. (2006). Attachment-related pathways to sexual coercion. In M. Mikulincer \& G. S. Goodman (Eds.), Dynamics of romantic love (pp.293-336) New York: Guilford Press.

De Lamater, J. \& Friedrich, W. (2002). Human sexual development. Journal of Sex Research, $39,10-14$.

DiIorio, C., Kelley, M. \& Hockenberry-Eaton, M. (1999). Communication about sexual issues: mothers, fathers, and friends. Journal of Adolescent Health, 24(3), 181-189.

Diz, M.C., Sueiro, E., Chas, M. D. y Dieguez, J.L. (2003). Comportamientos sexuales de adolescentes del medio rural gallego (y $3^{\mathrm{a}}$ parte). Cuadernos de Medicina Psicosomática y Psiquiatría de Enlace, 67/68, 46-60.

Doll, L., \& Carballo-Dieguez, A. (1998). Physical and sexual coercion and HIV risk. AIDS and. Behavior, 2, 31-32.

Donald, M., Lucke, J. C., Dunne, M. P., \& Raphael, B. (1995). Gender differences associated with young people's emotional reactions to sexual intercourse. Journal of Youth and Adolescence, 24, 453-464. 
Dworkin, S., Beckford, S.T. \& Ehrhardt, A. (2007). A Longitudinal Analysis of Sexual Scripts for Women Who Participated in a Gender-Specific HIV/STD Prevention Intervention. Archives of Sexual Behavior, 36, 269-279.

Dybvig-Pawelko, K. (2007). Sexual Initiation Strategies: Explication and Validation of a Concept. Tesis Doctoral en Internet. Arizona State University. ATT 3258081. http://gateway.proquest.com

East, L., Jackson, D., O'Brien, L. \& Peters, K. (2007) Use of the male condom by heterosexual adolescents and young people: literature review. Journal of Advanced Nursing, 59(2) 103-110.

Edgar, T., \& Fitzpatrick, M.A. (1993). Expectations for sexual interaction: A cognitive test of the sequencing of sexual communication behaviors. Health Communication, 4, 239-262.

Eggermont, S. (2006). Television viewing and adolescent judgement of sexual request scripts: A latent growth curve analysis in early and middle adolescence. Sex roles, 55, 457-468.

Ellen, J. M., Cahn, S., Eyre, S. L., \& Boyer, C. B. (1996). Type of adolescent sexual relationships and associated perceptions about condom use. Journal of Adolescent Health, $18,417-421$.

Elliot, A.J., \& Sheldon, K.M. (1997). Avoidance achievement motivation: A personal goals analysis. Journal of Personality and Social Psychology, 73, 171-185.

Erikson, E.H. (1950). Childhood and Society. New York:Norton.

Espadalé, E., Planes, M., y Gras, M.E. (2005). Percepción del riesgo de transmisión sexual del VIH en estudiantes de bachillerato. Psiquis, 26 (1), 28-32.

Eyre, S.L.; Millstein, S.G. (1999). What leads to sex? Adolescent preferred partners and reasons for sex. Journal of Research on Adolescence, 9, 277-307. 
Eyre, S. L., Read, N. W., \& Millstein, S. G. (1997). Adolescent sexual strategies. Journal of Adolescent Health, 20, 286-293

Falbo, T., \& Peplau, L. A. (1980). Power strategies in intimate relationships. Journal of Personality and Social Psychology, 38, 618-628.

Feeney, J. A., Peterson, C., Gallois, C. \& Terry, D. J. (2000). Attachment style as a predictor of sexual attitudes and behaviour in late adolescence. Psychology and Health, 14 (6), 11051122 .

Felson, R.B. (2002). Violence \& Gender Reexamined. Washington, D.C.: American Psychological Association.

Fishbein, M., \& Ajzen, I. (1975). Belief, Attitude, Intention, and Behavior: An Introduction to Theory and Research. Reading, MA: Addison-Wesley.

Ford, K., Song, W. \& Lepkowski, J.M. (2001). Characteristics of partners of american adolescents and their association with the use of condoms and other contraceptive methods. Family Planning Perspectives, 33, 100-105 \& 132.

Fortenberry, J.D., Harezlak J., Katz B.P. \& Orr D.P. (2002). Condom use as function of time in new and established adolescent sexual relationships. American Journal of Public Health, 92, 211-213.

Freud, S. (1905, 1953-1974). Three Essays on the Theory of Sexuality. The Standard Edition of the Complete Psychological Works of Sigmund Freud, Vol. 7 (pp. 123-246). London: Hogarth Press.

Freud, S. (1923/1990). The Ego and the Id. New York: W.W. Norton \& Company.

Friedman S, Flor PL, Kottiri BJ, Neaigus A, Sandoval M, Curtis R, Zenilman JM and Des Jarlais DC. (2001). Prevalence and correlates of anal sex with men among young adult women in an inner city minority neighborhood. AIDS, 15(15), 2057-2060. 
Fuertes, A. (1996). Redefinición sexual y de género. En J. Fernández (Ed.), Varones y mujeres: desarrollo de la doble realidad del sexo y del género (pp.189-210). Madrid: Pirámide.

Fuertes, A. (2000). La coerción y la violencia sexual en la pareja. En J. Navarro y J. Pereira (Eds.), Parejas en situaciones especiales (pp. 88-120). Barcelona: Paidós.

Fuertes, A., Ramos, M., De la Orden, M.V., Del Campo, A. y Lázaro, S. (2005). The involvement in sexual coercive behaviours of collage men: Prevalence and risk factors. Journal of Interpersonal Violence, 20, 872-891.

Fuertes, A., Ramos, M. y Fernández Fuertes, A. (2007). La coerción sexual en las relaciones de los y las adolescentes y jóvenes: naturaleza del problema y estrategias de intervención. Apuntes de psicología, 25(3), 341-356.

Fuertes, A., Ramos, M., Martínez, J.L., López, D. y Tabernero, C. (2006). Prevalencia y factores de vulnerabilidad y protección de la victimización sexual en las relaciones con los iguales en las mujeres universitarias españolas. Child Abuse y Neglect, 30, 799-814.

Furman, W., \& Simon, V. (1999) Advice from youth: Some lessons from the study of adolescent relationships. Journal of Social and Personal Relationships, 15, 723-739.

Furman, W., \& Wehner, E.A. (1994). Romantic views: Toward a theory of adolescent romantic relationships. En R. Montemayor, G.R. Adams, \& G.P. Gullota (Ed.) Advances in adolescent development: Volume 6, Relationships during adolescence (pp. 168-195). Thousand Oaks, CA: Sage.

Gable S.L., Reis H. T. \& Elliot A. J. (2000). Behavioral activation and inhibition in everyday life. Journal of personality and social psychology, 78(6), 1135-1149.

Gagnon, J. H. \& Simon, W. (1973). Sexual Conduct: The social sources of human sexuality. Chicago: Aldine.

Gagnon, J. H. (1990). The explicit and implicit use of the scripting perspective in sex research. Annual Review of Sex Research, 1, 1-43. 
Gangestad, S.W. y Simpson, J.A. (1990). Toward an evolutionary history of female sociosexual variation. Journal of Personality., 58, 69-96.

Garcia, L., \& Carrigan, D. (1998). Individual and gender differences in sexual self-perceptions. Journal of Psychology and Human Sexuality, 10, 59-70.

Garcia, L. (1998). Perceptions of resistance to unwanted sexual advances. Journal of Psychology and Human Sexuality, 10 (1), 43-52.

Gebhardt, W.A., Kuyper, L. \& Dusseldorp, E. (2006). Condom use at first intercourse with a new partner in female adolescents and young adults: The role of cognitive planning and motives for having sex. Archives of Sexual Behavior, 35(2), 217-223.

Gebhardt, W.A., Kuyper, L., \& Greunsven, G. (2003). Need for intimacy in relationships and motives for sex as determinants of adolescent condom use. Journal of Adolescent Health, 33(3), 154-164.

Gilbert, L.A., Walter, S.J., McKinney, S., \& Snell, J.L. (1999). Challenging discourse themes reproducing gender in heterosexual dating: An analog study. Sex Roles, 41, 753-774.

Giordano, P.C., Longmore, M.A. \& Manning, W.D. (2001). On the nature and developmental significance of adolescent romantic relationships. En Kinney, D. (Ed.), Sociological Studies of Chidren and Youth (pp.111-139). New York: Elsevier.

Gómez-Zapiain, J. (2005). Aproximación a los comportamientos sexuales y de riesgo en la adolescencia. En A. S. Rathus, J. S. Nevid y L. Fichner-Rathus (Eds.), Sexualidad Humana (pp. 289-292). Madrid: Pearson-Prentice Hall.

Grauerholz, E., \& Serpe, R. T. (1985). Initiation and response: The dynamics of sexual interaction. Sex Roles, 12, 1041-1059

Greer, A.E., \& Buss, D.M. (1994). Tactics for promoting sexual encounters. Journal of Sex Research, 31, 185-202. 
Greiling, H., \& Buss, D.M. (2000). Women's sexual strategies: The hidden dimension of extrapair mating. Personality and Individual Differences, 28, 929-963.

Grossman, I., Julien, D., Mathieu, M., \& Chartrand, E. (2002). The sexual initiation scale: Development and initial validation. The Canadian Journal of Human Sexuality, 11, (3-4).

Guzmán, B. L., Schlehofer-Sutton, M. M., Villanueva, C. M., Dello Stritto, M.E., Casad, B. J., \& Feria, A. (2003). Let's talk about sex: How comfortable discussions about sex impact teen sexual behavior. The Journal of Health Communication, 8, 583-598.598.

Hazan, C., \& Shaver, P. (1987). Conceptualizing romantic love as an attachment process. Journal of Personality and Social Psychology, 52,511-524

Hazan, C., and Shaver, P.R. (1994). Attachment as an organizational framework for research on close relationships. Psychological Inquiry, 5, 1-22

Herold, E. S., \& Marshall, S. K. (1996). Adolescent sexual development. In Adams, G. R., Montemayor, R., \& Gullotta, T. P. (Eds.), Psychosocial development during adolescence (pp. 62-94). Thousand Oaks, CA: Sage Publications.

Herold, E. S., \& Way, L. (1988). Sexual self-disclosure among university women. Journal of Sex Research, 24, 1-14.

Higgins, E. T. (1998). Promotion and prevention: Regulatory focus as a motivational principle. Advances in Experimental Social Psychology, 30, 1-46.

Hill, C. y Preston, L. (1996). Individual differences in the experience of sexual motivation: Theory and Measurement of dispositional sexual motives. The Journal of Sex Research, 33(1), 25-40.

Holland, J., Ramazanoglu, C., Scott, S., Sharpe, S. and Thomson, R. (1990). Don't Die of Ignorance? I nearly died of embarrassment. Condoms in Context WRAP Working Paper 2. Tufnell Press. 
Hopkins, K. W. (2000). Testing Reiss's autonomy theory on changes in non-marital coital attitudes and behavior of U.S. teenagers: 1960-1990. Scandinavian Journal of Sexology, 3, 113-125.

Horowitz, J. L. (2000). Gender differences in motivation for sexual intercourse: Implications for risky sexual behavior and substance use in a university and community sample. Dissertation Abstracts International, 63(2), 1030B.

Howard, J.A. (1988). Gender differences in sexual attitudes: Conservatism or powerlessness?. Gender \& Society, 2, 103-114.

Hull, C. L. 1943. Principles of Behavior: An Introduction to Behavior Theory. New York: Appleton-Century-Crofts.

Hunter, B.A. \& Shotland, R.L. (1996) "Token Resistance" and Compliance to Sexual Intercourse: Similarities and Differences in Men's and Women's Behavior, unpublished manuscript.

Hynie, M., Lydon, J., Cote, S., \& Wiener, S. (1998). Relational sexual scripts and women's condom use: The importance of internalized norms. Journal of Sex Research, 35, 370380 .

Impett, E. A. \& Tolman, D. L. (2006). Adolescent girls' sexual experiences and sexual satisfaction. Journal of Adolescent Research, 6, 628-646.

Impett, E. A., Peplau, L. A., \& Gable, S. L. (2005). Approach and avoidance sexual motivation: Implications for personal and interpersonal well-being. Personal Relationships, 12, 465482.

Ingham, R., Woodcock, A. \& Stenner, K. (1991). Getting to know you... Young people's knowledge of their partners at first intercourse. Journal of Community and Applied Social Psychology, 1, 117-132.

INJUVE (2000). Informe de la Juventud en España. Madrid: Instituto de la Juventud de España. 
Jenkins, S. S. (2004). Gender and self-determination in sexual motivation. Dissertation Abstracts International: Section B: The Sciences and Engineering, 64, 6330.

Jesser, C. J. (1978). Male responses to direct verbal sexual initiatives of females. Journal of Sex Research, 14, 118-128.

Kann, L., Kinchen, S.A., Williams, B.I., Ross, J.G., Lowry, R., Grunbaum, J. \& Kolbe, L.J. (2000).Youth risk behavior surveillance -United States, 1999. Journal of School Health, $70,271-285$.

Katchadourian, H.(1990). Sexuality. En S.S. Feldman y G.R. Elliot (Eds.), At the threshold: the developing (330-351): Cambridge, MA. Harvard University Press.

Kelly, J.A., \& Kalichman, S.C. (1995). Increased attention to human sexuality can improve HIV/AIDS prevention efforts: Key research issues and directions. Journal of Consulting and Clinical Psychology, 63, 907-918.

Kent, V. (1993). When can we stop using condoms? Brook Advisory Centres Annual Conference.

Kilmartin, C. T. (2000). The Masculine Self, second edition. Boston: McGraw Hill.

Kinsey, A. C., Pomeroy, W. B. \& Martin, C. E. (1948). Sexual Behavior in the Human Male. Philadelphia: W. B. Saunders.

Kinsey, A. C., Pomeroy W. B., Martin, C. E., \& Gebhard, P. H. (1953). Sexual behavior in the human female. New York: W. B. Saunders.

Knapp, M. L. (1980). La comunicación no verbal. Barcelona: Paidós

Kowalski, R. M. (1992). Nonverbal behaviors and perceptions of sexual intentions: Effects of sexual connotativeness, verbal response, and tape outcome. Basic and Applied Social Psychology, 13(4), 427-445. 
Krahé, B., Bieneck, S., \& Scheinberger-Olwig, R. (2007). Adolescents' sexual scripts: Schematic representations of consensual and nonconsensual heterosexual interactions. Journal of Sex Research, 44, 316-327.

Krahé, B., Bieneck, S., \& Scheinberger-Olwig, R. (2007). The role of sexual scripts in sexual aggression and victimization. Archives of Sexual Behavior, 37, 687-701.

Krahé, B., Scheinberger-Olwig, R., \& Kolpin, S. (2000) Ambiguous communication of sexual intentions and the prediction of sexual aggression. Sex Roles, 42, 313-337.

Kvalem, I.L. \& Træen, B. (2000). Self-efficacy, scripts of love and intention to use condoms among Norwegian adolescents. Journal of Youth \& Adolescents 29(3): 337-353.

LaPlante, M. N., McCormick, N., \& Brannigan, G. G. (1980). Living the sexual script: College students' views of influence in sexual encounters. The Journal of Sex Research, 16(4), 338-355.

Larsson, I. y Svedin, C. (2002). Teachers' and parents' report on 3 to 6 year-old children's sexual behavior: a comparison. Child Abuse and Neglect, 26, 247-266.

Laumann, E. O., J. H. Gagnon, R. T. Michael, and S. Michaels. 1994. The Social Organization of Sexuality. Chicago: University of Chicago Press.

Lear, D. 1995 . Sexual communication in the age of AIDS: the construction of risk and trust among young adults. Social Science Medicine, 41, 13111323.

Lefkowitz, E. S., Boone, T. L., \& Shearer, C. L. (2004). Communication with best friends about sex-related topics during emerging adulthood. Journal of Youth and Adolescence, 33, 339-351.

Lefkowitz, E. S., Boone, T. L., Sigman, M., \& Au, T. K. (2002). He said, she said: Gender differences in mother-adolescent conversations about sexuality. Journal of Research on Adolescence, 12, 217-242 
Leger, D. W. (1992). Biological Foundations of Behavior: An Integrative Approach. NY: Harper Collins Publishers Inc.

Leiblum, S. R., \& Rosen, R. C. (1991). Couples therapy for erectile disorder: Conceptual and clinical considerations. Journal of Sex \& Marital Therapy, 17(2), 147-159.

Leigh, B. C. (1989). Reasons for having and avoiding sex: Gender, sexual orientation, and relationship to sexual behavior. The Journal of Sex Research, 26(2):199-209.

Lewin, M. (1985). Unwanted intercourse: The difficulty of saying no. Psychology of Women Quarterly, 9, 184-192.

Lisak, D., \& Roth, S. (1988). Motivational factors in non-incarcerated sexually aggressive men. Journal of Personality and Social Psychology, 55, 795-803.

Littleton, H. L., \& Axsom, D. (2003). Rape and seduction scripts of university students: Implications for rape attributions and unacknowledged rape. Sex Roles, 49, 465-475.

Livingston, J. A., Buddie, A. M., Testa, M., \& VanZile-Tamsen, C. (2004). The role of sexual precedence in verbal sexual coercion. Psychology of Women Quarterly, 28, 287-297.

Livingston, J. A., Testa, M., \& VanZile-Tamsen, C. (2007). The reciprocal relationship between sexual victimization and sexual assertiveness. Violence Against Women, 13, 298-313.

Malamuth, N. M., Sockloskie, R. J., Kess, M. P; \& Tanaka, J. S. (1991). Characteristics of aggressors against women. Journal of Consulting and Clinical Psychology, 59(5), 670681.

Manning, W.D., Longmore, M.A., \& Giordano, P.C. (2000). The relationship context of contraceptive use at first intercourse. Family Planning Perspectives, 32, 104-110.

Manning, W., Longmore, M.A. \& Giordano, P.C. (2005). Adolescents' involvement in nonromantic sexual activity. Social Science Research, 34(2), 384-407. 
Martínez, J. L. (2000). Experiencias heterosexuales en la adolescencia: implicaciones para la educación sexual. Revista De Psicología General y Aplicada, 53, 191-209.

Marwell, G., \& Schmitt, D. R. (1967). Dimensions of compliance-gaining behavior: An empirical analysis. Sociometry, 30,350-364.

Masters, W. H., \& Johnson, V. E. (1966). Human Sexual Response. Boston: Little, Brown.

Mathes, E.W., King, C.A., Miller, J.K. et al. (2002). An evolutionary perspective on the interaction of age and sex differences in short-term sexual strategies. Psychological Reports, 90, 949-956.

Maticka-Tyndale, E., Herold, E. S., \& Mewhinney, D. (1998). Casual sex on spring break: Intentions and behaviors of Canadian students. The Journal of Sex Research, 35, 254-264.

McCabe, M. P. (1999). Sexual knowledge, experience, and feelings among people with disability. Sexuality and. Disability, 17(2), 157-170.

McCormick, N. B. (1979). Come-ons and put-offs: Unmarried students' strategies for having and avoiding sexual intercourse. Psychology of Women Quarterly, 4, 194-211.

McLaughlin, M. L., Cody, M. J., \& Robey, C. S. (1980). Situational influences on the selection of strategies to resist compliance-gaining attempts. Human Communication Research, 7, 14-36.

Meston, C. M., \& Buss, D. (2007). Why humans have sex. Archives of Sexual Behavior, 36, 477-507.

Meston, C. M., \& O'Sullivan, L. (2007). Such a tease: Intentional sexual provocation within heterosexual interactions. Archives of Sexual Behavior, 36, 531-542.

Metts, S. \& Cupach, W. (1989). The role of communication in human sexuality. En K. McKinney \& S. Sprecher, (Eds.), Human sexuality: the societal and interpersonal context. Norwood, New York: Ablex. 
Metts, S., \& Spitzberg, B. H. (1996). Sexual communication in interpersonal contexts: A script-based approach. En B. R. Burleson (Ed.), Communication Yearbook 19 (pp. 4991). Thousand Oaks, CA: Sage Publications.

Miller, B.C. \& Dyck, P. (1993). Adolescent sexuality. En P. Tolan \& B. Kohler (Eds.), Handbook of clinical research and practice with adolescents (pp.95-123). Nueva York: John Wiley \& Sons.

Miller, P.Y. \& Simon, W. (1982). Adolescent psychosexual development. En Adelson J. (Ed.), The Handbook of Adolescent Psychology. Nueva York: Wiley.

Miller, L. C., Bettencourt, B. A., DeBro, S. C., \& Hoffman, V. ( 1993 ). "Negotiating safer sex: Interpersonal dynamics". En J. B. Pryor \& G. D. Reeder (Eds.), The Social Psychology of HIV Infection, (pp.85-123). Hillsdale, New Jersey: Lawrence Erlbaum.

Miller, B. C., Christopherson, C. R., \& King, P. K. (1993). Sexual behavior in adolescence. En T.P. Gullota, G.R. Adams \& R. Montemayor, (Eds.), Adolescent Sexuality, (pp.5776). Newbury Park: Sage.

Miller, B.C., Norton, M.C., Curtis, T., Hill, E.J., Schvaneveldt, P.,Young, M.H. (1997). The Timing of Sexual Intercourse among Adolescents: Family, Peer, and other Antecedents. Youth and Society, 29, 54-83

Mischel, W. (1966). A Social-learning view of sex differences in behavior. In E. E. Maccoby (Ed.), The Development of Sex Differences (pp. 56-81). Stanford, Ca.: Stanford University Press.

Mitchell, K., \& Wellings, K. (1998). First sexual intercourse: Anticipation and communication. Interviews with young people in England. Journal of Adolescence, 21, 717-726.

Moore, S. \& Rosenthal, D. (1993). Sexuality in Adolescence. New York: Routledge. 
Moore, K. A., Miller, B. C., Glei, D., \& Morrison, D. R. (1995). Adolescent sex, contraception, and childbearing: A review of recent research. Washington, DC: Child Trends, Inc.

Muehlenhard, C. L., \& Peterson, Z. D. (2005). Wanting and not wanting sex: The missing discourse of ambivalence. Feminism and Psychology, 15, 15-20.

Muehlenhard, C.L., Koralewski, M.A., Andrews, S.L., \& Burdick, C.A. (1986). Verbal and nonverbal cues that convey interest in dating. Two studies. Behavior Therapy, 17, 404419.

Muehlenhard, C. L., \& Cook, S. (1988). Men's self-reports of unwanted sexual activity. The Journal of Sex Research, 24, 58-72.

Muehlenhard, C. L., \& Hollabaugh, L. C. (1988). Do women sometimes say no when they mean yes? The prevalence and correlates of women's token resistance to sex. Journal of Personality and Social Psychology, 54(5), 872-879.

Muehlenhard, C. L. (1988). Misinterpreted dating behaviors and the risk of date rape. Journal of Social and Clinical Psychology, 6(1), 20-37.

Muehlenhard, C. L., Andrews, S. L., \& Beal, G. K. (1996). Beyond "Just saying no": Dealing with men's unwanted sexual advances in heterosexual dating contexts. In E. S. Byers \& L. F. O'Sullivan (Eds.), Sexual coercion in dating relationships (pp. 141-168). New York: Haworth Press.

Murstein, B.I., \& Tuerkheimer, A. (1998). Gender differences in love, sex, and motivation for sex. Psychological Reports, 82, 435-450.

Navarro-Pertusa, E., Barberá, E. y Reig-Ferrer, A. (2003). Diferencias de género en motivación sexual. Psicothema, 15, 395-400.

Navarro-Pertusa, E., Reig-Ferrer, A., Barberá-Heredia, E. y Ferrer-Cascales, R. (2006). Grupo de iguales e iniciación sexual adolescente: Diferencias de género. International Journal of Clinical and Health Psychology, 6, 79-96. 
Nelson, P. A. (1978). Personality, sexual functions, and sexual behavior: an experiment in methodology. A dissertation presented in partial fulfillment of the requirements of the University of Florida. Tampa, Fl.

Nurius , P.S., Norris, J., Young, D., Graham, T.L., \& Gaylord, J. (2000). Interpreting and defensively responding to threat: Examining appraisals and coping with acquaintance sexual aggression. Violence \& Victims, 15, 187 208. Nurius, 187-208.

O’Sullivan, L. F., \& Allgeier, E. R. (1998). Feigning sexual desire: Consenting to unwanted sexual activity in heterosexual dating relationships. Journal of Sex Research, 35, 234-243.

O'Sullivan, L. F., \& Byers, E. S. (1992). College students' incorporation of initiator and restrictor roles in sexual dating interactions. Journal of Sex Research, 29, 435-446.

O'Sullivan, L.F. \& Gaines, M.E. (1998). Decision making in college students' heterosexual dating relationships: Ambivalence about engaging in sexual activity. Journal of Social and Personal Relationships, 15(3), 347 - 363.

Oliva, A.; Serra, L. y Vallejo, R. (1997). Patrones de comportamiento sexual y contraceptivo en la adolescencia. Infancia y aprendizaje, 77, 19-34.

Oliva, A., Serra, L., y Vallejo, R. (1992). Conducta sexual y contraceptiva entre jóvenes andaluces. Apuntes de Psicología, 35, 53-66.

Oliva, A., Serra, L., Vallejo, R, López, M. y Lozoya, J.A. (1993). Sexualidad y contracepción en la adolescencia: un estudio cualitativo. Sevilla: Servicio Andaluz de Salud, Consejería de Salud.

Sedikides, C., Oliver, M. B., \& Campbell, W. K. (1994). Perceived benefits and costs of romantic relationships for women and men: Implications for exchange theory. Personal Relationships, 1, 5-21.

Oliver, M. B., \& Hyde, J. S. (1993). Gender differences in sexuality: A meta-analysis.

Psychological Bulletin, 114, 29-51. 
Osman, S. L. (2003). Predicting men's rape perceptions based on the belief that "no" really means "yes." Journal of Applied Social Psychology, 33, 683-692.

Ott, M.A., Millstein, S.G., Ofner, S., \& Halpern-Felsher, B.L. (2006). Greater expectations: Adolescents' positive motivations for sex. Perspectives on Sexual and Reproductive Health, 38(2), 84-89.

Palenzuela, A. (2006). Intereses, conducta sexual y comportamientos de de riesgo para la salud sexual de escolares adolescentes participantes en un programa de educación sexual. Análisis y Modificación de Conducta, 32, 144: 451.

Pallant, J. (2001). SPSS Survival Manual. Milton Keynes: Open University Press.

Papadopoulos, G.N., Stamboulides, P., \& Triantafillou, T. (2000). The Psychological, Developmental and Behaviour of University Students: A Nationwide Survey in Greece. Journal of Psychology and Sexuality, 11(4), 93-111.

Patrick, M. E., Abar, C. C., \& Maggs, J. L. (2007). Reasons to have sex, personal goals, and sexual behavior during the transition to college. Journal of Sex Research, 44, 240-249.

Paul, E. L., McManus, B., \& Hayes, K.A. (2000). "Hookups": Characteristicsand correlates of college students'spontaneous and anonymoussexual experiences. The Journal of Sex Research, 37(1), 76-88.

Pepper, T. \& Weis, D.L. (1987). Proceptive and rejective strategies of U.S. and Canadian college women. Journal of Sex Research, 23, 455-480.

Peplau, L. A. (2003). Human sexuality: How do men and women differ? Current Directions in Psychological Science, 12(2), 37-40.

Planes, M., Gras, M.E., Cunill, M., Gómez, A.B., Romero, M.T., Font, S. i Vieta, (2004). Prevención de la transmisión sexual del VIH en adolescentes. Cuadernos de Medicina Psicosomática y Psiquiatría de Enlace, 71/72, 76-85. 
Ponton, L. E., \& Judice, S. (2004). Typical adolescent sexual development. Child and Adolescent Psychiatric Clinics of North America, 13, 497.

Purdie y Downey, 2000- Purdie, V., \& Downey, G. (2000). Rejection sensitivity and adolescent girls' vulnerability to relationship-centered difficulties. Child Maltreatment: Journal of American Professional Society on the Abuse of Children, 5(4), 338-349.

Ramos, M. y Fuertes, A. (2005). Vulnerabilidad frente a la victimización sexual: factores psicosociales y contextuales asociados. Revista de Sexología Integral, 2.

Ramos, M. (2004). Factores de protección y vulnerabilidad de la coerción sexual en adolescentes y jóvenes. Sexpol, 60, 16-18.

Ramos, M., Fuertes, A. y De la Orden, M.V. (2006). La victimización sexual en las relaciones con los iguales en una muestra de mujeres adolescentes y jóvenes: Prevalencia y creencias relacionadas con la victimización. Revista de Psicología Social, 21, 127-140.

Ramos, M., Fuertes, A., Martínez, J.L. y Hernández, A. (2003). Comportamientos y actitudes sexuales de los adolescentes de Castilla y León. Análisis y modificación de conducta, 29(124), 213-238.

Regan, P. C., \& Berscheid, E. (1996). Beliefs about the state, goals, and objects of sexual desire. Journal of Sex \& Marital Therapy, 22, 110-120.

Regan, P. C., \& Berscheid, E. (1999). Lust: What we know about human sexual desire. Thousand Oaks, CA: Sage.

Regan, P. C., \& Dreyer, C. S. (1999). Lust? Love? Status? Young adults' motives for engaging in casual sex. Journal of Psychology and Human Sexuality, 11, 1-24.

Regan, P. C. (1997). The impact of male sexual request style on perceptions of sexual interactions: The mediational role of beliefs about female sexual desire. Basic And Applied Social Psychology, 19(4), 519-532. 
Reis, H. T., \& Shaver, P. (1988). Intimacy as an interpersonal process. In S. Duck (Ed.), Handbook of personal relationships (pp. 367-389). Chichester, England: Wiley

Reiss, I. L (1960). Premarital Sexual Standards in America. New York: The Free Press of Glencoe.

Reiss, I. L. (1967). The Social Context of Premarital Sexual Permissiveness. New York: Holt, Rinehart \& Winston.

Reneau S. (2004). Unwanted Consensual Sexual Activity in Heterosexual Dating Relationships. Tesis Doctoral en Internet. University of Kansas. (107 páginas). http://www.womensstudies.ku.edu/graduate_certificate_research/Unwanted\%20Consensu al\%20Sexual\%20Activity\%20-\%20Long.doc

Renninger, L., Wade, T.J., \& Grammer, K. (2004). Getting that Female Glance: Patterns and Consequences of Male Non-verbal Behavior in Courtship Contexts. Evolution and Human Behavior, 25, 416-431.

Rickert, V.I., Neal, W.P., Wiemann, C.M. \& Berenson, A.B. (2000). Prevalence and predictors of low sexual assertiveness. Journal of Pediatric and Adolescent, 13 (2), 88-89.

Robinson, M. L., Holmbeck, G. N., \& Paikoff, R. (2007). Self-esteem enhancing reasons for having sex and the sexual behaviors of African American adolescents. Journal of Youth and Adolescence, 36, 453-464.

Rosenthal, D. A. \& Peart, R. (1996). The rules of the game: Teenagers communicating about sex. Journal of Adolescence, 19, 321-332.

Rosenthal, D.A., Gifford, S. \& Moore, S. (1998). Safe sex or safe love: Competing discourses?. AIDS Care, 10(1), 35-47.

Russell, B. y Oswald, D. (2001). Strategies and dispositional correlates of sexual coercion perpetrated by women: An exploratory investigation. Sex Roles, 45, 103-115. 
Sánchez, M. y Muñoz, A. (2001). Análisis de respuestas abiertas en un cuestionario sobre conductas relacionadas con el SIDA. Revista de Psicología Social, 16 (3), 261-273.

Sanderson, C. A., \& Cantor, N. (1995). Social dating goals in late adolescence: Implications for safer sexual activity. Journal of Personality and Social Psychology, 68, 1121-1134.

Sanderson, C. A., \& Karetsky, K. H. (2002). Intimacy goals and strategies of conflict resolution in dating relationships: A mediational analysis. Journal of Social and Personal Relationships, 19, 323-343.

Savin-Williams, R. C., \& Diamond, L. M. (2004). Sex. En R. M. Lerner \& L. Steinberg (Eds.), Handbook of adolescent psychology (2nd edition) (pp. 189-231). New York: John Wiley.

Schachner, D. A., \& Shaver, P. R. (2004). Attachment dimensions and sexual motives. Personal Relationships, 11, 179-195.

Schmitt, D.P. (1996). The sexual strategies measure: An assessment manual. Unpublished manuscript, Bradley University.

Schmitt, D. P., \& Buss, D. M. (1996). Strategic self-promotion and competitor derogation: Sex and context effects on the perceived effectiveness of mate attraction tactics. Journal of Personality and Social Psychology, 70, 1185-1204.

Seal, D.W., \& Ehrhardt, A.A. (2003). Masculinity and urban men: Perceived scripts for courtship, romantic, and sexual interactions with women. Culture, Health, and Sexuality, 5, 295-319.

Seal, D.W., Smith, M.D., Coley, B., Perry, J., and Gamez, M. (2008). Urban heterosexual couples' sexual scripts for three shared sexual experiences. Sex Roles, 58, 626-638.

Seibold, D.R., Cantrill, J.G., \& Meyers, R.A. (1994). Communication and interpersonal influence. En M. L. Knapp \& G. R. Miller (Eds.), Handbook of Interpersonal Communication. Beverly Hills, CA: SAGE. 
Shackelford, T. K., Pound, N., Goetz, A. T., \& LaMunyon, C. W. (2005). Human sperm competition and the far-reaching consequences of female infidelity. En Buss, D., A Handbook of Evolutionary Psychology. Hoboken, NJ: J. Wiley \& Sons.

Shotland, R. L., \& Craig, J. M. (1988). Can men and women differentiate between friendly and sexually interested behavior? Social Psychology Quarterly, 51, 66-73.

Shotland R. \& Goodstein L. (1992). Sexual Precedence reduces the perceived legitimacy of sexual refusal: An examination of attributions concerning date rape and consensual sex. Personality and Social Psychology Bullettin, 18(6), 756-764.

Shotland, R. L., \& Hunter, B. A. (1995). Women's "token resistant" and compliant sexual behaviors are related to uncertain sexual intentions and rape. Personality and Social Psychology Bulletin, 21, 226-236.

Shulman, S. \& Kipnis, O. (2001). Adolescent romantic relationships: A look from the future. Journal of Adolescence 24, 337-351.

Shulman, S., \& Scharf, M. (2000). Adolescent romantic behaviors and perceptions: Age- and gender-related differences, and links with family and peer relationships. Journal of Research on Adolescence, 10, 99-118.

Shulman, S., \& Seiffge-Krenke, I. (2001). Adolescent romance: Between experience and relationships. Journal of Adolescence, 24, 417-428.

Simon, W., \& Gagnon, J. H. (1986). Sexual scripts: Permanence and change. Archives of Sexual Behavior, 15, 97-120.

Simpson, J. A., \& Gangestad, S. W. (1991). Individual differences in sociosexuality: Evidence f or convergent and discriminant validity. Journal of Personality and Social Psychology, 60, 870-883.

Sipsma, E., Carrobles, J.A., Montorio, I. y Everaerd, W. (2000). Sexual aggression against women by men acquaintances: Attitudes and experiences among Spanish university students. Spanish Journal of Psychology, 3, 14-27. 
Skinner, E. A., \& Wellborn, J. G. (1994). Coping during childhood and adolescence: A motivational perspective. En D. Featherman, R. Lerner, \& M. Perlmutter (Eds.) Life-span development and behavior, Vol. 12 (pp. 91-133). Hillsdale, NJ: Erlbaum.

Smiler, A.P. (2007). "I wanted to get to know her better": Adolescent boy's dating motives, masculinity ideology, and sexual behavior. Journal of Adolescence (2007), doi: 10.1016/j.adolescence.2007.03.006.

Snyder, M., \& Cantor, N. (1998). Understanding personality and social behavior: A functionalist strategy. In D. T. Gilbert, S. T. Fiske, \& G. Lindzey (Eds.), The handbook of social psychology: Vol. 1. (4th ed., pp. 635-679). Boston: McGraw-Hill.

Sprague, J. \& Quadagno, D. (1989). Gender and sexual motivation: An exploration of two assumptions. Journal of Psychology and Human Sexuality, 2, 57-76.

SPSS 10 Guía para el análisis de datos. Documento en Internet.

Taris, T. W., \& Semin, G. R. (1997). Gender as a moderator of the effects of the love motive and relational context on sexual experience. Archives of sexual behaviour, 26(2), 159-80.

Townsend, J.M. (1995). Sex without emotional involvement. An evolutionary interpretation of sex differences. Archives of sexual behaviour, 24, 173-206.

Trivers, R. L. (1972) Parental investment and sexual selection. En B. Campbell (Ed.), Sexual Selection and the Descent of Man (pp.136-79). Chicago: Aldine-Atherton.

Tschann, J. M., Adler, N. E., Millstein, S. G., Gurvey, J. E., \& Ellen, J. M. (2002). Relative power between sexual partners and condom use among adolescents. Journal of Adolescent Health, 31, 17-25.

Turchick, J.A., Probst, D.R., Chau, M., Nigoff, A. \& Gidycz, C.A. (2007). Factors predicting the type of tactics used to resist sexual assault: A prospective study of college women. Journal of Consulting and Clinical Psychology, 75(4), 605-614. 
Verberg, N., Wood, E., Desmarais, S., Kalra, M., \& Senn, C.Y. (2000). Is "date rape" a gender neutral term?: Gender differences in definitions of date rape. Canadian Journal of Human Sexuality, 9(3), 181-190.

Wagner-Raphael, L.I., Seal, D.W., \& Ehrhardt, A.A. (2001). Close emotional relationships with women versus men: A qualitative study of 56 heterosexual men living in an inner-city neighborhood. The Journal of Men's Studies, 9, 243-256.

Weinstein, E. y Rosen, E. (1991). The development of adolescent sexual intimacy: implications for counseling. Adolescence, 26, 331-339.

Weis, D. L. (1998). Conclusion: The state of sexual theory. The Journal of Sex Research, 35, 100-114.

Weiss, R. (1998). A taxonomy of relationships. Journal of Social and Personal Relationships, $15,671-683$.

White, R.W. (1959). Motivation reconsidered: The concept of competence. Psychological Review, 66, 297-333.

Widman, L., Welsh, D. P., McNulty, J. K., \& Little, K. C. (2006). Sexual communication and contraceptive use in adolescent dating couples. Journal of Adolescent Health, 39, 89399.

Wiederman, M. W. (2005). The Gendered Nature of Sexual Scripts. The Family Journal, 13, 496-502.

Wight, D (1992). Impediments to safer heterosexual sex. A review of research with young people. AIDS Care, 4, 1, 11-23.

Wilson, W. C. (1975). The distribution of selected sexual attitudes and behaviors among the adult population of the United States. Journal of Sex Research, 11, 46-64. 
Zweig, J. M., Crockett, L. J., Sayer, A., \& Vicary, J. R. (1999). A longitudinal examination of the consequences of sexual victimization for rural young adult women. Journal of Sex Research, 36, 396-409. 

ANEXO I

\section{Universidad de Salamanca}

Los siguientes cuestionarios van dirigidos a conocer algunos aspectos sobre ti mismo y sobre tu relación con los demás. Tu participación es voluntaria.

Es importante que reflexiones las respuestas puesto que las conclusiones que obtenemos de estos datos van dirigidas a trabajar sobre las dificultades que encuentran algunas personas como tú. Por eso tu experiencia es indispensable.

Es muy importante que respondas con sinceridad, y puedes hacerlo con tranquilidad ya que no se pedirán datos de identificación personal. Todas las respuestas son válidas si reflejan tu verdadera experiencia, no hay respuestas buenas o malas.

Lo único que tendremos en cuenta para el estudio son datos generales que podeis completar a continuación.

\section{Muchas gracias por tu colaboración}

Sexo: Chico __ Chica _ _ _ Edad:

Nombre del centro en el que estudias:

Curso: 
Las personas tienen experiencias sexuales por diferentes motivos. Abajo hay una lista con algunos de esos motivos. Por favor, señala de 1 a 5 la importancia que han tenido cada uno de estos motivos en tus experiencias sexuales. Por experiencia sexual se entiende aquí "Toda conducta con significado sexual (besos, caricias, coito etc)" excluyendo por tanto, las que la persona considere como simples manifestaciónes de afecto.

Si no has tenido ninguna experiencia sexual, contesta lo que crees que contestarías si la hubieses tenido.

¿Qué importancia han tenido para ti cada uno de estos motivos a la hora de tener experiencias sexuales?

$\begin{array}{ccccc}1 & 2 & 3 & 4 & 5 \\ \text { Nada } & \text { Poco } & \text { Algo } & \text { Muy } & \text { Entremadamente } \\ \text { Importante } & \text { Importante } & \text { Importante } & \text { Importante } & \text { Importante }\end{array}$

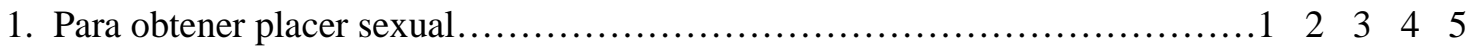

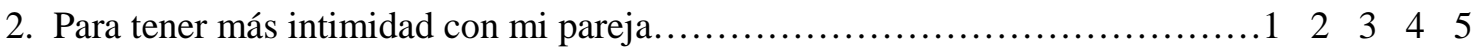

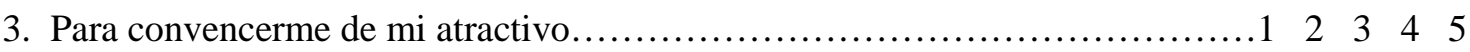

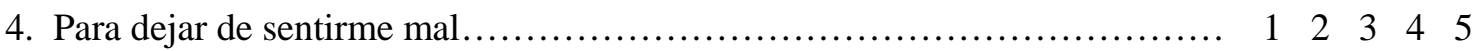

5. Por temor a que mi pareja pase de mi si no tenemos actividad sexual...........1 $2 \begin{array}{llll}2 & 3 & 4\end{array}$

6. Para evitar que otros se burlen de mi si no tengo actividad sexual.............. $123 \quad 3 \quad 4 \quad 5$

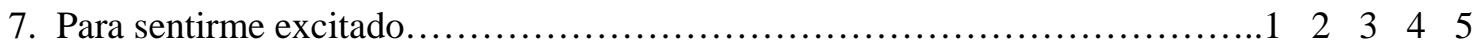

8. Para expresar mis sentimientos a mi pareja.............................. $123 \quad 3 \quad 4 \quad 5$

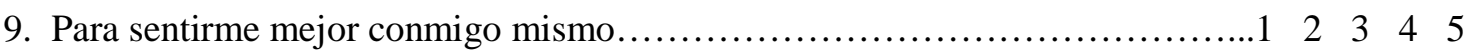

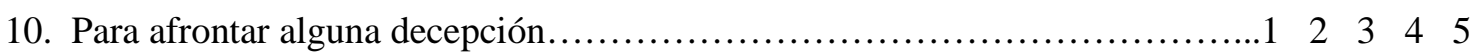

11. Para evitar que mi pareja se enfade si no accedo a tener actividad sexual......1 $23 \quad 3 \quad 4 \quad 5$

12. Para no parecer un pringado delante de mis amigos/as...................... $2 \begin{array}{llll}2 & 3 & 4 & 5\end{array}$

13. Para disfrutar sexualmente...........................................

14. Para conectar emocionalmente con mi pareja........................... $1223 \quad 4 \quad 5$ 
15. Para sentime más interesante...

$\begin{array}{lllll}1 & 2 & 3 & 4 & 5\end{array}$

16. Para dejar de sentirme deprimido $\begin{array}{llll}2 & 3 & 4 & 5\end{array}$

17. Para no disgustar o decepcionar a mi pareja

18. Para que la gente no hable de mí si no tengo actividad sexual... $1 \quad 2 \quad 3 \quad 4 \quad 5$

19. Para disfrutar de la actividad sexual.... $\begin{array}{lllll}1 & 2 & 3 & 4 & 5\end{array}$

20. Para sentirme más cerca de mi pareja. $\begin{array}{lllll}1 & 2 & 3 & 4 & 5\end{array}$

21. Para sentirme más seguro de mi mismo $\begin{array}{lllll}1 & 2 & 3 & 4 & 5\end{array}$

22. Para sentirme menos solo/a

23. Por temor a perder a mi pareja si no tenemos actividad sexual

24. Porque todos mi amigos/as tienen experiencias sexuales $\begin{array}{lllll}1 & 2 & 3 & 4 & 5\end{array}$

25. Para satisfacer necesidades sexuales $1 \quad 2 \quad 3 \quad 4 \quad 5$

26. Para demostrar a mi pareja lo que siento por ella. $1 \quad 2 \quad 3 \quad 4 \quad 5$

27. Para comprobar que soy deseable sexualmente $1 \quad 2 \quad 3 \quad 4 \quad 5$

28. Para animarme si estoy desanimado. $\begin{array}{llll}2 & 3 & 4 & 5\end{array}$

29. Para que los demás no me hagan de menos si no tengo experiencia sexual....1 $23 \quad 3 \quad 4 \quad 5$ 
A continuación tienes una serie de conductas sexuales. Señala la frecuencia con la que has realizado o experimentado cada conducta (o la frecuencia con la que otros han realizado la conducta contigo, dependiendo de cada frase).

$\begin{array}{ccccc}\text { Nunca } & \text { Una o } 2 \text { veces } & \text { De } 3 \text { a } 5 \text { veces } & \text { De } 6 \text { a } 10 \text { veces } & \text { Más de } 10 \\ 1 & 2 & 3 & 4 & 5\end{array}$

1. Beso con lengua........................................................ 23245

2. Caricias a senos femeninos con ropa..................................12 2345

3. Caricias a senos femeninos bajo la ropa.............................1 2345

4. Besar senos femeninos.............................................12 345

5. Caricias a genitales masculinos bajo la ropa.........................1 2345

6. Caricias a genitales femeninos bajo la ropa..........................1 2345

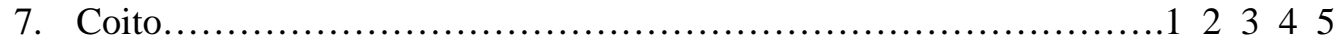

8. Sexo oral a genitales masculinos................................12345

9. Sexo oral a genitales femeninos....................................12345

10. Sexo oral mutuo hasta orgasmo mutuo.............................12345 
Version 1: Las siguientes 4 páginas del cuestionario son para que las contestes si tienes o has tenido pareja durante más de 3 meses. Si no, no contestes esta sección.

A continuanción hay una lista de estrategias de avance sexual. Estas son estrategias que las personas utilizan para intentar mantener alguna actividad sexual con los demás.

Por favor, utiliza la escala de abajo para valorar con qué frecuencia has utilizado o utilizas cada una de estas estrategias para tener alguna actividad sexual CON TU PAREJA (de más de 3 meses).

Importante: No cuentan las veces que has realizado estas conductas sin pretender tener actividad sexual.

¿Con qué frecuencia has utilizado cada estrategia con tu pareja para tener alguna actividad sexual?

$\begin{array}{ccccc}\text { Nunca } & \text { Una vez } & \text { De } 2 \text { a } 4 \text { veces } & \text { De } 5 \text { a } 10 & \text { Más de } 10 \\ 1 & 2 & 3 & 4 & 5\end{array}$

1. Acercarte e incrementar el contacto físico................................... 22345

2. Besar a tu pareja...................................................... 122345

3. Empezar a acariciar por debajo de la ropa...................................1 2345

4. Hacer que tu pareja te empiece a acariciar..................................... 232345

5. Responder a los acercamientos sexuales de tu pareja...........................12 345

6. Proponer ir a un lugar oportuno (tranquilo, oscuro).........................1 2345

7. Llevar a tu pareja a un lugar oportuno...................................... 12345

8. Hablar sobre sexo ( temas sexuales, anticonceptivos).........................12 2345

9. Enfadarte con tu pareja si no accede a tener una relación sexual.................122345

10. Decir directamente que deseas tener una relacion sexual.....................122345

11. Dejar que ocurra, no parar a tu pareja......................................... 12345

12. Chocar "accidentalmente" con tu pareja para acercarte........................123 345

13. Empezar a desnudarte o aflojar la ropa de tu pareja............................122345 
14. Bromear y/o insinuar algun interés sexual

15. Ignorar las señales de que tu pareja no desea una relación sexual

16. Decirle cosas halagadoras (cumplidos, "te quiero," etc)

17. Intentar convencer a tu pareja con argumentos o negociar para tener una relación sexual.

18. Hacerte notar y mostrarte atractivo/a y seductor/a. 12345

19. Emborrachar o aprovecharse de la borrachera de tu pareja para tener actividad sexual.

20. Usar movimientos o posturas provocativas

21. Presionar a tu pareja para tener actividad sexual (insistir mucho, decir que te lo debe, chantajear). 12345

22. Crear una atmosfera romántica. 12345

23. Intentar dar pena o hacer a tu pareja sentirse culpable 12345

24. Flirtear, tontear o actuar provocativamente. 123345

25. Amenazar fisicamente a tu pareja para tener actividad sexual 12345

26. Forzar fisicamente a tu pareja para tener actividad sexual 123345

27. Invitar o hacer un regalo o favor para tener actividad sexual. 12345

28. Usar algun código íntimo (palabras) que la persona va a entender. 12345

29. Hablar de lo que sientes por la otra persona 12345 
Version 1: Para contestar si tienes o has tenido pareja durante más de 3 meses.

1. Cuando es tu pareja la que utiliza estas estrategias para tener actividad sexual contigo ¿En qué medida aceptas tener actividad sexual cuando en realidad no lo deseas? Señala con una $\mathrm{X}$ la respuesta que más se adecúe a tu experiencia. Si no han intentado tener actividad sexual contigo, no contestes esta pregunta.

1. _. Nunca

2. _La minoria de las veces

3. _La mitad de las veces

4. _La mayoría de las veces

5. _. Siempre

2. Normalmente con tu pareja desearías tener... (Señala solo una opción):

1. __ Menos actividad sexual de la que tienes

2. __La misma actividad sexual que la que tienes

3. __Más actividad sexual de la que tienes

3. Indica en qué medida sueles utilizar preservativo en tus relaciones sexuales con tu pareja. Si no has tenido relaciones sexuales coitales, no contestes.

1. _. Nunca

2. _L La minoria de las veces

3. L La mitad de las veces

4. _La mayoría de las veces

5. _. Siempre

4. Las siguientes preguntas hacen referencia a tus relaciones de pareja.

1. ¿Cuantas relaciones de pareja pasadas has tenido? (en número)..........

2. De tus relaciones de pareja pasadas (no la actual) ¿Cual has sido la duración de la relación más larga? (contesta en $\mathrm{n}^{\circ}$ de meses)

3. ¿Tienes actualmente una relación de pareja? (SI o NO).

4. Si has contestado SI, indica la duración de ésta relación (en $n^{\circ}$ de meses) 


\section{Versión 1: Para contestar si tienes o has tenido pareja de más de 3 meses}

A continuanción hay una lista de estrategias de limitación sexual. Estas son estrategias que las personas utilizan para intentar evitar o limitar la actividad sexual con los demás. Por favor, utiliza la escala de abajo para valorar con qué frecuencia has utilizado o utilizas cada una de estas estrategias para evitar o limitar tu actividad sexual CON TU PAREJA.

¿Con qué frecuencia has utilizado cada estrategia con tu pareja para evitar o limitar la actividad sexual?

$\begin{array}{ccccc}\text { Nunca } & \text { Una vez } & \text { De } 2 \text { a } 4 \text { veces } & \text { De } 5 \text { a } 10 & \text { Más de } 10 \\ 1 & 2 & 3 & 4 & 5\end{array}$

1. Dejar claro lo que quieres y lo que no quieres hacer desde el principio 12345

2. Decir directamente que no quieres seguir en el momento .123345

3. Irte de la situación o lugar. 12345

4. Inventarte una excusa desde el principio

5. Interrumpir la actividad sexual con una excusa.

6. Dar señales no verbales de que no deseas actividad sexual (separarse, apartar manos etc.)

7. Quedarte inmóvil y/o rígido/a de forma notable.

8. Utilizar tácticas para retrasarlo (proponer una actividad no sexual). 12345

9. Mostrarte sobrepasado/a o abrumado/a (llorar, etc.)

10. Fingir que crees que el acercamiento sexual de tu pareja es una broma.

11. Pedir comprensión a tu pareja sobre porqué no quieres ir mas allá. 123345

12. Distraer a tu pareja (contando algo, haciendo preguntas, etc.)

13. Esperar que tu pareja no intente ir demasiado lejos 12345

14. Hablar de otro chico/a que te pudiera gustar. 
Versión 2: Las siguientes 4 páginas son para que las contestes si tienes o has tenido relaciones esporádicas (de días o semanas) con personas a las que no consideras tu pareja. Si no has tenido estas relaciones, no contestes esta sección.

A continuación hay una lista de estrategias de avance sexual. Estas son estrategias que las personas utilizan para intentar mantener alguna actividad sexual con los demás. Por favor, utiliza la escala de abajo para valorar con qué frecuencia has utilizado o utilizas cada una de estas estrategias para tener alguna actividad sexual CON ALGUIEN (desconocido/a, conocido/a o amigo/a).

Importante: No cuentan las veces que has realizado estas conductas sin pretender tener actividad sexual.

¿Con qué frecuencia has utilizado cada estrategia en tus relaciones esporádicas para tener alguna actividad sexual?

$\begin{array}{ccccc}\text { Nunca } & \text { Una vez } & \text { De 2 a } 4 \text { veces } & \text { De } 5 \text { a } 10 & \text { Más de } 10 \\ 1 & 2 & 3 & 4 & 5\end{array}$

1. Acercarte e incrementar el contacto físico......

2. Besar a la otra persona................................................. 12345

3. Empezar a acariciar por debajo de la ropa.................................... 22345

4. Hacer que la otra persona te empiece a acariciar.............................. 22345

5. Responder a los acercamientos sexuales de la otra persona.......................1 23445

6. Proponer ir a un lugar oportuno (tranquilo, oscuro)............................1 2345

7. Llevar a la otra persona a un lugar oportuno..................................1 23445

8. Hablar sobre sexo ( temas sexuales, anticonceptivos).........................12 345

9. Enfadarte con la otra persona si no accede a tener una relación sexual............1 23445

10. Decir directamente que deseas tener una relación sexual........................122345

11. Dejar que ocurra, no parar a la otra persona............................... 122345

12. Chocar "accidentalmente" con la otra persona para acercarte.....................1 23445

13. Empezar a desnudarte o aflojar la ropa de la otra persona.......................12 2445 
14. Bromear y/o insinuar algún interés sexual................................. 22345

15. Ignorar las señales de que la otra persona no desea una relación sexual...........122345

16. Decirle cosas halagadoras (cumplidos, "te quiero," etc.)......................122345

17. Intentar convencer a la otra persona con argumentos o negociar para tener una relación sexual...............................................122345

18. Hacerte notar y mostrarte atractivo/a y seductor/a.............................1 23445

19. Emborrachar o aprovecharse de la borrachera de la otra persona para tener actividad sexual..........................................122345

20. Usar movimientos o posturas provocativas.....................................1 2345

21. Presionar a la otra persona para tener actividad sexual (insistir mucho, decir que te lo debe, chantajear)..........................................122345

22. Crear una atmósfera romántica.............................................122345

23. Intentar dar pena o hacer a la otra persona sentirse culpable...................1 2345

24. Flirtear, tontear o actuar provocativamente.................................12 2345

25. Amenazar físicamente a la otra persona para tener actividad sexual...............122345

26. Forzar físicamente la otra persona para tener actividad sexual...................1 23345

27. Invitar o hacer un regalo o favor para tener actividad sexual.....................1 23345

28. Usar algún código íntimo (palabras) que la persona va a entender...............122345

29. Hablar de lo que sientes por la otra persona..................................1 2345 
Versión 2: Para contestar si tienes o has tenido relaciones esporádicas (de días o semanas) con personas a las que no consideras tu pareja.

1. Cuando es la otra persona (desconocido/a, conocido/a o amigo/a) la que utiliza estas estrategias para tener actividad sexual contigo ¿En qué medida aceptas tener actividad sexual cuando en realidad no lo deseas? Si nunca han intentado tener actividad sexual contigo, no contestes a esta pregunta.

1. __Nunca

2. __La minoría de las veces

3. __La mitad de las veces

4. __La mayoría de las veces

5. _. Siempre

2. Normalmente en tus relaciones esporádicas desearías tener... (Señala solo una opción):

1.__Menos actividad sexual de la que tienes

2. __La misma actividad sexual que la que tienes

3. __Más actividad sexual de la que tienes

3. Indica en qué medida sueles utilizar preservativo en tus relaciones sexuales con tus parejas esporádicas. Si no has tenido relaciones sexuales coitales, no contestes.

1. __Nunca

2. La minoría de las veces

3. __La mitad de las veces

4. __La mayoría de las veces

5. __Siempre

4. Indica el número de relaciones esporádicas (que hayan durado días o semanas) que has tenido.

5. Indica el número de personas (parejas estables o no) con las que has mantenido relaciones sexuales cóitales 


\section{Versión 2: Para contestar si tienes o has tenido relaciones esporádicas (de dias o semanas)} con personas a las que no consideras tu pareja.

A continuación hay una lista de estrategias de limitación sexual. Estas son estrategias que las personas utilizan para intentar evitar o limitar la actividad sexual con los demás.

Por favor, utiliza la escala de abajo para valorar con qué frecuencia has utilizado o utilizas cada una de estas estrategias para evitar o limitar tu actividad sexual CON ALGUIEN (desconocido/a, conocido/a o amigo/a).

¿Con qué frecuencia has utilizado cada estrategia en tus relaciones esporádicas para evitar o limitar la actividad sexual?

$\begin{array}{ccccc}\text { Nunca } & \text { Una vez } & \text { De } 2 \text { a } 4 \text { veces } & \text { De } 5 \text { a } 10 & \text { Más de } 10 \\ 1 & 2 & 3 & 4 & 5\end{array}$

1. Dejar claro lo que quieres y lo que no quieres hacer desde el principio.

2. Decir directamente que no quieres seguir en el momento

3. Irte de la situación o lugar.

4. Inventarte una excusa desde el principio

5. Interrumpir la actividad sexual con una excusa.

6. Dar señales no verbales de que no deseas actividad sexual (separarse, apartar manos etc.)

7. Quedarte inmóvil y/o rígido/a de forma notable. 12345

8. Utilizar tácticas para retrasarlo (proponer una actividad no sexual). 122345

9. Mostrarte sobrepasado o abrumado (llorar, etc.)

10. Fingir que crees que el acercamiento sexual de la otra persona es una broma 12345

11. Pedir comprensión a la otra persona sobre porqué no quieres ir mas allá. 12334

12. Distraer a la otra persona (contando algo, haciendo preguntas, etc.) .123345

13. Esperar que la otra persona no intente ir demasiado lejos 12345

14. Hablar de otro chico/a que te pudiera gustar.... 12345 
